\title{
Troost - Busca de interações entre trios de SNPs em estudos de associação de genoma inteiro
}

\section{Troost - Search for interactions among trios of SNPs in genome-wide association studies}

José Osório de Oliveira Azevedo Neto

\author{
TESE APRESENTADA AO PROGRAMA INTERUNIDADES DE PÓS- \\ GRADUAÇÃO EM BIOINFORMÁTICA DA UNIVERSIDADE DE SÃO PAULO \\ PARA OBTENÇÃO DO TÍTULO DE DOUTOR EM CIÊNCIAS
}

Orientador: Prof. Dr. Sergio Russo Matioli Co-orientadora: Prof ${ }^{a}$. Dra. Júlia Maria Pavan Soler

São Paulo, 7 de novembro de 2013 


\section{Ficha Catalográfica}

Azevedo Neto, José Osório de Oliveira

Troost - Busca de interações entre trios

de SNPs em estudos de associação de genoma inteiro

154 páginas

Tese (Doutorado) - Programa

Interunidades em Bioinformática da USP.

1. Epistasia 2. Estudos de associação I.

Universidade de São Paulo. Instituto de

Biociências. Departamento de Genética e

Biologia Evolutiva.

\section{Comissão Julgadora:}




\section{Resumo}

Os estudos de associação de genoma inteiro têm encontrado alguns marcadores associados a doenças notoriamente hereditárias com herança complexa, mas, muitas vezes, estes marcadores somente explicam uma pequena parte da herdabilidade. Este relativo insucesso é atribuído, entre outras causas, à epistasia, ou seja, interação entre diferentes locos genéticos. A busca por epistasia é complexa e exige intensos recursos computacionais. Diversos métodos têm sido propostos para abordar este problema, incluindo métodos estatísticos tradicionais, busca estocástica e métodos heurísticos. Poucos destes métodos são capazes de processar as grandes massas de dados produzidas nos estudos caso-controle de genoma inteiro, e ainda menos métodos buscam conjuntos de três ou mais marcadores. A busca exaustiva de conjuntos de marcadores epistáticos é inviável hoje em dia para estes conjuntos, mas o algoritmo BOOST (WAN et al., 2010) mostrou que ela é relativamente fácil para pares de locos, em especial com o uso de placas gráficas como processadores (GPGPU). Partindo deste recente sucesso, propomos um algoritmo em fases para a busca de trios de locos que interagem, utilizando a busca de pares como passo inicial, uma abordagem ainda não utilizada. Outra ideia fundamental do algoritmo proposto é a extensão da concepção de trio de marcadores para um trio de blocos haplotípicos, onde cada bloco é formado por marcadores próximos entre si. Usando os dados do WTCCC, o Troost (de TRio+bOOST) sugeriu trios potencialmente epistáticos em todas a sete doenças. Quando submetidos à confirmação em amostra independente, os trios não puderam ser confirmados, exceto os trios para diabetes tipo 1 (T1D). Duzentos e oito trios foram confirmados para T1D, com baixos valores-P e genótipos combinados de risco com altas razões de chances. Os SNPs que compõem estes trios estão todos na região MHC, sabidamente associada à doença, exceto por um deles que está no cromossomo cinco e não havia sido previamente relacionado à T1D. 


\section{Abstract}

Genome-wide association studies have found some markers associated with diseases with complex inheritance. However, these markers explain only a fraction of the previously estimated heritability of the trait. This relative failure has been credited, among other causes, to epistasis, i.e. the interaction among genotypes at different loci. The search for epistasis is complex and requires intense computational resources. Many methods have been proposed to approach this problem, including traditional statistics, stochastic search, and heuristic methods. Few of them are capable of extracting, from the large amount of data produced in genome-wide casecontrol studies, useful information about sets of markers associated with the trait in question. Exhaustive search of sets of interacting markers is unfeasible nowadays for sets of three or more markers, but the BOOST algorithm (WAN et al., 2010) showed that the search is relatively easy for pairs of SNPs, in particular with the use of graphic cards for general processing (GPGPU). Starting from this recent success, we propose an algorithm in phases for the search for trios of interacting loci, using the search for pairs as the initial step, an approach not tried yet, to our knowledge. Another important idea of our algorithm is the extension of the concept of trio of markers to a trio of haplotypic blocks, where each block is formed by neighbor markers. Using data from WTCCC, the Troost (from TRio+bOOST) algorithm suggested potentially epistatic trios in all seven diseases. When submitted to a confirmation in an independent sample, the results could not be confirmed, except for type-1 diabetes (T1D). Two hundred eight trios were confirmed for T1D, with low pvalues and risk combined genotypes with high odds ratio. The SNPs that form those trios are all in the MHC region, which is known to be strongly associated to T1D, except by one SNP in chromosome five that has not been previously associated with T1D. 


\section{Índice}

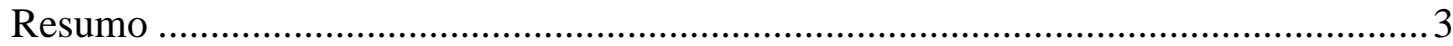

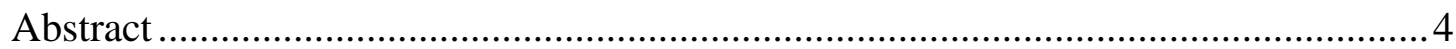

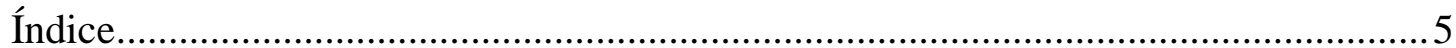

1 Introdução aos estudos de associação de genoma inteiro ...................................

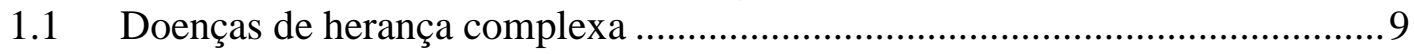

Exemplo de doença de herança complexa: o autismo ......................................... 9

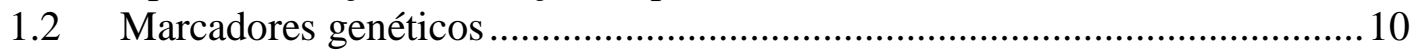

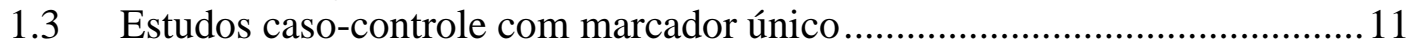

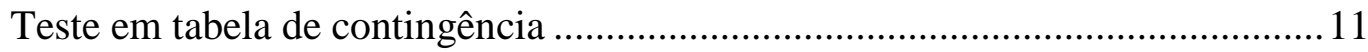

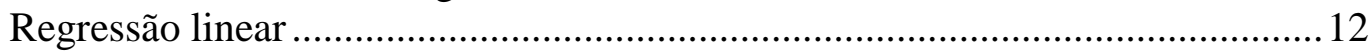

Extensão para incluir efeito de dominância ..................................................... 13

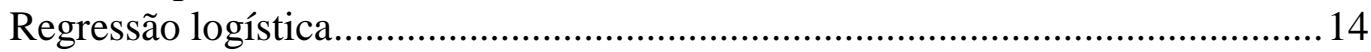

1.4 DbSNP e plataformas de genotipagem................................................. 15

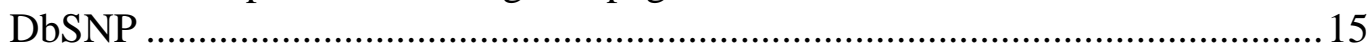

Plataformas de genotipagem de alta densidade ............................................. 16

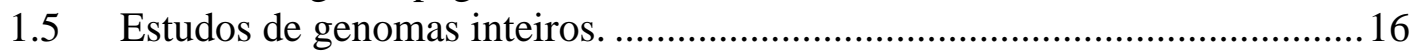

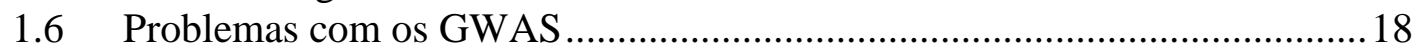

2 Introdução à epistasia - Interação de fatores genéticos entre si ..........................20

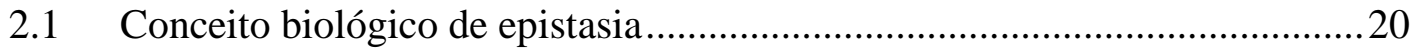

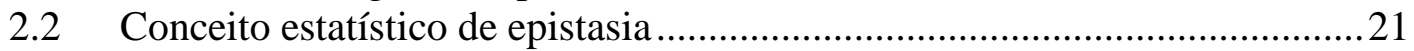

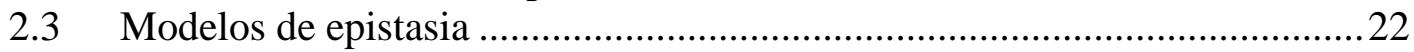

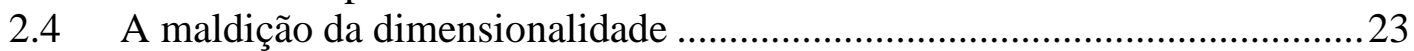

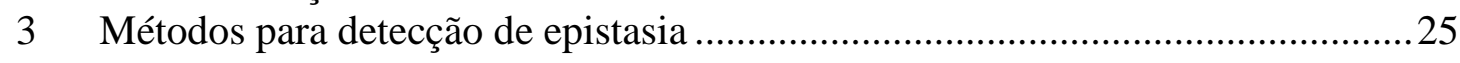

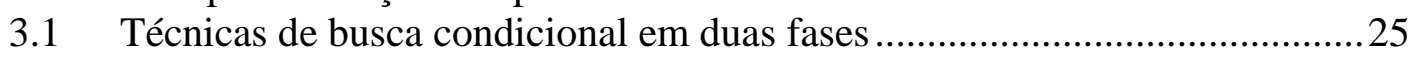

3.2 MDR - Multifactor Dimensionality Reduction ......................................26

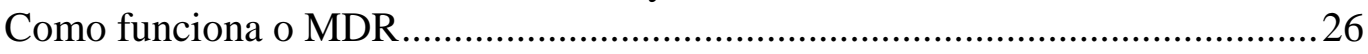

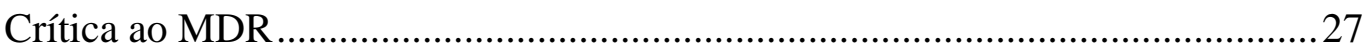

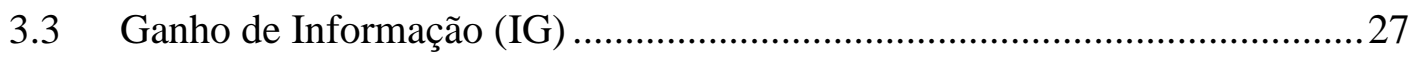

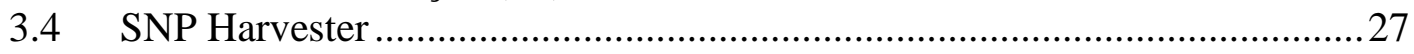

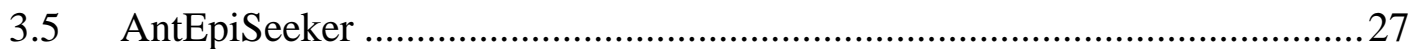

3.6 AGR - Redução de Grafos de Associação ..................................................28

3.7 Comparação dos métodos..............................................................................28

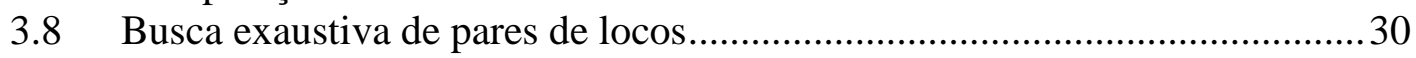

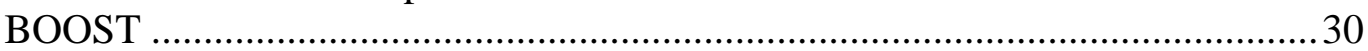

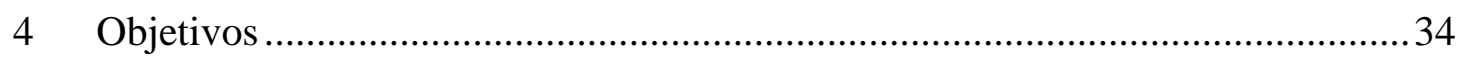

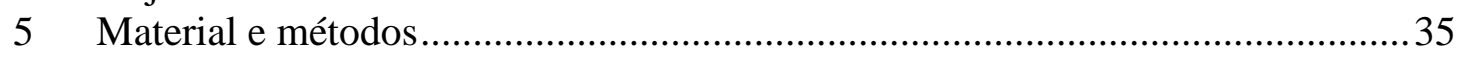

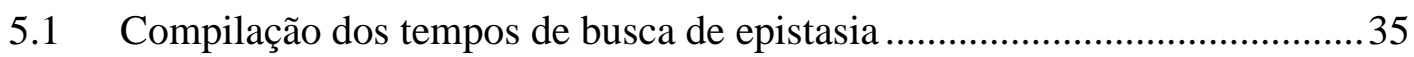

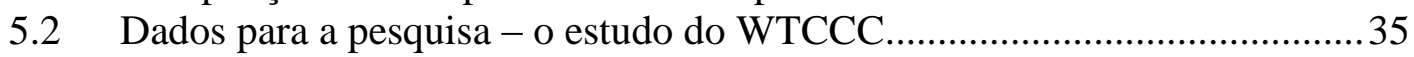

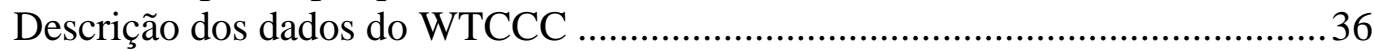

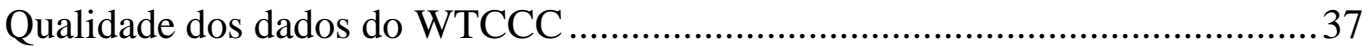

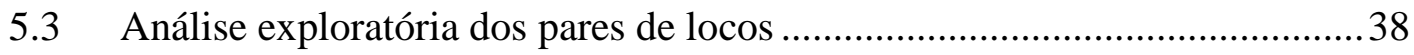

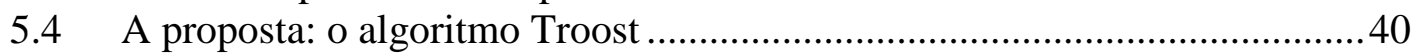

Ideia 1: Busca de trios epistáticos a partir dos pares ..........................................4 40

Ideia 2: Construir blocos haplotípicos entre os SNPs presentes nos pares fortes 43

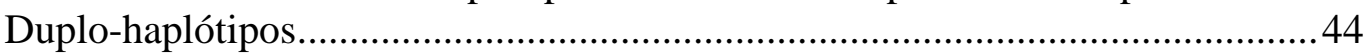

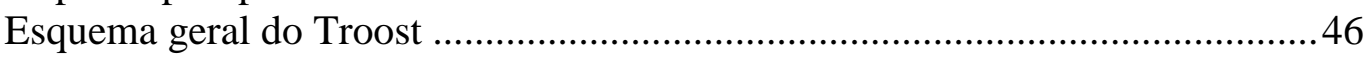

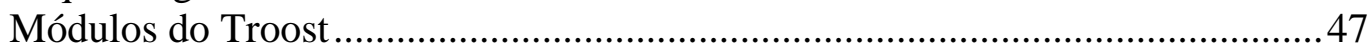

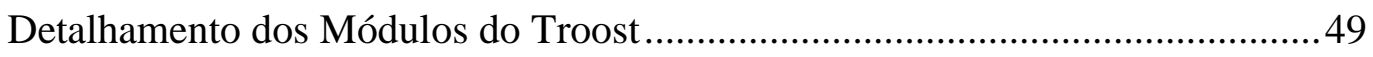

5.5 Confirmação dos resultados com amostras independentes .........................59

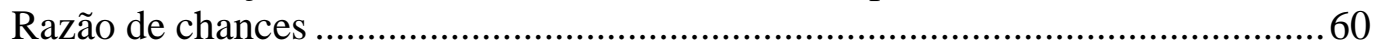




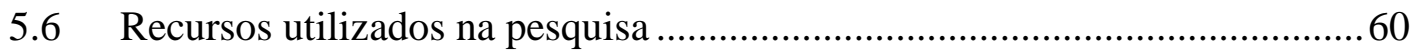

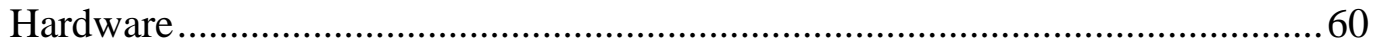

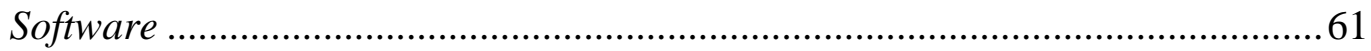

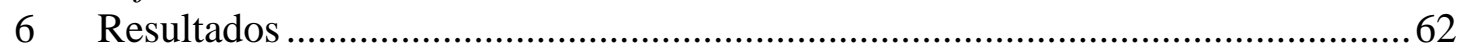

6.1 Tempo de execução de testes de epistasia...................................................62

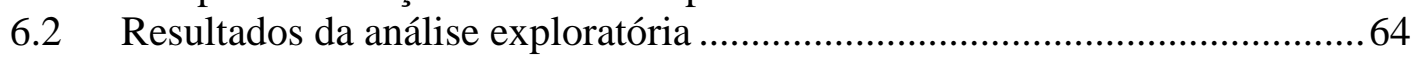

Entre os SNPs que aparecem nos pares, há predominância daqueles que têm

maior associação marginal? .......................................................................64

Os SNPs com maior efeito aditivo obscurecem os pares, ao aparecer num grande

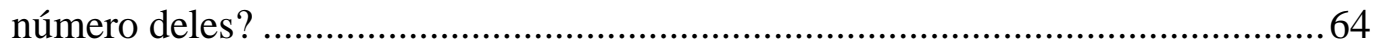

Quantos SNPs existem na lista de pares? .....................................................64

Há muitos pares de SNPs próximos, com alto desequilíbrio de ligação (LD) entre

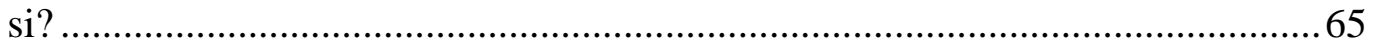

SNPs com alto LD aparecem pareados com os mesmos outros SNPs?...............65

É possível escolher um único SNP em grupos que têm alto LD entre si? ...........66

Existem padrões encadeados do tipo AB, BC, CD? ........................................66

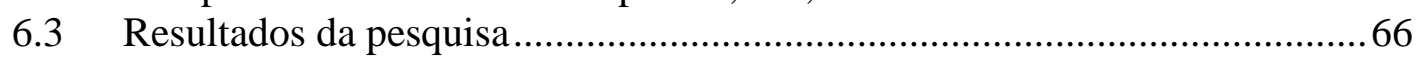

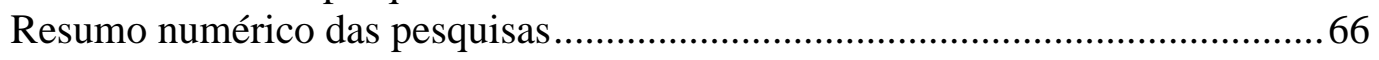

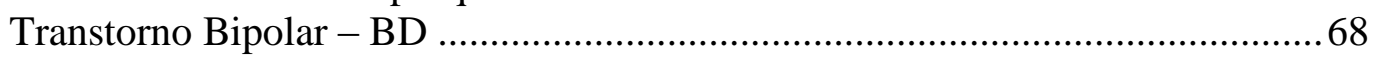

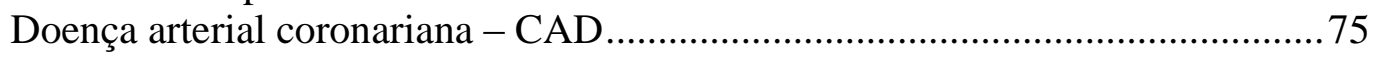

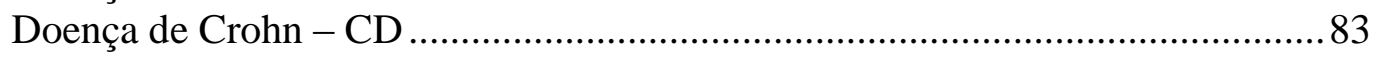

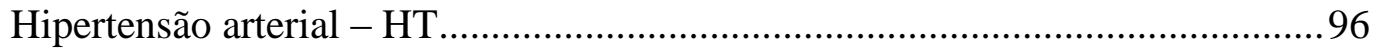

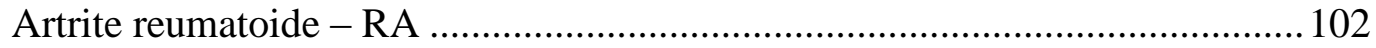

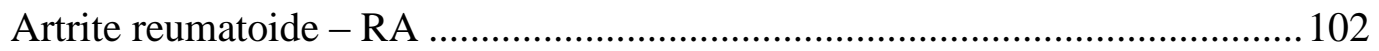

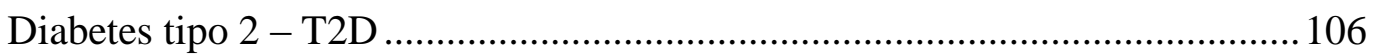

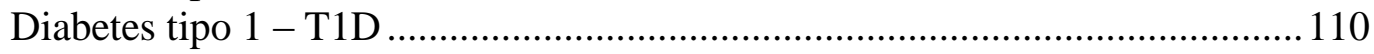

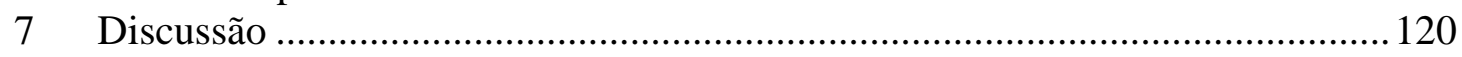

7.1 Uso das distâncias em centimorgans ...................................................... 120

7.2 Blocos haplotípicos definidos por pares................................................. 121

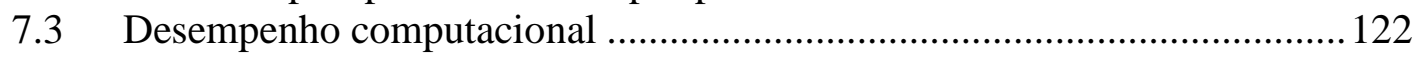

7.4 Sucesso: o Troost encontrou trios, mas não nos controles ........................... 123

7.5 BD, CAD, RA, T2D - A maldição do vencedor ....................................... 123

7.6 CD - Resultado confirmado, mas rejeitado .............................................. 124

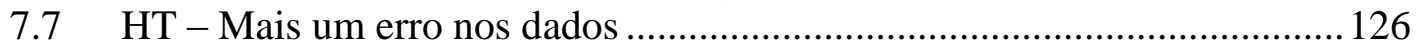

7.8 T1D - Novo SNP fora da MHC interage com ela..................................... 128

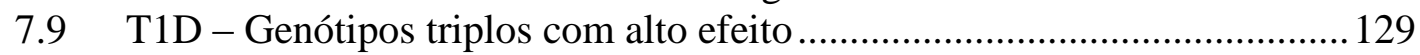

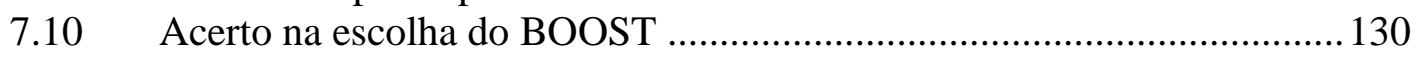

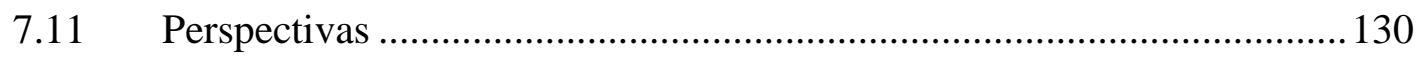

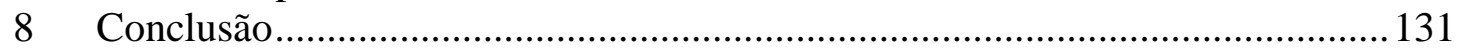

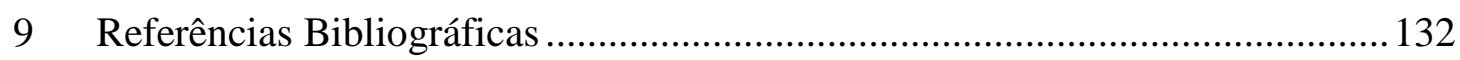

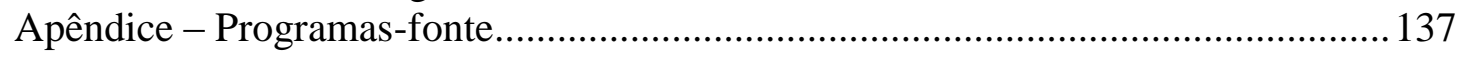

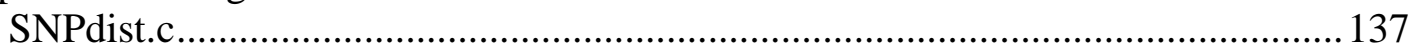

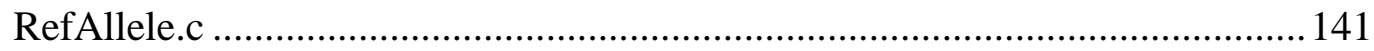

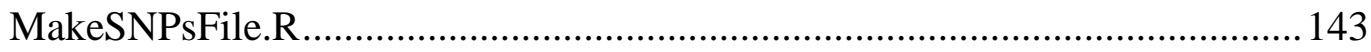

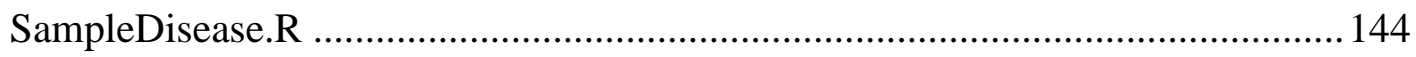

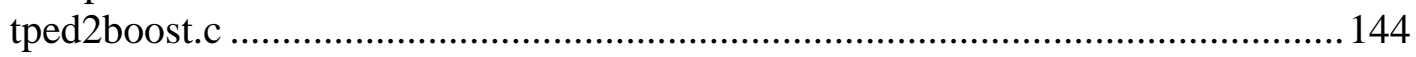

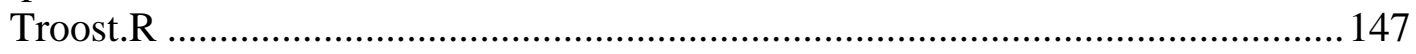

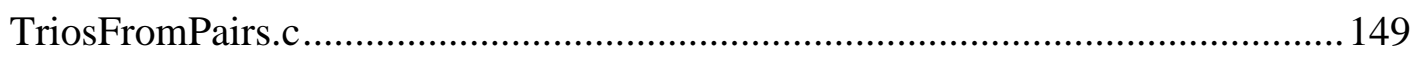

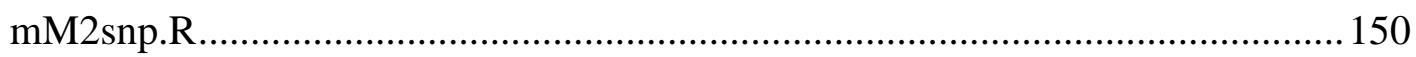

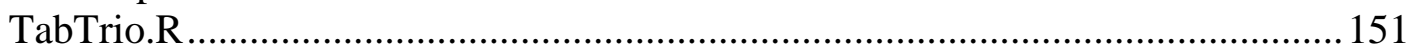

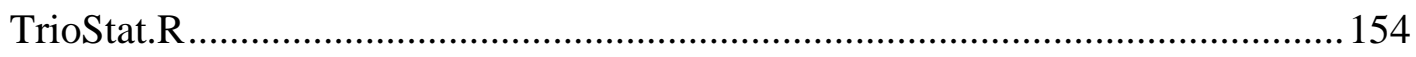




\section{Agradecimentos}

À minha esposa Cris e meus filhos Tomás e Laura, pelo apoio e por suportar os muitos fins de semana em que eu estava trabalhando nesta tese;

Ao meu orientador Sérgio e co-orientadora Júlia, pela sempre pronta e valiosa ajuda;

À minha irmã Sílvia, pelo apoio e comentários precisos;

À nossa secretária Patrícia, sempre disponível e competente;

À IBM, onde meu emprego em home-office com horário flexível permitiu-me cursar o doutorado e fazer esta tese, sem necessidade de bolsa;

Ao WTCCC pelo fornecimento dos preciosos dados genotípicos. 
This study makes use of data generated by the Wellcome Trust Case-Control Consortium. A full list of the investigators who contributed to the generation of the data is available from www.wtccc.org.uk. Funding for the project was provided by the Wellcome Trust under award 076113 and 085475. 


\section{Introdução aos estudos de associação de genoma inteiro}

\subsection{Doenças de herança complexa}

Uma das principais motivações do projeto Genoma Humano foi a identificação de genes causadores de doenças, para posterior descoberta das vias metabólicas envolvidas e possível desenvolvimento de drogas curativas ou preventivas. Entre estas importantes doenças podemos citar diabetes, asma, hipertensão arterial, esclerose múltipla, autismo, transtorno bipolar, câncer, esquizofrenia e obesidade.

Algumas destas doenças têm incidência elevada em populações do ocidente, outras nem tanto, mas nenhuma delas é classificada como doença rara. Estas doenças apresentam fortes evidências de possuírem causas genéticas, por serem recorrentes nas mesmas famílias. No entanto, elas definitivamente não possuem herança mendeliana simples. As buscas por genes causadores têm produzido alguns resultados, mas muito aquém do que era esperado quando grande quantidade de recursos humanos, financeiros e materiais foi investida no projeto genoma humano e nas centenas de estudos de associação já realizados, muitas vezes com a colaboração de dezenas de instituições de pesquisa distribuídas por diversos países e continentes.

\section{Exemplo de doença de herança complexa: o autismo}

O autismo é uma doença que desafia os geneticistas há muitas décadas. Nos Estados Unidos, uma criança em cada 150 é portadora de doença do espectro autista. (WANG et al., 2009a). É portanto uma doença grave, causadora não apenas de desconforto e gastos no sistema de saúde, mas também de sofrimento para vítimas e seus familiares. Em relação aos aspectos genéticos: se o casal já tiver um filho autista, a chance de um novo bebê ser também autista é de 10\% (WANG et al., 2009a). Esta chance cresce de 1 em 150 na população para 1 em 10 nessa família. No caso de gêmeos idênticos, se um deles apresenta sintomas de autismo, a chance de o outro também os apresentar é de 90\% (WANG et al., 2009a). Estes resultados sugerem que o autismo tenha um importante componente genético.

As buscas de marcadores relacionados a doenças têm se concentrado nos efeitos principais de cada marcador, supondo-os independentes dos demais genes. 
Genes associados à incidência de autismo foram encontrados, mas a maior parte da herdabilidade permanece inexplicada. (ALTSHULER; DALY, 2007)

O autismo é citado aqui apenas como exemplo de doença genética. No decorrer da nossa pesquisa, em nenhum momento lidamos com dados sobre autismo.

\subsection{Marcadores genéticos}

O genoma humano, representado pela sequência de referência, é uma sequência de consenso entre os poucos indivíduos cujos genomas foram sequenciados com esta finalidade. Ele reflete a uniformidade do genoma para a humanidade, mas não retrata as diferenças entre as pessoas. Cerca de $0,1 \%$ do genoma é diferente entre duas pessoas não aparentadas, o que equivale a cerca de um a cada mil nucleotídeos sequenciados. (HAPMAP CONSORTIUM, 2003). Esta variação genética entre as pessoas pode explicar porquê alguns indivíduos são mais suscetíveis a uma doença do que outros, e também pode explicar a recorrência de doenças em determinadas famílias. O projeto Genoma Humano pode ser visto como um primeiro passo para a análise profunda da relação entre a variação genética e a propensão a doenças hereditárias, pois produziu um mapa detalhado sobre o qual outras descobertas podem ser adicionadas. O próximo passo foi encontrar as diferenças comuns entre os genomas, e essas diferenças são determinadas por marcadores moleculares. $\mathrm{O}$ tipo mais comum de marcador molecular é o SNP (Single Nucleotide Polymorphism), ou polimorfismo de nucleotídeo único. É uma posição específica no genoma, a qual em geral tem uma base nitrogenada (A, C, G ou T) como a mais comum na população, o alelo comum, e outra como a menos comum, o alelo alternativo ou menos frequente. Os indivíduos normalmente são homozigotos para o alelo comum, mas podem ser heterozigotos ou homozigotos para o alelo alternativo. Embora possa haver mais que duas bases nitrogenadas polimórficas em um SNP, a sua imensa maioria é bialélica.

Há outros tipos de marcadores, tais como minissatélites, microssatélites e variações estruturais (inserções, exclusões, inversões e translocações). Mas os SNPs são, atualmente, os mais adotados nos estudos genômicos, por serem mais numerosos, proporcionarem uma cobertura mais densa do genoma e por serem mais facilmente abordáveis por métodos de genotipagem em larga escala. 


\subsection{Estudos caso-controle com marcador único}

Diversos são os métodos estatísticos usados para verificar se um marcador está associado com o fenótipo. O delineamento de estudo mais disseminado é o casocontrole, em que uma amostra de indivíduos caso (afetados pela doença) e uma amostra de indivíduos controle (livres da doença) são extraídas da população alvo de estudo. O genótipo em um marcador específico é medido para todos os indivíduos da amostra (FOULKES, 2009) (FALCONER; MACKAY, 1996).

\section{Teste em tabela de contingência}

Para verificar se um determinado SNP tem associação com o fenótipo é possível construir uma tabela de contingência, com os genótipos nas colunas e os fenótipos (neste caso, os grupos sob estudo) nas linhas, conforme a Tabela 1.

Tabela 1 - Exemplo de tabela de contingência para estudo caso-controle em marcador único

\begin{tabular}{ccccc}
\hline & AA & Aa & aa & Total \\
\hline Caso & 30 & 11 & 9 & 50 \\
Controle & 40 & 9 & 1 & 50 \\
Total & 70 & 20 & 10 & 100 \\
\hline
\end{tabular}

Cada célula contém o número de indivíduos que apresentam aquele determinado genótipo e fenótipo. Os números aqui apresentados são apenas exemplos.

É relevante a proporção entre casos e controles nos diferentes genótipos, quando comparada com a proporção entre os totais de casos e controles. Em qualquer das colunas AA, Aa ou aa, as proporções entre casos e controles podem ser diferentes da proporção total.

Há vários testes de significância para esta diferença, entre os quais o teste quiquadrado de Pearson, teste exato de Fisher e os testes por regressão logística (AGRESTI, 2002).

O teste qui-quadrado de Pearson pode ser usado com tabelas de vários tamanhos, mas apresenta problemas de imprecisão quando há células vazias ou com frequências esperadas menores do que cinco. Uma variação deste teste é o teste de Goodman para homogeneidade entre multinomiais (GOODMAN, 1964), apropriado quando o contraste em uma das dimensões é mais importante do que em outra, o que é 
apropriado para estudos caso-controle. O teste exato de Fisher não apresenta o problema das células com baixo valor, mas só tem uma formulação algébrica explícita no caso de tabelas 2 × 2 (AGRESTI, 2002). Para tabelas maiores, o teste exato precisa recorrer a métodos numéricos, que são úteis para estudos com genes candidatos mas revelam-se muito lentos quando usados em estudos de genoma inteiro. Por todas as limitações expostas acima das tabelas de contingência, o teste mais usado no momento é a regressão logística (CORDELL, 2009).

\section{Regressão linear}

Para um fenótipo quantitativo, expresso em uma escala contínua, podemos aplicar a regressão linear. A variável preditora, a ser definida no eixo X, é o genótipo de um marcador, codificado assim, por exemplo: $\mathrm{AA}=-1, \mathrm{Aa}=0$, aa $=1$. Nesta notação, o alelo $A$ não é obrigatoriamente dominante, é em geral o alelo mais frequente na população, enquanto o alelo $a$ é o alelo alternativo e não o recessivo. Nesse caso, o fenótipo quantitativo é a variável "resposta", denominada Y. O modelo inicialmente supõe um efeito proporcional ao número de alelos, e portanto não é nem dominante nem recessivo. Temos então a seguinte equação:

Em que:

$$
Y=\alpha+\beta x+\varepsilon
$$

$Y$ é a variável resposta, o fenótipo quantitativo;

$\alpha$ é o ponto de interceptação da reta no eixo Y;

$\beta$ é efeito linear do marcador, ou inclinação da reta;

$x$ é a variável preditora, que é o genótipo apresentado num marcador específico,

podendo valer $-1,0$, ou $+1^{1}$, conforme o genótipo seja AA, Aa ou aa respectivamente; $\varepsilon$ é o erro aleatório, seguindo premissas clássicas (NETER et al., 1996).

$\alpha$ e $\beta$ são parâmetros a serem estimados pelo modelo.

A Figura 1 é um gráfico da regressão linear aplicada a estudos de associação com fenótipo quantitativo.

\footnotetext{
${ }^{1}$ Alguns estudos adotam $[0,1,2]$ ou $[1,2,3]$, o que é equivalente para os fins da pesquisa.
} 


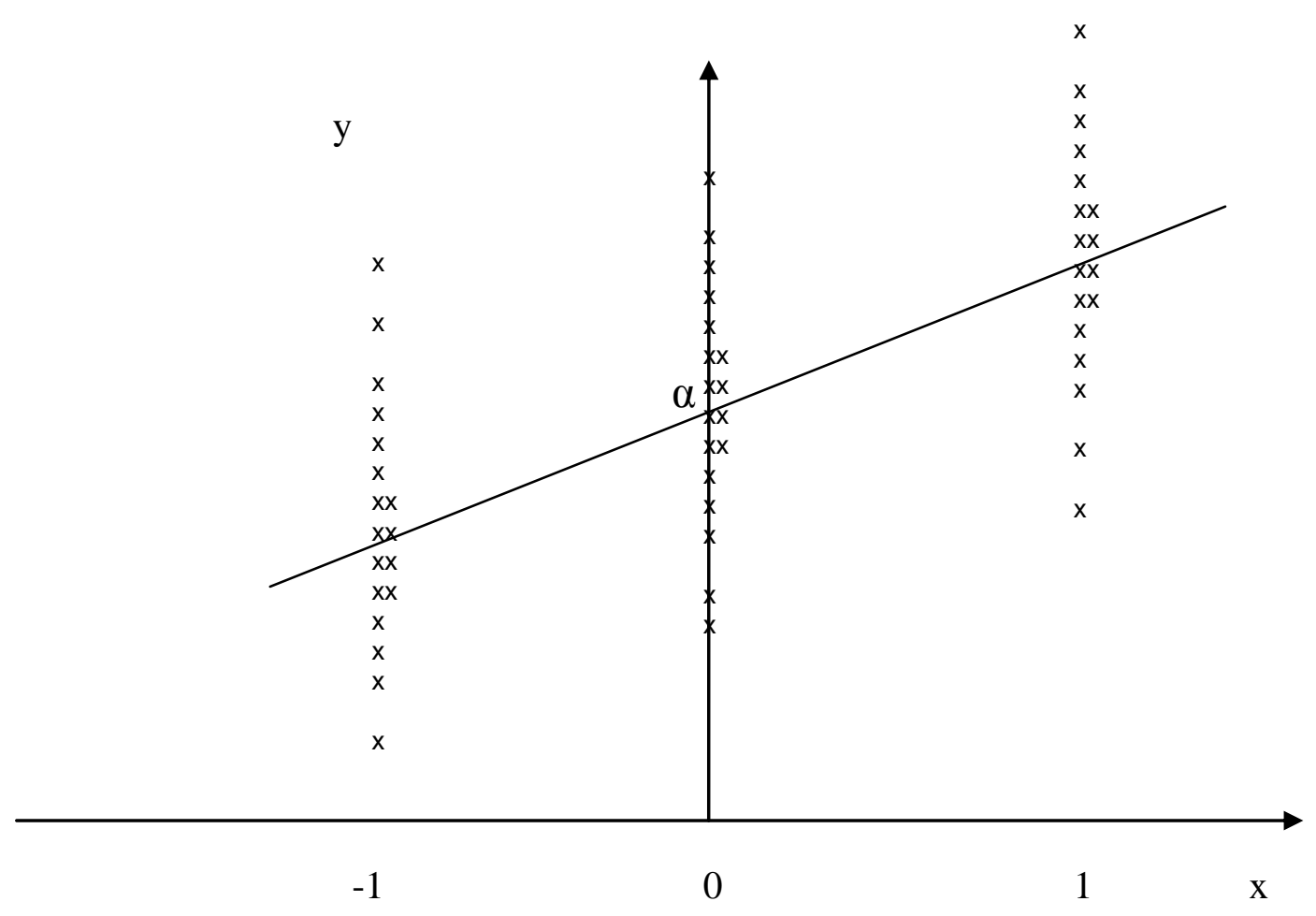

Figura 1 - Exemplo de regressão linear simples em estudo de associação de marcador único com fenótipo quantitativo.

Nosso teste de hipótese fica:

$\mathrm{H}_{0}: \beta=0$, ou seja, o efeito do marcador é nulo

$\mathrm{H}_{1}: \beta \neq 0$, ou seja, existe efeito do marcador

O teste da hipótese de interesse é feito por meio de estatísticas T (NETER et al., 1996).

\section{Extensão para incluir efeito de dominância}

O modelo descrito acima é limitado, pois pressupõe um efeito sempre proporcional ao número de alelos. Mas um alelo pode ser dominante, recessivo, ou até mesmo causar o fenótipo somente no indivíduo heterozigoto. Para cobrir estes casos, podemos sofisticar o modelo, usando a capacidade da regressão linear de calcular parâmetros adicionais (FOULKES, 2009). Criando uma variável adicional z, a partir do genótipo:
AA $\quad \rightarrow \mathrm{x}=-1, \mathrm{z}=0$
Aa $\quad \rightarrow x=0, z=1$
aa $\quad \rightarrow \mathrm{x}=1, \mathrm{z}=0$ 
Neste caso, o modelo de regressão fica descrito como:

$$
\mathrm{Y}=\alpha+\beta \mathrm{x}+\gamma \mathrm{z}+\varepsilon
$$

Teremos dois efeitos do marcador, ambos calculados pelo modelo:

$\beta$ é o efeito aditivo;

$\gamma$ é o efeito de dominância.

Com esta parametrização tem-se (FALCONER; MACKAY, 1996):

$$
\begin{aligned}
& \alpha=\left(\mu_{\mathrm{aa}}+\mu_{\mathrm{AA}}\right) / 2 \\
& \beta=\left(\mu_{\mathrm{AA}}-\mu_{\mathrm{aa}}\right) / 2 \\
& \gamma=\mu_{\mathrm{Aa}}-\alpha
\end{aligned}
$$

Com a introdução do efeito de dominância, é adicionado um grau de liberdade.

\section{Regressão logística}

Para muitas doenças e outros fenótipos, não há uma variável quantitativa, mas sim somente uma variável categórica binária: ou o indivíduo tem a doença diagnosticada (fenótipo $\mathrm{Y}=1$ ), ou não a tem (fenótipo $\mathrm{Y}=0$ ); ou é caso, ou é controle. Nesta situação adotamos uma variação da regressão linear chamada regressão logística, aperfeiçoada por vários estatísticos durante o século $\mathrm{XX}$, entre eles Berkson em 1944. Nesta, não há a modelagem direta do fenótipo, mas sim da probabilidade de que o indivíduo seja um caso. Para variáveis binárias, uma grandeza frequentemente utilizada é a razão de chances $r=p /(1-p)$, onde $p$ é a probabilidade do indivíduo apresentar a doença. A regressão logística usa o logaritmo da razão de chances como a variável a ser usada no modelo linear, ou seja, assume-se que o genótipo $(0,1$ ou 2$)$ afeta linearmente o logaritmo da razão de chances de apresentar o fenótipo, e testa-se se esse efeito é significante (AGRESTI, 2002).

Chamemos de z o logaritmo da razão de chances. A probabilidade de apresentar o fenótipo fica:

$$
P(Y=1)=p=\frac{1}{1+e^{z}}
$$

Esta é uma curva sigmoide, chamada função logística, que transforma a variável z em um número entre zero e um. Sua função inversa é chamada de logito:

$$
z=\operatorname{logito}(p)=\log \frac{p}{1-p}
$$


onde verifica-se claramente o logaritmo da razão de chances. Em geral adotase um modelo linear para $\mathrm{z}$, por exemplo $\mathrm{Z}=\alpha+\beta X$, em que $\mathrm{X}$ representa o genótipo do marcador de que estamos tratando.

A Figura 2 é um gráfico da regressão logística aplicada a um estudo de associação de marcador único. Maiores detalhes podem ser encontrados em AGRESTI, 2002.

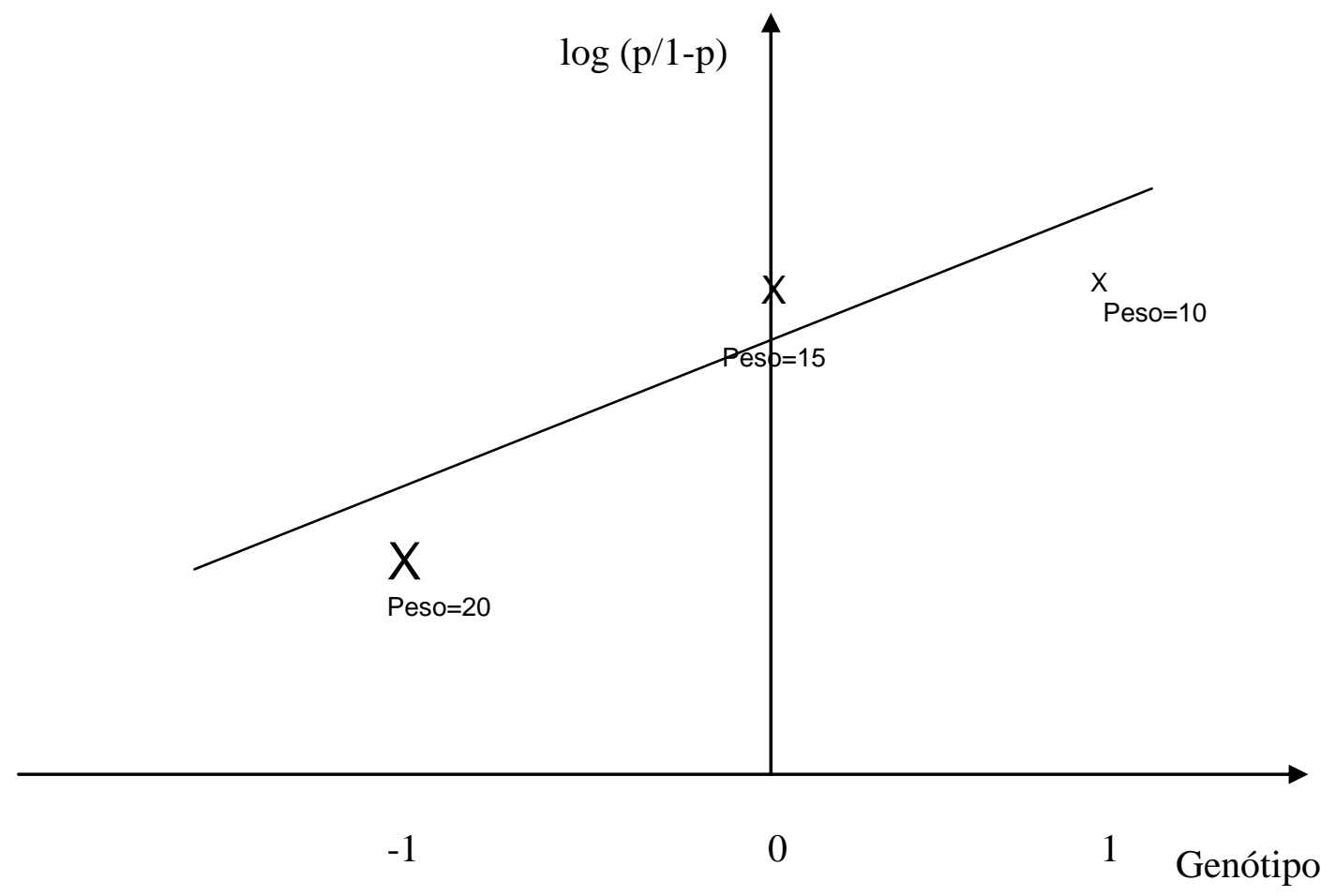

Figura 2 - Regressão logística em marcador único

\subsection{DbSNP e plataformas de genotipagem DbSNP}

O principal banco de dados de SNPs é o banco de dados de polimorfismos de nucleotídeo único, ou DbSNP, mantido pelo NCBI - National Center for Biotechnology Information. Em agosto de 2013, o DbSNP possuía 62 milhões de SNPs humanos de referência (fonte: anúncio NCBI em http://www.ncbi.nlm.nih.gov /mailman/pipermail/dbsnp-announce/2013q3/000133.html). Grandes projetos de mapeamento da variação genética humana, como o HapMap (HAPMAP CONSORTIUM, 2005) e o 1000 Genomes (DURBIN et al., 2010) são os maiores 
responsáveis pela inserção de novos SNPs no DbSNP. O DbSNP, a despeito do nome, não armazena somente SNPs, possuindo também informações sobre variações estruturais e microssatélites.

\section{Plataformas de genotipagem de alta densidade}

Ao mesmo tempo em que o mapa das variações genéticas tem sido construído, as empresas de biotecnologia desenvolvem novas plataformas de SNPs. São chips (arranjos bidimensionais de marcadores de DNA) preparados para genotipar centenas de milhares de SNPs do mesmo indivíduo. No desenvolvimento da plataforma, SNPs representativos de todo o genoma são escolhidos, com pelo menos um SNP em cada trecho entre hotspots, que são pontos do genoma onde há muita probabilidade de recombinação genética na meiose. Provas de DNA são produzidas para cada SNP, e todos são alinhados em uma matriz. Uma amostra de DNA de cada indivíduo é aplicada em cada chip, produzindo um padrão visual de resposta, em geral vermelho, verde ou marrom. Os chips são então submetidos a uma varredura óptica, produzindo, para cada SNP impresso no chip, uma medida de intensidade de luz para cada alelo (o comum e o alternativo). Neste processo, o genótipo dos SNPs não é obtido diretamente, mas por meio da aplicação de algoritmos de agrupamento (por exemplo, BirdSeed da Affymetrix e GenCall da Illumina), que fazem a categorização das medidas de intensidade de luz dos alelos em classes genotípicas e atribuem probabilidades de que cada SNP de cada indivíduo seja homozigoto para cada um dos alelos ou heterozigoto. As plataformas mais conhecidas são aquelas produzidas pelas empresas Illumina e Affymetrix, que produzem plataformas com até um milhão de SNPs.

Os SNPs que apresentam genótipos ambíguos são descartados. Como resultado, temos o genótipo de cada SNP em cada indivíduo, com alguns SNPs faltantes para alguns indivíduos.

\subsection{Estudos de genomas inteiros.}

Antes da adoção das plataformas de genotipagem, eram precisos genes candidatos para serem testados, ou pelo menos uma região candidata em um cromossomo específico. Estes estudos são muito úteis, desde que se tenha razão para suspeitar que haja uma mutação causal naquela região. Usando as novas plataformas, 
altamente densas, é possível procurar por genes em todo o genoma da espécie, de modo que a variação causal não escape da busca. Isto é às vezes chamado de "busca sem hipótese" ou "busca agnóstica".

Estes estudos de associação em larga escala genômica são chamados de GWAS, do inglês "Genome-Wide Association Studies". Muitos desses estudos têm sido conduzidos para diversas doenças, e alguns deles concluíram positivamente que marcadores específicos estão associados com a doença (CORDELL, 2009). O NCBI tem um banco de dados que armazena todos esses estudos, chamado de base de dados de genótipos e fenótipos, ou DbGAP e que está hospedado no endereço http://www.ncbi.nlm.nih.gov/gap .

Um estudo de genoma inteiro é uma sequência de testes com todos os marcadores de uma plataforma de alta densidade, um de cada vez, como se cada marcador da plataforma fosse um "gene candidato". Os dados típicos para um estudo de associação são apresentados na Tabela 2.

Tabela 2 - Exemplo dos dados necessários para um GWAS, onde 0 significa homozigose do alelo de referência, 1 é heterozigose e 2 é homozigose do alelo alternativo

\begin{tabular}{lllllllllll}
\hline Indivíduo & $\begin{array}{l}\text { Caso } \\
\text { Controle }\end{array}$ & & SNP1 & SNP2 & SNP3 & SNP4 & SNP5 & SNP6 & $\ldots$ & SNP \\
\hline Ind1 & Caso & 0 & 0 & 1 & 0 & 2 & 0 & $\ldots$ & 0 \\
Ind2 & Caso & 0 & 0 & 0 & 1 & 0 & 1 & $\ldots$ & 1 \\
Ind3 & Controle & 0 & 1 & 0 & 0 & 2 & 0 & $\ldots$ & 0 \\
Ind4 & Caso & 2 & 0 & 1 & 0 & 0 & 0 & $\ldots$ & 0 \\
Ind5 & Controle & 0 & 2 & 0 & 1 & 0 & 0 & $\ldots$ & 2 \\
Ind6 & Controle & 0 & 2 & 1 & 0 & 0 & 1 & $\ldots$ & 0 \\
Ind7 & Caso & 1 & 0 & 0 & 0 & 0 & 1 & $\ldots$ & 1 \\
$\ldots$ & $\ldots$ & $\ldots$ & $\ldots$ & $\ldots$ & $\ldots$ & $\ldots$ & $\ldots$ & $\ldots$ & $\ldots$ \\
Ind2000 & Controle & 0 & 0 & 1 & 0 & 2 & 0 & $\ldots$ & 0 \\
\hline
\end{tabular}

Somente uma pequena fração dos SNPs validados está presente nas plataformas de genotipagem. E ainda há muitos SNPs a serem descobertos. Assim, quando uma associação significativa é encontrada entre um marcador e uma doença, este marcador provavelmente não é a variação que causa a doença. É mais provável que ele seja um marcador vizinho, em desequilíbrio de ligação com a variação causal (FOULKES, 2009). Em geral, este fenômeno ocorre entre locos genômicos ligados 
(próximos), mas isto nem sempre é verdade para populações com uma história recente de miscigenação, o que pode conduzir a resultados falsos positivos dos estudos de associação.

\subsection{Problemas com os GWAS}

Em geral, o primeiro passo da análise de estudos de associação em genômica é a realização de análises unilocos, isto é, de cada SNP independentemente (CORDELL, 2009). Estas análises são razoavelmente simples, mas garantir testes de associação com alta sensibilidade (probabilidade de resultado verdadeiro positivo) e alta especificidade (probabilidade de resultado verdadeiro negativo) não é fácil. Para chegar a uma conclusão confiável, são necessárias amostras de tamanho da ordem de milhares, complementadas pela validação em amostras independentes. Muitos estudos, inclusive a maioria daqueles produzidos antes de 2006, não conseguiram encontrar associações estatisticamente significantes para a doença em estudo em qualquer dos milhares de marcadores testados. Outros encontraram alguma associação, mas ela, em geral, não pôde ser confirmada em estudos subsequentes (HIRSCHHORN; DALY, 2005). A principal razão para isto é que o efeito individual de marcadores do tipo SNP é esperado ser pequeno, o que, combinado com a necessidade de correção no nível de significância global considerando o problema dos múltiplos testes, dificulta ainda mais a identificação de sinais de associação. Como uma grande quantidade de marcadores é testada, cobrindo todo o genoma, o limiar estatístico para uma associação ser considerada significante tem que ser mais estrito. Se o limiar normal para um teste individual é 5\% de significância, ou um valor-p menor ou igual a 0,05 , um em cada 20 testes vai mostrar-se significante por acaso. Há uma abordagem clássica para evitar uma quantidade muito grande de associações positivas falsas, chamada de correção de Bonferroni: dividir o nível de significância requerido pelo número de testes. Numa plataforma de 300 mil SNPs, por exemplo, isto levaria o valor-p exigido para $1,67 \times 10^{-7}$. Mas esta correção é conservadora demais, porque os marcadores estão correlacionados e a correção de Bonferroni tem como premissa a independência entre as variáveis classificadoras. Muitas associações verdadeiras seriam perdidas se fosse adotada uma correção tão rigorosa. Outras correções mais justas para o limiar, que minimizaram este problema, foram propostas, mas elas ainda impõem que seja usada uma grande amostra e também que haja 
confirmação em estudos subsequentes, o que é dispendioso em termos de tempo e recursos (HIRSCHHORN; DALY, 2005).

Neste contexto, um segundo passo na análise destes estudos tem sido buscar um conjunto de SNPs em associação com a doença. A pesquisa do espaço genômico para se obter estes conjuntos tem sido feita principalmente sob dois enfoques: busca de uma sequência de SNPs adjacentes pertencentes a um haplótipo com efeito significativo, ou busca de SNPs em epistasia espalhados ao longo do genoma. Este último caso norteia o tema desta pesquisa. 


\section{Introdução à epistasia - Interação de fatores genéticos entre si}

\subsection{Conceito biológico de epistasia}

Epistasia é interação gênica, ou seja, um fenótipo é causado por uma combinação de genes e não por um só. Bateson introduziu esta expressão em 1909, com um exemplo simples, baseado em pelagem de camundongos, em que um gene mascara o outro (Figura 3) (BATESON; MENDEL, 1909).

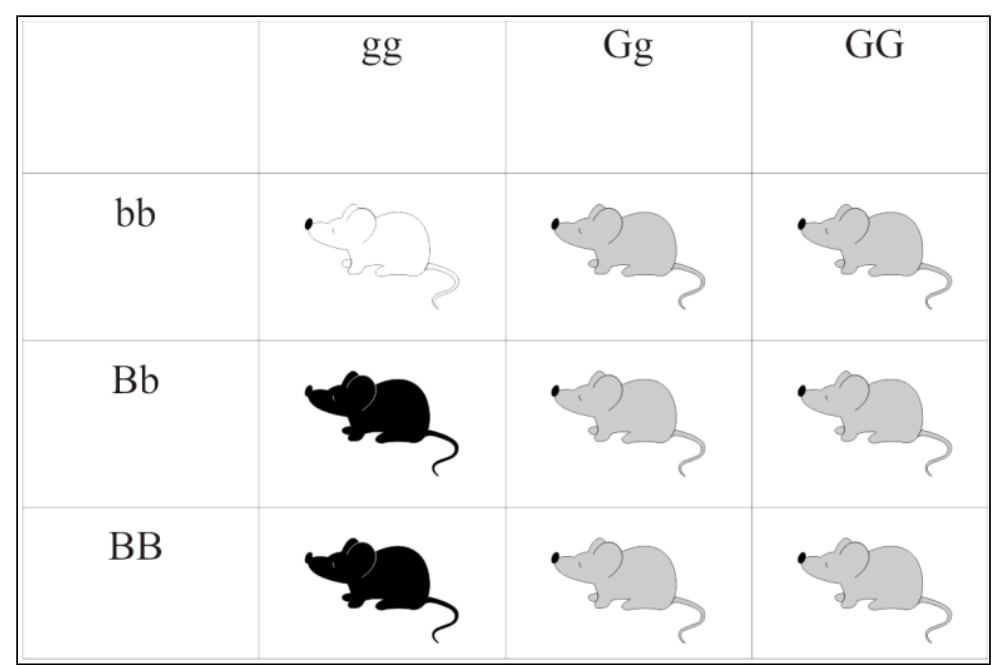

Figura 3 - Conceito de epistasia segundo Bateson. A presença do alelo para cinza na posição G (gray) mascara o efeito do alelo para preto na posição B (black).

Neste caso, a presença de um alelo $G$ impede que os alelos $B$ e b se manifestem. Isso poderia ser produzido por uma rede metabólica como a apresentada abaixo (Figura 4).

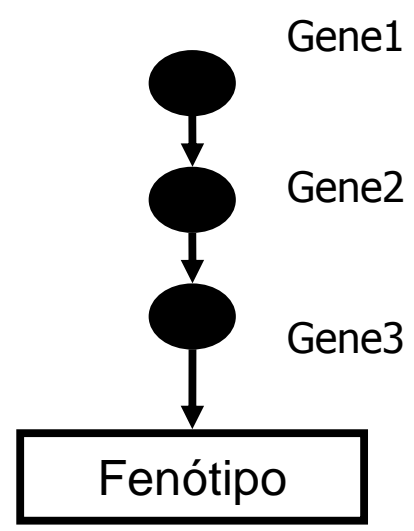

Figura 4 - Possível rede metabólica com epistasia. 
Há outro tipo de interação gênica, chamada heterogeneidade, que muitos biólogos não consideram como epistasia, conforme a Figura 5.

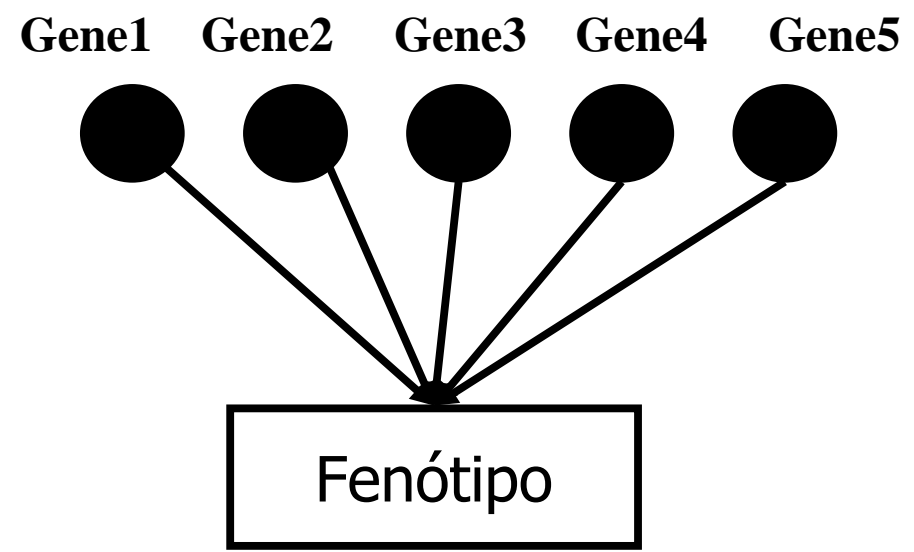

Figura 5 - Heterogeneidade: vários genes causam o fenótipo, mas cada um não interfere nos demais.

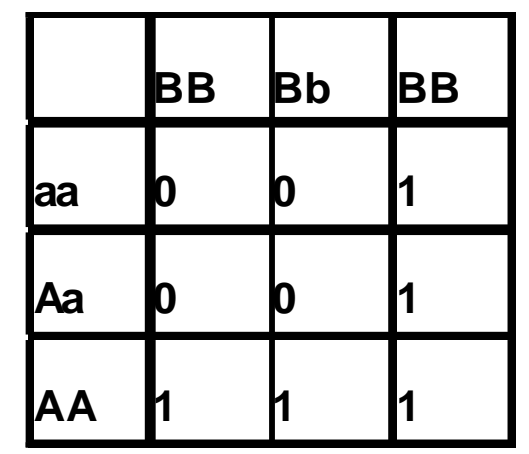

Tabela 3 - Heterogeneidade

Neste exemplo, ambos os genes, quando em homozigose, causam o fenótipo de maneira independente. Embora os dados da Tabela 3 mostrem associação, este tipo de rede metabólica não é considerado epistasia no conceito clássico (CORDELL, 2002). É como se fossem tipos diferentes da mesma doença.

\subsection{Conceito estatístico de epistasia}

Em 1918, R. A. Fischer propôs um conceito de epistasia diferente, que ele denominou de "epistacy": epistasia é qualquer afastamento da linearidade na resposta de um fenótipo a um gene, quando levamos em conta o genótipo em outro gene (FISHER, 1918). Na prática as redes metabólicas são muito mais complexas que os exemplos acima. Há uma transição indistinta entre os tipos de interação. Estatisticamente, os testes detectam qualquer tipo de interação, inclusive o caso da heterogeneidade, sem consideração de interesse biológico. Este é o conceito mais adotado pelos estatísticos e é aquele que será adotado neste trabalho.

O teste estatístico para epistasia é feito adaptando a equação (1) para dois locos. Considere-se um fenótipo quantitativo Y e um modelo linear para estimar seu valor esperado, $\mathrm{E}(\mathrm{Y} \mid \mathrm{X})$, como função de efeitos genéticos de dois locos bialélicos, L1 e L2. Considere-se ainda as variáveis preditoras $x 1$ e $x 2$, associadas aos efeitos 
aditivos dos locos L1 e L2, tal que x1, x2 = 0, 1 ou 2, conforme o indivíduo seja AA, Aa ou aa respectivamente.

Deste modo, no modelo linear a seguir, estimam-se os efeitos aditivos a1 e a2, e o efeito de interação i:

$$
\mathrm{Y}=\mathrm{Y}_{0}+\mathrm{a}_{1} \mathrm{x}_{1}+\mathrm{a}_{2} \mathrm{X}_{2}+\mathrm{ix}_{1} * \mathrm{X}_{2}+\varepsilon
$$

Considera-se que os dois locos estão em epistasia quando i é estatisticamente diferente de zero.

A formalização para incluir efeitos de dominância forma o modelo completo com interação (FIM, de Full Interaction Model). Deste modo, no modelo linear a seguir, adiciona-se as variáveis preditoras $z_{1}$ e $z_{2}$, que valem 1 para o heterozigoto e zero para os homozigotos. Estimam-se então os efeitos aditivos a1 e a2, os efeitos de dominância d1 e d2, e os efeitos de epistasia $i_{a a}, i_{a d}$, $i_{d a}$ e $i_{d d}$.

$$
\mathrm{Y}=\mathrm{Y}_{0}+\mathrm{a}_{1} \mathrm{X}_{1}+\mathrm{d}_{1} \mathrm{Z}_{1}+\mathrm{a}_{2} \mathrm{X}_{2}+\mathrm{d}_{2} \mathrm{Z}_{2}+\mathrm{i}_{\mathrm{aa}} \mathrm{X}_{1} * \mathrm{X}_{2}+\mathrm{i}_{\mathrm{ad}} \mathrm{X}_{1} * \mathrm{Z}_{2}+\mathrm{i}_{\mathrm{da}} \mathrm{Z}_{1} * \mathrm{X}_{2}+\mathrm{i}_{\mathrm{dd}} \mathrm{Z}_{1} * \mathrm{Z}_{2}+\varepsilon
$$

Considera-se que os dois locos estão em epistasia quando pelo menos um dos coeficientes $i_{a a}, i_{a d}, i_{d a}$ ou $i_{d d}$ são estatisticamente diferentes de zero.

Este modelo apresenta oito graus de liberdade, o que pode exigir grande quantidade de amostras para testar os parâmetros de interesse. Se fossem considerados três ou mais locos, este problema seria ainda maior.

Note-se que a formalização dos modelos acima, feitas para um fenótipo quantitativo, podem ser estendidas para a classe de modelos de regressão logística quando o fenótipo é caso-controle (FALCONER; MACKAY, 1996).

\subsection{Modelos de epistasia}

Redes metabólicas reais são muito complexas. Os marcadores podem estar em regiões codificadoras, quando afetam a produção de proteínas ou RNA, ou em regiões reguladoras, afetando a quantidade e as ocasiões em que proteínas são produzidas. Portanto, as formas com que genes podem interagir são quase infinitas. Hallgrímsdóttir e Yuster enumeraram 387 casos possíveis de epistasia entre dois locos 
com penetrância ${ }^{2}$ total e incompleta em fenótipos caso-controle, que podem ser reduzidos a 69 considerando as simetrias. (HALLGRÍMSDÓTTIR; YUSTER, 2008). Esta classificação é útil como um passo para desvendar a rede metabólica, após a descoberta dos locos epistáticos (GAO et al., 2010), mas não contribui para encontrálos, pois, caso sejam usados modelos específicos para cada caso de epistasia, o problema dos múltiplos testes seria grandemente agravado. A definição estatística de epistasia é mais útil para encontrar os conjuntos de marcadores que interagem, pois possibilita menos testes por grupo de marcadores.

\subsection{A maldição da dimensionalidade}

Esta é uma expressão bastante usada em bioinformática e computação (em inglês "the curse of dimensionality"), cunhada por Richard Bellman (BELLMAN, 1957), quando se enfrenta problemas cuja solução exige algoritmos com complexidade $^{3}$ exponencial ou fatorial. Se quisermos fazer busca exaustiva de conjuntos de SNPs, quando aumentamos o número de SNPs a analisar, de um para dois ou de dois para três, na verdade estamos acrescentando uma nova dimensão na análise, e isso é punido com um enorme aumento no tempo computacional, como veremos a seguir.

$\mathrm{Na}$ busca exaustiva de epistasia, a princípio é preciso analisar cada conjunto de marcadores separadamente. Se há $n$ SNPs e necessita-se analisar epistasia de até $p$ locos, o número de análises será $C_{n, p}$, o que equivale a $[n(n-1) \ldots(n-p+1)] / p !$. Essa complexidade combinatorial, embora não tão ruim quanto uma fatorial, ainda pode ser considerada uma "maldição", pois é aproximadamente exponencial quando se varia o número de locos $p$ em cada conjunto. Para os valores comuns na busca por epistasia $p$ entre 2 e 10, e $n$ de 300 mil a um milhão - para cada loco acrescentado em $p$, o tempo de processamento é multiplicado por aproximadamente cem mil.

Para analisar um caso possível, suponha-se que haja mil indivíduos na amostra (um número comum nesses testes, mas nem sempre suficiente) e 300.000 SNPs coletados. Para testar somente o efeito aditivo de cada marcador, será necessário fazer 300.000 regressões lineares de mil pontos cada uma.

\footnotetext{
${ }^{2}$ Penetrância: entre todos os indivíduos que possuem um certo genótipo, a fração deles que apresenta o fenótipo de interesse. É expressa normalmente como uma porcentagem.

${ }^{3}$ Complexidade: De que maneira aumenta o tempo de processamento de um algoritmo computacional quando aumentamos um parâmetro importante, tal como o número de itens sendo analisado.
} 
Consideremos agora o ajuste do modelo de epistasia usando dois locos apenas, mas adotando o modelo interativo completo (FIM), como explicado acima. Para analisar todos os pares de locos possíveis, será necessário fazer 45 bilhões de regressões lineares, estimando e testando pelo menos quatro parâmetros cada uma. Para três locos, seriam necessárias 450 trilhões de regressões, o que não é factível com os recursos computacionais atuais.

A busca de epistasia em estudos de associação pode ser encarada como um problema de seleção de variáveis que interagem e com efeito sobre a variável de interesse. Outras ciências, em especial a economia, desenvolveram métodos de seleção de variáveis, mas estes métodos são apropriados para algumas dezenas de variáveis somente. Conforme pudemos ver na Tabela 2, podemos ter centenas de milhares de SNPs, e cada um deles é uma variável. Os estudos de associação em genética precisam desenvolver seus próprios métodos, adequados a essa grande quantidade de variáveis.

Este tópico será discutido ainda mais adiante, no item 3.8 - Busca exaustiva de pares de locos. 


\section{Métodos para detecção de epistasia}

A multidimensionalidade não significa que se deva abandonar os problemas, e sim que é necessário usar técnicas mais sofisticadas (BELLMAN, 1961). Muitas técnicas diferentes têm sido propostas. A seguir são revistas as técnicas mais significativas.

\subsection{Técnicas de busca condicional em duas fases}

Muitos dos algoritmos propostos para processar uma grande massa de dados possuem duas fases. A primeira é uma fase rápida, porém pouco precisa, que admite muitos falsos positivos. É nesta primeira fase que está o desafio de retirar informação da grande quantidade de dados em um tempo hábil. Em seguida, admitindo como entrada somente os dados saídos da primeira fase, vem uma segunda fase mais rigorosa, em que os falsos positivos são reduzidos ao mínimo. O volume menor de dados na segunda fase permite que as técnicas tenham maior complexidade computacional e ainda sejam utilizáveis.

Entre as técnicas mais populares, estão as de busca condicional. Podemos fazer pareamento somente com os SNPs que apresentam maior efeito aditivo. Na primeira fase todos os SNPs são analisados individualmente por regressão logística, sem considerar a epistasia. Nesta fase são selecionados alguns SNPs que apresentam efeito aditivo importante, mesmo que não significante quando aplicada a correção para múltiplos testes. Em seguida é feita a análise de epistasia, em que os pares ou trios de SNPs sempre contêm um ou mais SNPs com efeito aditivo. Esta estratégia reduz significativamente o tempo de processamento exigido, mas nunca irá detectar epistasia que não seja acompanhada de efeito aditivo importante (CORDELL, 2009). Aparentemente, muitos genes envolvidos em epistasia não apresentam efeito aditivo apreciável (CHAPMAN; CLAYTON, 2007; WANG et al., 2009b). EVANS et al. (2006) compararam estas estratégias de busca condicional com a busca exaustiva (FIM), e concluíram que a busca exaustiva tem vantagens, mas somente é praticável no caso de dois locos.

Entre as técnicas que não requerem pelo menos um SNP com efeito aditivo importante, podemos destacar:

- Multifactor Dimensionality Reduction (MDR), (RITCHIE et al., 2001). 
- Ganho de informação (MOORE et al., 2006), do mesmo grupo do MDR.

- SNP Harvester (SH) (YANG et al., 2009a).

- AntEpiSeeker (WANG et al., 2010)

- Association Graph Reduction (KILPATRICK, 2009)

Outros dois métodos populares, o BEAM - Bayesian Epistasis Association Mapping (ZHANG; LIU, 2007), e Random Forests (BREIMAN, 2001), embora promissores, não foram analisados aqui por terem sido considerados inferiores a outros métodos em mais de uma das revisões consultadas.

\subsection{MDR - Multifactor Dimensionality Reduction}

Em 2001, um grupo da Vanderbilt University, no Tenessee, publicou o artigo Multifactor-Dimensionality Reduction Reveals High-Order Interactions among Estrogen-Metabolism Genes in Sporadic Breast Cancer, o qual introduz uma nova técnica na pesquisa de epistasia. O grupo é liderado por Jason Moore, da Darmouth Medical School, New Hampshire. O método teve aperfeiçoamentos apresentados em novos artigos de 2003 e 2006.

\section{Como funciona o MDR}

O MDR utiliza os seguintes passos: (RITCHIE et al., 2001)

- Selecionar um conjunto de SNPs a serem estudados

- Para cada possível combinação de n dos SNPs iniciais, calcular a proporção de casos/controles para os 3n genótipos possíveis. Genótipos com mais casos do que controles são de alto risco. Genótipos com menos casos do que controles são de baixo risco.

- Agrupar os genótipos desta combinação de SNPs entre alto risco e baixo risco. Usar este agrupamento como um modelo preditivo.

- Fazer a medição acima para 9/10 dos indivíduos. Usar o décimo restante para testar o desempenho do modelo. Refazer dez vezes, mudando o décimo de teste. Escolher o modelo que faz as melhores predições.

- Ordenar os genótipos da lista vencedora por proporção caso/controle. Entre os vencedores, testar a significância, com testes mais robustos. 


\section{Crítica ao MDR}

O algoritmo MDR não é um verdadeiro redutor de dimensionalidade, pois exige que o programa percorra todo o espaço de combinação de SNPs escolhidos. A própria existência do passo 1 - escolha dos SNPs a parear - é uma demonstração disso, pois existe somente para reduzir o número de combinações a testar. O tempo de processamento ainda cresce exponencialmente com o número de SNPs.

\subsection{Ganho de Informação (IG)}

No passo 1 do MDR é feita a seleção inicial dos SNPs. MOORE et al. (2006) sugerem usar uma abordagem de entropia, verificando quais SNPs apresentam uma distribuição não equitativa entre caso e controle, para algum dos três genótipos possíveis. São selecionados somente os SNPs cuja má distribuição superar um limiar.

\subsection{SNP Harvester}

Can Yang e seus companheiros da Universidade de Hong Kong propuseram este método em 2009 (YANG et al., 2009a). Eles classificam seu método como uma busca estocástica, em oposição à força bruta (busca exaustiva) e busca de cobiça. Já CHEN et al. (2009) preferem classificar o SNP Harvester como "busca heurística determinística". Ele é comparado favoravelmente com o método BEAM - Bayesian epistasis association mapping (BEAM), proposto por ZHANG, Y.; LIU, J. S. (2007). Também recebe avaliação favorável em KILPATRICK (2009). Possuindo baixa complexidade computacional, ele se propõe a ser o primeiro passo na seleção inicial dos SNPs.

Uma característica dos métodos de busca estocástica como o SNPHarvester é que geralmente os resultados não podem ser reproduzidos, a não ser que tenham sido especificamente projetados para isto, com armazenagem da semente aleatória e publicação do algoritmo pseudo-aleatório utilizado, o que não é o caso do SNPHarvester.

\subsection{AntEpiSeeker}

A ideia deste método é aplicar o algoritmo de colônia de formigas à busca de epistasia. A ideia é simular o modo como as formigas descobrem a melhor rota entre o formigueiro e a fonte de comida. Pode ser classificado entre os métodos de busca 
estocástica. Wang et al. (2010) propõem que seu algoritmo seja o mais rápido. No entanto ele é excessivamente parametrizado. $\mathrm{O}$ usuário pode escolher quanto tempo a análise vai levar, somente mudando os parâmetros. Os autores sugerem "regras de ouro" para a escolha dos parâmetros, sem maiores justificativas, mas nem sempre seguem as próprias regras. Por exemplo, na seção Parameter Setting, sugere iltCountSmall >=0,1L. Já na seção Results on WTCCC RA data, refere que os parâmetros foram ajustados de acordo com a regra geral apresentada em Parameter setting. Como o total de SNPs neste caso é $\mathrm{L}=332.831$, esperávamos iItCountSmall $>=33.000$. No entanto, no website do projeto temos o arquivo de parâmetros com o valor 6.000. Este valor afeta linearmente o tempo de execução. Se fosse usado o valor recomendado, o tempo de execução iria para cerca de 20 dias, superior ao SNPHarvester.

\subsection{AGR - Redução de Grafos de Associação}

Kilpatrick, em sua tese de mestrado de 2009, faz uma boa revisão dos métodos para busca de epistasia. Propõe também um novo método de busca baseado em grafos, apresentando comparação com o SNP Harvester e com Random Forests. O AGR aparece como muitas vezes mais rápido que os outros. No entanto, observando mais de perto os parâmetros utilizados, notamos que o AGR foi utilizado como uma técnica de efeito aditivo em dois estágios, sendo incapaz de encontrar epistasia caso algum dos locos não apresente efeito aditivo apreciável.

É verdade que é possível mudar os parâmetros e eliminar este problema. Porém, analisando o algoritmo com cuidado, neste caso a complexidade fica combinatorial, ou seja, o algoritmo deixa de ser rápido e apresenta os mesmos problemas que a busca exaustiva.

\subsection{Comparação dos métodos}

Chen et al. (2009), mostram o resultado dos testes dos principais métodos para detecção de epistasia em GWAS. Além do MDR, ganho de informação, SNP Harvester e BEAM, eles analisam mais um, Penalized Logistic Regression (PLR), proposto por PARK; HASTIE, (2008).

Após enumerar e classificar os métodos, os autores testam o desempenho das estratégias usando dois conjuntos simulados de SNPs, com 100 e 1000 SNPs. Para 
cada método, eles avaliam os seguintes aspectos: desempenho computacional, como cresce o desempenho com o número de SNPs, sensibilidade e especificidade. A Tabela 4 apresenta os dados comparativos das estratégias utilizadas.

Tabela 4 - Tempo de execução de cada algoritmo, em segundos. Extraído de Chen et al, 2009.

\begin{tabular}{lrrrrrr}
\hline & IG & FIM & MDR & BEAM & SH & PLR \\
\hline 100 SNP & 3 & 4 & 1120 & 12 & 6 & $>1,7 \times 10^{5}$ \\
1000 SNP & 114 & 205 & $1,4 \times 10^{6}$ & 855 & 21 & --
\end{tabular}

Note que os testes foram feitos para mil SNPs, enquanto as modernas plataformas de genotipagem chegam a um milhão de SNPs. Portanto, a complexidade do algoritmo utilizado e o tempo de processamento são da maior importância. De todos os métodos analisados, o SNP Harvester é o mais promissor neste item. Mostrou um aumento de 6 para 21 segundos quando aumentamos o número de SNPs de cem para mil. Todos os outros mostraram um aumento muito maior, sendo que o MDR e o PLR mostraram aumentos proibitivos. No quesito de complexidade computacional, o SNP Harvester parece ser o único método capaz de enfrentar a multidimensionalidade, entre os propostos até agora.

Este sucesso no tempo de processamento vem com um custo: o SNP Harvester não é bem avaliado nos outros dois quesitos do teste, sensibilidade e especificidade. A comparação é apresentada através da curva ROC - Receiver Operating Characteristc, que é um grafico da sensibilidade contra a especificidade Para um certo grau de sensibilidade (isto é, $\mathrm{P}(\mathrm{V}+)$ ), a especificidade (istoé, $\mathrm{P}(\mathrm{V}-)$ ) do $\mathrm{SH}$ é fraca, o que significa que ele produz muitos resultados falso-positivos, quando comparado aos outros métodos. No entanto, esta proporção de falso-positivos melhora, reduzindo-se, quando aumentamos o número de SNPs analisados, superando vários dos outros métodos na sensibilidade em graus baixos de especificidade. 


\subsection{Busca exaustiva de pares de locos}

A maldição da dimensionalidade impede análises exaustivas de três locos ou mais. Mas para dois locos ela é factível. Já em 2005, Marchini et al. mostraram que é possível fazer análise exaustiva de todos os pares de locos de uma plataforma de 350 mil SNPs em cerca de 33 horas, usando um cluster de computadores poderosos. Apesar disso, não temos notícia de que este tipo de análise tenha sido feito em outros estudos nos anos seguintes, talvez porque os recursos computacionais requeridos ainda fossem elevados.

\section{BOOST}

Em 2010, Wan e outros da Universidade de Hong-Kong propuseram o BOOST, um novo algoritmo para busca exaustiva de pares epistáticos (WAN et al., 2010). A descoberta deles não chega a ser revolucionária, pois a complexidade do algoritmo continua combinatorial, ou seja, só serve para pares de locos e não para conjuntos maiores. No entanto, eles conseguem fazer essa busca exaustiva de pares de locos de uma maneira muito rápida, até 63 vezes mais rápido que o PLINK (PURCELL et al., 2007), concorrente recomendado em uma recente revisão (CORDELL, 2009). Eles usam um modelo diferente do PLINK. Enquanto este usa regressão logística, incluindo os termos de interação, com 4 graus de liberdade, o BOOST usa um modelo log-linear de tabela de contingência $3 \times 3 \times 2$. Este modelo é equivalente ao modelo com regressão logística conforme descrito no próprio artigo e fundamentado em AGRESTI, 2002. A descoberta chave é uma função de aproximação para o cálculo da razão de verossimilhanças que possui forma analítica explícita e cujo cálculo é muito rápido. Contribuiu também uma eficiente representação booleana dos dados, em mapas de bits. Normalmente os estudos usam uma matriz de $\mathrm{n}$ indivíduos por m locos, com valores 0,1 e 2, para os genótipos AA, Aa e aa, respectivamente. O BOOST usa uma matriz de $\mathrm{n}$ indivíduos por $3 \mathrm{~m}$ genótipos, com valores 0 e 1 somente.

O BOOST é um algoritmo em duas fases. Na primeira fase, a razão de verossimilhanças é calculada para todos os cem bilhões de pares possíveis, usando a função de aproximação rápida. A primeira fase seleciona entre 300 a 600 mil pares de locos que irão à segunda fase. A segunda fase realiza o teste qui-quadrado da razão de verossimilhanças de forma precisa para cada par. O BOOST então faz a correção de 
Bonferroni, que é muito exigente, e somente uns poucos pares são considerados significantes.

\section{Detalhamento do BOOST}

Como o BOOST é parte integrante do algoritmo proposto neste trabalho, oferecemos aqui mais detalhes sobre seu funcionamento.

Entrada: Genótipos da forma 0,1 ou 2. 0 é o homozigoto para o alelo de referência, estabelecido de antemão. 1 é o heterozigoto e 2 é o homozigoto para o alelo alternativo. O arquivo tem uma linha para cada indivíduo (amostra) e uma coluna para cada SNP. A primeira coluna do arquivo é o fenótipo: 1 para casos, 0 para controles. Pode ser um arquivo para cada cromossomo, que internamente ao BOOST serão justapostos como colunas. Neste caso a coluna de fenótipos tem que ser igual em todos os arquivos. O BOOST não aceita como entrada qualquer outro formato ou detalhe, tais como alelos de referência, identificação dos SNPs ou indivíduos, ou informação para excluir amostras ou SNPs do cálculo.

O parâmetro principal é o limiar do valor de interação (InteractionBoost) para passagem da primeira para a segunda fase, que tem como default o valor 30 .

\section{Resumo do método}

O BOOST constrói uma tabela de contingência $3 \times 3 \times 2$, onde 3 são os genótipos de cada SNP e 2 são os níveis caso e controle do fenótipo. A seguir ele aplica dois modelos log-lineares para serem comparados: o modelo saturado, que leva em conta a interação, e o modelo homogêneo, que não leva em conta a interação. Os dois modelos levam em conta os efeitos aditivo de cada SNP. Então o BOOST calcula a razão de verossimilhanças entre os dois modelos e faz o teste de significância da interação. Cada um dos dois modelos log-lineares equivale a um modelo de regressão logística.

A estatística principal calculada pelo BOOST é a Interaction BOOST. Ela vale 2( $\left(\mathrm{L}_{\mathrm{S}}-\mathrm{L}_{\mathrm{H}}\right)$, ou seja, o dobro da diferença entre os logaritmos de duas verossimilhanças: a do modelo log-linear saturado e a do modelo log-linear homogêneo. Isso equivale ao logaritmo da razão de chances entre os dois modelos, para aquele par de SNPs. Por exemplo, vejamos o que significa o limiar de InteractionBoost $=30$. Esta estatística 
InteractionBoost tem uma distribuição qui-quadrado com 4 graus de liberdade. Esse limiar de 30 corresponde a um valor-p não-corrigido de $4,89 \times 10^{-6}$.

\section{Associação marginal}

Um dos resultados reportados pelo BOOST é uma estatística chamada Marginal Association, que mede o efeito individual (aditivo) de cada SNP. Ela não é descrita nos artigos, mas pudemos conferi-la no programa-fonte. Ela é calculada por entropia, tal como entendida na teoria da informação: se uma variável aleatória discreta tem n possíveis resultados, cada um com probabilidade $\mathrm{p}_{\mathrm{i}}$, sua entropia é:

$$
H(X)=-\sum p_{i} \ln \left(p_{i}\right) \text { se } p_{i} \neq 0 ; 0 \text { se } p_{i}=0
$$

Como o logaritmo de uma probabilidade menor do que um é sempre negativo, a entropia é sempre positiva. O melhor estimador para a probabilidade é a proporção encontrada no estudo. Para o BOOST, a associação marginal do SNP i é:

$$
A M g=2 n[H(\text { caso-controle })+H(\text { genótipos })-H(\text { interna })]
$$

Em que H(caso-controle) é a entropia da distribuição geral caso-controle, igual para todos os SNPs. Por exemplo, se o número de casos é igual ao de controles, $\mathrm{p}_{\mathrm{i}}=0,5 \mathrm{e}$ $H($ caso-controle $)=0,693$. Já no caso do WTCCC, que tinha 2000 casos e 3000 controles, $\mathrm{p}_{\mathrm{i}}=0,4$ e $H($ caso-controle $)=0,673$.

$H$ (genótipos) é a entropia da distribuição entre os três genótipos, em que $\mathrm{p}_{\mathrm{i}}=$ p(AA), p(Aa) ou p(aa). Finalmente, H(interna) é a entropia da distribuição da tabela de contingência completa $3 \times 2$, onde cada proporção é $\mathrm{n}_{\mathrm{ij}} / \mathrm{n}$.

A medida do efeito individual por entropia é útil, mas ela é pouco usada por não ter uma distribuição estatística associada, que permita-nos calcular a significância da medida. 


\section{GBOOST}

O grupo do BOOST foi além, adaptando o BOOST para rodar em placa de vídeo (GPU - Graphical Processing Unit), com uso de processamento paralelo, com o artigo "GBOOST: uma ferramenta baseada em GPU para detectar interações genegene em estudos de associação de genoma inteiro" (YUNG et al., 2011). Eles conseguiram reduzir em 40 vezes o tempo de processamento do BOOST. Os dados do WTCCC (Welcome Trust Case-Control Consortium) (CARDON et al., 2007) de diabetes tipo 2, com cerca de 350 mil locos, foram analisados em menos de uma hora e meia.

A velocidade desse algoritmo, aliada ao preço acessível da placa, agora permite que praticamente todo estudo de genoma inteiro seja analisado para busca de pares epistáticos. Já a busca exaustiva de trios, quartetos e conjuntos maiores continua proibitiva. Uma busca de trios em 350 mil SNPs, supondo que o GBOOST fosse adaptado para trios, levaria cerca de 21 anos, mesmo usando placa de vídeo. 


\section{Objetivos}

Dentro do problema geral da busca de marcadores genéticos em todo o genoma potencialmente associados a fenótipos do tipo caso/controle, o objetivo principal deste trabalho foi a proposta de um algoritmo para busca de trios de lócus epistáticos, utilizando a busca exaustiva de pares como primeira fase, e explorando duas idéias principais:

a) Uso da interação entre pares para busca de trios "fechados";

b) Agrupamento de SNPs próximos em blocos haplotípicos.

Outros objetivos foram a implementação deste algoritmo em um conjunto de ferramentas computacionais e seu teste usando os dados fornecidos pelo WTCCC. A hipótese principal a ser testada é a de que os trios sugeridos pelo Troost estão associados à doença em questão. 


\section{Material e métodos}

\subsection{Compilação dos tempos de busca de epistasia}

Muitos dos artigos revistos para esta tese reportavam testes reais ou simulados feitos com um ou mais dos algoritmos descritos aqui. Como estamos interessados em algoritmos capazes de lidar com uma grande massa de dados, compilamos estudos com mais de dez mil locos e os apresentamos na Tabela 7. Procuramos comparar, na medida do possível, o desempenho de cada algoritmo, corrigindo os tempos reportados por dois fatores: CPU utilizada e número de locos analisados, considerando a complexidade de cada algoritmo. Os testes que encontramos na literatura até julho de 2011estão reportados, desde que tenham sido feitos com dez mil locos ou mais.

Os tempos de execução foram corrigidos para as CPUs informadas de acordo com o índice comercial Passmark (http://www.cpubenchmark.net). Não há o objetivo de se fazer uma correção precisa, pois os autores revisados forneceram informação sobre a CPU utilizada e não sobre o sistema completo. No entanto, embora imprecisa, a correção é importante para a comparação de algoritmos. Esta correção nunca foi superior a dez vezes.

Os tempos estão apresentados em horas:minutos:segundos, quando assim formatados, ou em dias, quando em formato decimal. Na penúltima coluna, vemos o tempo extrapolado, de acordo com a complexidade do algoritmo, para a busca de interações de pares entre um milhão de SNPs. A última coluna é uma extrapolação para busca de trios epistáticos, que não pode ser feita para alguns dos algoritmos.

Embora haja na literatura casos de comparação de algoritmos lado a lado (CHEN et al., 2009, 2011), não encontramos compilação alguma semelhante a esta que desenvolvemos neste trabalho.

\subsection{Dados para a pesquisa - o estudo do WTCCC}

Optamos por usar somente dados reais. O maior estudo de associação já feito é o do WTCCC (CARDON et al., 2007): "Estudo de associação de genoma inteiro com 14 mil casos de sete doenças e 3 mil controles compartilhados". Solicitamos e obtivemos os dados deste estudo, que são os dados que usamos nesta pesquisa. Todos 
os casos e controles são da Grã-Bretanha e têm ascendência europeia. Foram genotipados usando a plataforma Affymetrix 550K.

Recebemos quase 40 gigabytes de dados criptografados, com chave fornecida pelo correio somente.

Para a fase exploratória, escolhemos a primeira das doenças, pela ordem alfabética em inglês: transtorno bipolar, também chamada de distúrbio bipolar.

\section{Descrição dos dados do WTCCC}

Apesar de ter disponíveis os dados ópticos e as probabilidades de cada genótipo, optamos por usar somente os dados já processados, que trazem o genótipo mais provável para cada indivíduo em cada SNP. O algoritmo de "calling" foi o Chiamo e o formato de dados escolhido foi o transposed Plink, com extensão de arquivo .tped.

Recebemos nove conjunto de dados (datasets): um para cada uma das sete doenças, cada um com cerca de duas mil amostras (indivíduos) e dois grupos de controles, cada um com 1500 indivíduos. Estes conjuntos são chamados de NBS, de National Blood Service, e 58C ou 1958 BBC, de British Birth Cohort. Cada conjunto de dados está dividido em 22 arquivos, um para cada cromossomo.

Os arquivos .tped tem uma linha para cada SNP daquele cromossomo e duas colunas para cada indivíduo ou amostra. Portanto são arquivos "largos", com $1500 \mathrm{ou}$ 2000 colunas mais separadores, e "longos", tendo entre 6 mil e 45 mil linhas. Como exemplo, apresentamos aqui o início das primeiras linhas do arquivo dos controles NBS, cromossomo 22:

22 SNP_A-2148100 025711193 C C C C A C A C C C C C A C A C... 22 SNP_A-2039623 016875470 G G G G G G A A G G A G A A $G$ G... 22 SNP_A-2135203 033388119 C G C C C C C G C C C C C C C C...

Portanto os dados que temos são:

$\mathrm{CR}$ - cromossomo

AffymID - identificação Affymetrix

0 (reservada para posição de mapa em centimorgans, não fornecida)

pos - posição no cromossomo de acordo com o build 136 da DBSNP

G1 e G2 - Genótipo de cada SNP, em ordem alfabética de bases. Existe A C mas nunca $\mathrm{C}$ A. 
Os indivíduos estão listados em um arquivo próprio para cada conjunto de dados, que traz sexo e região do Reino Unido. Usamos estes arquivos somente como referência para as listas de exclusão de indivíduos, de modo a identificar quais colunas dos arquivos tped devem ser excluídas.

Há ainda um conjunto de arquivos, um por cromossomo, que lista os SNPs com os dados: cromossomo, posição, ID EGAV, ID Affymetrix e ID rs. Este conjunto é chamado de "snps", em minúsculas, e foi utilizado no processamento das distâncias. Embora acompanhe cada conjunto de dados, é o mesmo conjunto, ou seja, é um conjunto só para todo o estudo do WTCCC.

O último conjunto de arquivos fornecido pelo WTCCC é apelidado de summary. Ele traz uma linha para cada marcador com os dados estatísticos compilados no estudo. A primeira linha traz os títulos das colunas:

id rs Id pos a11e1e1 a11e1e2 average_maximum_posterior_ca11 controls_AA controls_AB controls_BB controls_NULL cases_AA cases_AB cases_BB cases_NULL frequentist_add frequentist_gen bayesian_add bayesian_gen sex_frequentist_add sex_frequentist_gen good_clustering

Usamos estes arquivos somente com dois propósitos específicos: acertar a posição de uns poucos SNPs cujas distâncias aparecem zeradas no .tped, e para excluir SNPs que não atingiram os padrões de qualidade do WTCCC, já que o summary lista somente os SNPs válidos. Já no final de nossa pesquisa, descobrimos que a última coluna é importante e os SNPs que apresentam good_clustering igual a zero devem ser excluídos, mesmo que não constem da lista de exclusão.

Os programas BOOST e GBOOST fizeram uma seleção mais estrita da qualidade dos SNPs, ficando com cerca de 330 mil SNPs. Na nossa pesquisa, preferimos adotar os critérios de exclusão do WTCCC, e o conjunto final foi de 459 mil SNPs.

\section{Qualidade dos dados do WTCCC}

De modo geral, os dados recebidos são de alta qualidade. Todos os arquivos têm o exato número de linhas e de colunas esperado, de acordo com o número de indivíduos do conjunto de dados e de SNPs daquele cromossomo. A codificação das bases, A, C, G e T em maiúsculas, e 0 para dados perdidos, é $100 \%$ respeitada, e isso 
numa quantidade muito grande de dados. A rs ID só está ausente nos SNPs da Affymetrix que não tinham correspondente na DBSNP.

Mas há alguns problemas:

- Em quatro casos (em 550 mil), os SNPs aparecem com cromossomos diferentes do arquivo em que se encontram.

- O arquivo de summary traz distâncias em bases num build diferente do build utilizado nos arquivos tped e snps.

- A rs Id do summary não bate com a do tped em alguns casos.

- Nos arquivos snps e tped, em cerca de $1 \%$ dos casos os SNPs estão com a distância zerada. Isto nos obrigou a buscar estas distâncias no projeto HapMap.

- Há listas de exclusão de SNPs para cada doença, incluindo os critérios usados para a exclusão, mas os SNPs com mau agrupamento foram excluídos numa fase posterior do estudo do WTCCC e não fazem parte dessas listas.

\subsection{Análise exploratória dos pares de locos}

A principal proposta deste trabalho é propor um algoritmo de busca de epistasia utilizando o BOOST como primeira fase. Antes de especificá-lo por completo, fizemos uma análise exploratória dos pares de locos identificados, no sentido de responder a perguntas do tipo:

a) Entre os SNPs que aparecem nos pares, há predominância dos que tem efeito aditivo?

b) Os SNPs com maior efeito aditivo obscurecem os pares, ao aparecer num grande número deles?

c) Quantos SNPs existem na lista de pares?

d) Existem padrões encadeados do tipo $\mathrm{AB}, \mathrm{BC}, \mathrm{CD}$ ?

e) Há muitos pares de SNPs próximos, com alto desequilíbrio de ligação (LD) entre si?

f) SNPs com alto LD aparecem pareados com os mesmos outros SNPs?

g) É possível escolher um único SNP em grupos que têm alto LD entre si?

Esta análise visou apontar modificações importantes no algoritmo proposto. 
$\mathrm{Na}$ verdade, poucos pares atingiram o nível de significância normalmente especificado, após a correção de Bonferroni. Exigir usar somente pares significantes após esta correção inviabilizaria a análise exploratória. A solução foi adotar um nível de significância bastante liberal, tendo consciência que, entre os pares analisados, muitos estarão lá por mera chance, e não por serem realmente significativos.

A seguir detalhamos os métodos que usamos nesta análise.

O BOOST tem duas fases. A primeira é exaustiva, analisando cerca de 100 bilhões de pares de SNPs. O limiar default do BOOST é 30, ou seja, são selecionados os pares com InteractionBoost maior ou igual a 30.

Com os dados de uma das doenças, rodamos o BOOST, porém escolhendo um nível bastante liberal do valor-P, de modo que retornassem cerca de 70 mil pares. Estes pares devem corresponder a um número locos não maior que o dobro disto. A pressuposição é que muitos desses pares, mesmo que não tenham atingido o valor-P necessário para a prova inequívoca de que influem no fenótipo, possam influir de fato no fenótipo.

Tabela de pares: O GBOOST retorna uma lista com todos os pares. Esta lista contém o índice de cada loco participante e o efeito de interação encontrado.

- Para melhor visualizar a tabela de pares, listar sempre o SNP com maior efeito aditivo primeiro.

- Ordenar a tabela de pares por maior efeito aditivo do primeiro loco. Procurar agrupamentos ou padrões interessantes

- Ordenar a tabela por efeito de epistasia. Procurar agrupamentos de interesse.

Tabela de locos: Construir uma tabela dos locos que participam dos pares selecionados, preenchendo as seguintes colunas:

○ identificação do loco;

○ cromossomo;

○ região;

○ posição no cromossomo em bases;

○ distância de mapa genético; 
○ associação marginal;

○ número de pares em que este loco aparece.

- Ordenar por cada uma destas três últimas colunas, e observar padrões entre os primeiros e últimos em cada ordenação.

- Propor gráficos adicionais, frutos da observação acima.

\subsection{A proposta: o algoritmo Troost}

Propomos neste trabalho duas ideias que não encontramos antes sendo usadas para esta finalidade:

1. A partir dos pares que interagem, buscar trios que interagem.

2. Agrupar marcadores em blocos haplotípicos a partir dos pares de SNPs que foram selecionados.

\section{Ideia 1: Busca de trios epistáticos a partir dos pares}

A busca de pares epistáticos recebeu um grande impulso com o GBOOST. Na Figura 6, ilustramos os pares de marcadores com interações de diferentes forças. No entanto, a busca exaustiva de conjuntos maiores, de três ou mais marcadores que interagem, continua impraticável. Esta pesquisa propõe-se a fazer esta busca de trios em duas fases, usando o GBOOST como primeira fase. Nomeamos nosso algoritmo como Troost, de TRio + bOOST. Na Figura 7, ilustramos como podemos usar pares de SNPs para compor trios. Chamamos de "trios fechados" aqueles em que os três pares possíveis entre os três marcadores têm interações fortes. Trios abertos são trios de marcadores em que dois dos três pares possíveis estão entre os pares com interação forte.

Outros algoritmos como, por exemplo, AntEpiSeeker (WANG et al., 2010) e o AGR (KILPATRICK, 2009), usam duas fases, sendo a primeira uma seleção dos SNPs de maior efeito aditivo. Dessa fase inicial, não há qualquer informação sobre interação. Perde-se qualquer conjunto que tenha SNPs com baixo efeito aditivo. 


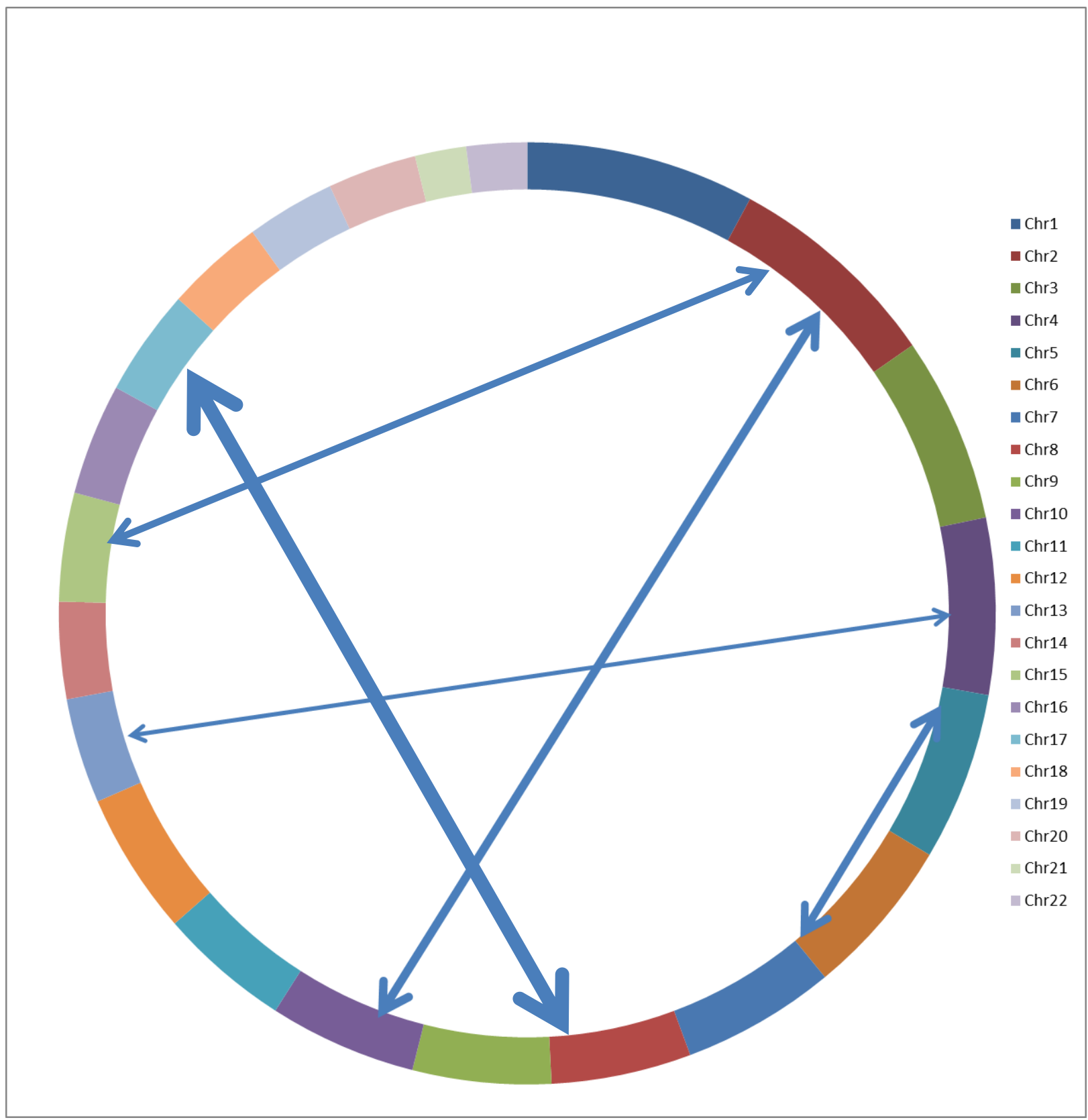

Figura 6 - Pares de SNPs - a espessura do traço indica a força da interação. Entre bilhões de pares possíveis, são consideradas apenas algumas dezenas de milhares com interações mais fortes.

Com nossa proposta, partimos de uma primeira fase muito mais informativa. Os locos não foram selecionados por seu efeito aditivo, mas sim por seu efeito de interação par a par. Durante a busca exaustiva, demos oportunidade a todos os 450 mil locos de mostrarem com quais outros eles mais interagem e em que grau. Esperamos que, a partir deste conjunto com informação sobre pares, seja possível montar conjuntos de três marcadores, em que a interação fique evidente.

Com uma ferramenta como o GBOOST disponível, não vemos mais sentido em fazer a primeira fase selecionando somente locos com efeito aditivo. A segunda fase partiu de um conjunto de centenas de milhares de pares com já com indício de apresentarem epistasia. Por ser uma busca exaustiva, todos os pares que apresentem 
epistasia devem estar representados, mesmo que incluam locos sem qualquer efeito aditivo.

Não encontramos até o momento na literatura abordagem semelhante, que se aproveite da informação adicional proveniente da busca exaustiva par a par. Cada um dos SNPs foi analisado em conjunto com cada um de todos os outros, num total de 105 bilhões de pares. Foi calculado um valor para esta interação. Temos em mãos um conjunto de relacionamentos entre SNPs, e podemos usá-lo para procurar grupos maiores.

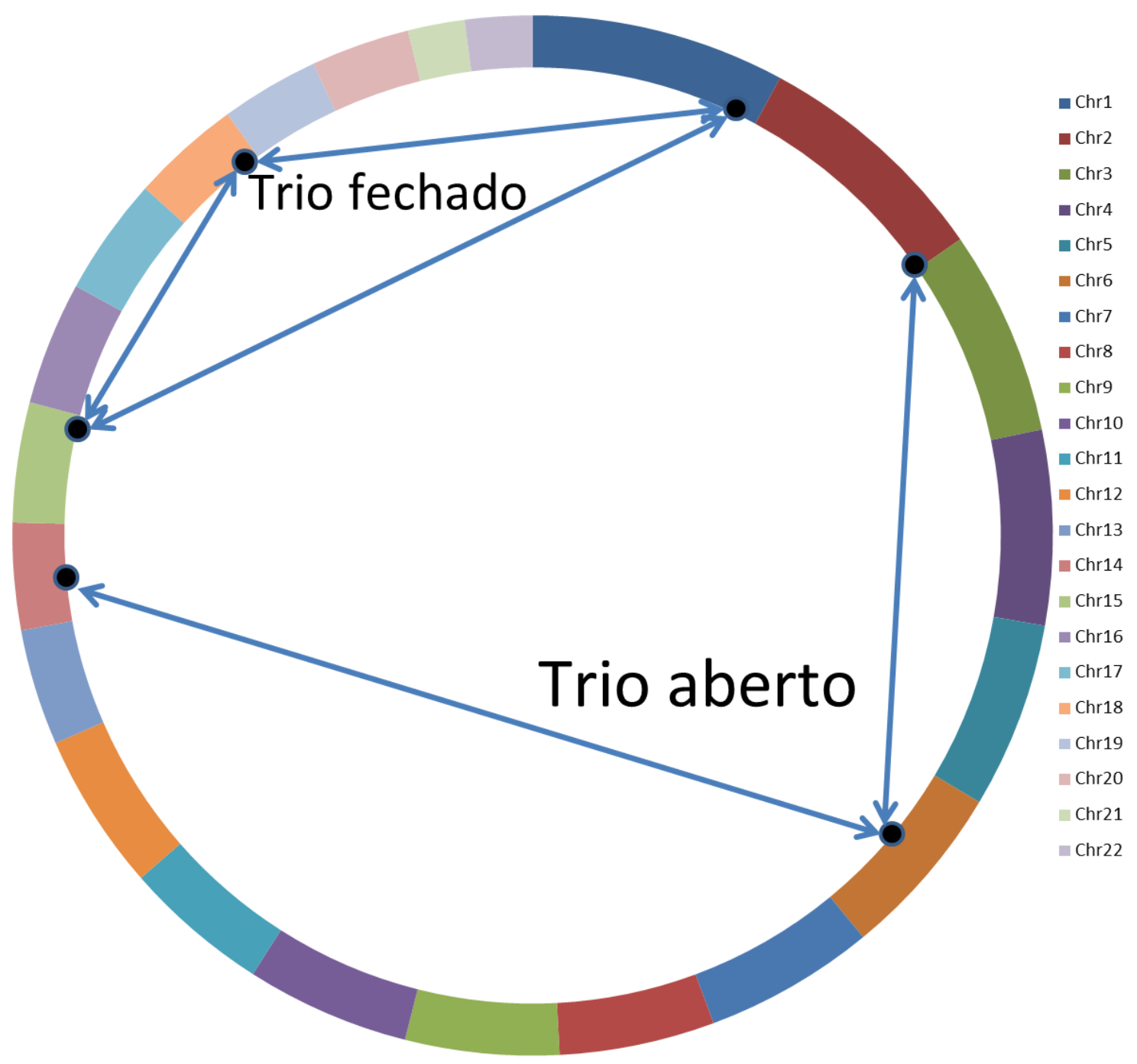

Figura 7 - Trios de SNPs ou blocos haplotípicos 


\section{Ideia 2: Construir blocos haplotípicos entre os SNPs presentes nos pares fortes}

Marcadores próximos estão fortemente relacionados. O projeto HapMap (HAPMAP CONSORTIUM, 2007), estudou em detalhe a estrutura de agrupamento dos marcadores, baseada nas diferentes taxas de recombinação em cada trecho do genoma. O projeto HapMap publicou mapas genéticos do genoma humano, usando muito mais SNPs do que os presentes na plataforma Affymetrix 550K usada pelo WTCCC.

O que encontramos em nossa análise exploratória foi que esta estrutura de agrupamento dos SNPs é ainda mais visível quando olhamos somente os SNP presentes entre os pares fortes, cerca de 60 mil SNPs em cada um dos nossos estudos.

Entre os pares fortes, um SNP pode aparecer em um dos pares, enquanto seu vizinho aparece em outro. É provável que esta região, este bloco haplotípico que contém estes dois SNPs tenha alguma influência na doença. Se continuarmos nossa análise observando somente marcadores individuais, concluiremos que não existe um trio de marcadores com possível influência. Mas, se agruparmos os SNPs em um bloco, vislumbramos a formação de um trio, e podemos testar sua influência com o uso de haplótipos. A Figura 8 ilustra o conceito de blocos haplotípicos e como eles podem reduzir o número de pares, aumentando a chance de encontrarmos trios.

Para construir os blocos haplotípicos, ou seja, para decidir quando dois SNPs são próximos o suficiente para que os estudemos em conjunto, podemos calcular as distâncias entre eles de duas maneiras: em pares de bases ou em centimorgans. Elas não são diretamente conversíveis de uma para outra. As distâncias em pares de bases são muito precisas, uma vez que se estabeleça a versão do DBSNP que estamos utilizando. Já a distância em centimorgans, ou distância de mapa genético, é uma quantidade menos precisa, porém é diretamente relacionada ao nosso objetivo: estudar um par de SNPs próximos como um haplótipo, que raramente é rompido de uma geração para outra. Como estamos usando esta distância para construir blocos haplotípicos, usamos distância em centimorgans e não a distância em bases. 


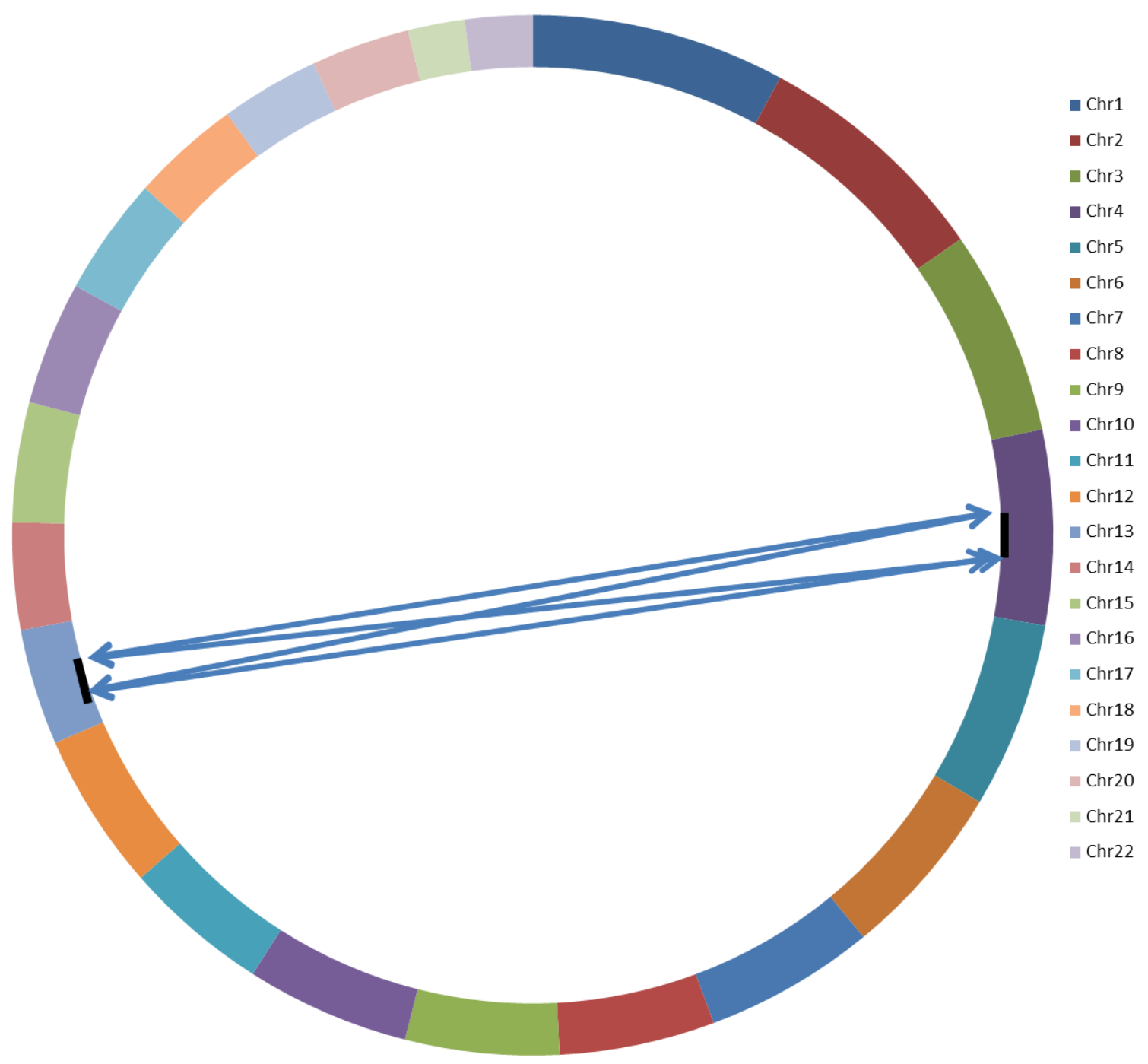

Figura 8 - Blocos haplotípicos ou milimorgans (mMs). No exemplo, quatro pares de SNPs se reduzem a um par de $\mathrm{mMs}$

\section{Duplo-haplótipos}

Em nossos programas, chamamos bloco haplotípico como milimorgan, ou $\mathrm{mM}$, pois seu tamanho raramente vai além de $0,1 \mathrm{cM}$.

Os dados que temos trazem genótipos para cada SNP, não para cada bloco haplotípico. Para trabalharmos com blocos haplotípicos, precisamos converter nossos dados em haplótipos.

Em cada mM que possui dois SNPs, temos dois genótipos, que podem ser cada um 0, 1 ou 2. Chamemos os dois SNPs de A e B. Na notação tradicional da genética 
mendeliana, esses valores correspondem a AA, Aa, aa para o primeiro SNP e BB, Bb e bb para o segundo. Os haplótipos possíveis seriam quatro: $\mathrm{AB}, \mathrm{Ab}, \mathrm{aB}$ e ab, mas cada cromossomo assume um dos quatro valores. Agrupando os dados para os dois cromossomos, teríamos dezesseis valores possíveis, que se reduzem a dez pois alguns são simétricos. Por exemplo, abAB é equivalente a ABab. Desses dez valores, dois são especiais: $\mathrm{ABab}$ e $\mathrm{AbaB}$. Eles pertencem aos indivíduos heterozigotos para os dois locos e não são equivalentes, sendo formados por haplótipos diferentes. O processo de fazer a distinção entre estes dois valores é chamado de faseamento. Os dados disponíveis não possibilitam fazer o faseamento com $100 \%$ de certeza, mas permitiriam fazê-lo dentro de alguma incerteza. Neste trabalho optamos por não fazer o processo de faseamento e considerar os dois haplótipos num mesmo grupo.

Tabela 5 - Haplótipos e duplo-haplótipos definidos por dois SNPs. O quadriculado em cinza e branco mostra os haplótipos, vistos como pares de alelos na vertical. A e B maiúsculos denotam os alelos de referência, mais frequentes.

\begin{tabular}{|c|c|c|c|}
\hline $\begin{array}{c}\text { Duplo- } \\
\text { haplótipo }\end{array}$ & $\begin{array}{l}\text { Genótipo } \\
\text { do SNP }\end{array}$ & $\begin{array}{l}\text { Haplótipo } \\
1^{\circ} \mathrm{Crom}\end{array}$ & $\begin{array}{l}\text { Haplótipo } \\
2^{\circ} \text { Crom }\end{array}$ \\
\hline \multirow{2}{*}{00} & 0 & $A$ & $A$ \\
\hline & 0 & B & B \\
\hline \multirow{2}{*}{01} & 0 & A & A \\
\hline & 1 & B & b \\
\hline \multirow{2}{*}{02} & 0 & A & A \\
\hline & 2 & b & $b$ \\
\hline \multirow{3}{*}{10} & 1 & A & $a$ \\
\hline & 0 & B & B \\
\hline & 1 & A & $a$ \\
\hline \multirow{3}{*}{11} & 1 & B & $b$ \\
\hline & 1 & A & $a$ \\
\hline & 1 & $\mathrm{~b}$ & B \\
\hline \multirow{2}{*}{12} & 1 & A & a \\
\hline & 2 & $\mathrm{~b}$ & b \\
\hline \multirow{2}{*}{20} & 2 & $\mathrm{a}$ & $a$ \\
\hline & 0 & $B$ & B \\
\hline \multirow{2}{*}{21} & 2 & $\mathrm{a}$ & a \\
\hline & 1 & B & b \\
\hline \multirow{2}{*}{22} & 2 & $\mathrm{a}$ & $a$ \\
\hline & 2 & $\mathrm{~b}$ & b \\
\hline
\end{tabular}

Quando trabalhamos somente com um SNP, podemos analisar os dados de dois modos: por alelo ou por genótipo. O PLink analisa por alelo, supondo um efeito quantitativo para cada alelo. Já o BOOST e o SNPHarvester analisam por genótipo, e conseguem detectar efeitos não lineares do heterozigoto. De maneira análoga, podemos analisar blocos haplotípicos considerando os efeitos quantitativos de cada haplótipo, ou podemos analisar os efeitos individuais de cada genótipo completo, considerando os dois cromossomos. Newton Morton (MORTON, 1983), cunhou o 
termo em inglês "diplotype", ou em português "diplótipo". O termo "diplotype" não aparece na Genetics Home Reference do NIH, mas ele consta no glossário do site SNPedia com a seguinte definição: "o que o genótipo é para o alelo, o diplótipo é para o haplótipo; uma combinação específica de dois haplótipos". Optamos por chamar de duplo-haplótipo nossa combinação. O duplo-haplótipo é um conceito muito semelhante ao diplótipo, mas com as seguintes peculiaridades:

- Não foi feito o faseamento do duplo heterozigoto

- É especificado por dois SNPs no máximo

- Adota a seguinte codificação: a partir dos valores 0, 1 ou 2 dos genótipos dos dois SNPs, temos nove valores possíveis para os duplohaplótipos: 00, 01, 02, 10,11, 12, 20, 21 e 22 .

- Pode ter um só SNP, quando os dois pares de SNPs que definem o bloco partilham o mesmo SNP. Neste caso, nosso duplo-haplótipo não é um verdadeiro diplótipo; é um genótipo simples e assume somente os valores 00,11 ou 22 .

O valor 11 é o assumido pelos indivíduos que são heterozigotos para os dois SNPs do bloco. Este valor na verdade é composto de dois outros valores, conforme a fase, ou seja, se os alelos de referência e alternativo estão no mesmo cromossomo ou invertidos. A Tabela 5 apresenta uma visão dos duplo-haplótipos com a nossa nomenclatura 0-1-2 e sua correspondência com a nomenclatura tradicional do tipo $\mathrm{AaBb}$.

\section{Esquema geral do Troost}

- Preparação de dados

- Busca exaustiva de pares de SNPs (GBoost)

- Selecionar pares de SNPs com interação acima de um limiar (dezenas de milhares entre bilhões)

- Agrupar SNPs próximos em blocos haplotípicos (mMs).

- Converter pares de SNPs em pares de mMs

- Buscar trios de mMs "fechados", ou seja, trios em que todos os três pares possíveis entre eles aparecem entre os pares fortes

- Analisar qualitativa e estatisticamente os trios. 
A Figura 9 mostra o esquema geral do Troost. Nos fluxogramas deste trabalho, retângulos representam tarefas ou programas, e elipses representam dados de entrada ou saída.

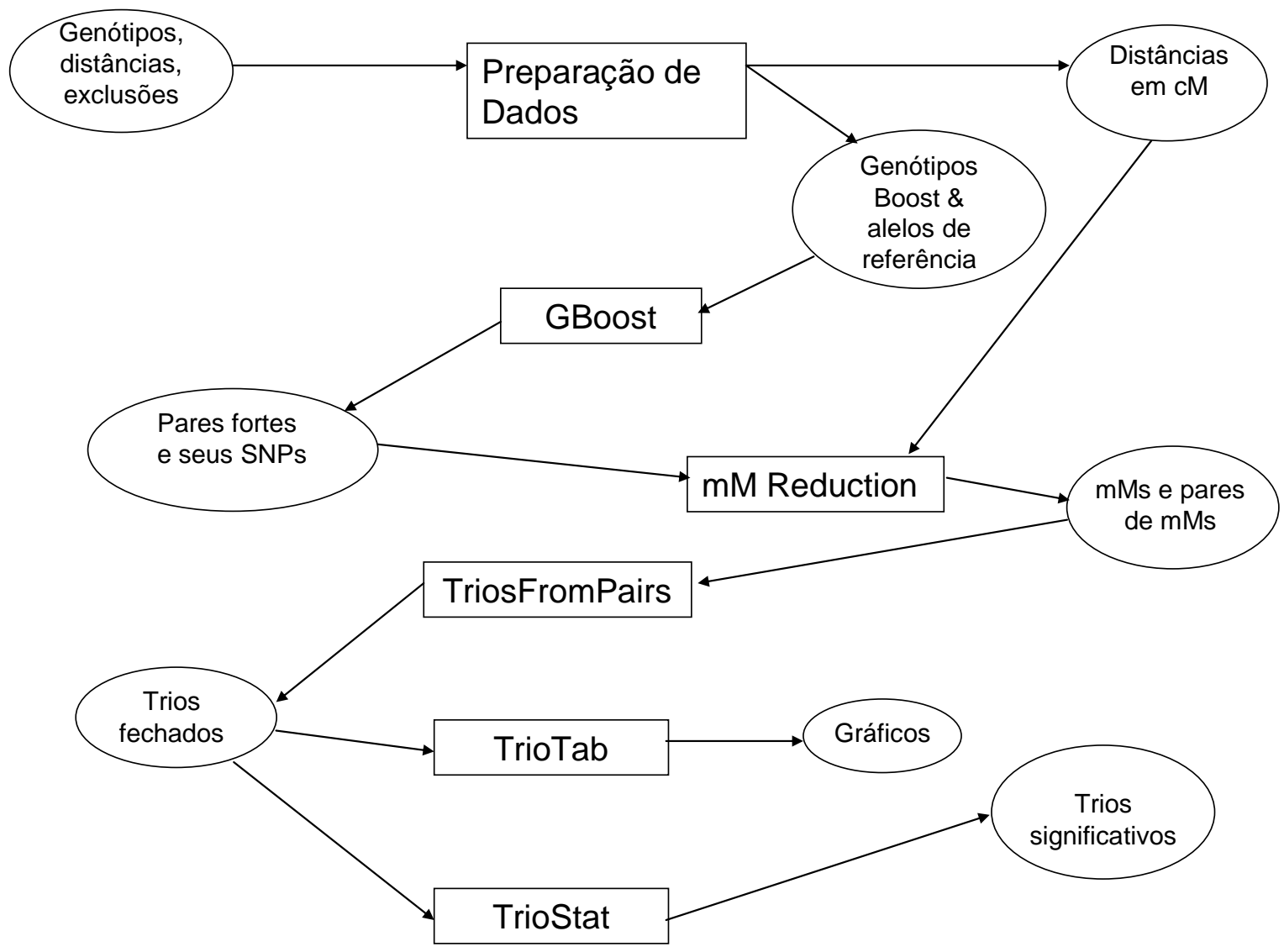

Figura 9 - Sequência de processamento do Troost

\section{Módulos do Troost}

\section{Preparação de dados}

- SNPdist.exe - Calcula de distâncias de mapa genético e ordena os SNPs

- RefAllele.exe - Estabelece alelos de referência e calcula MAF - Minor Allele Frequency para cada SNP.

- SampleDisease.R - Exclui indivíduos da lista de exclusão e sorteia amostra de mil casos e mil controles. Reserva amostras para confirmação, para evitar a "maldição do vencedor" - resultados aparentemente significantes, mas que não são confirmados em estudos posteriores com amostras independentes.

- Tped2boost.exe - Converte genótipos para o formato BOOST 


\section{GBoost}

Roda o GBoost e obtém lista de pares fortes (centenas de milhares). Está em linguagem $\mathrm{C}$, usando tecnologia CUDA para rodar na placa de vídeo.

\section{mMreduction.R}

Reduz pares de SNPs a pares de blocos haplotípicos, apelidados de milimorgans ou mMs.

- Seleciona pares fortes, com interação acima de um limiar (a princípio, 34)

- Retira pares entre SNPs muito próximos

- Constrói blocos haplotípicos (mMs) a partir da distância de mapa genético entre os SNPs presentes nos pares fortes, agrupando os SNPs próximos em mesmo mM.

- Remove pares entre SNPs do mesmo mM

- Cada par de mMs é representado por vários pares de SNPs. Escolhe somente o par de SNPs mais forte para representar o par de mMs. Os outros são considerados redundantes e são removidos. Há uma redução significativa do número de pares.

\section{TriosFromPairs.C}

Encontra trios fechados de SNPs.

A saída do mMreduction é uma lista de pares fortes de mMs. A partir desta lista, o TriosFromPairs procura trios fechados de SNPs, ou seja, conjuntos de 3 SNPs em que os três pares possíveis entre eles estão todos entre os pares fortes. A saída é uma lista de trios de mMs.

\section{TrioTab.R}

Para um trio de mMs, converte os dados de SNPs em duplo-haplótipos, calcula tabelas de contingência do trio e também dos três pares formadores, e traça gráficos de barras comparando caso e controle para a avaliação qualitativa. 


\section{TrioStat.R}

Faz o teste estatístico do trio de mMs, estabelecendo se é significante ou não e calculando um valor-P.

\section{Detalhamento dos Módulos do Troost}

Os programas-fonte dos módulos do Troost estão no Apêndice - Programasfonte, e também na página do laboratório em http://bioinfo.ib.usp.br .

\section{Preparação de dados}

A Figura 10 retrata a preparação dos dados, com os programas, entradas e saídas. Quatro programas foram desenvolvidos como preparação dos dados antes de rodar o BOOST: SNPdist, RefAllele, SelSample e tped2boost. Cada um deles implementa algum detalhe importante para a análise posterior, sendo mais do que conversores de dados.

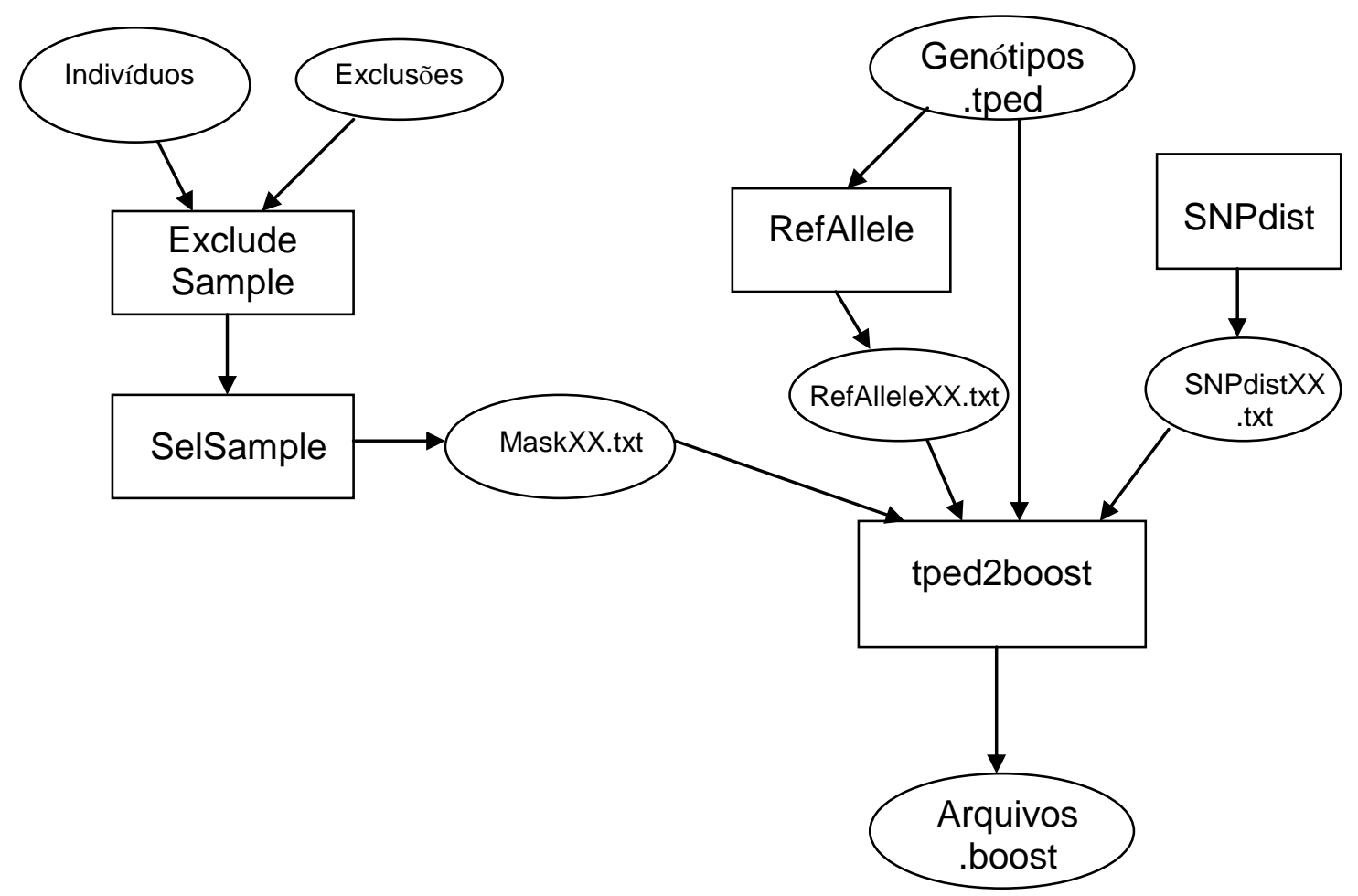

Figura 10 - Preparação de dados 


\section{SNPdist.exe}

O primeiro passo para construir estes blocos foi conseguir distâncias genéticas acuradas para cada SNP presente no estudo, expressas em pares de bases e também em centimorgans. Os SNPs foram estritamente ordenados por estas distâncias. Consideramos que esta é a única ordenação natural para os SNPs, em oposição outros critérios artificiais de ordenação tais como pela identificação rs (oficial da DBSNP) ou a identificação Affymetrix. O WTCCC entrega seus arquivos de genótipos e a listagem dos SNPs em ordens diferentes, e nenhuma das duas é igual a qualquer das três citadas aqui.

As listas de SNPs do WTCCC (arquivos snps e tped) vêm com distâncias em bases iguais às distâncias que obtivemos do HapMap, exceto cerca de 1\% dos SNPs, que vieram do WTCCC com as distâncias zeradas. Em vez de descartar estes SNPs sem distâncias, optamos por corrigi-las.

O programa SNPdist tem três funções:

- Corrigir as distâncias em bases que vieram zeradas nas listas de SNPs do WTCCC (arquivos snps e tped).

- Ordenar os SNPs por distância em bases

- Calcular as distâncias de mapa genético em centimorgans

O SNPdist admite como entradas:

- Lista de SNPs do WTCCC, que são os arquivos snps.

- Arquivos Summary do WTCCC

- Mapa genético do Hapmap

- Lista de snps do HapMap, na forma dos arquivos allele frequencies. Eles foram usados apenas como lista de SNPs, e não para pegarmos as frequências de alelos.

Este programa foi executado 22 vezes, uma para cada cromossomo, produzindo os arquivos snpdistXX.txt, onde XX é o cromossomo. Esse conjunto vale 
para todas as sete doenças do WTCCC, ou seja, não precisamos executar novamente este programa.

As distâncias zeradas são corrigidas procurando o SNP no arquivo allele frequencies do HapMap, por três critérios diferentes, pela ordem: rs ID do snps, rs Id do summary, Affym ID. Encontrando a ID respectiva no arquivo allele frequencies, aceita a distância correspondente. Se não achar o SNP no allele frequencies por qualquer dos três critérios, pega a distância do arquivo Summary do WTCCC e faz "lift" para a build 36 com base no SNP mais próximo.

Saída: O SNPdist tem como saída um arquivo snpdistXX.txt, onde XX é o número do cromossomo. É um arquivo texto, separado por tabulações, com uma linha por SNP, com os seguintes campos: cromossomo, índice do SNP dentro do cromossomo, Affymetrix ID, posição em bases de acordo com o build 36 do HapMap, posição de mapa genético em centimorgans. Exemplo:

$\begin{array}{lllll}22 & 0 & \text { SNP_A-2314782 } & 15257135 & 0.730867 \\ 22 & 1 & \text { SNP_A-4290489 } & 15268900 & 0.737961 \\ 22 & 2 & \text { SNP_A-2151351 } & 15272143 & 0.739396\end{array}$

O SNPdist.exe é um programa de linha de comando para o sistema operacional Windows. Foi desenvolvido em linguagem $\mathrm{C}$, usando a plataforma de desenvolvimento Eclipse CDT versão Juno e compilador MinGW. Um complemento ao SNPdist é o programa batch que o aciona para todos os cromossomos, SNPDistAll.bat

A Figura 11 ilustra as entradas e saídas do SNPdist.

\section{RefAllele.exe}

Ao definir o formato do genótipo como 0,1 ou 2, o GBoost exige o estabelecimento de alelos de referência e alternativo. No entanto, o formato tped provido pelo WTCCC fornece as bases nitrogenadas do genótipo, sem definir qual delas é a referência. Portanto, foi necessário, antes de converter o formato, definir para cada SNP qual é o alelo de referência, cujo homozigoto será codificado com zero, e qual é o alelo alternativo, que terá o 2 como código para o homozigoto. Esta é a função do RefAllele. 


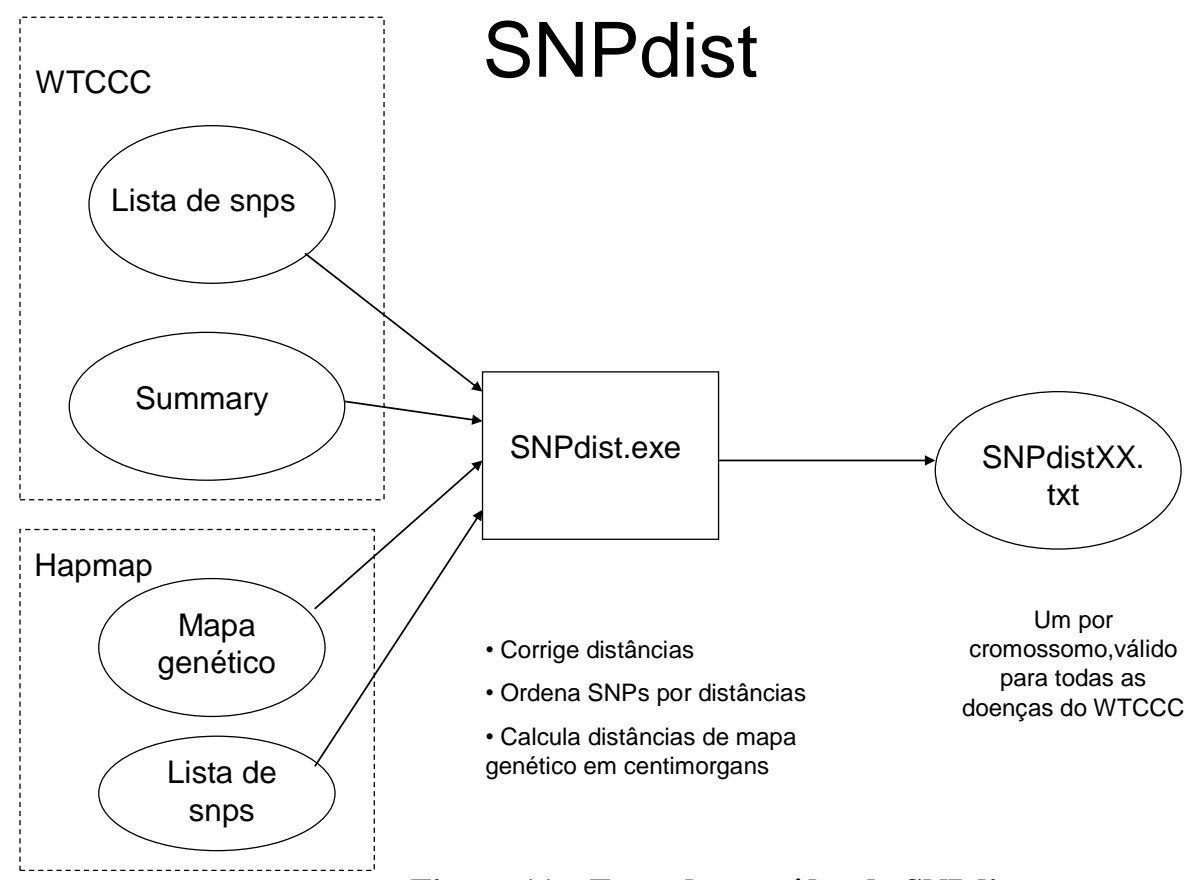

Figura 11 - Entradas e saídas do SNPdist

$\mathrm{Na}$ categorização dos genótipos decidimos colocar como referência o alelo mais frequente, embora conscientes que isto não é importante nos métodos utilizados. Também optamos por estabelecer o mesmo alelo de referência para todos os conjuntos do WTCCC. Com isto só temos que estabelecer referências uma única vez, diminuindo a chance de erros e confusões. Para isto, nossa amostra foram todos os três mil controles e catorze mil casos. Para cada SNP o alelo de referência foi escolhido como o mais frequente na amostra.

O RefAllele roda uma vez para cada cromossomo. Em cada rodada, computa todos os nove conjuntos de dados, dois de controles e sete de casos, para aquele cromossomo. Estes ficam listados um arquivo texto que chamamos de ref01.1st.

Entradas: arquivo de lista; arquivos tped listados

Saída: arquivo RefAlleleXX.txt, onde XX é o número do cromossomo. Formato texto separado por tabulações, com um SNP por linha. Campos: cromossomo, Affymetryx ID, Alelos, MAF\%, número total de ocorrências de cada base (x4), número de genótipos ausentes. O primeiro alelo listado é o de referência e o segundo é o alternativo. MAF\% é a proporção de alelos alternativos. Exemplo: 


$\begin{array}{lllllllll}22 & \text { SNP_A-4234155 } & \text { TC } & 37.9 \% & 0 & 12865 & 0 & 21123 & 0 \\ 22 & \text { SNP_A-2223191 } & \text { CT } & 44.9 \% & 0 & 18729 & 0 & 15259 & 0 \\ 22 & \text { SNP_A-4202732 } & \text { GA } & 25.4 \% & 8630 & 0 & 25358 & 0 & 0\end{array}$

O RefAllele foi escrito em C no Eclipse CDT e compilado no MinGW. Complementam o RefAllele o arquivo de lista ref01.lst e o batch de invocação refall.bat que roda o RefAllele para todos os cromossomos.

\section{MakeSNPsFile.R}

Monta arquivo único de SNPs a partir do SNPdistXX.txt, RefAlleleXX.txt e snpsXX

\section{SampleDisease.R}

O WTCCC provê também, para cada conjunto de dados, uma lista de indivíduos cuja exclusão é sugerida, por diversos motivos técnicos. Entre estes motivos temos:

- $\quad$ ancestralidade não europeia;

- duplicação;

- parentesco próximo com outra amostra;

- erro na genotipagem;

- número de SNPs perdidos maior que 3\%;

- heterozigose média fora da faixa de 0,225 a 0,3 .

Precisamos, portanto, excluir estes indivíduos dos dados entregues ao GBoost.

A partir da lista de indivíduos e da lista de exclusão, o SampleDisease gera um arquivo contendo somente zeros e uns. 0 significa indivíduo a excluir, e 1 é para um indivíduo válido. A ordem dos indivíduos é a da lista de indivíduos, que dita a ordem em que aparecem os genótipos no arquivo tped. Exemplo de nome do arquivo: SampleBDincluded.txt.

O SampleDisease deve ser rodado uma vez para cada um dos nove conjuntos de dados. Pode ser rodado novamente se forem produzidas novas listas de exclusão com outros critérios. 
Depois de excluir os indivíduos, o SampleDisease sorteia uma sub-amostra dos restantes.

O WTCCC provê três mil controles e dois mil casos para cada doença, sendo portanto desbalanceado. Isto não é problema para métodos estabelecidos como a regressão logística, mas cria problemas numa análise exploratória, onde precisamos enxergar claramente nos gráficos quais os genótipos protetores e de risco. Decidimos portanto trabalhar com um número igual de casos e de controles.

Outra objetivo é reservar amostras para futura confirmação de algum resultado encontrado. Por este motivo, optamos por trabalhar no Troost com uma subamostra de mil casos e mil controles, todos eles válidos, escolhida aleatoriamente entre as unidades amostrais. Temos assim outra subamostra de 800 a 900 casos e quase 2000 controles reservada para confirmação posterior.

Esta última parte do SampleDisease toma como entrada um arquivo com zeros e uns, sendo que os zeros correspondem aos indivíduos excluídos. Ele então sorteia mil amostras entre os uns, convertendo os restantes para zeros, e grava um arquivo com o mesmo tamanho da entrada, porém com mais zeros. Este arquivo servirá como entrada para o tped2boost, que excluirá da conversão os indivíduos com zeros. Chamamos este arquivo de MaskXX.txt, onde XX é o acrônimo da doença ou conjunto de controles.

O SampleDisease deve rodar duas vezes para cada estudo que façamos: uma para produzir os controles, uma para os casos. No nosso caso, rodamos nove vezes, uma para cada conjunto de dados, e a mesma máscara produzida para os controles NBS foi usada sete vezes, uma para cada estudo que fizemos.

\section{tped2boost.exe}

Este programa toma como entrada os genótipos do arquivo tped, e ainda os dados preparados pelos programas anteriores: SNPdist, RefAllele e SelSample, e produz um arquivo de genótipos no formato BOOST, que servirá de entrada para o GBoost. 
Os arquivos tped têm os genótipos em forma de bases nitrogenadas. Com ajuda da referência RefAlleleXX.txt, o tped2boost converte isso para o formato 0/1/2 requerido pelo GBoost.

Cada arquivo .boost tem os indivíduos nas linhas e os SNPs nas colunas, ao contrário dos tpeds. O GBoost aceita arquivos separados por cromossomo.

Entradas: tped, SNPDist, "case" ou "control", RefAllele, máscara de amostras (MaskXX.txt). Os tpeds de transtorno bipolar têm que ser convertidos com MaskBD.txt. Os tpeds de NBS têm que usar MaskNBS.txt.

Saída: arquivo .boost

Batches: $|t 2 b| c o n v e r t e B D t u d o . b a t$

|t2bltpedlconcat.bat

O tped2Boost foi escrito em C no Eclipse CDT, usando compilador MinGW.

O tped2boost roda uma vez para cada conjunto de dados. Após o tped2boost, e antes de rodar o GBoost, é preciso concatenar um arquivo de dados com um de controles, para cada cromossomo.

\section{Troost.R - automatiza todo um estudo}

Os módulos a seguir são chamados ou executados todos dentro do módulo Troost.R, que automatiza um estudo de trios para uma certa doença.

\section{Concatenação de casos e controles}

Uma vez escolhidos o conjunto de controles e o conjunto de casos, a primeira coisa a fazer é concatenar os arquivos .boost de genótipos de ambos. É formado um arquivo .boost para cada cromossomo, contendo tanto os casos como os controles.

\section{GBoost}

Já falamos do BOOST e GBoost na seção 3.8. Obtivemos os programas fonte e executáveis do GBoost, mas precisamos recompilá-los para que rodassem com os novos drivers do fabricante da placa. Para isto, usamos o ambiente de desenvolvimento e compilador recomendados pela NVidia, o Microsoft Visual C++ 
Express. A ele adicionamos o ambiente CUDA Toolkit da NVidia, e recompilamos o GBoost com sucesso.

Entradas: arquivo lista XXXfull.txt, onde XXX é a sigla da doença, listando todos os 22 arquivos que o GBoost processará, um para cada cromossomo.

Saídas:

- GPUInteractionRecordsXX.txt, listando os pares com InteractionBoost acima de 30 .

- GPUMarginalAssociationXX.txt, listando o efeito individual de cada SNP, calculado por entropia.

\section{Conversão de índices BOOST}

Cada SNP é dado pelo seu índice geral desde o primeiro SNP, começando em zero. Como os arquivos estão separados por cromossomo, precisamos converter estes índices boost em cromossomo mais índice dentro do cromossomo. Isto é feito com a ajuda da tabela Initial SNP indexes.txt, que lista o índice inicial para cada cromossomo.

\section{mMreduction.R}

Seleciona pares fortes, com interação acima de um limiar (a princípio, 34)

1) Lê todos os SNPdistXX.txt em uma tabela

2) Indexa-a pelo índice boost

3) Calcula distâncias absolutas.

O SNPdist.txt contém, entre outros campos, a distância em centimorgans até o início do cromossomo. Esta distância é de no máximo $280 \mathrm{cM}$. A diferença entre as distâncias de dois SNPs é a distância em centimorgans entre eles, que reflete diretamente a chance de haver recombinação entre as duas posições. Porém, ela não permite este cálculo entre SNPs de cromossomos diferentes. Isto exige verificar previamente se os SNPs estão no mesmo cromossomo. Na linguagem R, examinar uma condição prévia pode inviabilizar uma operação vetorizada, que é a mais eficiente nesta linguagem. Por conveniência computacional, criamos o conceito de distância absoluta, dada pela fórmula:

absdist $=$ chr $* 1000+$ Dist $\mathrm{cM}$ 
Este número fica distribuído entre 1000 e 22100. Ele tem a vantagem de permitir o cálculo de distância entre SNPs de cromossomos diferentes. Para quaisquer SNPs entre cromossomos diferentes, a distância entre eles será maior do que $600 \mathrm{cM}$, evitando que interpretemos como próximos qualquer par de SNPs que estejam em cromossomos diferentes.

4) Lê os pares do GBoost

5) Seleciona somente os pares com interação maior que 34

6) Remove pares entre SNPs muito próximos entre si, com distância mútua menor que $0,1 \mathrm{cM}$

7) Lista os SNPs presentes entre os pares fortes selecionados

8) Usando esta lista, constrói blocos haplotípicos (mMs) a partir da distância de mapa genético entre os SNPs presentes nos pares fortes, agrupando os SNPs próximos em um mesmo mM.

O algoritmo de montagem de blocos é muito simples: SNPs vizinhos separados por menos de $0,02 \mathrm{cM}$ são colocados no mesmo mMs. Os SNPs vizinhos separados por mais de $0,02 \mathrm{cM}$ são colocados em mMs diferentes.

Tentamos algumas variações mais complexas, mas após ajustar os parâmetros, este algoritmo foi que produziu blocos mais próximos do que visualmente parecem-se com blocos.

9) Remove pares entre SNPs do mesmo mM

10) Cada par de mMs é representado por vários pares de SNPs. Escolhe somente o par de SNPs mais forte para representar o par de mMs. Os outros são considerados redundantes e são removidos. Há uma redução significativa do número de pares.

11) Escreve arquivos de saída:

- mMRxx.txt - lista dos pares de mMs, que será lida pelo TriosFromPairs.

- PairsXX.txt, com todos os pares fortes de SNPs não-vizinhos, já com seus mMs

- nrPairsXX.txt - subconjunto do anterior, somente com os pares de mMs não-redundantes. 
- SNPsInPairsXX.txt - lista de SNPs nos pares fortes, com seus mMs.

\section{TriosFromPairs.C}

Percorre a lista de pares de mMs. Para cada $\mathrm{mM}$ presente em dois pares $A B$ e $A C$, verifica se existe o terceiro par $B C$. Se encontrou, reporta este trio $\mathrm{ABC}$ como trio fechado.

Entrada: mMRxx.txt

Saída: triosrXX.txt

\section{mM2snp.R}

Este módulo é apenas uma preparação para o próximo. Apenas alguns poucos trios de mMs são encontrados pelo TriosFromPairs. Este curto módulo em R recupera quais os três pares de SNPs que deram origem a este trio, e em seguida lista os dois SNPs que estão em cada mM, em ordem crescente de MAF.

Entradas: triosrXX.txt, nrpairsXX.txt, MAF.txt

Saída: SNPs same mM MAF order XX.txt

\section{TrioTab.R}

Analisa qualitativamente cada trio:

- Combina os dois SNPs de cada bloco haplotípico, com três valores possíveis, em duplo-haplótipos com até nove valores possíveis.

- Imprime a tabela e o gráfico de barras de cada mM, considerado individualmente.

- Imprime a tabela e o gráfico de barras de cada um dos três pares de mMs.

- Imprime o gráfico de barras do trio de mMs. Para reduzir o gráfico para um tamanho apresentável, de cada $\mathrm{mM}$ remove os valores (níveis) com representação inferior a 5\%, substituindo-os por NA.

\section{TrioStat.R}

Para o teste estatístico da interação do trio, inicialmente implementamos a regressão logística penalizada, tal como proposta por Park \& Hastie em 2008. Ela é conhecida como PLR, de Penalized Logistic Regression. Apesar da robustez da 
metodologia, somente foi possível encontrar efeitos significantes de interação em alguns dos trios analisados após várias tentativas de combinações diferentes dos parâmetros do PLR, possivelmente devido ao elevado número de caselas com frequência nulas. Assim, optamos por uma análise mais tradicional e que impõe menos estrutura para os dados: o teste qui-quadrado. Este teste foi o utilizado no SNPHarvester (YANG et al., 2009b).

Nossas tabelas de contingência têm quatro dimensões -3 mMs mais o fenótipo - e cada $\mathrm{mM}$ pode ter até 9 duplo-haplótipos, resultando em tabelas de até 1458 células, muitas delas vazias. Por ser assintótico, isto é um problema para o teste qui-quadrado, e para contorná-lo usamos a seguinte estratégia: as três dimensões dos mMs foram reduzidas a uma só, listando todos os genótipos combinados possíveis. Esse "achatamento" da tabela para duas dimensões é corriqueiro para este tipo de teste e até tem uma função própria no ambiente R. A tabela resultante tem duas dimensões: uma com os genótipos, em número de até 729, e outra com o fenótipo, caso ou controle. Em seguida, agrupamos os genótipos com baixa frequência (todos aqueles com frequência total representando menos de $1 \%$ do total de casos e controles) em uma categoria "outros". Estamos cientes que, com esta estratégia, podemos deixar de analisar alguns genótipos com desequilíbrio alto, como 0-19 por exemplo, mas estes genótipos explicariam uma parcela pequena dos casos da doença, e isto é compensado com uma diminuição nos graus de liberdade e uma consequente maior facilidade em encontrar alguma significância.

Como complemento, também aplicaremos à mesma tabela o teste quiquadrado de homogeneidade entre multinomiais de Goodman (GOODMAN, 1964). O teste de Goodman se destina a comparar duas populações multinomiais - caso e controle, no nosso estudo.

\subsection{Confirmação dos resultados com amostras independentes}

Os dados do WTCCC trazem 2000 casos para cada doença e 3000 controles compartilhados. Como dissemos, optamos por usar somente mil casos e mil controles, por dois motivos: para garantir amostras balanceadas de casos e controle e para reservar amostras para confirmação posterior dos resultados encontrados. 
Estudos de associação de genoma completo com frequência trazem resultados positivos que não se confirmam em estudos posteriores, isto é, falsos positivos. Esta etapa de confirmação, seja no mesmo estudo ou em estudos posteriores, é quase mandatória (MCCARTHY et al., 2008). No entanto, é preferível que esta confirmação venha de conjuntos genotipados por técnicas diferentes, o que não dispomos aqui. Portanto, nossa confirmação é apenas parcial e está sujeita às limitações da tecnologia de genotipagem da Affymetrix disponível em 2006.

Tabela 6 - Amostras em cada conjunto de dados

\begin{tabular}{lrrrcrrrrr}
\hline & \multicolumn{1}{c}{ Casos } & \multicolumn{3}{c}{ Controles } \\
\hline Conjunto de dados: & BD & CAD & CD & HT & RA & T1D & T2D & NBS & \multicolumn{1}{c}{ 58C } \\
\hline Amostras totais & 1998 & 1988 & 2005 & 2001 & 1999 & 2000 & 1999 & 1500 & 1504 \\
Excluídas & 130 & 62 & 257 & 49 & 139 & 37 & 75 & 42 & 24 \\
Válidas & 1868 & 1926 & 1748 & 1952 & 1860 & 1963 & 1924 & 1458 & 1480 \\
Usadas no Troost & 1000 & 1000 & 1000 & 1000 & 1000 & 1000 & 1000 & 1000 & 0 \\
Usadas na confirmação & 868 & 926 & 748 & 952 & 860 & 963 & 924 & 0 & 1480 \\
\hline
\end{tabular}

A Tabela 6 mostra as quantidades de amostras (indivíduos) usadas em cada conjunto de dados, tanto no Troost quanto na confirmação. Devido às amostras excluídas, cada doença tem um número de casos diferente, variando entre 748 e 963 amostras. Adotamos os controles da coorte de britânicos nascidos em 1958, que nos fornece 1480 controles válidos. Usamos na confirmação os mesmos testes estatísticos descritos acima no módulo TrioStat.R.

\section{Razão de chances}

Após a confirmação da significância dos trios de T1D, calculamos a razão de chances de cada genótipo combinado do trio e destacamos os genótipos que têm razão de chances mais pronunciada. A razão de chances é a razão de duas proporções casos/controles: a dos que têm o genótipo em questão sobre a proporção dos que não têm aquele genótipo. Para este cálculo, usamos como amostra a soma das subamostras usadas pelo Troost e pela confirmação.

\subsection{Recursos utilizados na pesquisa}

\section{Hardware}

O item principal para a realização desta pesquisa é a placa de vídeo (GPU) com tecnologia NVidia e arquitetura CUDA, a mesma placa utilizada pelos autores do 
GBOOST: NVidia GTX-285. Há placas mais modernas, mas a um custo superior às possibilidades do programa e um desempenho não tão superior.

Esta placa foi instalada em um PC de penúltima geração, com as seguintes especificações:

Processador Intel Core i7 2700K @ 3,50 GHz

Memória RAM 8 GB

HD 2 TB

Fonte de 650 watts

Sistema operacional Windows 7. Este sistema foi escolhido pois o GBoost e a placa já rodavam nele, e é para ele que a NVidia dá o melhor suporte à sua tecnologia CUDA.

\section{Software}

- R x64 for Windows versões 2.15.1 e 2.15.2 - pacote estatístico e ambiente de programação - software livre

- Eclipse Juno com CDT e StatET - ambiente de desenvolvimento em linguagens $\mathrm{C}$ e $\mathrm{R}$ - software livre

- MinGW - compilador C para Windows - software livre

- Microsoft Visual C++ Express - para compilar o GBoost - gratuito para uso não-comercial

- Microsoft Excel 2003 \& 2010 (para a análise exploratória)

- Driver NVidia 311.06

- $\quad$ NVidia CUDA Toolkit 4.2

- Windows Batch. Com o decorrer do projeto, foi substituída pelo R como linguagem de script.

\section{Ferramentas auxiliares}

- Vim 7.3 - VI improved - editor de textos para arquivos grandes - software livre.

- UltraVNC Server \& Viewer 1.0.9.6.2 - para acesso remoto - software livre

- FileZilla 3.5.3 - FTP Client - software livre

- CutePDF Writer 3.0 - impressora em PDF - software livre

- 7-Zip 9.20 - compressor de arquivos - software livre 


\section{Resultados}

\subsection{Tempo de execução de testes de epistasia}

Os tempos de execução e outras características dos algoritmos de epistasia são apresentados na Tabela 7. Dois algoritmos se destacaram por ter tempos rápidos: o GBOOST e o Random Forests, mas não nos interessamos por este último por não ter sido capaz de encontrar os locos epistáticos em muitos casos (KILPATRICK, 2009). Embora eficiente, o Random Forests não é eficaz.

O algoritmo SNPHarvester busca pares e trios ao mesmo tempo, e por isto é muito mais rápido que os outros para busca de trios. Nenhum algoritmo com complexidade combinatorial conseguiu um tempo razoável para três locos, nem mesmo o GBOOST. Esperamos que nossa estratégia em dois estágios consiga contornar este problema. 
Tabela 7 - Tempo de execução de testes de epistasia com dez mil locos ou mais

\begin{tabular}{|c|c|c|c|c|c|c|c|c|c|c|c|}
\hline \multirow[b]{2}{*}{ Autor } & \multirow[b]{2}{*}{ Ano } & \multirow[b]{2}{*}{ Algoritmo } & \multirow[b]{2}{*}{$\begin{array}{l}\text { Teste } \\
\text { estatístico }\end{array}$} & \multirow[b]{2}{*}{$\begin{array}{l}\text { Complexi- } \\
\text { dade }\end{array}$} & \multirow[b]{2}{*}{$\begin{array}{l}\text { Número } \\
\text { de } \\
\text { locos }\end{array}$} & \multirow[b]{2}{*}{$\begin{array}{l}\text { Número } \\
\text { de indi- } \\
\text { víduos }\end{array}$} & \multirow[b]{2}{*}{$\begin{array}{l}\text { Locos } \\
\text { inte- } \\
\text { ragindo }\end{array}$} & \multirow[b]{2}{*}{$\begin{array}{l}\text { Tipo de } \\
\text { dados }\end{array}$} & \multirow[b]{2}{*}{$\begin{array}{l}\text { Tempo } \\
\text { corrigido } \\
\text { por CPU } \\
\text { (horas ou } \\
\text { dias) }\end{array}$} & \multicolumn{2}{|c|}{ Extrapolações } \\
\hline & & & & & & & & & & $\begin{array}{l}\text { 1M SNPs, } 2 \\
\text { locos (horas } \\
\text { ou dias) }\end{array}$ & $\begin{array}{l}360 \mathrm{~K} \\
\text { SNPs, } 3 \\
\text { locos } \\
\text { (anos) }\end{array}$ \\
\hline Kilpatrick & 2009 & AGR & $\chi^{2}$ & $\begin{array}{l}\text { Combinatorial } \\
\text { (2 estágios) }\end{array}$ & 10.000 & 2.000 & & Simulados & $0: 00: 00 \mathrm{~h}$ & $?$ & \\
\hline Kilpatrick & 2009 & Random Forests & Índice Gini & Linear & 10.000 & 2.000 & & Simulados & $0: 00: 10 \mathrm{~h}$ & $0: 16: 03 \mathrm{~h}$ & \\
\hline Kilpatrick & 2009 & SNPHarvester & $\chi^{2}$ & $\begin{array}{l}\text { Efetivamer } \\
\text { linear }\end{array}$ & 10.000 & 2.000 & & Simulados & 3:18:38h & $13,79 d$ & \\
\hline Wang et al. & 2010 & AntEpiSeeker & $\chi^{2}$ & $\begin{array}{l}\text { Efetivamente } \\
\text { linear }\end{array}$ & 332.831 & 3.503 & 2 & Reais & $1,24 \mathrm{~d}$ & ? & \\
\hline Wang et al. & 2010 & $\begin{array}{l}\text { SNPHarvester } \\
\text { Modelo completo com }\end{array}$ & $\begin{array}{l}\chi^{2} \\
\text { Regressão }\end{array}$ & $\begin{array}{l}\text { Efetivamente } \\
\text { linear }\end{array}$ & 332.831 & 3.503 & 7 & Reais & $3,47 d$ & $10,41 d$ & \\
\hline Marchini et al. & 2005 & interação (FIM) & linear & Combinatorial & 300.000 & 4.000 & 2 & Simulados & $1,41 d$ & $15,68 d$ & 668 \\
\hline Marchini et al. & 2005 & $\begin{array}{l}\text { FIM em dois estágios } \\
\text { Z-teste (PLINK com - -fast - }\end{array}$ & $\begin{array}{l}\text { Regressão } \\
\text { linear } \\
\text { Regressão }\end{array}$ & $\begin{array}{l}\text { Entre linear e } \\
\text { combinatorial }\end{array}$ & 300.000 & 4.000 & 2 & Simulados & $0: 00: 20 \mathrm{~h}$ & $0: 01: 08 \mathrm{~h}$ & \\
\hline Cordell & 2009 & -epistasis) & linear & Combinatorial & 89.294 & 2.000 & 2 & Reais & $3,50 \mathrm{~d}$ & $439 d$ & 18703 \\
\hline Cordell & 2009 & Random Forests & Índice Gini & Linear & 89.294 & 5.000 & 2 & Reais & $1: 15: 00 \mathrm{~h}$ & $13: 59: 55 \mathrm{~h}$ & \\
\hline $\begin{array}{l}\text { Cordell } \\
\text { PLINK website }\end{array}$ & 2009 & $\begin{array}{l}\text { BEAM } \\
\text { Z-teste (PLINK com - -fast - }\end{array}$ & $\begin{array}{l}\text { Estatística B } \\
\text { Regressão }\end{array}$ & $?$ & 47.724 & 5.000 & 2 & Reais & $2,00 d$ & $?$ & \\
\hline - epistasis & 2007 & -epistasis) & linear & Combinatorial & 100.000 & 500 & 2 & $?$ & 4:48:00h & $20 d$ & 852 \\
\hline Wan et al. & 2010 & BOOST & BOOST & Combinatorial & 360.000 & 17.000 & 2 & Reais & $12: 00: 00 h$ & $3,86 \mathrm{~d}$ & 164 \\
\hline Yang et al. & 2008 & SNPHarvester & $\chi^{2}$ & $\begin{array}{l}\text { Efetivamente } \\
\text { linear }\end{array}$ & 332.831 & 3.503 & 7 & Reais & $2,80 \mathrm{~d}$ & $8,41 d$ & \\
\hline Wang et al. & 2010 & AntEpiSeeker corrigido & & Quadrático? & 332.831 & 3.503 & 2 & Reais & $6,81 d$ & $20,46 d$ & \\
\hline Yung et al. & 2011 & GBOOST & GBOOST & Combinatorial & 360.000 & 17.000 & 2 & Reais & $01: 34 \mathrm{~h}$ & $12: 05 \mathrm{~h}$ & 21 \\
\hline
\end{tabular}




\subsection{Resultados da análise exploratória}

Recordemos das perguntas que nos propusemos na análise exploratória e quais respostas obtivemos, numa análise preliminar do transtorno bipolar:

\section{Entre os SNPs que aparecem nos pares, há predominância daqueles que têm maior associação marginal?}

À primeira vista sim, entre os cem pares mais fortes apareciam SNPs com forte associação marginal, mas estes pares eram entre SNPs muito próximos. Após a remoção dos pares entre SNPs próximos não vemos muitos SNPs com associação marginal apreciável entre os pares fortes. O primeiro par a apresentar um valor de associação maior que dez é o $91^{\circ}$. O primeiro a apresentar associação maior que cinco é o sétimo. Entre os 100 primeiros, 18 apresentam um SNP com associação maior que cinco, e somente num, o $87^{\circ}$, ambos SNPs de um par tem associação maior que cinco.

\section{Os SNPs com maior efeito aditivo obscurecem os pares, ao aparecer num grande número deles?}

Não. Ainda aparecem muitos pares sem SNPs com alto efeito aditivo. Os dois SNPs com maior efeito aditivo não aparecem na lista de pares, em nenhum par.

Dos 459 mil SNPs, 43,6 mil tem efeito aditivo maior que 5 .

Após remover os pares redundantes, dos 100 SNPs com maior informação mútua, somente 3 aparecem entre os pares fortes. Isso mostra que a estatística InteractionBoost é eficiente em medir somente interação, sendo pouco "contaminada" pelo efeito aditivo dos SNPs.

Relembrando, chamamos de pares redundantes aos pares de SNPs que representam os mesmos blocos haplotípicos, ou mMs.

\section{Quantos SNPs existem na lista de pares?}

Nosso universo é formado de 459 mil SNPs, formando 105 bilhões de pares. Destes, o GBoost seleciona os pares com InteractionBoost maior do que 30, o que nos dá cerca de 330 mil pares. Cerca de 400 mil SNPs participam destes pares. 
Então exigimos um limiar mais estrito: InteractionBoost maior do que 34. Isto reduz para cerca de 50 mil pares fortes, contendo cerca de 64 mil SNPs.

\section{Há muitos pares de SNPs próximos, com alto desequilíbrio de ligação (LD) entre si?}

Entre os cem pares mais fortes, existem sim. Os primeiros 48 pares são todos muito próximos, com distância máxima de $0,04 \mathrm{cM}$ ou 21 mil bases. A partir da posição 73 , os pares distantes aparecem em maior número. Nos próximos 100 , do $74^{\circ}$ ao $174^{\circ}$, apenas 13 são próximos. Por esta razão, refizemos a análise removendo os pares entre SNPs próximos, com distância mútua menor que $0,1 \mathrm{cM}$. Removemos assim 130 pares. A escolha deste limiar de distância de mapa genético foi criteriosa, pois, após a remoção, restaram somente cinco com distância entre 0,1 e 1 cM.

O lado interessante disto é que há muito poucos pares próximos no conjunto dos pares fortes. Isto significa que os pares mais significativos não estão lá por representarem epistasia real, nem tampouco por simples acaso decorrente do alto número de testes, e sim porque têm alto LD entre si.

Notamos que, mesmo nestes pares com SNPs muito próximos, os SNPs não são vizinhos imediatos, ou seja, há outros SNPs entre eles. Isto significa que a amostra é razoavelmente grande, de modo que os dados para SNPs vizinhos não são idênticos.

\section{SNPs com alto LD aparecem pareados com os mesmos outros SNPs?}

Antes da remoção dos redundantes, parece que sim. Notamos que havia muitos pares redundantes, ou seja, seus SNPs eram distantes entre si, mas um grupo de pares na verdade representava somente um par de blocos haplotípicos. Foi esta observação que conduziu ao conceito de pares de blocos haplotípicos, uma das principais ideias desta tese. Por exemplo, o SNP 439009 no cromossomo vinte é um dos três que apareceu dezenove vezes entre os pares fortes. Dezoito dessas vezes foram pareando com a mesma região do cromossomo dois. A situação se repete para o SNP 152987 no cromossomo cinco, que pareia todas as dezenove vezes com a mesma região do cromossomo vinte (distante $18 \mathrm{cM}$ do citado anteriormente).

A construção dos milimorgans e remoção dos pares redundantes corrige esta situação. 


\section{É possível escolher um único SNP em grupos que têm alto LD entre si?}

Aparentemente, haverá perda de dados se fizermos assim. Optamos por um tratamento por haplótipos, para não termos que escolher um SNP para cada mM..

\section{Existem padrões encadeados do tipo $A B, B C, C D$ ?}

Entre SNPs, não existem. Mas após a conversão para blocos haplotípicos, ou mMs, existem alguns. Chamamos estes padrões encadeados de trios fechados, e sua busca tornou-se peça fundamental no nosso algoritmo.

\subsection{Resultados da pesquisa}

\section{Resumo numérico das pesquisas}

Oito estudos foram realizados com o Troost: um para cada doença do WTCCC, mais um estudo adicional em que controles foram utilizados como casos. Os estudos foram batizados com as iniciais da doença respectiva em inglês:

$\mathrm{BD}$ - transtorno bipolar

$\mathrm{CAD}$ - doença arterial coronariana, ou aterosclerose

$\mathrm{CD}$ - doença de Crohn

HT - hipertensão arterial

RA - artrite reumatoide

T1D - diabetes tipo 1

T2D - diabetes tipo 2

58C - estudo de controle, colocando como casos os controles 1958 Birth Cohort.

Dados comuns a todos os estudos:

Número total de SNPs válidos: 459.446

Número total de amostras: 2000, sendo mil casos e mil controles, todos válidos.

Total de pares analisados pelo GBoost: 105.545.083.735

O sumário dos resultados obtidos com a análise de trios de mMs é apresentado na Tabela 8. 
Tabela 8 - números de pares, SNPs, mMs e trios obtidos nos sete estudos feitos

\begin{tabular}{|c|c|c|c|c|c|c|c|c|}
\hline Item & BD & CAD & CD & HT & RA & T1D & T2D & $\begin{array}{l}58 \mathrm{C} \\
\text { como } \\
\text { casos }\end{array}$ \\
\hline $\begin{array}{l}\text { Pares }>30 \\
\text { Pares }\end{array}$ & 335842 & 337650 & 339412 & 338428 & 336237 & 349782 & 336505 & 330830 \\
\hline próximos >34 & 120 & 118 & 176 & 175 & 282 & 1587 & 136 & 404 \\
\hline Pares fortes & 51050 & 50813 & 50700 & 50782 & 49960 & 56425 & 50469 & 49961 \\
\hline SNPs em pares & 63912 & 63822 & 63596 & 63492 & 62652 & 64435 & 63411 & 62656 \\
\hline mMs & 25071 & 24961 & 25024 & 24939 & 24782 & 25036 & 25039 & 24767 \\
\hline Maior mM & 0,173 & 0,177 & 0,151 & 0,162 & 0,143 & 0,152 & 0,177 & 0,142 \\
\hline $\begin{array}{l}\mathrm{mMs}>0,1 \mathrm{cM} \\
\text { Pares no }\end{array}$ & 7 & 11 & 6 & 7 & 6 & 7 & 7 & 8 \\
\hline $\begin{array}{l}\text { mesmo mM } \\
\text { Pares não- }\end{array}$ & 0 & 0 & 0 & 0 & 0 & 11 & 0 & 0 \\
\hline $\begin{array}{l}\text { reaundantes de } \\
\text { mMs } \\
\text { mMs em } 2 \text { ou }\end{array}$ & 24551 & 24511 & 24429 & 24386 & 24113 & 24617 & 24410 & 24083 \\
\hline mais pares & 5403 & 5459 & 5385 & 5356 & 5306 & 5395 & 5375 & 5271 \\
\hline Trios fechados & 2 & 3 & 5 & 2 & 1 & 315 & 1 & 0 \\
\hline
\end{tabular}

Pares >30: número de pares com InteractionBoost maior do que 30; Pares próximos >34: número de pares com distância de mapa genético mútua maior que $0,1 \mathrm{cM}$ com InteractionBoost maior que 34 (estes pares foram excluídos da análise); Pares fortes: número de pares entre SNPs não-próximos com InteractionBoost maior do que 34; SNPs em pares: número total de SNPs que participam dos pares fortes; Maior mM: tamanho em centimorgans do maior bloco haplotípico; $\mathbf{m M s}>\mathbf{0 , 1} \mathbf{c M}$ : número de mMs maiores do que 0,1 centimorgan; Pares no mesmo mM: número de pares entre SNPs que estão no mesmo mM. Estes pares são removidos antes da busca dos trios; mMs em dois ou mais pares: número de mMs que participam de dois ou mais pares; Trios fechados: número de trios fechados encontrados. Trios fechados são grupos de $3 \mathrm{mMs}$ tais que os três pares possíveis entre os 3 mMs estão na lista de pares de mMs. 


\section{Transtorno Bipolar - BD}

\section{BD - Lista dos trios encontrados}

Os trios fechados encontrados, com seus blocos haplotípicos, SNPs e dados dos SNPs, estão listados na Tabela 9.

Descrição das colunas nas Tabela 9, 14, 19, 27, 32 e 35:

- Trio - identificação do trio encontrado

- $\mathbf{m M ~ - ~ n u ́ m e r o ~ d o ~ b l o c o ~ h a p l o t i ́ p i c o . ~ E s t a ~ n u m e r a c ̧ a ̃ o ~ e ́ ~ e s p e c i ́ f i c a ~ d e ~ c a d a ~}$ estudo (doença)

- $\quad$ SNP - índice geral do SNP, de 0 a 459445

- Crom - cromossomo

- Affymetrix Id - identificação do SNP na plataforma de genotipagem

- $\quad$ rs Id - Identificação do SNP na base de dados do NCBI

- Alelos - Alelo de referência e alternativo, nesta ordem

- MAF - (Minor Allele Frequency)- Frequência do alelo alternativo, em \%.

Tabela 9 - BD - Lista dos trios encontrados, seus mMs e SNPS

\begin{tabular}{|c|c|c|c|c|c|}
\hline Trio & $\mathbf{m M}$ & Crom & SNP & Affymetrix Id & rs Id \\
\hline \multirow{5}{*}{ BD1 } & \multirow{2}{*}{588} & \multirow{2}{*}{1} & \multirow{2}{*}{$\begin{array}{l}10081 \\
10085\end{array}$} & SNP_A-2114220 & \multirow{2}{*}{$\begin{array}{l}\text { rs } 1475398 \\
\text { rs } 2154381\end{array}$} \\
\hline & & & & SNP_A-4244342 & \\
\hline & 1899 & 1 & 36192 & SNP_A-4225737 & rs10926141 \\
\hline & \multirow{2}{*}{21127} & \multirow{2}{*}{16} & 394988 & SNP_A-4298603 & rs3785404 \\
\hline & & & 394997 & SNP_A-4196839 & rs 8047317 \\
\hline \multirow{4}{*}{ BD2 } & \multirow{2}{*}{892} & \multirow{2}{*}{1} & 17138 & SNP_A-2138484 & rs 7511900 \\
\hline & & & 17120 & SNP_A-2157424 & rs6582984 \\
\hline & 12322 & 8 & 229782 & SNP_A-2254171 & rs11776090 \\
\hline & 18015 & 12 & $\begin{array}{l}341079 \\
341074\end{array}$ & $\begin{array}{l}\text { SNP_A-4216814 } \\
\text { SNP_A-4274304 }\end{array}$ & $\begin{array}{l}\text { rs1920942 } \\
\text { rs1426426 }\end{array}$ \\
\hline
\end{tabular}




\section{BD - Gráficos do efeito individual e de interação tripla}

\section{Trio BD1}

Tabela 10 - Detalhes dos mMs e SNPs do trio BD1

\begin{tabular}{|c|c|c|c|c|c|c|c|c|c|}
\hline Trio & $\mathrm{mM}$ & Crom & rs Id & MAF & Pos BP & $\begin{array}{l}\text { Dist } \\
\text { BP }\end{array}$ & $\begin{array}{l}\text { Dist } \\
\text { cM }\end{array}$ & $\begin{array}{l}\text { Taxa } \\
\text { (cM/Mb) }\end{array}$ & $\begin{array}{l}\text { Assoc. } \\
\text { Marginal }\end{array}$ \\
\hline \multirow{4}{*}{ BD1 } & \multirow{2}{*}{588} & \multirow{2}{*}{1} & rs1475398 & 27,05 & 65755845 & \multirow{2}{*}{12444} & \multirow{2}{*}{0,0045} & \multirow{2}{*}{0,361} & 2,46 \\
\hline & & & rs2154381 & 30,39 & 65768289 & & & & 1,89 \\
\hline & 1899 & 1 & rs10926141 & 46,65 & 238375005 & 0 & 0 & & 1,94 \\
\hline & 21127 & 16 & $\begin{array}{l}\text { rs3785404 } \\
\text { rs8047317 }\end{array}$ & $\begin{array}{l}14,31 \\
42,46\end{array}$ & $\begin{array}{l}23774158 \\
23789545\end{array}$ & 15387 & 0,0152 & 0,987 & $\begin{array}{l}4,64 \\
124\end{array}$ \\
\hline
\end{tabular}

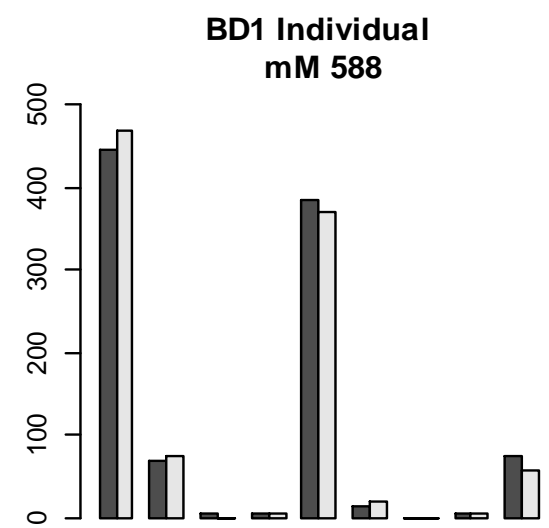

$\begin{array}{lllllllll}00 & 01 & 02 & 10 & 11 & 12 & 20 & 21 & 22\end{array}$

Duplo-haplotipos

mM 1899

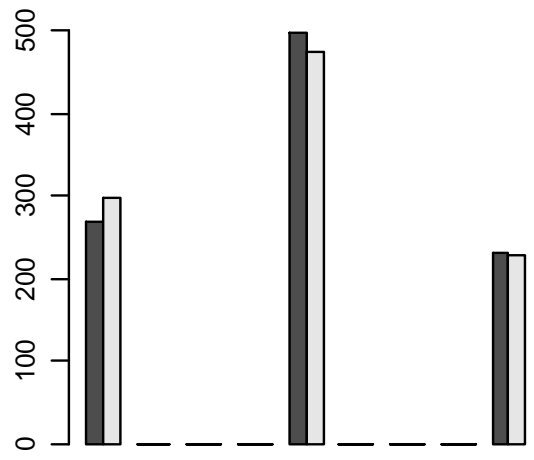

$\begin{array}{lllllllll}00 & 01 & 02 & 10 & 11 & 12 & 20 & 21 & 22\end{array}$

Duplo-haplotipos
mM 21127

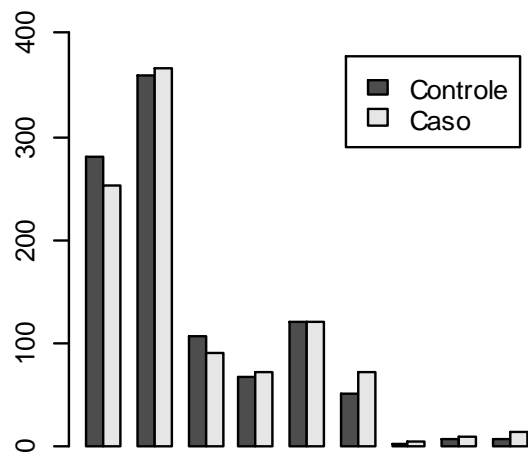

$\begin{array}{lllllllll}00 & 01 & 02 & 10 & 11 & 12 & 20 & 21 & 22\end{array}$

Duplo-haplotipos

Figura 12 - Trio BD1 - contagens de amostras em cada duplo-haplótipo de cada mM

Análise dos efeitos individuais dos mMs: A Figura 12 apresenta a comparação das contagens de controles e casos para cada duplo haplótipos, observando os mMs individualmente. Um efeito muito pequeno é observado em alguns genótipos, como é o caso dos genótipos 00, 02 e 12 do mM 21127. Os detalhes dos SNPs que compõem estes mMs estão apresentados na Tabela 10.

Trio BD1 - Análise da interação tripla: A Figura 13 apresenta a comparação das contagens de controles e casos para cada genótipo combinado dos três mMs. Não seria possível mostrar todos os 729 genótipos possíveis, então removemos os duplohaplótipos de cada mM que representam menos de 5\% das amostras (100 indivíduos). Após esta remoção, o mM com mais duplo-haplótipos foi batizado de $\mathrm{A}$ e é representado no interior de cada sub-gráfico, para que o total de sub-gráficos seja menor. No topo de cada gráfico apresentamos a correspondência entre a nomenclatura $\mathrm{ABC}$ e o número de cada mM. 
Podemos notar dois pares de barras com desequilíbrio na proporção controle/caso: A01, B00, C00, com risco de 33/66; e A11, B00, C22, com risco de $7 / 24$.

\section{Gráficos de pares}

Nas páginas seguintes, entre outros resultados, apresentaremos para cada doença os gráficos dos efeitos individuais dos mMs e o gráfico da interação tripla de cada trio. Além destes dois, o leitor pode ter interesse em conferir os gráficos de cada um dos três pares formados em cada trio, com as contagens de controles e casos em cada genótipo combinado. Optamos por colocar estes gráficos de pares em um documento suplementar acessível em:

\section{http://bioinfo.ib.usp.br/troost/Doc_suplementar_graficos_de_pares.pdf.}

Cada trio encontrado possui três figuras, uma para cada par possível no trio. Cada figura inclui os nove gráficos do par, bem como a doença, número do par $(1,2$ ou 3) e os mMs que compõem aquele par.

É esperado encontrar efeitos visíveis nestes gráficos, pois os pares de SNPs que deram origem aos pares de blocos são escolhidos entre os mais fortes, ou seja, pares de SNPs para os quais a estatística Interaction BOOST é superior a 30. Porém, não temos muito interesse nestes efeitos. Veja mais detalhes na seção 3.8 - Busca exaustiva de pares de locos, subitem Detalhamento do BOOST. A finalidade destes gráficos de pares é apoiar o gráfico de interação tripla, pois possibilitam verificar se um efeito de uma interação tripla aparece também em uma interação de um par. 
BD1 Interacao Tripla B00 COO
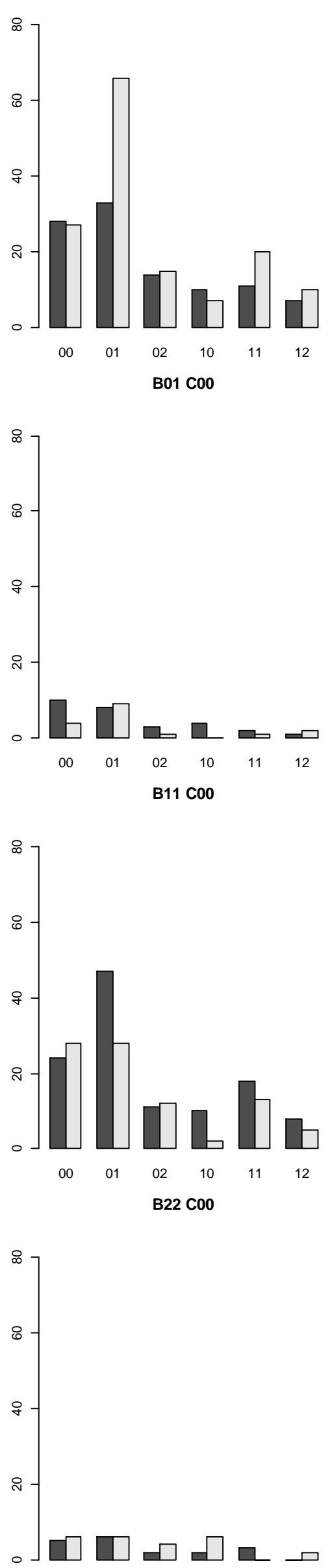

mM A=21127 $B=588 \quad C=1899$

B00 C11

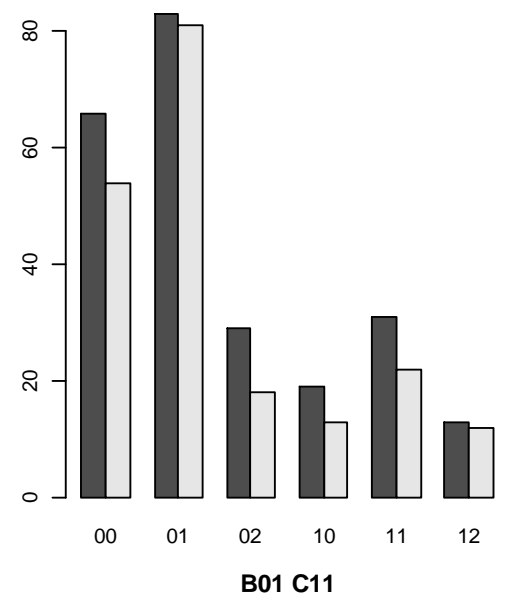

B01 C11
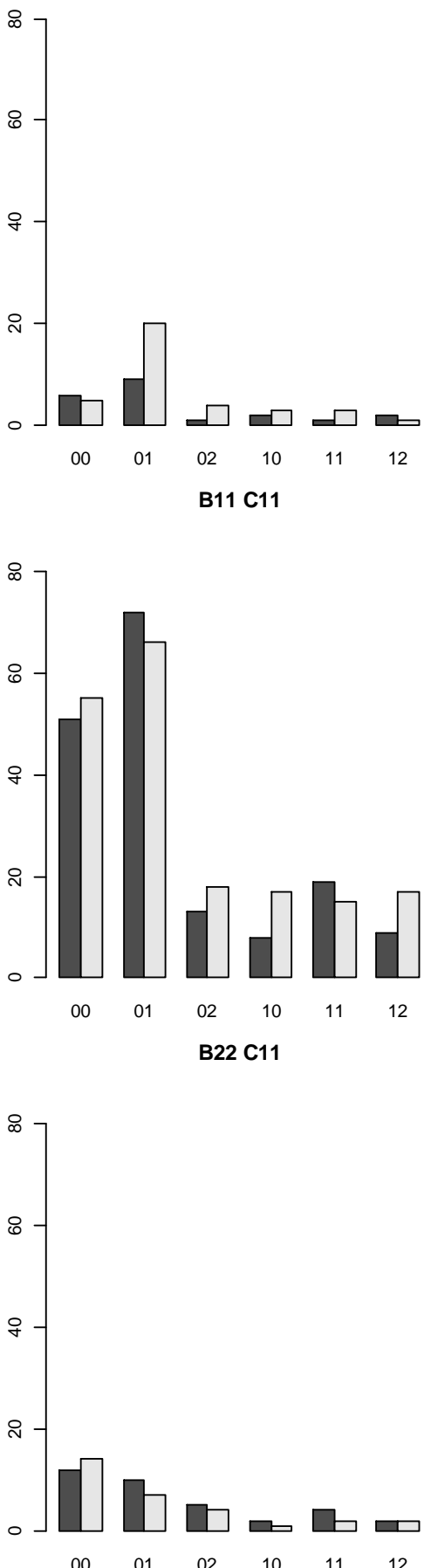
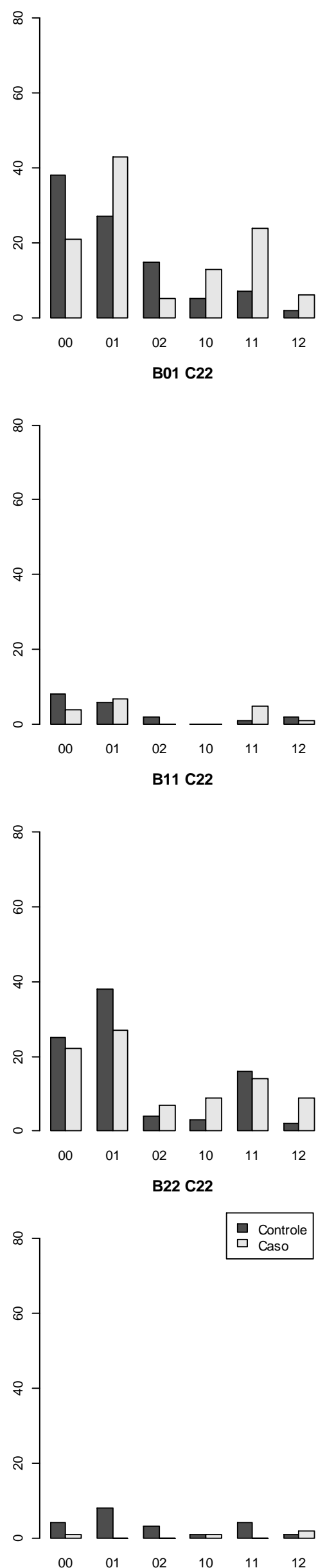

Figura 13 - Trio BD1 - interação tripla - contagem de amostras em cada genótipo combinado 


\section{Trio BD2}

Tabela 11 - Detalhes dos mMs e SNPs do trio BD2

\begin{tabular}{|c|c|c|c|c|c|c|c|c|c|}
\hline Trio & $\mathrm{mM}$ & Crom & rs Id & MAF & Pos BP & $\begin{array}{l}\text { Dist } \\
\text { BP }\end{array}$ & $\begin{array}{l}\text { Dist } \\
\text { cM }\end{array}$ & $\begin{array}{l}\text { Taxa } \\
\text { (cM/Mb) }\end{array}$ & $\begin{array}{l}\text { Assoc. } \\
\text { Marginal }\end{array}$ \\
\hline \multirow{3}{*}{ BD2 } & 892 & 1 & $\begin{array}{l}\text { rs7511900 } \\
\text { rs6582984 }\end{array}$ & $\begin{array}{l}10,47 \\
39,91\end{array}$ & $\begin{array}{l}107202353 \\
107076650\end{array}$ & 125703 & 0,0187 & 0,149 & $\begin{array}{l}0,61 \\
3,26\end{array}$ \\
\hline & 12322 & 8 & rs 11776090 & 42,61 & 29045136 & 0 & 0 & & 0,59 \\
\hline & 18015 & 12 & $\begin{array}{l}\text { rs1920942 } \\
\text { rs1426426 }\end{array}$ & $\begin{array}{r}9,69 \\
24,95\end{array}$ & $\begin{array}{l}114170466 \\
114157575\end{array}$ & 12891 & 0,0145 & 1,128 & $\begin{array}{l}5,68 \\
1,59\end{array}$ \\
\hline
\end{tabular}

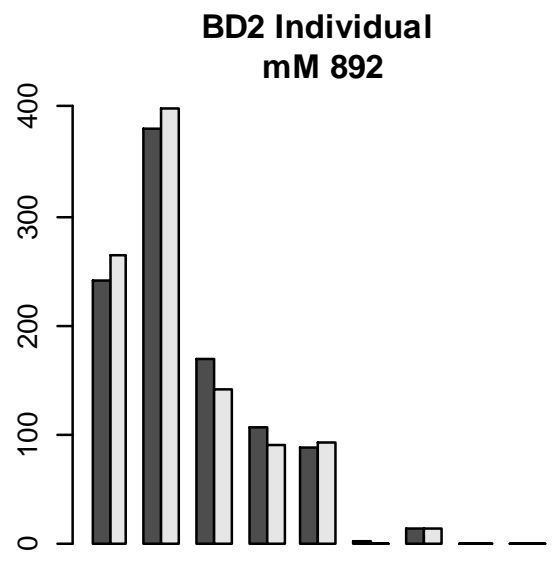

$\begin{array}{lllllllll}00 & 01 & 02 & 10 & 11 & 12 & 20 & 21 & 22\end{array}$

Duplo-haplotipos
mM 12322

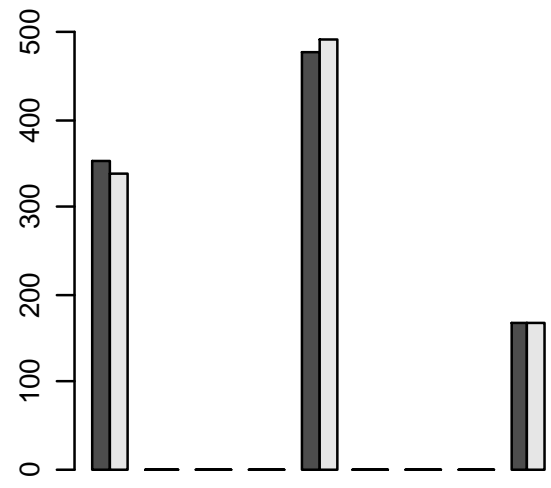

$\begin{array}{lllllllll}00 & 01 & 02 & 10 & 11 & 12 & 20 & 21 & 22\end{array}$

Duplo-haplotipos
$\mathrm{mM} 18015$

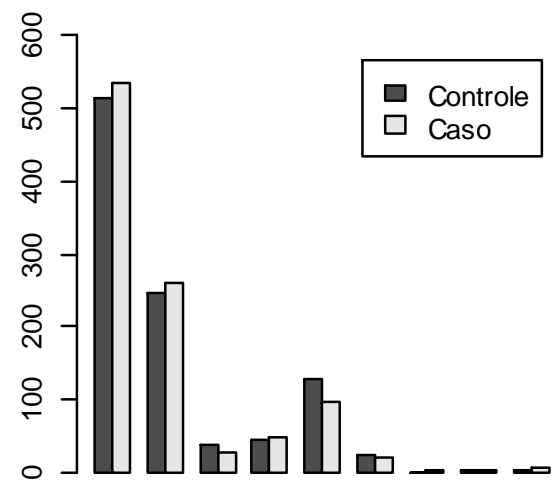

$\begin{array}{lllllllll}00 & 01 & 02 & 10 & 11 & 12 & 20 & 21 & 22\end{array}$

Duplo-haplotipos

Figura 14 - Trio BD2 - contagens de amostras em cada duplo-haplótipo de cada mM

Análise dos mMs individuais: Na Figura 14 não conseguimos ver efeitos individuais marcantes. Os detalhes dos SNPs que compõem os mMs estão apresentados na Tabela 11 .

Análise visual da interação tripla no trio BD2: consideramos dignas de análise posterior as seguintes combinações de duplo-haplótipos, com suas proporções controle/caso: A01, B00, C11 - risco 73/114; A10, B00, C22 - risco 3/17; A02, B01, C22 - protetor 13/3; A00, B11, C00 - risco 5/17; A01, B11, C11 - protetor 31/12. Estes desequilíbrios podem ser visualizados na Figura 15. 

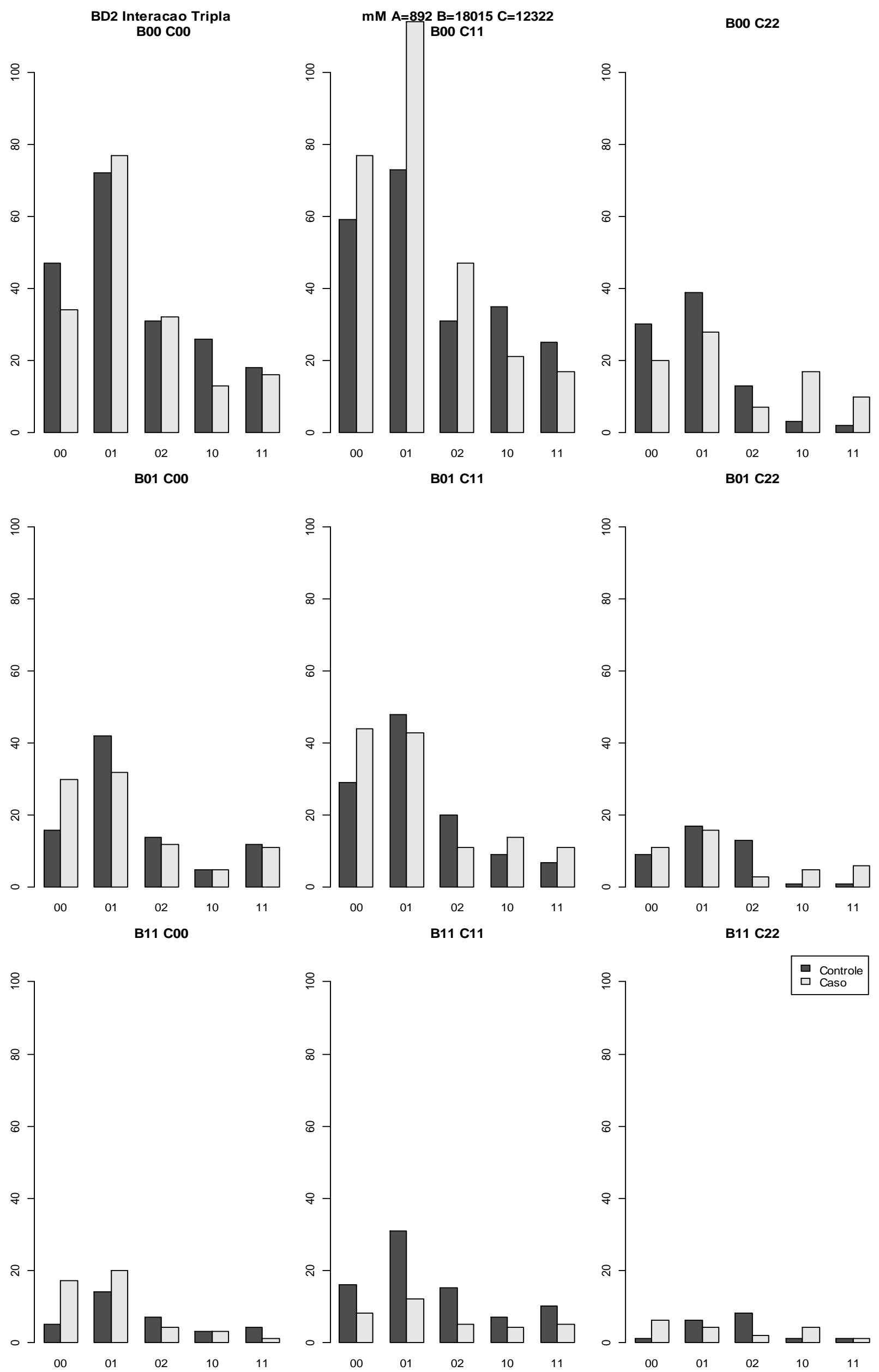

Figura 15 - Trio BD2 - interação tripla - contagem de amostras em cada genótipo combinado 


\section{BD - Teste estatístico de cada trio}

Para cada trio fechado encontrado pelo Troost, construímos sua tabela de contingência, reduzimos para duas dimensões - genótipo e fenótipo - e agrupamos todos os genótipos com baixa representação em uma categoria Outros. Fizemos o teste qui-quadrado de Pearson e o de Goodman. Já detalhamos este teste no item 5.4, subitem Detalhamento dos Módulos do Troost, módulo TrioStat.R. Os resultados estão na Tabela 12.

Tabela 12 - BD - Teste estatístico dos trios. Genótipos: número genótipos possíveis no trio. GenFreq: genótipos com frequência de 1\% ou superior. P-X2: valor-P no teste qui-quadrado de Pearson. SignX2: significante no teste de Pearson. PGoodman: valor-P no teste de homogeneidade de Goodman. SignGood: significante no teste de Goodman.

\begin{tabular}{lrrllrl}
\hline Trio & Genotipos & GenFreq & P-X2 & SignX2 & PGoodman & SignGood \\
\hline BD1 & 216 & 30 & $2,6 \times 10^{-04}$ & Sim & $1,4 \times 10^{-04}$ & Sim \\
BD2 & 189 & 30 & $1,8 \times 10^{-06}$ & Sim & $6,1 \times 10^{-07}$ & Sim \\
\hline
\end{tabular}

\section{Trio BD1}

Este trio apresenta 216 genótipos, que foram reduzidos a 30 com o agrupamento dos genótipos com representação abaixo de 20 indivíduos. O teste quiquadrado de Pearson mostrou um valor-P de $2,6 \times 10^{-4}$, portanto significante, considerando níveis de significância corrigidos para múltiplos testes da ordem de $10^{-3}$. $\mathrm{O}$ teste de homogeneidade de Goodman resultou num valor-P ainda menor de $1,44 \times 10^{-4}$. Mostramos os genótipos com maior desequilíbrio na Tabela 13.

Tabela 13 - Trio BD1 - Genótipos com desequilíbrio

\begin{tabular}{lllrr}
\hline $\mathbf{m M}$ & $\mathbf{m M}$ & $\mathbf{m M}$ & & \\
$\mathbf{2 1 1 2 7}$ & $\mathbf{5 8 8}$ & $\mathbf{1 8 9 9}$ & Controle & Caso \\
\hline 01 & 00 & 00 & 33 & 66 \\
11 & 00 & 22 & 7 & 24 \\
\hline
\end{tabular}

\section{Trio BD2}

Os 189 genótipos possíveis foram reduzidos a 30. O valor-P do teste de Pearson foi $1,8 \times 10^{-6}$ e o de Goodman $1,80 \times 10^{-7}$, ambos significantes.

Escolhemos alguns genótipos específicos deste trio para mostrar o desequilíbrio, listando-os na Tabela 14.

Tabela 14 - Trio BD2 - Genótipos com desequilíbrio

\begin{tabular}{lllrr}
\hline & $\mathbf{m M}$ & $\mathbf{m M}$ & & \\
$\mathbf{m M} \mathbf{8 9 2}$ & $\mathbf{1 8 0 1 5}$ & $\mathbf{1 2 3 2 2}$ & Controle & Caso \\
\hline 01 & 00 & 11 & 73 & 114 \\
01 & 11 & 11 & 31 & 12 \\
10 & 00 & 22 & 3 & 17 \\
\hline
\end{tabular}




\section{BD - Confirmação com amostras independentes}

Para confirmar os resultados, usamos os 868 casos válidos não usados no estudo principal do Troost, e todos os 1480 controles do conjunto 58C - 1958 British Birth Cohort. Nossos resultados estão na Tabela 15.

Tabela 15 - Confirmação dos trios de BD. Veja o significado das colunas na Tabela 12.

\begin{tabular}{|c|c|c|c|c|c|c|c|}
\hline Trio & Genotipos & GenFreq & P-X2 & & SignX2 & PGoodman & SignGood \\
\hline BD1 & 189 & 28 & & 0,19 & Não & 0,18 & Não \\
\hline BD2 & 189 & 27 & & 0,56 & Não & 0,52 & Não \\
\hline
\end{tabular}

Nenhum dos dois trios foi confirmado como significante.

\section{Doença arterial coronariana - CAD}

\section{CAD - Lista dos trios encontrados}

Os trios fechados encontrados, com seus blocos haplotípicos, SNPs e dados dos SNPs, estão listados na Tabela 16. Uma descrição dos campos está na seção correspondente de $\mathrm{BD}$ - transtorno bipolar.

Tabela 16 - CAD - Lista dos trios encontrados, seus mMs e SNPS

\begin{tabular}{|c|c|c|c|c|c|}
\hline Trio & $\mathrm{mM}$ & Crom & SNP & Affymetrix Id & rs Id \\
\hline \multirow{6}{*}{ CAD1 } & \multirow{2}{*}{855} & \multirow{2}{*}{1} & 15561 & SNP_A-1815544 & rs1889060 \\
\hline & & & 15543 & SNP_A-4303120 & rs7556086 \\
\hline & \multirow{2}{*}{11257} & \multirow{2}{*}{7} & 212092 & SNP_A-1933080 & rs1358064 \\
\hline & & & 212099 & SNP_A-2110941 & rs802041 \\
\hline & \multirow{2}{*}{24742} & \multirow{2}{*}{22} & 455944 & SNP_A-2065946 & rs5997780 \\
\hline & & & 455933 & SNP_A-2307722 & rs136343 \\
\hline \multirow{6}{*}{ CAD2 } & \multirow{2}{*}{1456} & \multirow{2}{*}{1} & 28164 & SNP_A-4280671 & rs6428453 \\
\hline & & & 28151 & SNP_A-2180526 & rs6428449 \\
\hline & \multirow{2}{*}{7478} & \multirow{2}{*}{5} & 140323 & SNP_A-1882570 & rs12659288 \\
\hline & & & 140314 & SNP_A-2245294 & rs890970 \\
\hline & \multirow{2}{*}{23950} & \multirow{2}{*}{20} & 443066 & SNP_A-1968454 & rs619289 \\
\hline & & & 443064 & SNP_A-1858687 & rs826941 \\
\hline \multirow{6}{*}{ CAD3 } & \multirow{2}{*}{7237} & \multirow{2}{*}{4} & 136902 & SNP_A-2295412 & rs17071302 \\
\hline & & & 136922 & SNP_A-1889968 & rs11724604 \\
\hline & \multirow{2}{*}{14666} & \multirow{2}{*}{10} & 275350 & SNP_A-2174080 & rs11013210 \\
\hline & & & 275331 & SNP_A-2145432 & rs7899129 \\
\hline & \multirow{2}{*}{18869} & \multirow{2}{*}{13} & 356696 & SNP_A-1827011 & rs5009567 \\
\hline & & & 356681 & SNP_A-2196520 & rs2204502 \\
\hline
\end{tabular}




\section{CAD - Gráfico do efeito de cada bloco haplotípico}

\section{Trio CAD1}

Tabela 17 - Detalhes dos mMs e SNPs do trio CAD1

\begin{tabular}{|c|c|c|c|c|c|c|c|c|c|}
\hline Trio & $\mathrm{mM}$ & Crom & rs Id & MAF & Pos BP & $\begin{array}{l}\text { Dist } \\
\text { BP }\end{array}$ & Dist cM & $\begin{array}{l}\text { Taxa } \\
\text { (cM/Mb) }\end{array}$ & $\begin{array}{l}\text { Assoc. } \\
\text { Marginal }\end{array}$ \\
\hline \multirow{6}{*}{ CAD1 } & \multirow{2}{*}{855} & \multirow{2}{*}{1} & rs1889060 & 29,56 & 96198384 & \multirow{2}{*}{119610} & \multirow{2}{*}{0,014174} & \multirow{2}{*}{0,119} & 1,61 \\
\hline & & & rs7556086 & 36,79 & 96078774 & & & & 0,04 \\
\hline & \multirow{2}{*}{11257} & \multirow[t]{2}{*}{7} & rs1358064 & 18,14 & 86779605 & \multirow{2}{*}{41268} & \multirow{2}{*}{0,015122} & \multirow{2}{*}{0,366} & 5,98 \\
\hline & & & rs802041 & 26,05 & 86820873 & & & & 0,48 \\
\hline & \multirow{2}{*}{24742} & \multirow{2}{*}{22} & rs5997780 & 27,6 & 29564009 & \multirow{2}{*}{82474} & \multirow{2}{*}{0,029737} & \multirow{2}{*}{0,361} & 3,27 \\
\hline & & & rs 136343 & 34,75 & 29481535 & & & & 3,27 \\
\hline
\end{tabular}

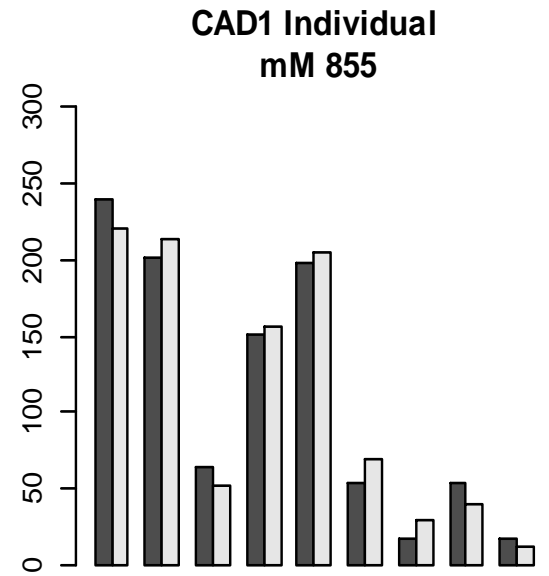

$\begin{array}{lllllllll}00 & 01 & 02 & 10 & 11 & 12 & 20 & 21 & 22\end{array}$

Duplo-haplotipos
$\mathrm{mM} 11257$

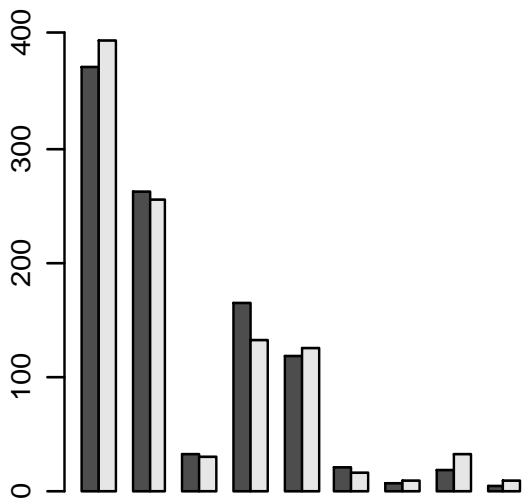

$\begin{array}{lllllllll}00 & 01 & 02 & 10 & 11 & 12 & 20 & 21 & 22\end{array}$

Duplo-haplotipos
$\mathrm{mM} 24742$

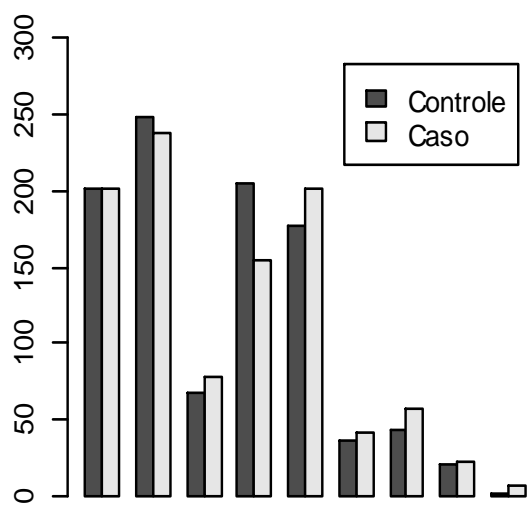

$\begin{array}{lllllllll}00 & 01 & 02 & 10 & 11 & 12 & 20 & 21 & 22\end{array}$ Duplo-haplotipos

Figura 16 - Trio CAD1 - contagens de amostras em cada duplo-haplótipo de cada mM

A Figura 16 mostra as contagens dos duplo-haplótipos de cada mM. Novamente aqui não vemos efeito individual nos dois primeiros mMs. No último deles, podemos ver um leve efeito protetor do duplo-haplótipo 10. Os detalhes dos SNPs que compõem os mMs estão apresentados na Tabela 17.

No gráfico de interação tripla visto na Figura 17, aparentemente muitos genótipos apresentam desequilíbrio entre caso e controle. Observando a escala no eixo $\mathrm{Y}$, vemos que isso é possivelmente enganoso, pois os genótipos combinados apresentam pequena quantidade de casos e controles, de poucas dezenas no máximo, porque neste trio os casos e controles estão bem distribuídos entre os duplohaplótipos. Portanto, o desequilíbrio pode não ser significante. 

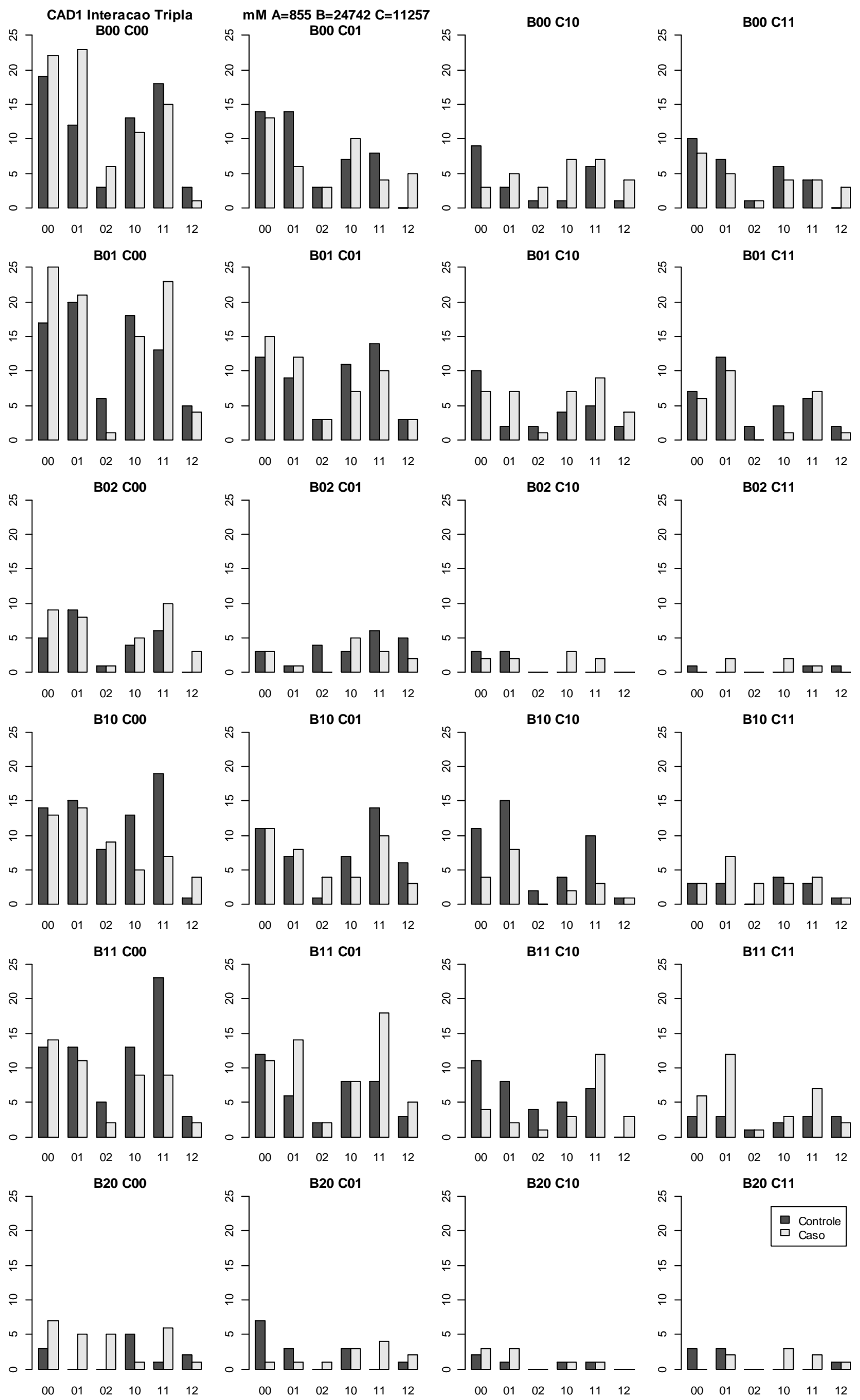

Figura 17 - Trio CAD1 - interação tripla - contagem de amostras em cada genótipo combinado 


\section{Trio CAD2}

Tabela 18 - Detalhes dos mMs e SNPs do trio CAD2

\begin{tabular}{|c|c|c|c|c|c|c|c|c|c|}
\hline Trio & $\mathrm{mM}$ & Crom & rs Id & MAF & Pos BP & $\begin{array}{l}\text { Dist } \\
\text { BP }\end{array}$ & Dist cM & $\begin{array}{l}\text { Taxa } \\
\text { (cM/Mb) }\end{array}$ & $\begin{array}{l}\text { Assoc. } \\
\text { margin }\end{array}$ \\
\hline \multirow{6}{*}{ CAD2 } & \multirow{2}{*}{1456} & \multirow{2}{*}{1} & rs6428453 & 13,86 & 196592080 & \multirow{2}{*}{66531} & \multirow{2}{*}{0,015476} & \multirow{2}{*}{0,233} & 2,68 \\
\hline & & & rs6428449 & 31,65 & 196525549 & & & & 0,73 \\
\hline & \multirow{2}{*}{7478} & \multirow{2}{*}{5} & rs12659288 & 14,08 & 7755167 & \multirow{2}{*}{19258} & \multirow{2}{*}{0,007898} & \multirow{2}{*}{0,410} & 1,37 \\
\hline & & & rs890970 & 48,28 & 7735909 & & & & 1,02 \\
\hline & \multirow{2}{*}{23950} & \multirow{2}{*}{20} & rs619289 & 15,74 & 41728027 & \multirow{2}{*}{4465} & \multirow{2}{*}{0,003512} & \multirow{2}{*}{0,787} & 1,31 \\
\hline & & & rs826941 & 19,88 & 41723562 & & & & 3,10 \\
\hline
\end{tabular}

CAD2 Individual mM 1456

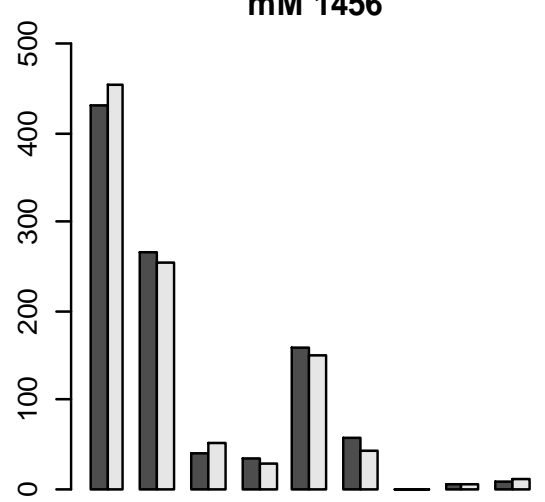

$\begin{array}{lllllllll}00 & 01 & 02 & 10 & 11 & 12 & 20 & 21 & 22\end{array}$

Duplo-haplotipos
mM 7478

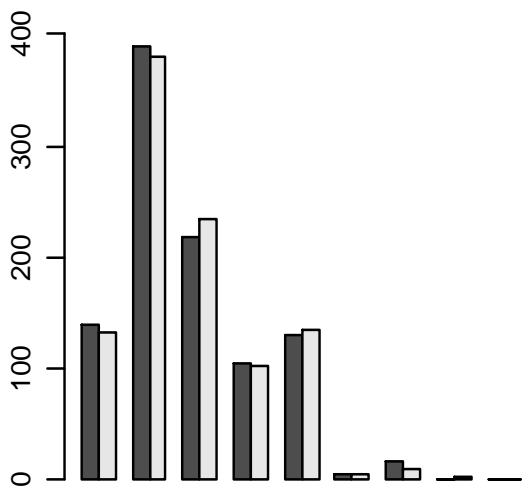

$\begin{array}{lllllllll}00 & 01 & 02 & 10 & 11 & 12 & 20 & 21 & 22\end{array}$

Duplo-haplotipos
$\mathrm{mM} 23950$

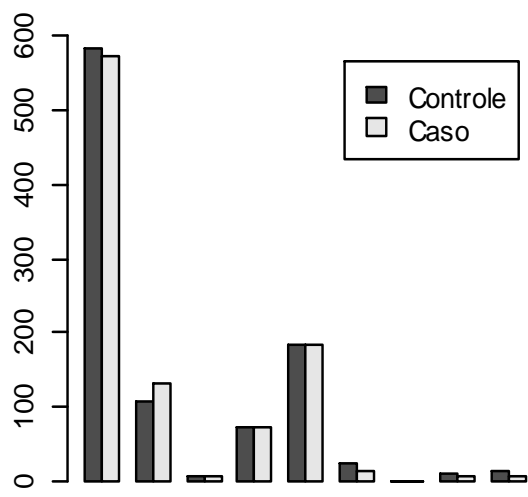

$\begin{array}{lllllllll}00 & 01 & 02 & 10 & 11 & 12 & 20 & 21 & 22\end{array}$

Duplo-haplotipos

Figura 18 - Trio CAD2 - contagens de amostras em cada duplo-haplótipo de cada mM

Na Figura 18 - mMs individuais, não vemos desequilíbrio entre caso e controle em qualquer dos duplo-haplótipos. Já na Figura 19, da interação tripla, vemos genótipos com desequilíbrio moderado, como por exemplo B00-C00-A02, de risco, e B00-C01-A02, protetor. Os detalhes dos SNPs que compõem os mMs estão apresentados na Tabela 18 . 

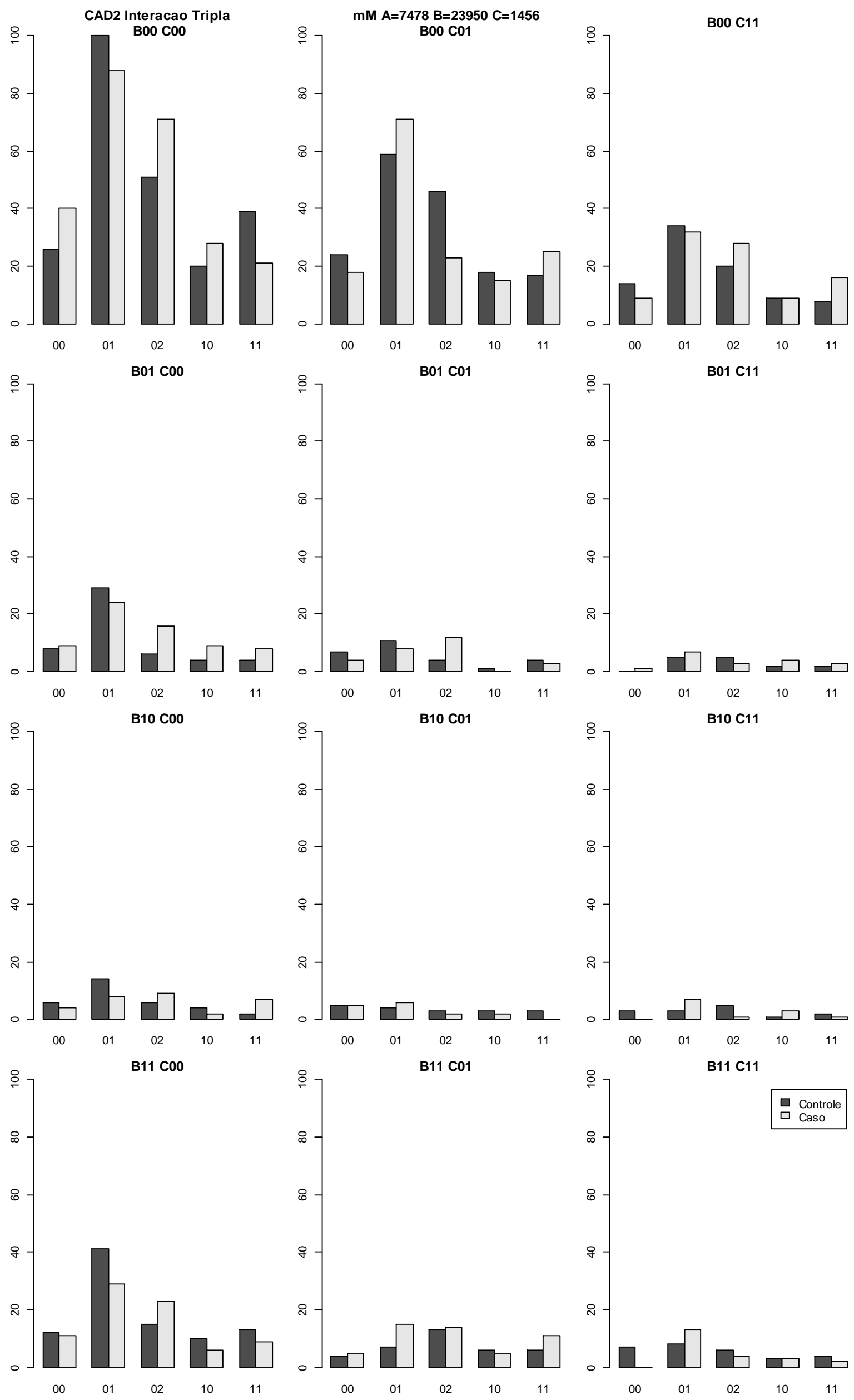

Figura 19 - Trio CAD2 - interação tripla - contagem de amostras em cada genótipo combinado 


\section{Trio CAD3}

Tabela 19 - Detalhes dos mMs e SNPs do trio CAD3

\begin{tabular}{|c|c|c|c|c|c|c|c|c|c|}
\hline Trio & $\mathrm{mM}$ & Crom & rs Id & MAF & Pos BP & $\begin{array}{l}\text { Dist } \\
\text { BP }\end{array}$ & Dist cM & $\begin{array}{l}\text { Taxa } \\
\text { (cM/Mb) }\end{array}$ & $\begin{array}{l}\text { Assoc. } \\
\text { Marginal }\end{array}$ \\
\hline \multirow{3}{*}{ CAD3 } & 7237 & 4 & $\begin{array}{l}\text { rs17071302 } \\
\text { rs11724604 }\end{array}$ & $\begin{array}{l}19,34 \\
25,08\end{array}$ & $\begin{array}{l}182574198 \\
182613304\end{array}$ & 39106 & 0,03585 & 0,917 & $\begin{array}{l}2,24 \\
341\end{array}$ \\
\hline & 14666 & 10 & $\begin{array}{l}\text { rs11013210 } \\
\text { rs7899129 }\end{array}$ & $\begin{array}{l}24,13 \\
41,75\end{array}$ & $\begin{array}{l}23289115 \\
23169844\end{array}$ & 119271 & 0,03183 & 0,267 & $\begin{array}{l}0,31 \\
0,72\end{array}$ \\
\hline & 18869 & 13 & $\begin{array}{l}\text { rs5009567 } \\
\text { rs2204502 }\end{array}$ & $\begin{array}{l}20,15 \\
47,49\end{array}$ & $\begin{array}{l}84292808 \\
84211395\end{array}$ & 81413 & 0,020933 & 0,257 & $\begin{array}{l}4,37 \\
5,14\end{array}$ \\
\hline
\end{tabular}

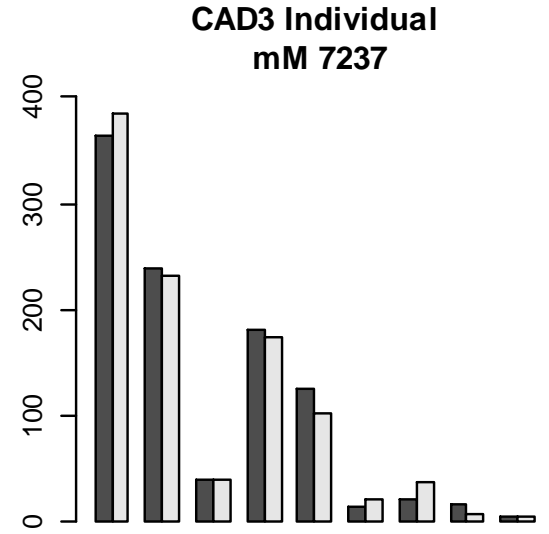

$\begin{array}{lllllllll}00 & 01 & 02 & 10 & 11 & 12 & 20 & 21 & 22\end{array}$

Duplo-haplotipos
$\mathrm{mM} 14666$

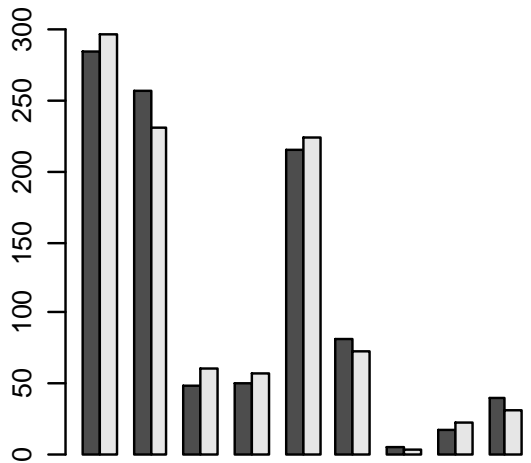

$\begin{array}{lllllllll}00 & 01 & 02 & 10 & 11 & 12 & 20 & 21 & 22\end{array}$

Duplo-haplotipos
mM 18869

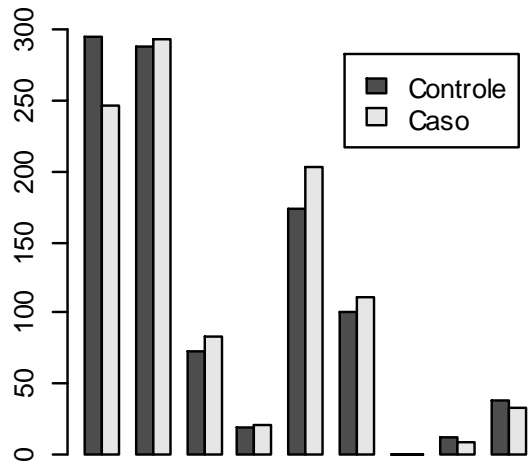

$\begin{array}{lllllllll}00 & 01 & 02 & 10 & 11 & 12 & 20 & 21 & 22\end{array}$

Duplo-haplotipos

Figura 20 - Trio CAD3 - contagens de amostras em cada duplo-haplótipo de cada mM

Na Figura 20, dos mMs individuais, não vemos desequilíbrios importantes entre caso e controle, exceto um possível efeito protetor do duplo-haplótipo 00 do mM18869. Na Figura 21, da interação tripla, notamos desequilíbrio protetor em vários genótipos em que $A=11$ e $B=00$ ou 01 , mas as contagens não são altas. Há também desequilíbrios de risco, dos quais o mais evidente é B01-C00-A01. Os detalhes dos SNPs que compõem os mMs estão apresentados na Tabela 19. 

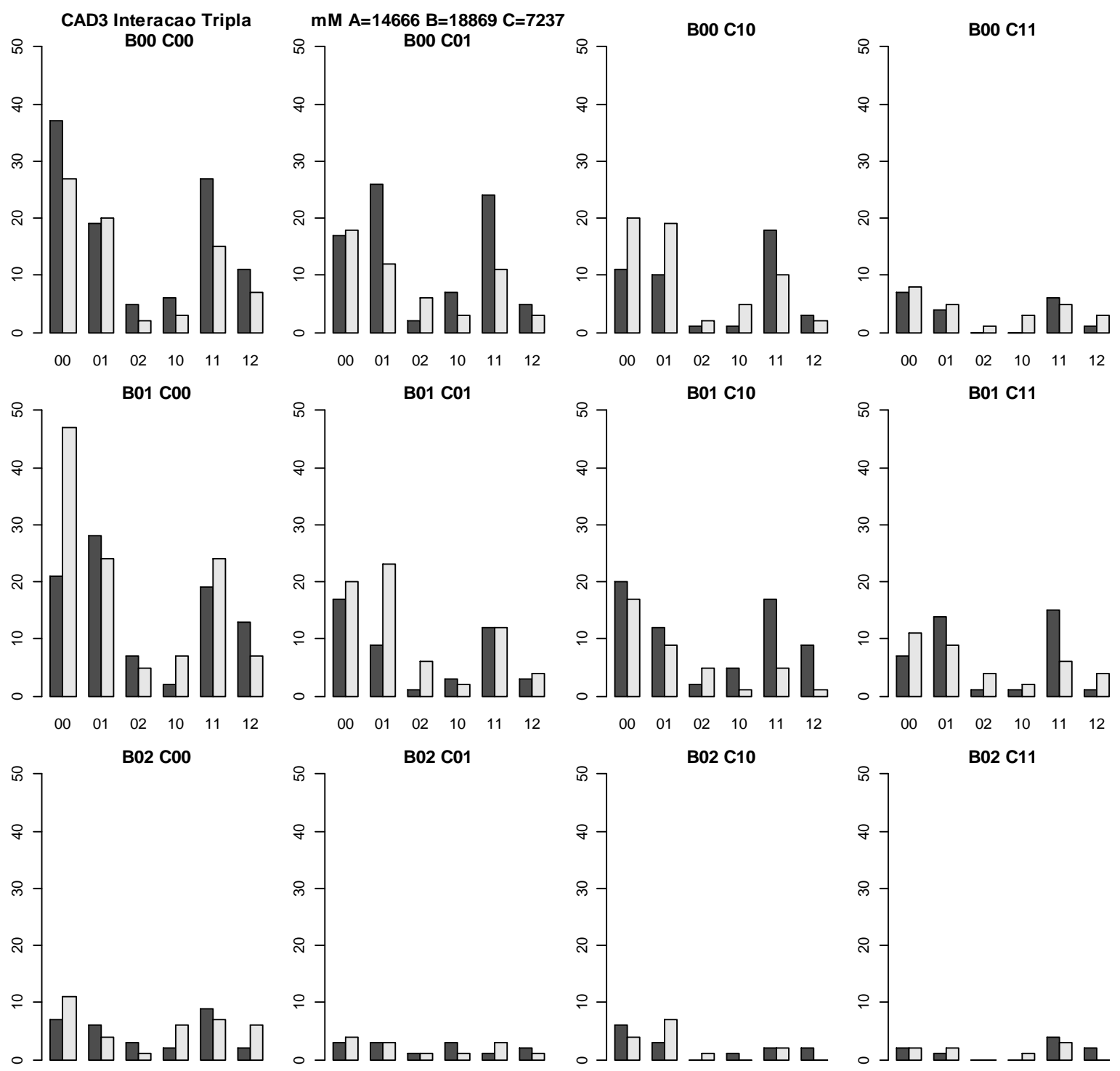

$\begin{array}{llllll}00 & 01 & 02 & 10 & 11 & 12\end{array}$

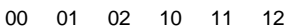

$\begin{array}{llllll}00 & 01 & 02 & 10 & 11 & 12\end{array}$
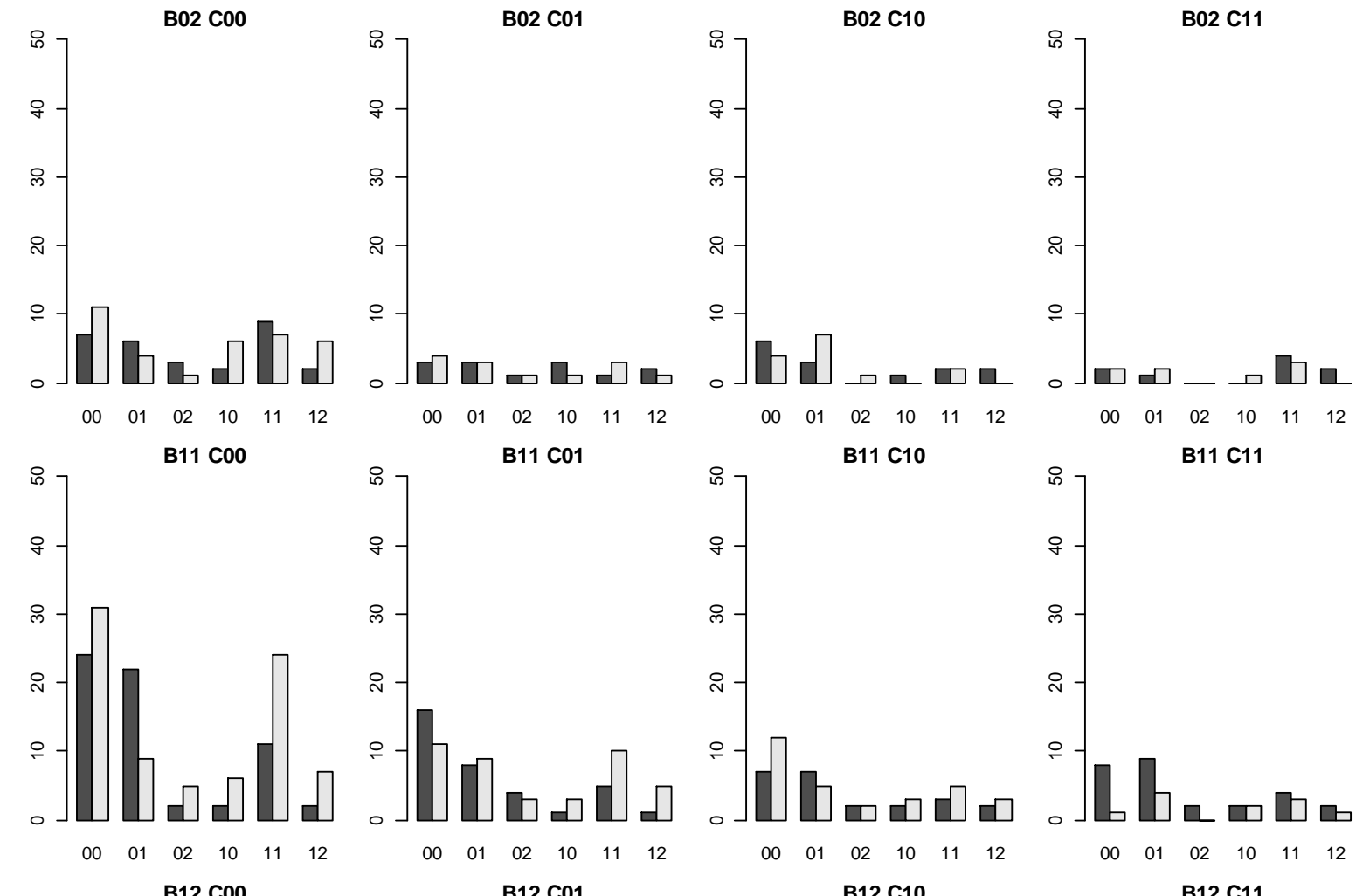

$\begin{array}{llllll}00 & 01 & 02 & 10 & 11 & 12\end{array}$
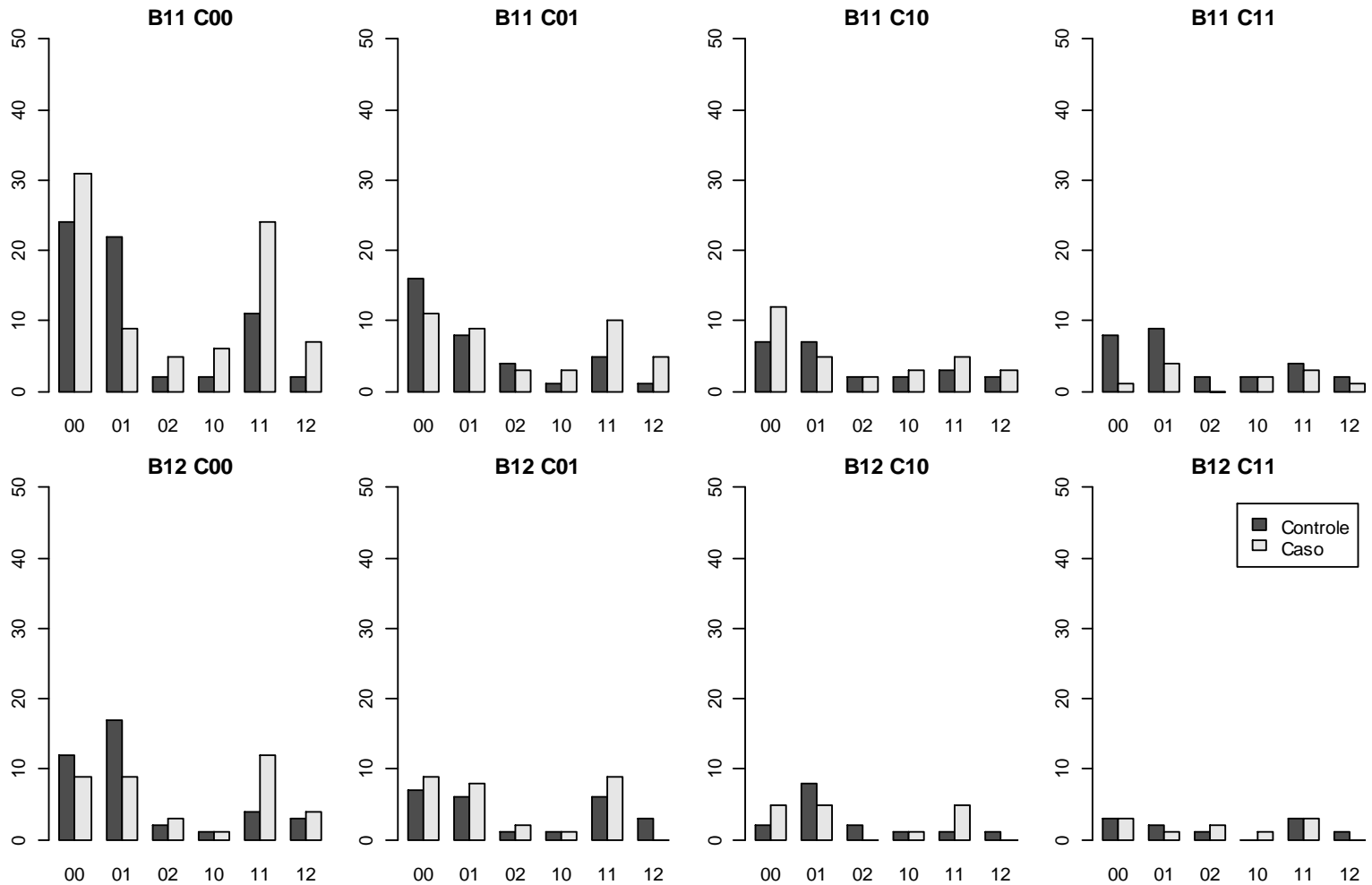

Figura 21 - Trio CAD3 - interação tripla - contagem de amostras em cada genótipo combinado 


\section{CAD - Teste estatístico de cada trio}

Os três trios de doença arterial coronariana foram testados como descrito nos métodos. Os resultados estão descritos na Tabela 20 - CAD - . Os trios CAD2 e CAD3 foram considerados significantes. Os genótipos com desequilíbrio entre caso e controle estão na Tabela 21.

Tabela 20 - CAD - Teste estatístico dos trios. Veja o significado das colunas na Tabela 12.

\begin{tabular}{lrrrlrl}
\hline Trio & Genotipos & GenFreq & P-X2 & SignX2 & PGoodman & SignGood \\
\hline CAD1 & 729 & 28 & 0,111 & Não & 0,097 & Não \\
CAD2 & 648 & 27 & $7,3 \times 10^{-03}$ & Sim & $5,4 \times 10^{-03}$ & Sim \\
CAD3 & 648 & 28 & $9,9 \times 10^{-06}$ & Sim & $4,2 \times 10^{-06}$ & Sim \\
\hline
\end{tabular}

Tabela 21 - CAD - Genótipos com desequilíbrio

\begin{tabular}{lllcll}
\hline Trio & CAD2 & & & & \\
mM & mM & & & & \\
7478 & 23950 & mM 1456 & Controle & Caso & \\
\hline 02 & 00 & 01 & 46 & & 23 \\
\hline Trio & CAD3 & & & & \\
mM & mM & & & & \\
14666 & 18869 & mM 7237 & Controle & Caso & \\
\hline 00 & 01 & 00 & 21 & & 47 \\
\hline
\end{tabular}

\section{CAD - Confirmação com amostras independentes}

Para confirmar os resultados, usamos os 926 casos não usados como Troost, e todos os 1480 controles do conjunto 58C - 1958 British Birth Cohort. Os resultados estão na Tabela 22. Nenhum dos dois trios foi confirmado como significante.

Tabela 22 - CAD - Confirmação dos trios. Veja o significado das colunas na Tabela 12.

\begin{tabular}{lrrrcrc}
\hline Trio & Genotipos & GenFreq & P-X2 & SignX2 & PGoodman & SignGood \\
\hline CAD2 & 729 & 25 & 0,75 & Não & 0,78 & Não \\
CAD3 & 648 & 31 & 0,46 & Não & 0,43 & Não \\
\hline
\end{tabular}




\section{Doença de Crohn - CD}

\section{CD - Lista dos trios encontrados}

Os trios fechados encontrados, com seus blocos haplotípicos, SNPs e dados dos SNPs, estão listados na Tabela 23. Uma descrição dos campos está na seção correspondente de $\mathrm{BD}$ - transtorno bipolar.

Tabela 23 - CD - Lista dos trios encontrados, seus mMs e SNPS

\begin{tabular}{|c|c|c|c|c|c|}
\hline Trio & $\mathrm{mM}$ & Crom & SNP & Affymetrix Id & rs Id \\
\hline \multirow{4}{*}{ CD1 } & 740 & 1 & $\begin{array}{l}13193 \\
13213\end{array}$ & $\begin{array}{l}\text { SNP_A-4246699 } \\
\text { SNP-A-1823572 }\end{array}$ & $\begin{array}{l}\text { rs11587847 } \\
\text { rs12723667 }\end{array}$ \\
\hline & 1520 & 1 & 29490 & SNP_A-1942932 & rs10900473 \\
\hline & & & 29476 & SNP_A-4259031 & rs3862948 \\
\hline & 8669 & 5 & $\begin{array}{l}165427 \\
165429\end{array}$ & $\begin{array}{l}\text { SNP_A-4231324 } \\
\text { SNP-A-1984392 }\end{array}$ & $\begin{array}{l}\text { rs } 489816 \\
\text { rs501869 }\end{array}$ \\
\hline \multirow{5}{*}{ CD2 } & 763 & 1 & 13643 & SNP_A-2289868 & rs6576739 \\
\hline & & & 13630 & SNP_A-2277759 & rs674647 \\
\hline & 9565 & 6 & 181341 & SNP_A-1957896 & rs1753251 \\
\hline & & & 181329 & SNP_A-2046572 & rs12210719 \\
\hline & 18931 & 13 & 359263 & SNP_A-2178063 & rs9300532 \\
\hline \multirow{4}{*}{ CD3 } & 6605 & 1 & 128517 & SNP A-2226841 & rs967534 \\
\hline & 0095 & 4 & 128439 & SNP_A-1866378 & rs17273728 \\
\hline & 14653 & 10 & 274722 & SNP_A-1882094 & rs9663367 \\
\hline & 17762 & 12 & 337737 & SNP_A-1911945 & rs10860174 \\
\hline \multirow{3}{*}{ CD4 } & 10917 & 7 & 205685 & SNP A-4266315 & rs1525791 \\
\hline & 16617 & 11 & 316483 & SNP_A-2162071 & rs17116117 \\
\hline & 19316 & 14 & 365213 & SNP_A-4292036 & rs10483456 \\
\hline \multirow{3}{*}{ CD5 } & 16617 & 11 & 316483 & SNP_A-2162071 & rs 17116117 \\
\hline & 19316 & 14 & 365213 & SNP_A-4292036 & rs10483456 \\
\hline & 22061 & 17 & 411498 & SNP_A-4245079 & rs 12150025 \\
\hline
\end{tabular}




\section{CD - Gráfico do efeito de cada bloco haplotípico}

\section{Trio CD1}

Tabela 24 - Detalhes dos mMs e SNPs do trio CD1

\begin{tabular}{|c|c|c|c|c|c|c|c|c|c|}
\hline Trio & $\mathrm{mM}$ & Crom & rs Id & MAF & Pos BP & $\begin{array}{l}\text { Dist } \\
\text { BP }\end{array}$ & Dist cM & $\begin{array}{l}\text { Taxa } \\
\text { (cM/Mb) }\end{array}$ & $\begin{array}{l}\text { Assoc. } \\
\text { Marginal }\end{array}$ \\
\hline \multirow{6}{*}{ CD1 } & \multirow{2}{*}{740} & \multirow{2}{*}{ 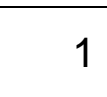 } & rs11587847 & 34,06 & 82950180 & \multirow{2}{*}{63067} & \multirow{2}{*}{0,010406} & \multirow{2}{*}{0,165} & 0,43 \\
\hline & & & rs 12723667 & 36,32 & 83013247 & & & & 0,34 \\
\hline & \multirow{2}{*}{1520} & \multirow{2}{*}{1} & rs10900473 & 22,21 & 203480506 & \multirow{2}{*}{113924} & \multirow{2}{*}{0,009992} & \multirow{2}{*}{0,088} & 0,29 \\
\hline & & & rs3862948 & 23,86 & 203366582 & & & & 1,00 \\
\hline & \multirow{2}{*}{8669} & \multirow{2}{*}{5} & rs489816 & 48,56 & 163069554 & \multirow{2}{*}{6041} & \multirow{2}{*}{0,003305} & \multirow{2}{*}{0,547} & 1,21 \\
\hline & & & rs501869 & 49,98 & 163075595 & & & & 0,48 \\
\hline
\end{tabular}
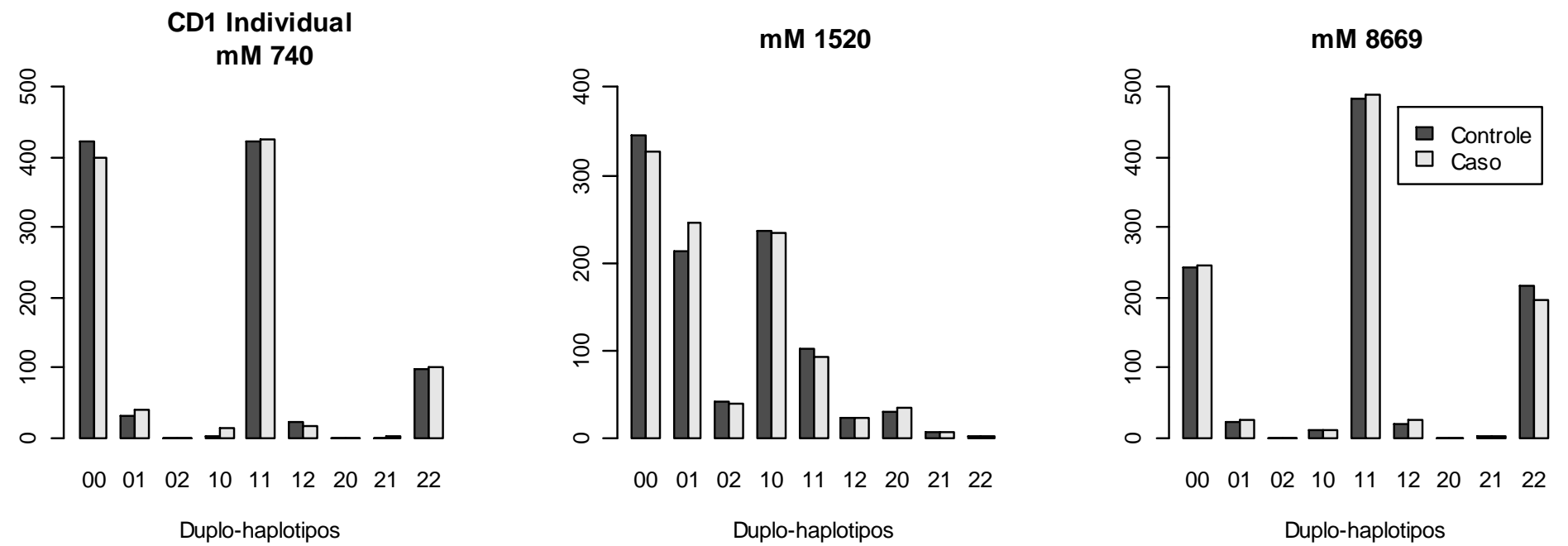

Figura 22 - Trio CD1 - contagens de amostras em cada duplo-haplótipo de cada mM

Olhando os mMs individualmente na Figura 22, não vemos desequilíbrio em qualquer duplo-haplótipo. $\mathrm{Na}$ interação tripla (Figura 23), notamos o genótipo protetor B00-C22-A00 e o de risco B11-C22-A01. Outros genótipos em que B=22 parecem ser de alto risco, mas o número de amostras é muito pequeno. Os detalhes dos SNPs que compõem os mMs estão apresentados na Tabela 24. 

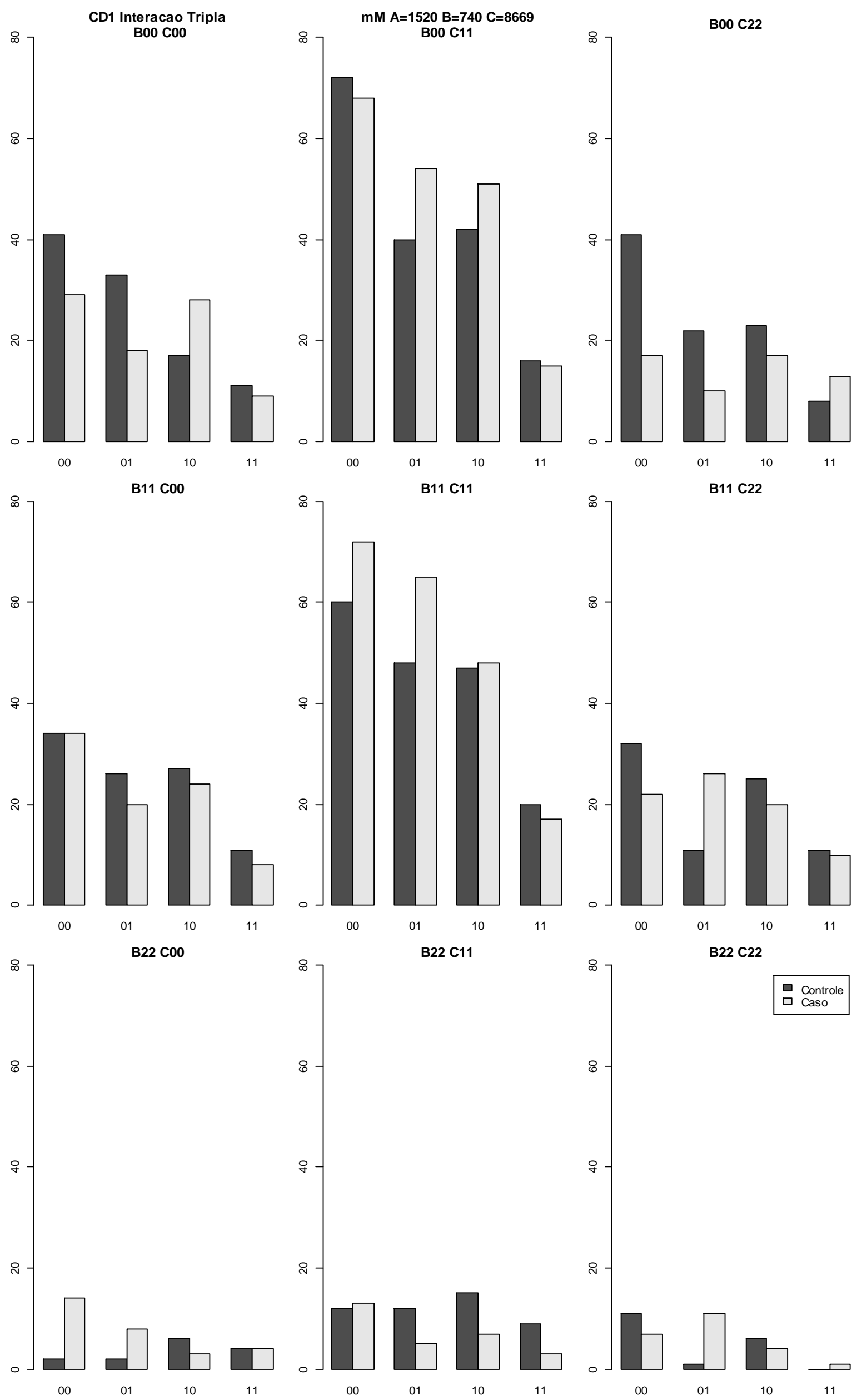

Figura 23 - Trio CD1 - interação tripla - contagem de amostras em cada genótipo combinado 


\section{Trio CD2}

Tabela 25 - Detalhes dos mMs e SNPs do trio CD2

\begin{tabular}{|c|c|c|c|c|c|c|c|c|c|}
\hline Trio & $\mathrm{mM}$ & Crom & rs Id & MAF & Pos BP & $\begin{array}{l}\text { Dist } \\
\text { BP }\end{array}$ & Dist cM & $\begin{array}{l}\text { Taxa } \\
\text { (cM/Mb) }\end{array}$ & $\begin{array}{l}\text { Assoc. } \\
\text { Marginal }\end{array}$ \\
\hline \multirow{6}{*}{ CD2 } & \multirow{2}{*}{763} & \multirow{2}{*}{1} & rs6576739 & 25,45 & 85240907 & \multirow{2}{*}{43722} & \multirow{2}{*}{0,006425} & \multirow{2}{*}{0,147} & 0,80 \\
\hline & & & rs674647 & 33,89 & 85197185 & & & & 2,80 \\
\hline & \multirow{2}{*}{9565} & \multirow{2}{*}{6} & rs1753251 & 8,09 & 70959002 & \multirow{2}{*}{22350} & \multirow{2}{*}{0,002414} & \multirow{2}{*}{0,108} & 0,06 \\
\hline & & & rs12210719 & 22,38 & 70936652 & & & & 2,32 \\
\hline & \multirow[t]{2}{*}{18931} & \multirow[t]{2}{*}{13} & rs9300532 & 24,05 & 98601554 & \multirow[t]{2}{*}{38262} & \multirow{2}{*}{0,009415} & \multirow{2}{*}{0,246} & 3,81 \\
\hline & & & rs9517637 & 40,3 & 98639816 & & & & 0,63 \\
\hline
\end{tabular}

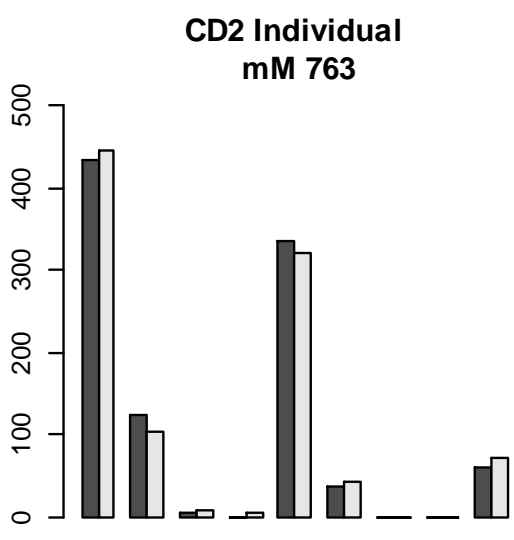

$\begin{array}{lllllllll}00 & 01 & 02 & 10 & 11 & 12 & 20 & 21 & 22\end{array}$

Duplo-haplotipos
mM 9565

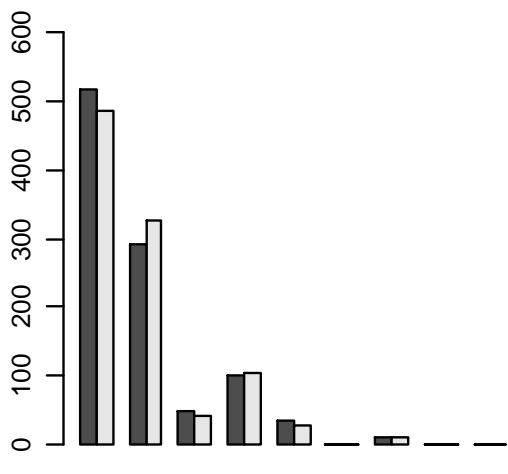

$\begin{array}{lllllllll}00 & 01 & 02 & 10 & 11 & 12 & 20 & 21 & 22\end{array}$

Duplo-haplotipos
mM 18931

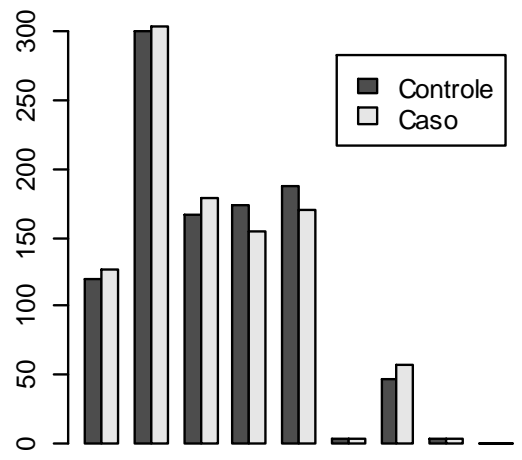

$\begin{array}{lllllllll}00 & 01 & 02 & 10 & 11 & 12 & 20 & 21 & 22\end{array}$

Duplo-haplotipos

Figura 24 - Trio CD2 - contagens de amostras em cada duplo-haplótipo de cada mM

Não vemos desequilíbrios pronunciados nos $\mathrm{mMs}$ individuais mostrados na Figura 24. Na interação tripla da Figura 25, notamos o genótipo protetor B00-C01A01 e o de risco B11-C01-A01. Os detalhes dos SNPs que compõem os mMs estão apresentados na Tabela 25. 

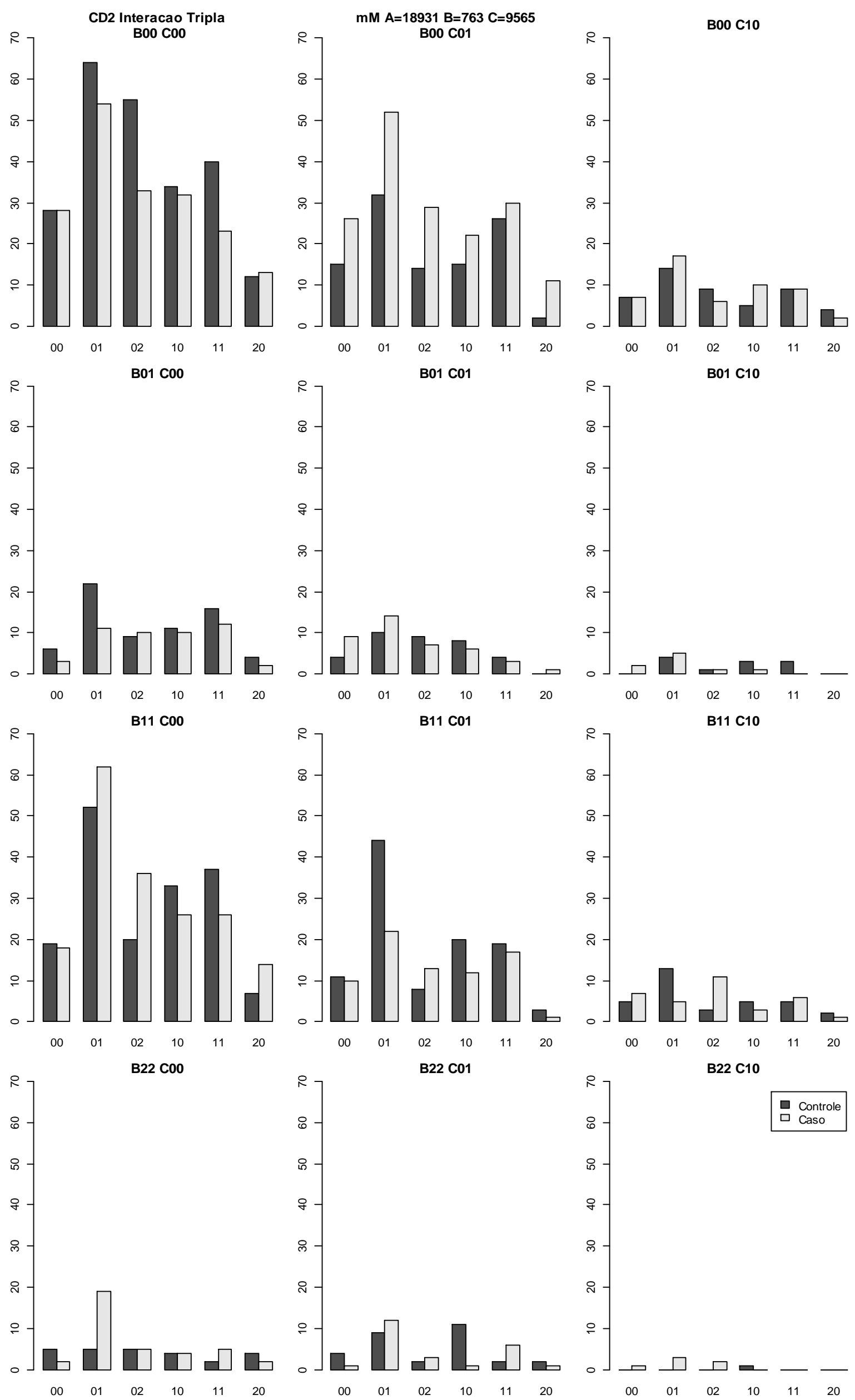

Figura 25 - Trio CD2 - interação tripla - contagem de amostras em cada genótipo combinado 


\section{Trio CD3}

Tabela 26 - Detalhes dos mMs e SNPs do trio CD3

\begin{tabular}{|c|c|c|c|c|c|c|c|c|c|}
\hline Trio & $\mathrm{mM}$ & Crom & rs Id & MAF & Pos BP & $\begin{array}{l}\text { Dist } \\
\text { BP }\end{array}$ & Dist cM & $\begin{array}{l}\text { Taxa } \\
\text { (cM/Mb) }\end{array}$ & $\begin{array}{l}\text { Assoc. } \\
\text { Marginal }\end{array}$ \\
\hline \multirow{3}{*}{ CD3 } & 6695 & 4 & $\begin{array}{l}\text { rs967534 } \\
\text { rs17273728 }\end{array}$ & $\begin{array}{r}38 \\
40,89\end{array}$ & $\begin{array}{l}128379976 \\
128030744\end{array}$ & 349232 & 0,050962 & 0,146 & $\begin{array}{l}0,59 \\
6,40\end{array}$ \\
\hline & 14653 & 10 & rs9663367 & 28,86 & 19816916 & & & & 0,00 \\
\hline & 17762 & 12 & $\begin{array}{l}\text { rs10860174 } \\
\text { rs1558729 }\end{array}$ & $\begin{array}{r}22,3 \\
28,52\end{array}$ & $\begin{array}{l}96213319 \\
96242149\end{array}$ & 28830 & 0,016856 & 0,585 & $\begin{array}{l}0,98 \\
1,68\end{array}$ \\
\hline
\end{tabular}

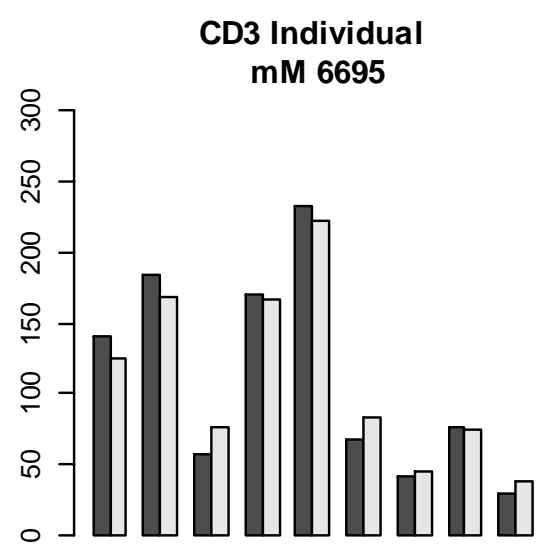

$\begin{array}{lllllllll}00 & 01 & 02 & 10 & 11 & 12 & 20 & 21 & 22\end{array}$
mM 14653

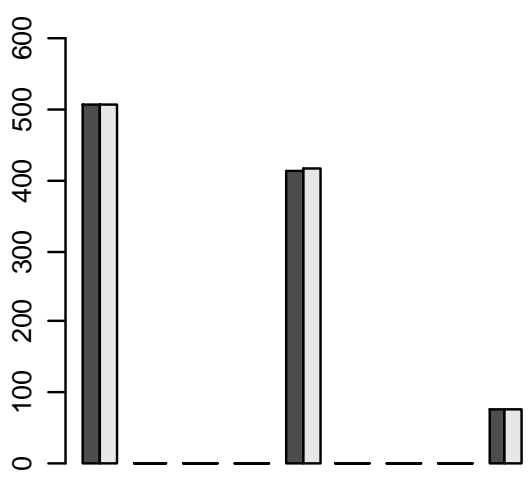

$\begin{array}{lllllllll}00 & 01 & 02 & 10 & 11 & 12 & 20 & 21 & 22\end{array}$

Duplo-haplotipos
mM 17762

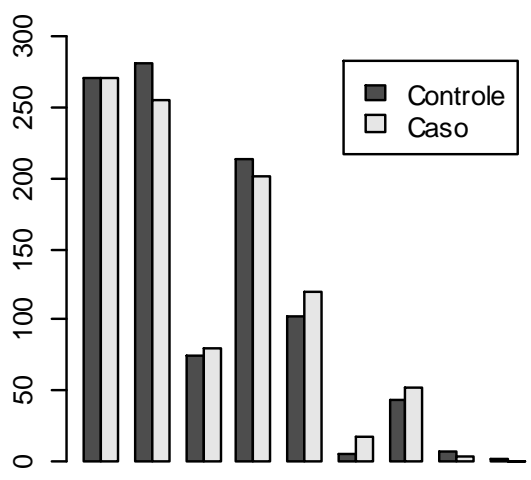

$\begin{array}{lllllllll}00 & 01 & 02 & 10 & 11 & 12 & 20 & 21 & 22\end{array}$

Duplo-haplotipos

Figura 26 - Trio CD3 - contagens de amostras em cada duplo-haplótipo de cada mM

Não vemos desequilíbrios pronunciados nos mMs individuais mostrados na Figura 26. Na interação tripla (Figura 27), encontramos o genótipo aparentemente protetor B01-C00-A01. Os detalhes dos SNPs que compõem os mMs estão apresentados na Tabela 26. 

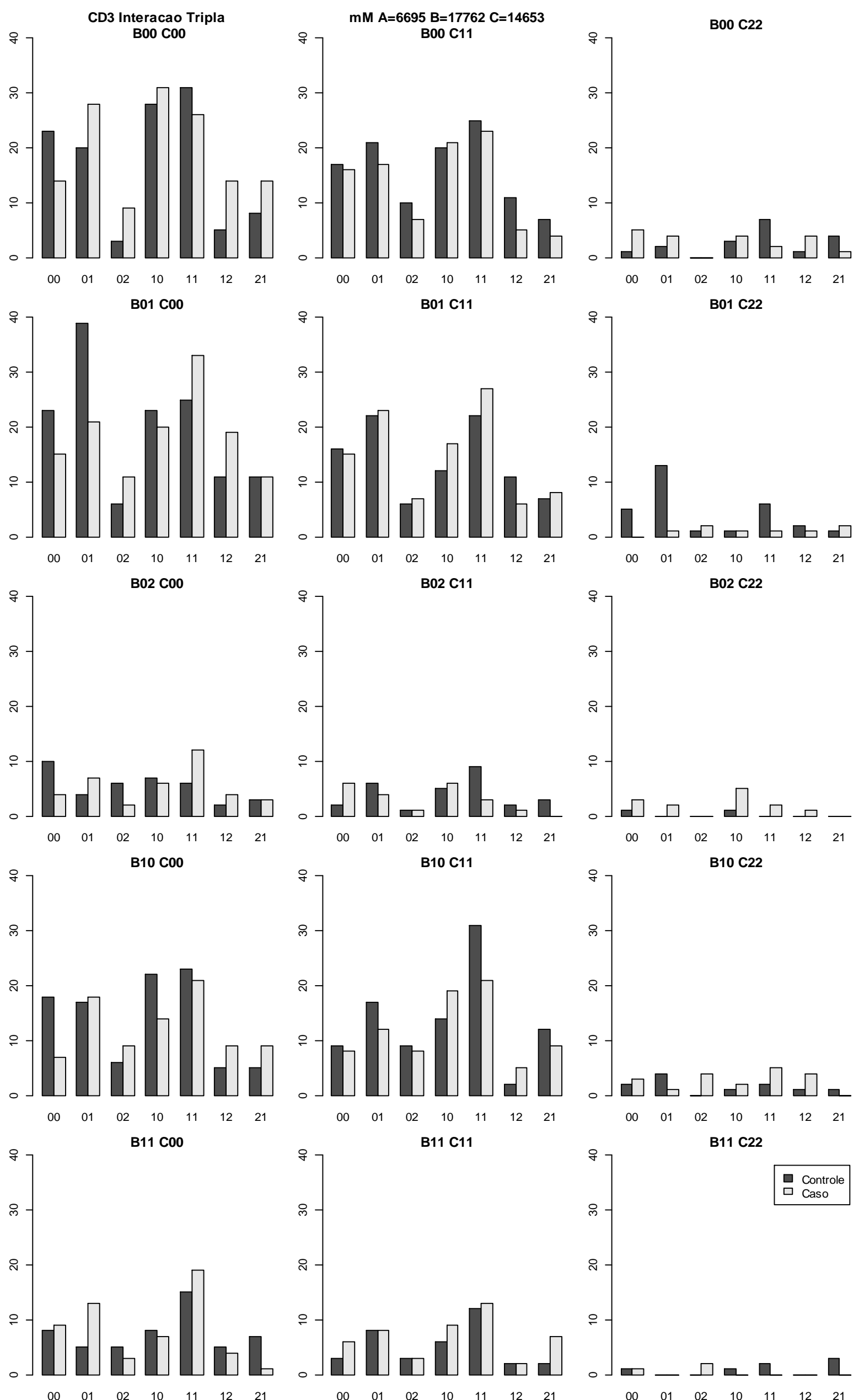

Figura 27 - Trio CD3 - interação tripla - contagem de amostras em cada genótipo combinado 


\section{Trio CD4}

Tabela 27 - Detalhes dos mMs e SNPs do trio CD4

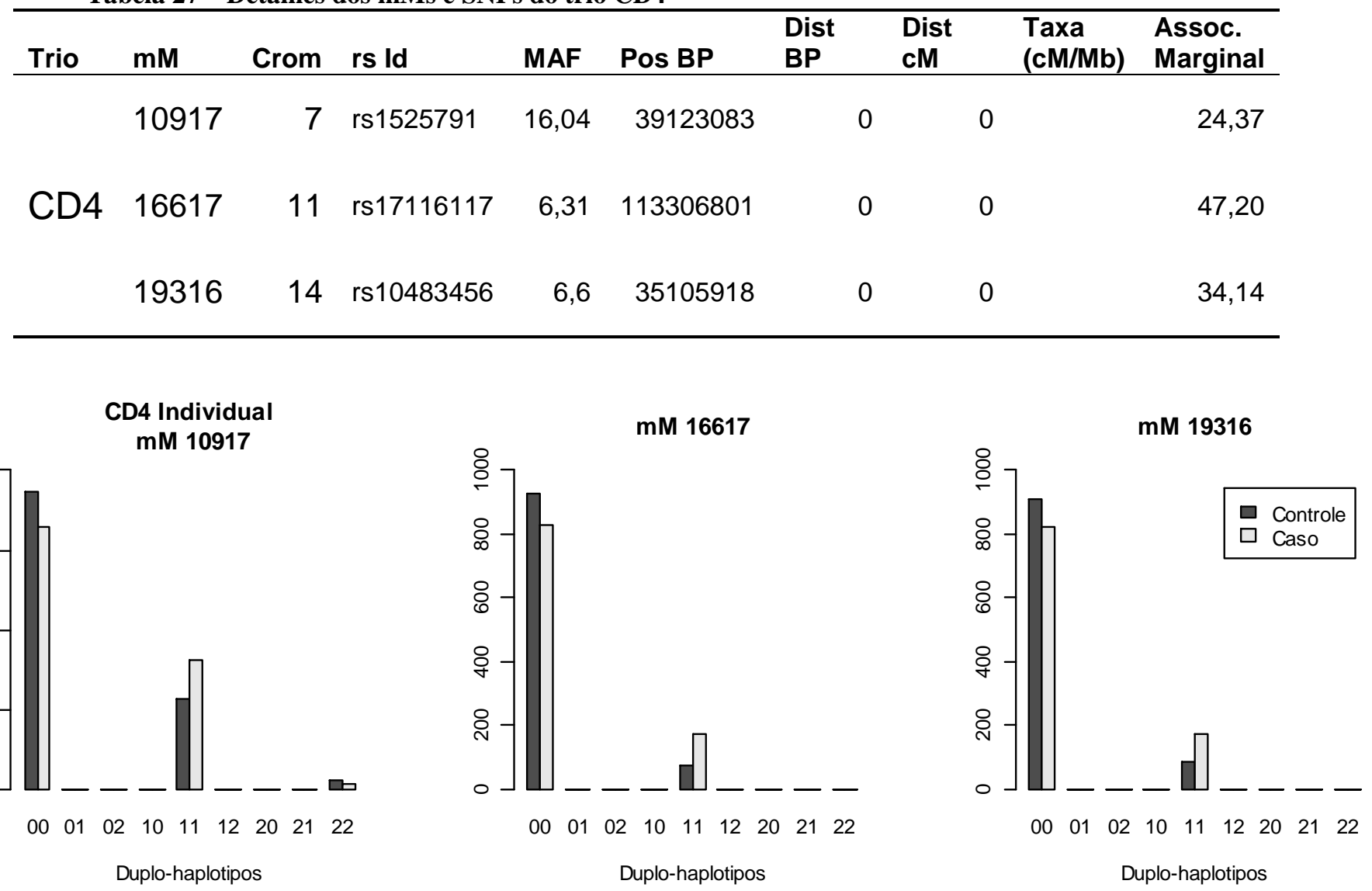

Figura 28 - Trio CD4 - contagens de amostras em cada duplo-haplótipo de cada mM

Na Figura 28 vemos que os genótipos 11 de todos os três mMs parecem ser de risco. Note no eixo Y que as quantidades são altas. Isto mostra o efeito marginal alto dos SNPs que compõem estes mMs, e isto pode ser verificado na Tabela 27.

Na Figura 29, de interação tripla, vemos que o genótipo triplo 11 apresenta um efeito de risco muito forte. Note no eixo $\mathrm{Y}$ as quantidades altas. 

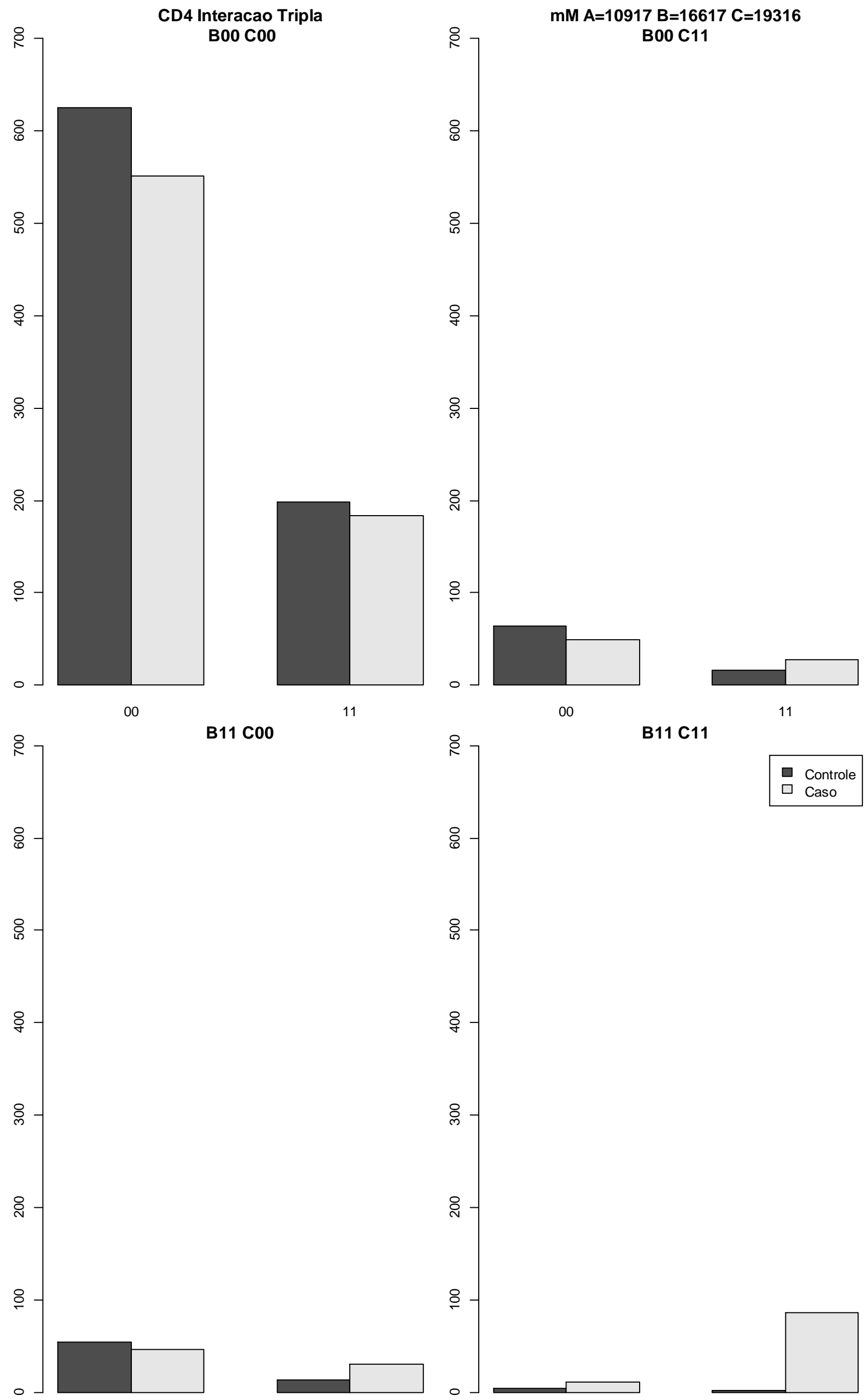

$\begin{array}{ll}\square & \text { Controle } \\ \square & \text { Caso }\end{array}$

Figura 29 - Trio CD4 - interação tripla - contagem de amostras em cada genótipo combinado 
Trio CD5

Tabela 28 - Detalhes dos mMs e SNPs do trio CD5

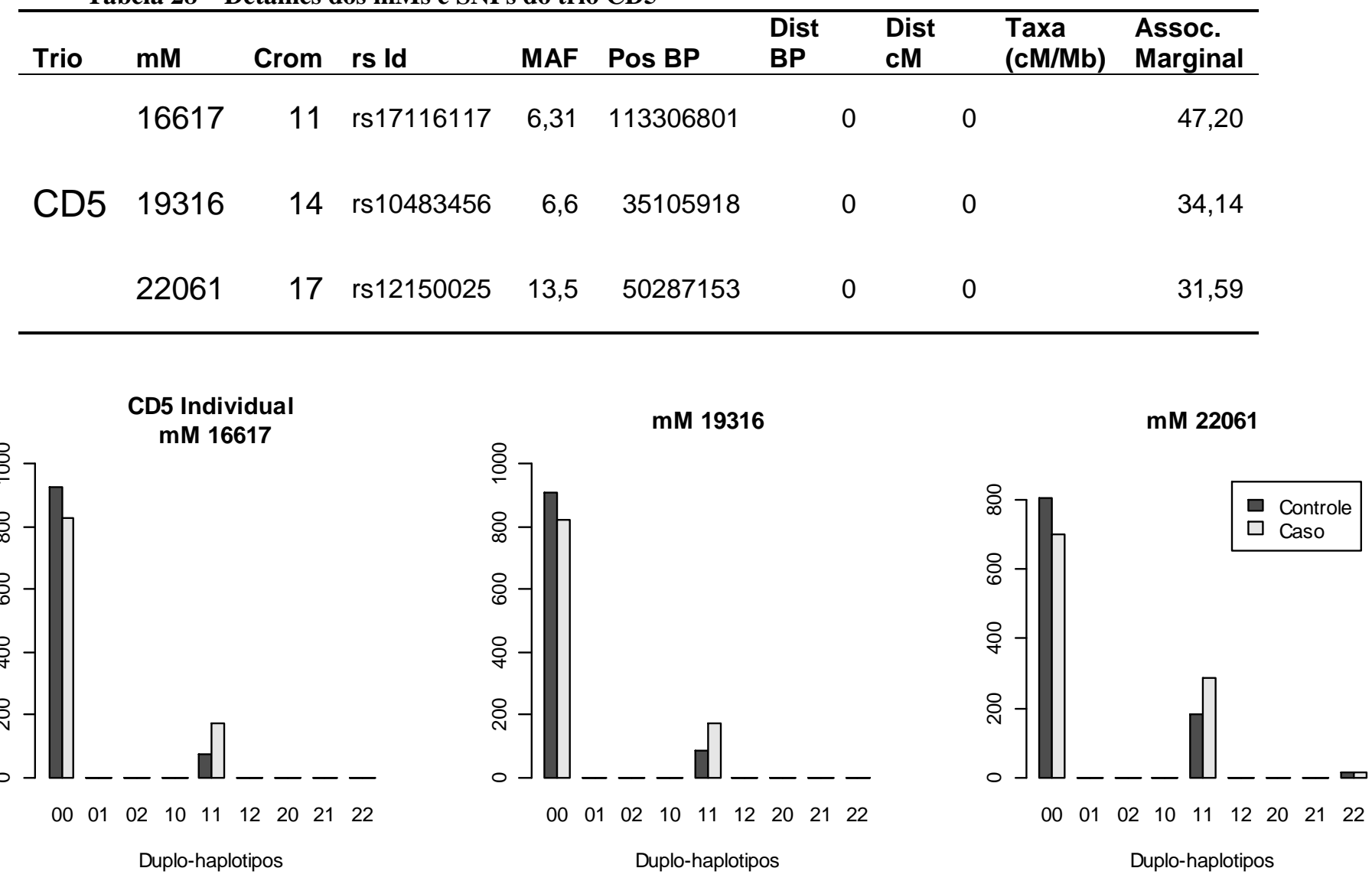

Figura 30 - Trio CD5 - contagens de amostras em cada duplo-haplótipo de cada mM

Na Figura 30, vemos que os genótipos 11 de todos os três mMs parecem ser de risco. Note no eixo Y que as quantidades são altas. Isto mostra o efeito marginal alto dos SNPs que compõem estes mMs, e isto pode ser verificado na Tabela 28.

Na Figura 31, vemos que o genótipo triplo 11 apresenta um efeito de risco muito forte. Note no eixo Y as quantidades altas. 

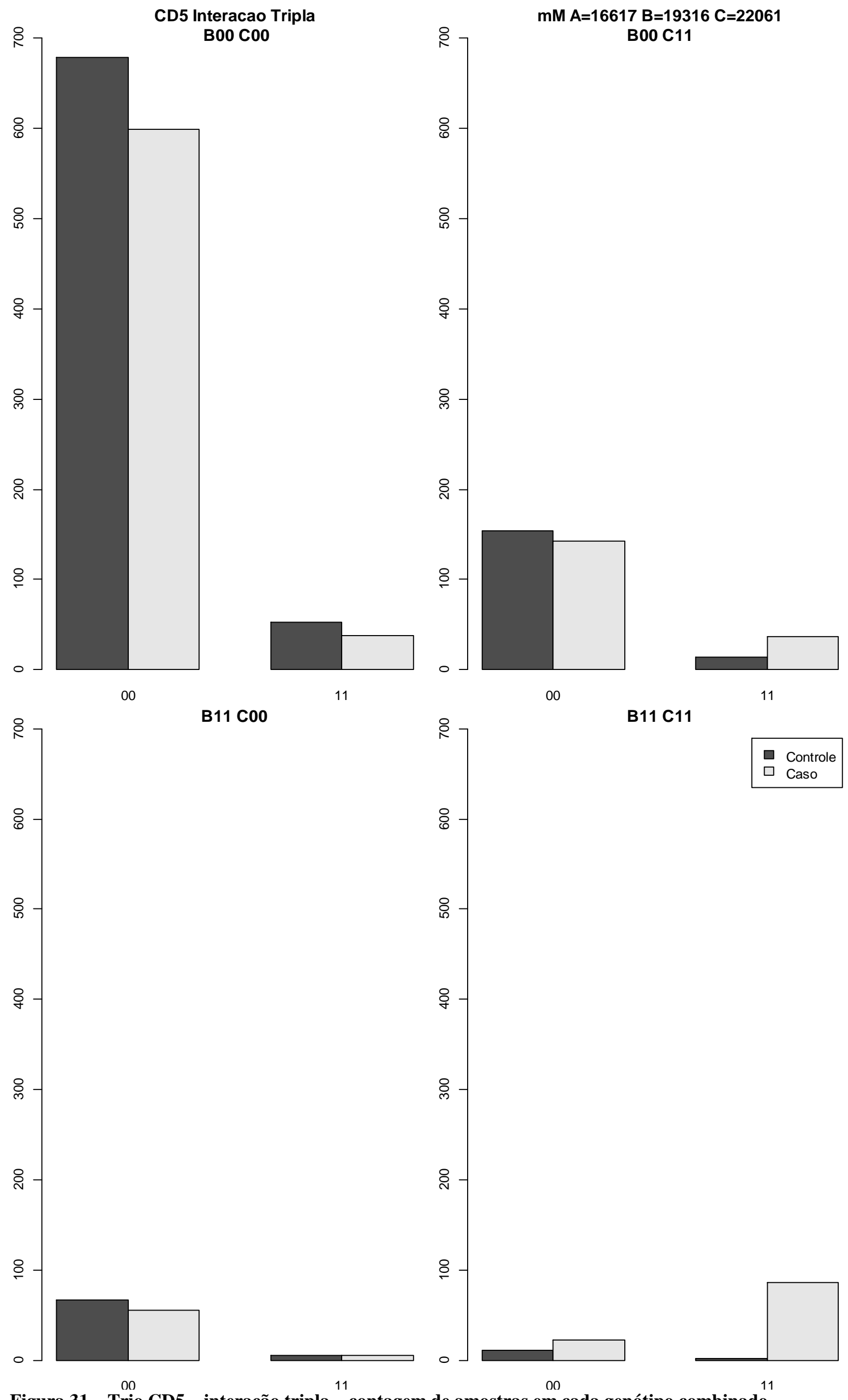

Figura 31 - Trio CD5 - interação tripla ${ }^{11}$ contagem de amostras em cada genótipo combinado 


\section{CD - Teste estatístico de cada trio}

Os trios fechados encontrados para a doença de Crohn foram submetidos aos dois testes. O resultado está na Tabela 29.

Tabela 29 - CD - Teste estatístico dos trios. Veja o significado das colunas na Tabela 12.

\begin{tabular}{lrrllrl}
\hline Trio & Genotipos & GenFreq & P-X2 & SignX2 & PGoodman & SignGood \\
\hline CD1 & 576 & 26 & $5,4 \times 10^{-03}$ & Sim & $4,0 \times 10^{-03}$ & Sim \\
CD2 & 384 & 30 & $5,1 \times 10^{-04}$ & Sim & $2,9 \times 10^{-04}$ & Sim \\
CD3 & 243 & 30 & 0,37 & Não & 0,35 & Não \\
CD4 & 18 & 9 & $7,9 \times 10^{-19}$ & Sim & $5,5 \times 10^{-20}$ & Sim \\
CD5 & 18 & 8 & $2,4 \times 10^{-19}$ & Sim & $1,6 \times 10^{-20}$ & Sim \\
\hline
\end{tabular}

A menos do trio $\mathrm{CD} 3$, todos os trios foram considerados significantes, com destaque para os baixos valores-P obtidos para os trios CD4 e CD5.

Tabela 30 - CD - Genótipos com desequilíbrio

\begin{tabular}{lllrrr}
\hline Trio & CD1 & & & & \\
mM 1520 & mM 740 & mM 8669 & Controle & Caso & \\
\hline 00 & 00 & 22 & 41 & & 17 \\
\hline Trio & CD2 & & & & \\
mM 18931 & mM 763 & mM 9565 & Controle & Caso & \\
\hline 01 & 22 & 00 & 5 & & 19 \\
01 & 11 & 01 & 44 & 22 \\
\hline Trio & CD4 & & & & \\
mM 10917 & mM 16617 & mM 19316 & Controle & Caso & \\
\hline 11 & 11 & 00 & 13 & & 30 \\
11 & 11 & 11 & 2 & 86 \\
\hline Trio & CD5 & & & & \\
mM 16617 & mM 19316 & mM 22061 & Controle & Caso & \\
\hline 11 & 00 & 11 & 14 & 37 \\
11 & 11 & 11 & 2 & 86 \\
\hline
\end{tabular}

A Tabela 30 lista os genótipos com desequilíbrio pronunciado. Nos trios CD4 e CD5, note o forte desequilíbrio dos genótipos triplamente heterozigotos, de alto risco. A semelhança dos resultados está relacionada com a semelhança dos trios, já que dois dos três mMs se repetem nos dois trios. 


\section{CD - Confirmação com amostras independentes}

Para confirmar os resultados, usamos os 748 casos não usados como Troost, e todos os 1480 controles do conjunto 58C - 1958 British Birth Cohort. Os resultados estão na Tabela 31.

Tabela 31 - CD - Confirmação dos trios. Veja o significado das colunas na Tabela 12.

\begin{tabular}{lrrrcrc}
\hline Trio & Genotipos & GenFreq & P-X2 & SignX2 & PGoodman & SignGood \\
\hline CD1 & 576 & 23 & 0,15 & Não & 0,09 & Não \\
CD2 & 384 & 27 & 0,95 & Não & 0,92 & Não \\
CD4 & 27 & 9 & $1,9 \times 10^{-29}$ & Sim & $1,1 \times 10^{-17}$ & Sim \\
CD5 & 27 & 9 & $1,3 \times 10^{-27}$ & Sim & $2,1 \times 10^{-17}$ & Sim \\
\hline
\end{tabular}

Os trios CD1 e CD2 não se confirmaram como significante. Já para os trios CD4 e CD5 os baixos valores-P se confirmaram, mesmo usando dados de casos e controles independentes. Porém, confirmamos depois que os dados do WTCCC não eram confiáveis para estes SNPs. Tratamos disto em detalhe na discussão. 


\section{Hipertensão arterial - HT}

\section{HT - Lista dos trios encontrados}

Os trios fechados encontrados, com seus blocos haplotípicos, SNPs e dados dos SNPs, estão listados na Tabela 32. Uma descrição dos campos está na seção correspondente de $\mathrm{BD}$ - transtorno bipolar.

Tabela 32 - HT - Lista dos trios encontrados, seus mMs e SNPS

\begin{tabular}{|c|c|c|c|c|c|}
\hline Trio & $\mathrm{mM}$ & Crom & SNP & Affymetrixld & rs Id \\
\hline \multirow{5}{*}{ HT1 } & 8774 & 5 & 166751 & SNP_A-2278615 & rs4867943 \\
\hline & \multirow{2}{*}{9314} & \multirow{2}{*}{6} & 174904 & SNP_A-2180943 & rs1611635 \\
\hline & & & 174793 & SNP_A-1919197 & rs2747436 \\
\hline & \multirow{2}{*}{9317} & \multirow{2}{*}{6} & 174960 & SNP_A-1985589 & rs10484549 \\
\hline & & & 174942 & SNP_A-2302189 & rs3129012 \\
\hline \multirow{6}{*}{ HT2 } & \multirow{2}{*}{9314} & \multirow{2}{*}{6} & 174793 & SNP_A-1919197 & rs2747436 \\
\hline & & & 174866 & SNP_A-2141090 & rs2523408 \\
\hline & \multirow{2}{*}{9317} & \multirow{2}{*}{6} & 174960 & SNP_A-1985589 & rs 10484549 \\
\hline & & & 174973 & SNP_A-4274364 & rs1264703 \\
\hline & \multirow[t]{2}{*}{18576} & \multirow[t]{2}{*}{13} & $\begin{array}{l}351875 \\
35187 ?\end{array}$ & SNP_A-1828706 & rs1413999 \\
\hline & & & 351872 & SNP_A-1842044 & rs9569549 \\
\hline
\end{tabular}

\section{HT - Gráfico do efeito de cada bloco haplotípico}

\section{Trio HT1}

Tabela 33 - Detalhes dos mMs e SNPs do trio HT1

\begin{tabular}{|c|c|c|c|c|c|c|c|c|c|}
\hline Trio & $\mathrm{mM}$ & Crom & rs Id & MAF & Pos BP & $\begin{array}{l}\text { Dist } \\
\text { BP }\end{array}$ & Dist cM & $\begin{array}{l}\text { Taxa } \\
\text { (cM/Mb) }\end{array}$ & $\begin{array}{l}\text { Assoc. } \\
\text { Marginal }\end{array}$ \\
\hline \multirow{3}{*}{ HT1 } & 8774 & 5 & rs4867943 & 32,16 & 169558250 & 0 & 0 & NA & 1,21 \\
\hline & 9314 & 6 & $\begin{array}{l}\text { rs1611635 } \\
\text { rs } 2747436\end{array}$ & $\begin{array}{l}19,09 \\
29,43\end{array}$ & $\begin{array}{l}29944442 \\
29759914\end{array}$ & 184528 & 0,1223 & 0,663 & $\begin{array}{l}2,50 \\
0,59\end{array}$ \\
\hline & 9317 & 6 & $\begin{array}{l}\text { rs10484549 } \\
\text { rs3129012 }\end{array}$ & $\begin{array}{r}5,71 \\
19,76\end{array}$ & $\begin{array}{l}30134269 \\
30096621\end{array}$ & 37648 & 0,0084 & 0,222 & $\begin{array}{l}0,23 \\
2,61\end{array}$ \\
\hline
\end{tabular}




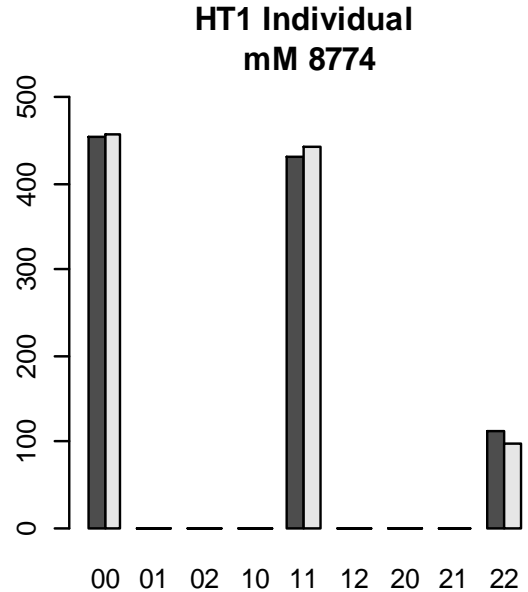

Duplo-haplotipos
$\mathrm{mM} 9314$

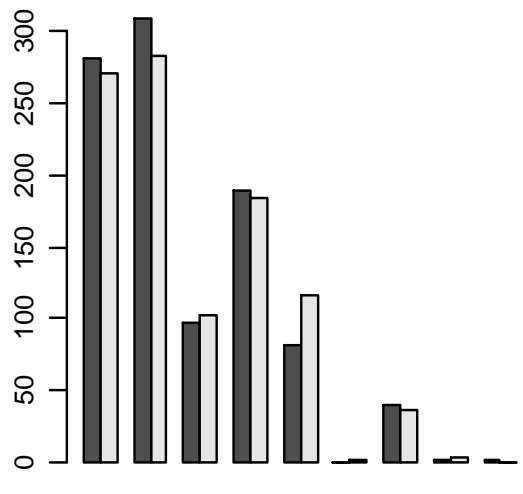

$\begin{array}{lllllllll}00 & 01 & 02 & 10 & 11 & 12 & 20 & 21 & 22\end{array}$

Duplo-haplotipos
mM 9317

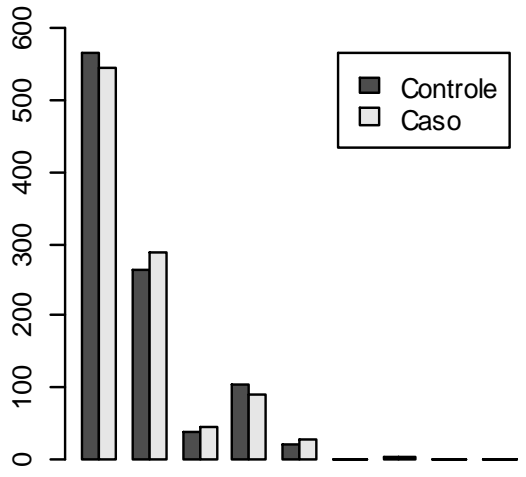

$\begin{array}{lllllllll}00 & 01 & 02 & 10 & 11 & 12 & 20 & 21 & 22\end{array}$

Duplo-haplotipos

Figura 32 - Trio HT1 - contagens de amostras em cada duplo-haplótipo de cada mM

Não vemos desequilíbrios pronunciados nos mMs individuais mostrados na Figura 32. Na interação tripla (Figura 33), encontramos o genótipo aparentemente protetor B00-C00-A01 e o de risco B01-C00-A11. Os detalhes dos SNPs que compõem os mMs estão apresentados na Tabela 33. 

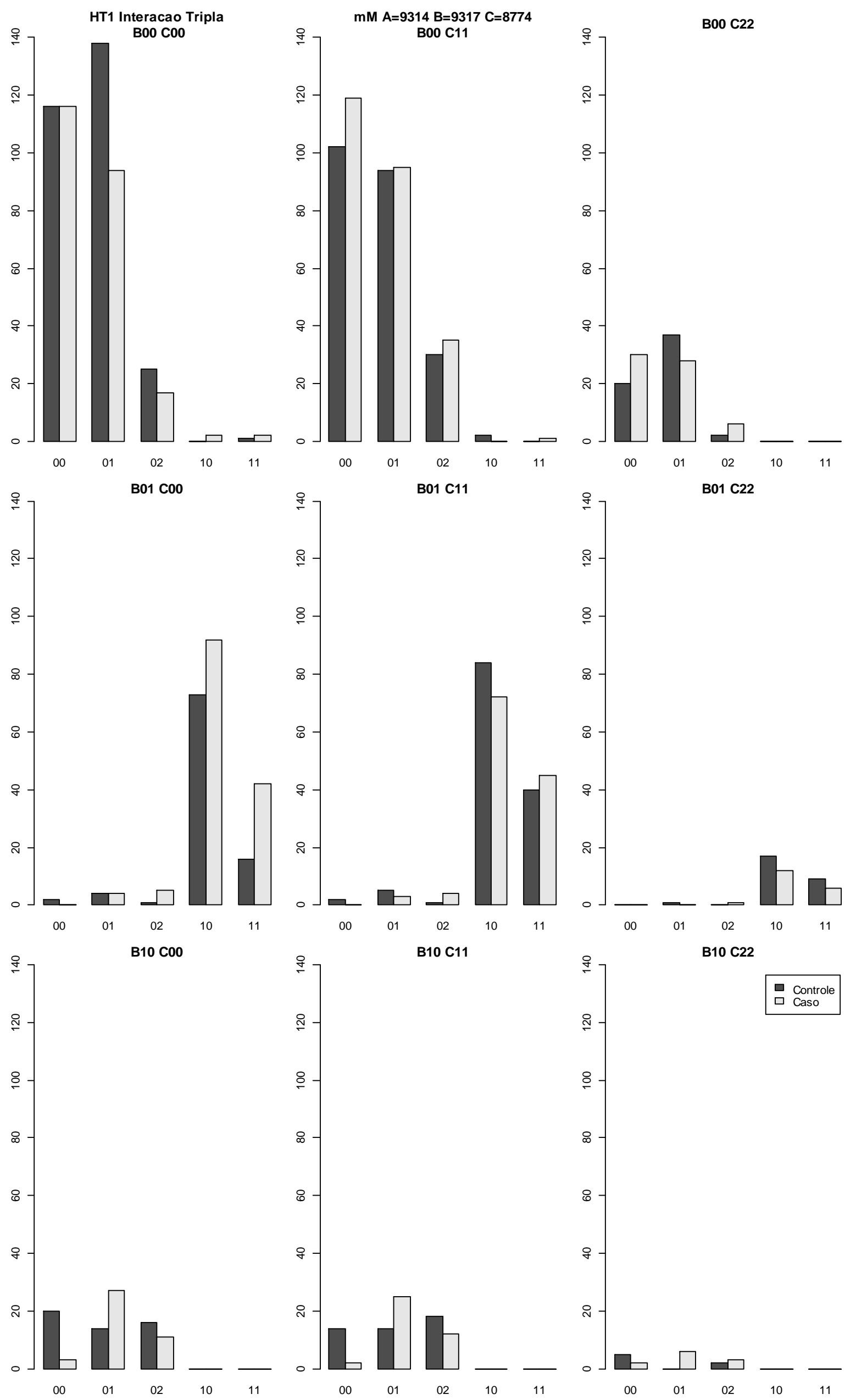
Figura 33 - Trio HT1 - interação tripla - contagem de amostras em cada genótipo combinado

\section{Trio HT2}

Tabela 34 - Detalhes dos mMs e SNPs do trio HT2

\begin{tabular}{|c|c|c|c|c|c|c|c|c|c|}
\hline Trio & $\mathrm{mM}$ & Crom & rs Id & MAF & Pos BP & $\begin{array}{l}\text { Dist } \\
\text { BP }\end{array}$ & Dist cM & $\begin{array}{l}\text { Taxa } \\
\text { (cM/Mb) }\end{array}$ & $\begin{array}{l}\text { Assoc. } \\
\text { Marginal }\end{array}$ \\
\hline \multirow{3}{*}{ HT2 } & 9314 & 6 & $\begin{array}{l}\text { rs2747436 } \\
\text { rs2523408 }\end{array}$ & $\begin{array}{r}29,43 \\
32,7\end{array}$ & $\begin{array}{l}29759914 \\
29886088\end{array}$ & 126174 & 0,0684 & 0,542 & $\begin{array}{l}0,59 \\
5,57\end{array}$ \\
\hline & 9317 & 6 & $\begin{array}{l}\text { rs10484549 } \\
\text { rs1264703 }\end{array}$ & $\begin{array}{r}5,71 \\
25,51\end{array}$ & $\begin{array}{l}30134269 \\
30173395\end{array}$ & 39126 & 0,0137 & 0,351 & $\begin{array}{l}0,23 \\
0,80\end{array}$ \\
\hline & 18576 & 13 & $\begin{array}{l}\text { rs } 1413999 \\
\text { rs9569549 }\end{array}$ & $\begin{array}{l}42,44 \\
42,46\end{array}$ & $\begin{array}{l}56384915 \\
56355405\end{array}$ & 29510 & 0,0017 & 0,059 & $\begin{array}{l}0,56 \\
0,44\end{array}$ \\
\hline
\end{tabular}

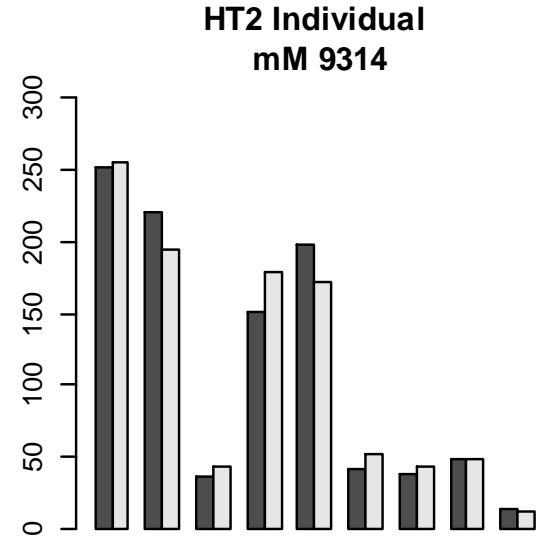

$\begin{array}{lllllllll}00 & 01 & 02 & 10 & 11 & 12 & 20 & 21 & 22\end{array}$

Duplo-haplotipos
$\mathrm{mM} 9317$

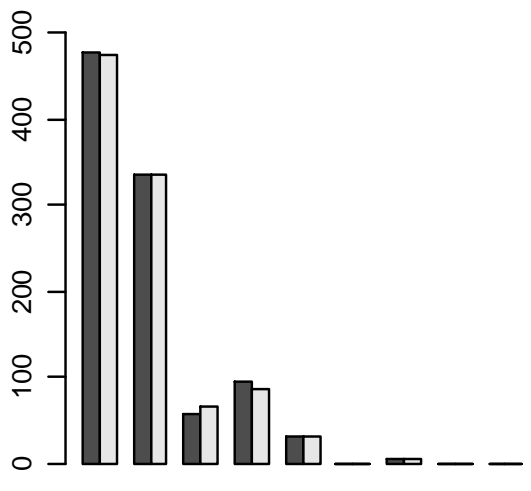

$\begin{array}{lllllllll}00 & 01 & 02 & 10 & 11 & 12 & 20 & 21 & 22\end{array}$

Duplo-haplotipos
mM 18576

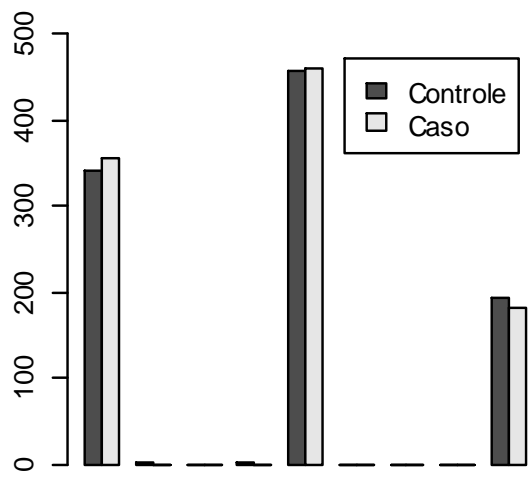

$\begin{array}{lllllllll}00 & 01 & 02 & 10 & 11 & 12 & 20 & 21 & 22\end{array}$ Duplo-haplotipos

Figura 34 - Trio HT2 - contagens de amostras em cada duplo-haplótipo de cada mM

$\mathrm{Na}$ Figura 34, exceto por um pequeno efeito nos genótipos 10 e 11 do mM 9314, não vemos desequilíbrios. Na interação tripla (Figura 35), há vários desequilíbrios pronunciados, entre os quais B00-C11-A11. Os detalhes dos SNPs que compõem os mMs estão apresentados na Tabela 34. 

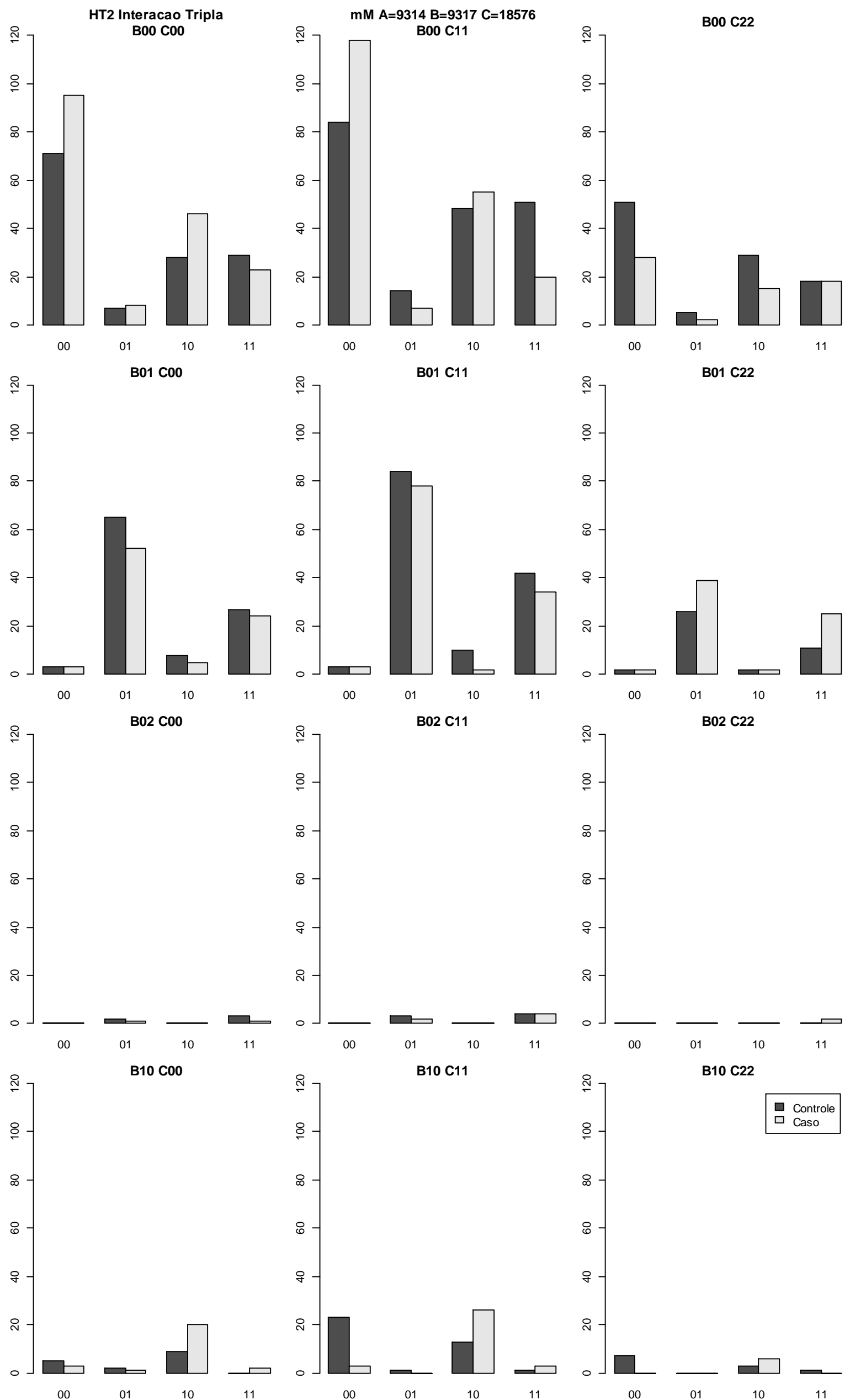

Figura 35 - Trio HT2 - interação tripla - contagem de amostras em cada genótipo combinado 


\section{HT - Teste estatístico de cada trio}

Submetemos os trios de HT aos dois testes qui-quadrado de homogeneidade de tabela de contingência. Os resultados estão na Tabela 35, mostrando dois trios significantes, e com valores-P muito baixos.

Tabela 35 - HT - Teste estatístico dos trios. Veja o significado das colunas na Tabela 12.

\begin{tabular}{rrrllll}
\hline Trio & Genotipos & GenFreq & P-X2 & SignX2 & PGoodman & SignGood \\
\hline HT1 & 162 & 21 & $1,2 \times 10^{-05}$ & Sim & $6,6 \times 10^{-06}$ & Sim \\
HT2 & 378 & 24 & $1,4 \times 10^{-08}$ & Sim & $3,8 \times 10^{-09}$ & Sim \\
\hline
\end{tabular}

Tabela 36 - HT - Genótipos com desequilíbrio

\begin{tabular}{lllrr}
\hline Trio: & HT1 & & & \\
mM 9314 & mM 9317 & mM 8774 & Controle & Caso \\
\hline 01 & 00 & 00 & 138 & 94 \\
11 & 01 & 00 & 16 & 42 \\
00 & 10 & 00 & 20 & 3 \\
\hline Trio: & HT2 & & & \\
mM 9314 & mM 9317 & mM 18576 & Controle & Caso \\
\hline 11 & 00 & 11 & 51 & 20 \\
00 & 10 & 11 & 23 & 3 \\
\hline
\end{tabular}

A Tabela 36 lista os genótipos com desequilíbrio pronunciado dos trios HT1 e HT2.

\section{HT - Confirmação com amostras independentes}

Para confirmar os resultados, usamos os 952 casos não usados como Troost, e todos os 1480 controles do conjunto 58C - 1958 British Birth Cohort. Como mostrado na Tabela 37, nenhum dos trios teve significância confirmada.

Tabela 37 - HT - Confirmação dos trios. Veja o significado das colunas na Tabela 12.

\begin{tabular}{|c|c|c|c|c|c|c|}
\hline Trio & pos & & & SignX2 & PGoodman & SignGood \\
\hline HT1 & 168 & 21 & 0,24 & Não & 0,26 & ～Não \\
\hline HT2 & 378 & 24 & 0,90 & Não & 0,91 & Não \\
\hline
\end{tabular}




\section{Artrite reumatoide - RA}

\section{RA - Lista dos trios encontrados}

O trio fechado encontrado, com seus blocos haplotípicos, SNPs e dados dos SNPs, está listado na Tabela 38. Uma descrição dos campos está na seção correspondente de $\mathrm{BD}$ - transtorno bipolar.

Tabela 38 - RA - Lista dos trios encontrados, seus mMs e SNPS

\begin{tabular}{llrlll}
\hline Trio & mM & Crom & SNP & Affymetrixld & rs Id \\
\hline & \multirow{2}{*}{11829} & 8 & 224816 & SNP_A-2294070 & rs 17656755 \\
& & & 224817 & SNP_A-4236442 & rs41341450 \\
RA1 & 21082 & 16 & 398974 & SNP_A-2069261 & rs12598565 \\
& & & 398963 & SNP_A-1848074 & rs4245626 \\
& \multirow{2}{*}{21622} & 17 & 407633 & SNP_A-2122338 & rs11078396 \\
& & & 407632 & SNP_A-4250154 & rs9905702 \\
\hline
\end{tabular}

\section{RA - Gráfico do efeito de cada bloco haplotípico}

\section{Trio RA1}

Tabela 39 - Detalhes dos mMs e SNPs do trio RA1

\begin{tabular}{|c|c|c|c|c|c|c|c|c|}
\hline Trio & $\mathrm{mM}$ & Crom & rs Id & MAF & Pos BP & Dist cM & $\begin{array}{l}\text { Taxa } \\
\text { (cM/Mb) }\end{array}$ & $\begin{array}{l}\text { Assoc. } \\
\text { Marginal }\end{array}$ \\
\hline \multirow{6}{*}{ RA1 } & \multirow{2}{*}{11829} & \multirow{2}{*}{8} & rs17656755 & 30,89 & 6965809 & \multirow{2}{*}{0,0178} & \multirow{2}{*}{0,856} & 1,28 \\
\hline & & & rs41341450 & 44,29 & 6986630 & & & 0,63 \\
\hline & \multirow{2}{*}{21082} & \multirow{2}{*}{16} & rs12598565 & 10,28 & 61937540 & \multirow{2}{*}{0,0171} & \multirow{2}{*}{0,226} & 0,46 \\
\hline & & & rs4245626 & 32,14 & 61862031 & & & 2,68 \\
\hline & \multirow[t]{2}{*}{21622} & \multirow[t]{2}{*}{17} & rs11078396 & 6,46 & 17588121 & \multirow[t]{2}{*}{0,0131} & \multirow[t]{2}{*}{0,975} & 0,83 \\
\hline & & & rs9905702 & 40,22 & 17574657 & & & 2,54 \\
\hline
\end{tabular}

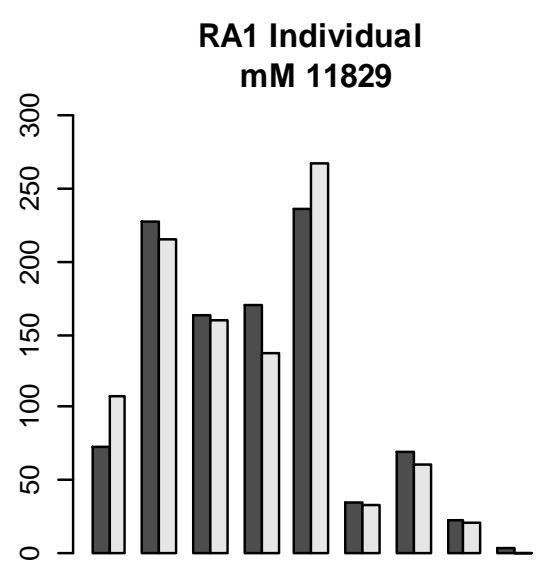

$\begin{array}{lllllllll}00 & 01 & 02 & 10 & 11 & 12 & 20 & 21 & 22\end{array}$

Duplo-haplotipos
mM 21082

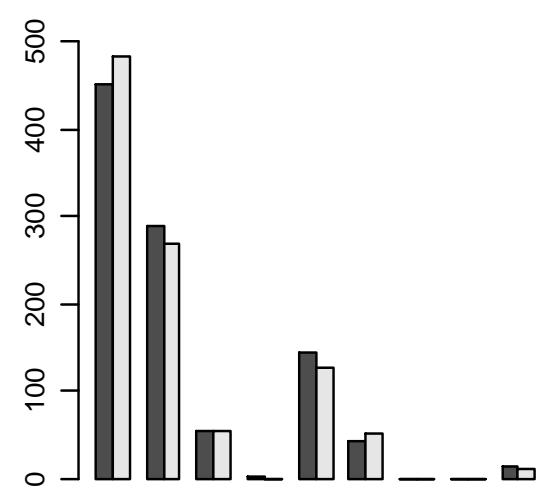

$\begin{array}{lllllllll}00 & 01 & 02 & 10 & 11 & 12 & 20 & 21 & 22\end{array}$

Duplo-haplotipos
mM 21622

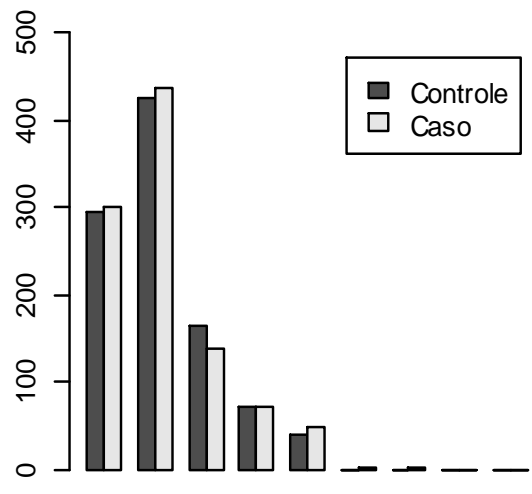

$\begin{array}{lllllllll}00 & 01 & 02 & 10 & 11 & 12 & 20 & 21 & 22\end{array}$ Duplo-haplotipos

Figura 36 - Trio RA1 - contagens de amostras em cada duplo-haplótipo de cada mM 
Não vemos desequilíbrios pronunciados nos mMs individuais mostrados na Figura 36, embora pequenas diferenças apareçam no mM 11829 nos genótipos 00, 10 e 11. Na interação tripla (Figura 37), um genótipo de risco se destaca: B00-C01-A11. Os detalhes dos SNPs que compõem os mMs estão apresentados na Tabela 39. 


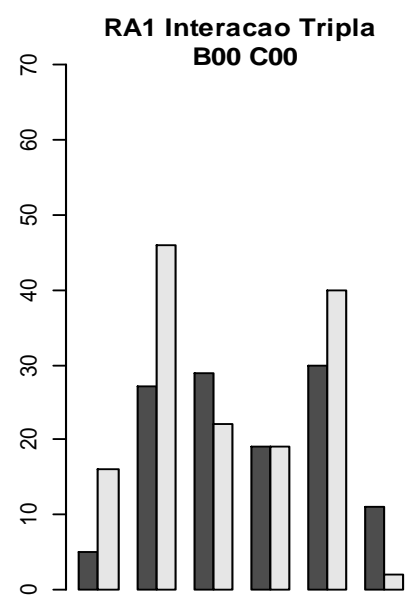

$\begin{array}{llllll}00 & 01 & 02 & 10 & 11 & 20\end{array}$

B01 C00
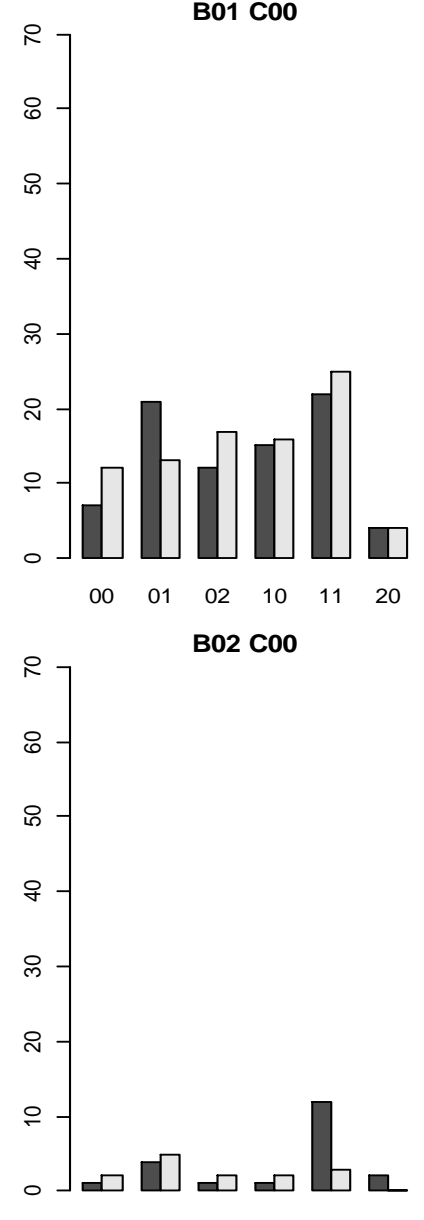

$\begin{array}{llllll}00 & 01 & 02 & 10 & 11 & 20\end{array}$ B11 C00

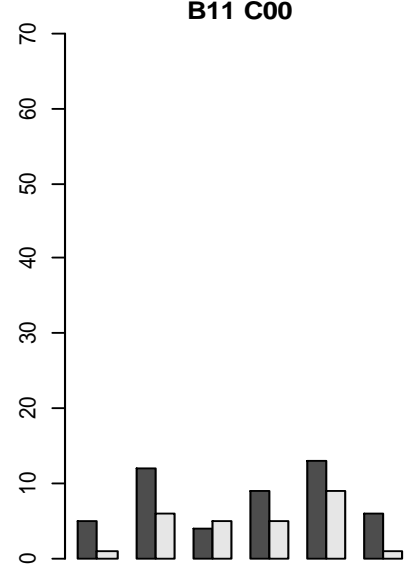

$\begin{array}{llllll}0 & 01 & 02 & 10 & 11 & 20\end{array}$

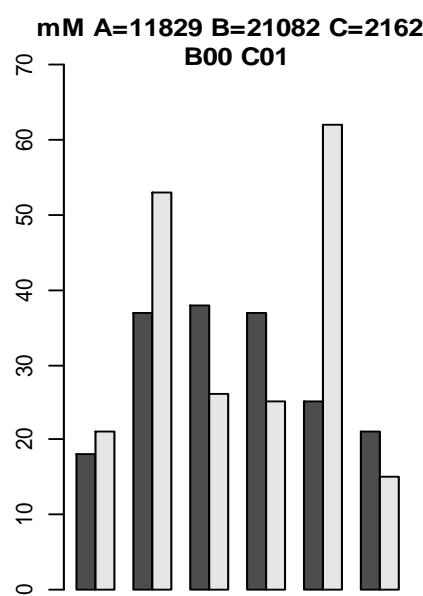

$\begin{array}{llllll}00 & 01 & 02 & 10 & 11 & 20\end{array}$

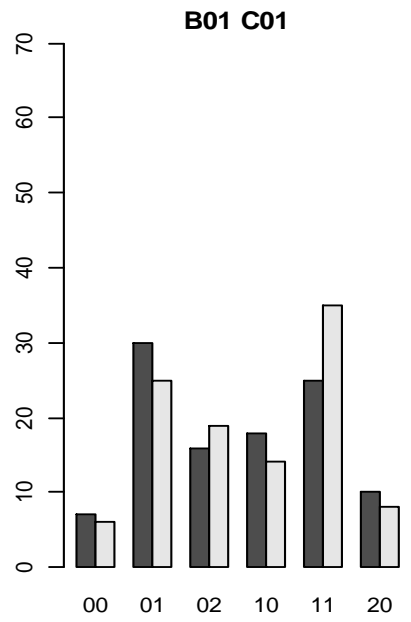

B02 C01

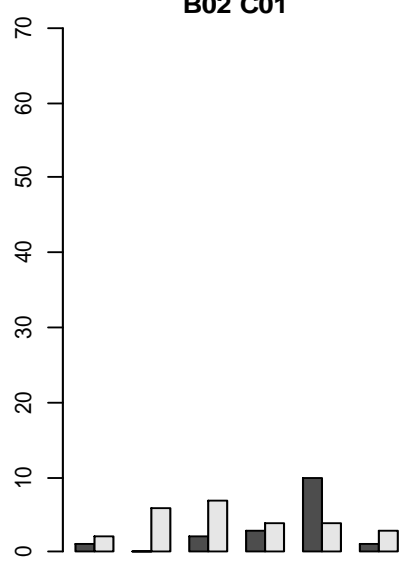

$\begin{array}{llllll}00 & 01 & 02 & 10 & 11 & 20\end{array}$

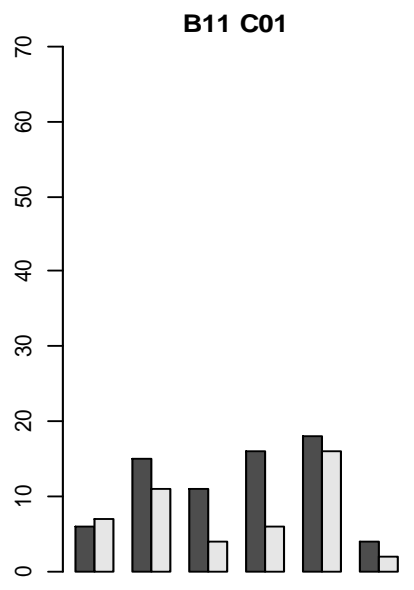

$\begin{array}{llllll}00 & 01 & 02 & 10 & 11 & 20\end{array}$
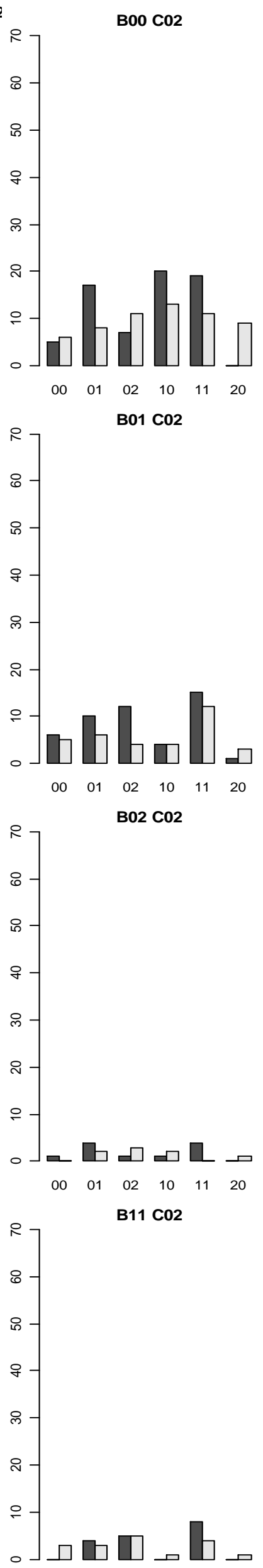

$\begin{array}{llllll}00 & 01 & 02 & 10 & 11 & 20\end{array}$
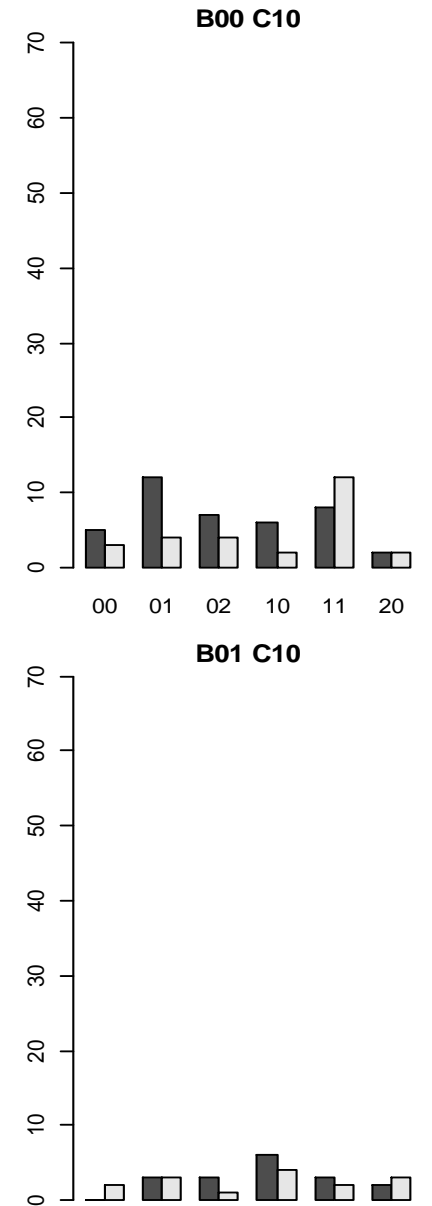

$\begin{array}{llllll}00 & 01 & 02 & 10 & 11 & 20\end{array}$
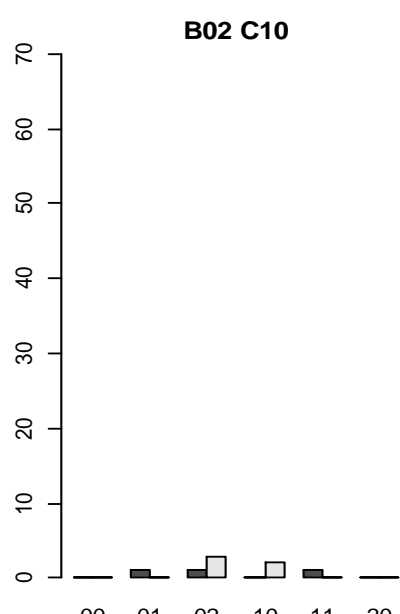

B11 C10

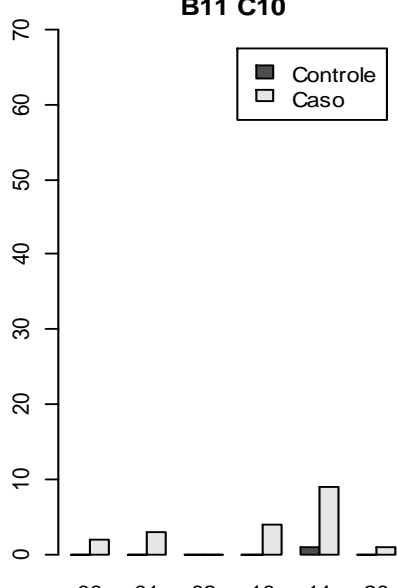

Figura 37 - Trio RA1 - interação tripla - contagem de amostras em cada genótipo combinado 


\section{RA - Teste estatístico de cada trio}

O trio encontrado para artrite reumatoide foi submetido aos testes programados. O resultado está na Tabela 40. Ele é significante.

Tabela 40 - RA - Teste estatístico dos trios. Veja o significado das colunas na Tabela 12.

\begin{tabular}{rrrcccc}
\hline Trio & Genotipos & GenFreq & P-X2 & SignX2 & PGoodman & SignGood \\
\hline RA1 & 441 & 29 & $7,6 \times 10^{-04}$ & Sim & $4,6 \times 10^{-04}$ & Sim \\
\hline
\end{tabular}

Tabela 41 - RA - genótipos em desequilíbrio

\begin{tabular}{lllrr}
\hline Trio & RA1 & & & \\
mM 11829 & mM 21082 & mM 21622 & Controle & Caso \\
\hline 11 & 00 & 01 & 25 & 62 \\
\hline
\end{tabular}

A Tabela 41 mostra os genótipos em desequilíbrio do trio RA1.

\section{RA - Confirmação com amostras independentes}

Para confirmar os resultados, usamos os 860 casos não usados como Troost, e todos os 1480 controles do conjunto 58C - 1958 British Birth Cohort. O resultado está na Tabela 42. O trio não foi confirmado como significante.

Tabela 42 - RA - Confirmação dos trios. Veja o significado das colunas na Tabela 12.

\begin{tabular}{rrrrlrl}
\hline Trio & Genotipos & GenFreq & P-X2 & SignX2 & PGoodman & SignGood \\
\hline RA1 & 432 & 32 & 0,66 & Não & 0,68 & Não \\
\hline
\end{tabular}




\section{Diabetes tipo 2 - T2D}

\section{T2D - Lista dos trios encontrados}

O trio fechado encontrado, com seus blocos haplotípicos, SNPs e dados dos SNPs, está listado na Tabela 43. Uma descrição dos campos está na seção correspondente de $\mathrm{BD}$ - transtorno bipolar.

Tabela 43 - T2D - Lista dos trios encontrados, seus mMs e SNPS

\begin{tabular}{lrrrll}
\hline Trio & mM & Crom & SNP & Affymetrixld & rs Id \\
& \multirow{2}{*}{923} & 1 & 17347 & SNP_A-1812595 & rs7521681 \\
& & & & & \\
T2D1 & 15409 & 10 & 291689 & SNP_A-4289552 & rs1158655 \\
& & & 291706 & SNP_A-1853647 & rs2111638 \\
& \multirow{2}{*}{23058} & \multirow{2}{*}{18} & 428664 & SNP_A-2100443 & rs17337377 \\
& & & 428658 & SNP_A-1837675 & rs11876265 \\
\hline
\end{tabular}

\section{T2D - Gráfico do efeito de cada bloco haplotípico}

\section{Trio T2D1}

Tabela 44 - Detalhes dos mMs e SNPs do trio T2D1

\begin{tabular}{|c|c|c|c|c|c|c|c|}
\hline Trio & $\mathrm{mM}$ & Crom & rs Id & MAF & Pos BP & Dist cM & $\begin{array}{l}\text { Assoc. } \\
\text { Marginal }\end{array}$ \\
\hline \multirow{4}{*}{ T2D1 } & 923 & 1 & rs7521681 & 15,23 & 108124058 & 0 & 1,40 \\
\hline & \multirow[t]{2}{*}{15409} & \multirow[t]{2}{*}{10} & rs1158655 & 7,91 & 113631247 & 0,0091 & 0,70 \\
\hline & & & rs2111638 & 35,08 & 113686474 & 0,0091 & 2,86 \\
\hline & 23058 & 18 & rs17337377 & 26,56 & 71848193 & 0,0074 & 1,14 \\
\hline
\end{tabular}

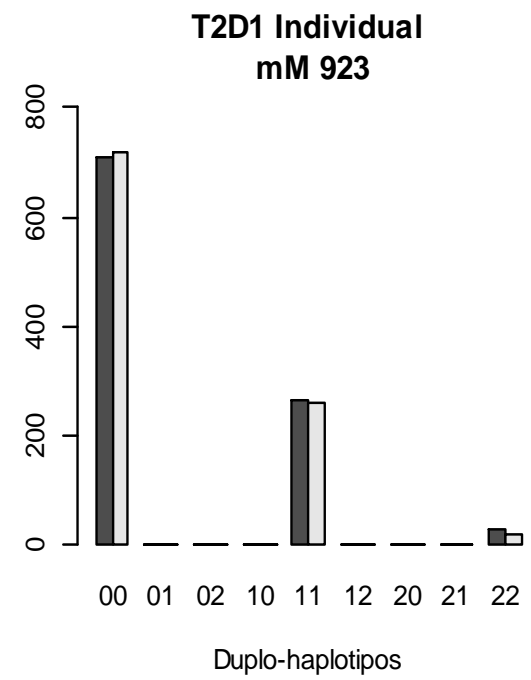

mM 15409

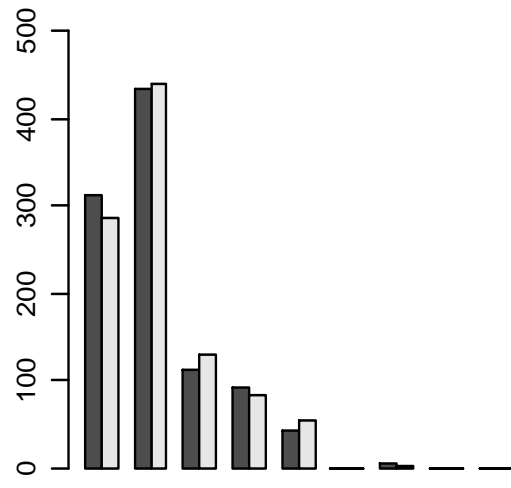

$\begin{array}{lllllllll}00 & 01 & 02 & 10 & 11 & 12 & 20 & 21 & 22\end{array}$

Duplo-haplotipos
mM 23058

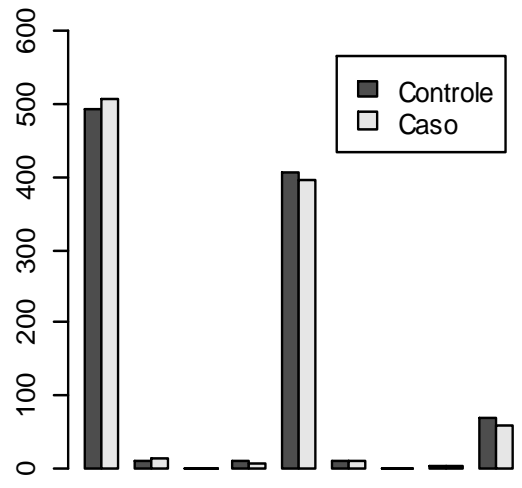

$\begin{array}{lllllllll}00 & 01 & 02 & 10 & 11 & 12 & 20 & 21 & 22\end{array}$ Duplo-haplotipos

Figura 38 - Trio T2D1 - contagens de amostras em cada duplo-haplótipo de cada mM

Nas contagens de mMs individuais da Figura 38, não observamos desequilíbrios entre controles e casos. Na interação tripla (Figura 39), observamos 
desequilíbrio em alguns genótipos, entre os quais B00-C00-A00 (risco) e B00-C11A00 (protetor). Os detalhes dos SNPs que compõem os mMs estão apresentados na Tabela 44. 

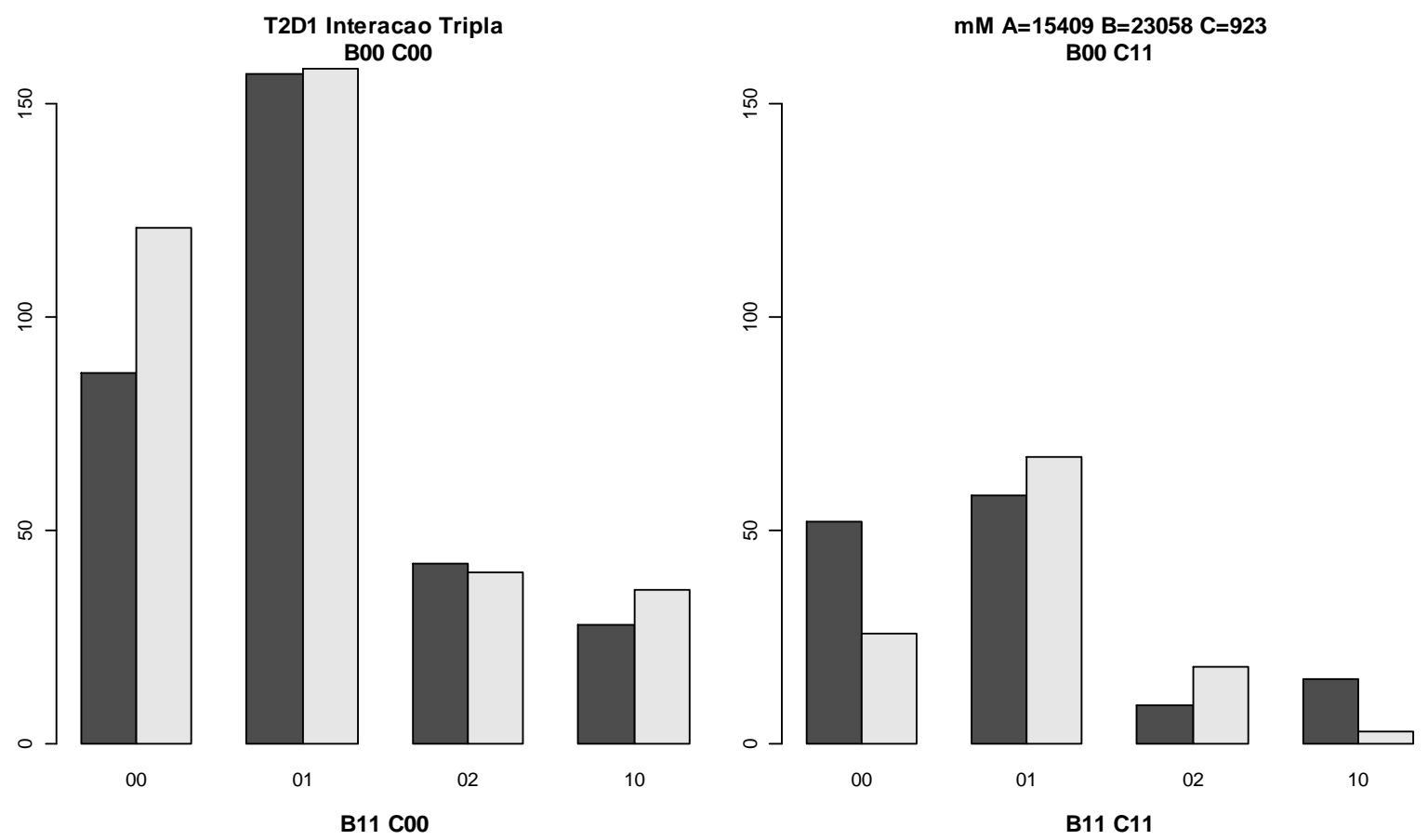

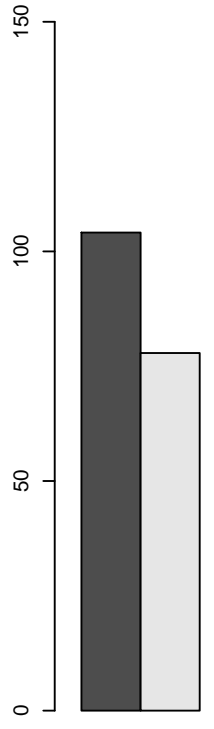

00

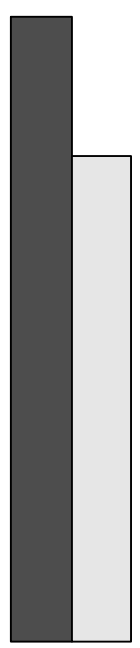

01 B22 C00

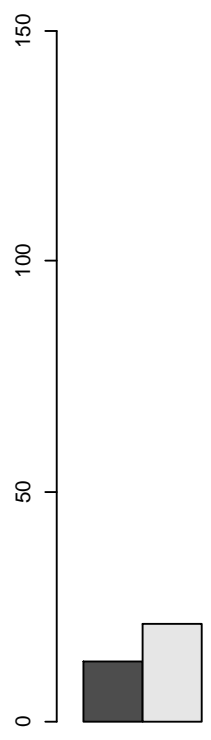

00
02
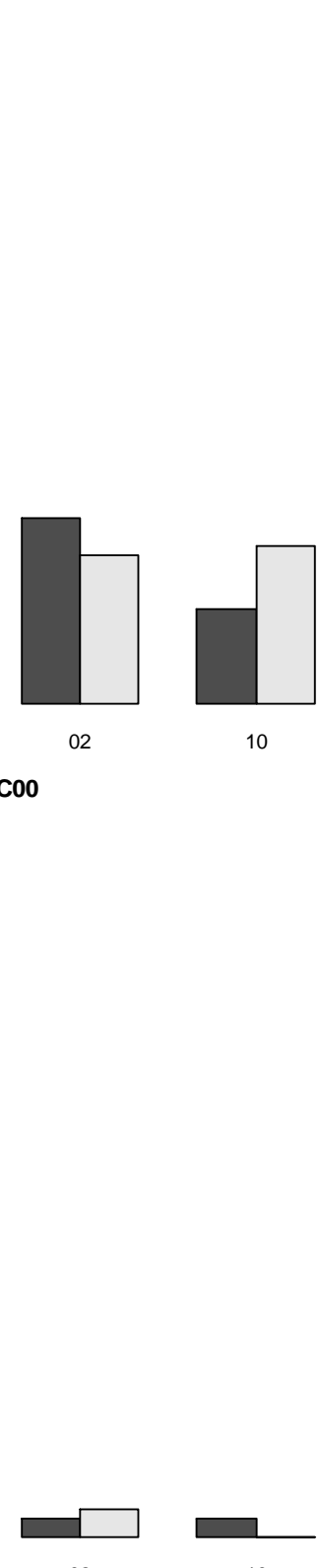

10

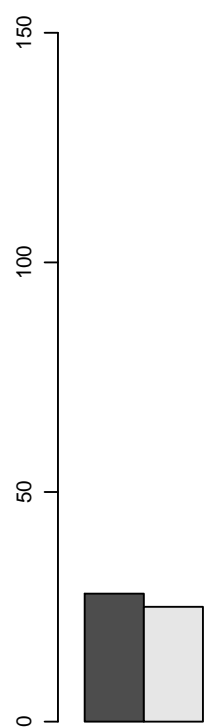

00

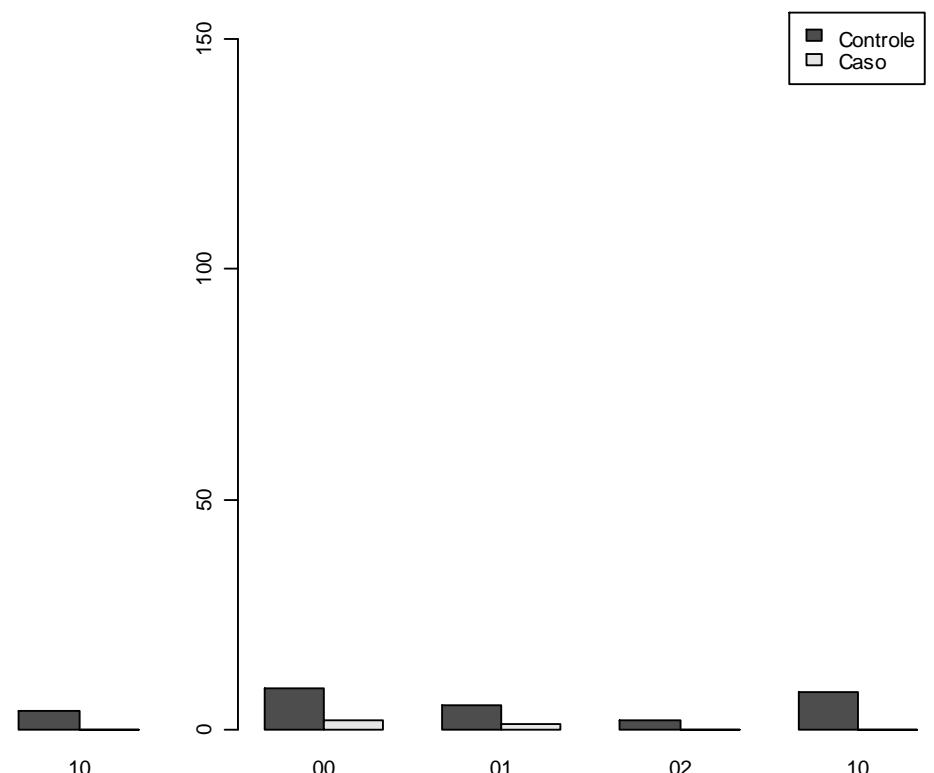

Figura 39 - Trio T2D1 - interação tripla - contagem de amostras em cada genótipo combinado 


\section{T2D - Teste estatístico de cada trio}

$\mathrm{O}$ trio fechado encontrado para diabetes tipo 2 foi testado como planejado. $\mathrm{O}$ resultado está na Tabela 45.

Tabela 45 - T2D - Teste estatístico do trio. Veja o significado das colunas na Tabela 12.

\begin{tabular}{lrrlrr}
\hline Trio & Genotipos & GenFreq & P-X2 & SignX2 & PGoodman \\
\hline T2D1 & 126 & 18 & $9,6 \times 10^{-06}$ & Sim & $5,5 \times 10^{-0}$ \\
\hline \multicolumn{7}{l}{ Tabela 46 - T2D - genótipos em desequilíbrio } \\
\hline Trio & T2D1 & & \\
mM 15409 & mM 23058 & mM 923 & Controle & Caso \\
\hline 00 & 00 & 11 & 52 & 26 \\
02 & 11 & 11 & 9 & 26 \\
\hline
\end{tabular}

Dois genótipos têm o desequilíbrio mais pronunciado, e os listamos na Tabela 46.

\section{T2D - Confirmação com amostras independentes}

Para confirmar os resultados, usamos os 924 casos não usados como Troost, e todos os 1480 controles do conjunto 58C - 1958 British Birth Cohort. Os resultados estão na Tabela 47. Não conseguimos confirmação.

Tabela 47 - T2D - Confirmação do trio. Veja o significado das colunas na Tabela 12.

\begin{tabular}{lrrrcrc}
\hline Trio & Genotipos & GenFreq & P-X2 & SignX2 & PGoodman & SignGood \\
\hline T2D1 & 147 & 20 & 0,97 & Não & 0,97 & Não \\
\hline
\end{tabular}




\section{Diabetes tipo 1 - T1D}

O estudo de diabetes tipo 1 (T1D) é um caso especial entre as doenças do WTCCC. Estudando cada uma das outras seis doenças, nosso método encontrou entre um e cinco trios fechados. Para T1D, em contraste, encontramos nada menos que 315 trios, que se reduziram a 208 após removermos os SNPs com mau agrupamento óptico. Porém, quase todos estes trios são formados por SNPs situados na região MHC - Complexo Principal de Histocompatibilidade, no cromossomo seis. O estudo do BOOST já havia encontrado grande quantidade de pares significantes nesta região. Estes 315 trios incluem somente 23 blocos haplotípicos na região MHC, em diferentes combinações entre si e com diferentes SNPs formando os pares e trios. Exceto pelo mM 9254, todos os outros apresentam pelo menos um SNP com associação marginal superior a dez, e portanto todos os trios apresentam SNPs com associação marginal. 


\section{Trio T1D1}

Há um único trio de T1D que não tem todos os SNPs na região MHC. Ele tem dois blocos haplotípicos na região MHC e um bloco no cromossomo cinco. Optamos por mostrar os gráficos deste trio somente. Destacamos seus mMs e SNPs na Tabela 48.

Tabela 48 - Detalhes dos mMs e SNPs do trio T1D1

\begin{tabular}{|c|c|c|c|c|c|c|c|}
\hline Trio & $\mathrm{mM}$ & Crom & rs Id & MAF & Pos BP & $\begin{array}{l}\text { Dist } \\
\text { cM }\end{array}$ & $\begin{array}{l}\text { Assoc. } \\
\text { Marginal }\end{array}$ \\
\hline \multirow{5}{*}{ T1D1 } & 7542 & 5 & rs7701403 & 25,1 & 23379949 & 0 & 2,2 \\
\hline & \multirow{2}{*}{9263} & \multirow{2}{*}{6} & rs2894180 & 9,4 & 31280634 & 0,008 & 2,8 \\
\hline & & & rs3095238 & 14,2 & 31269189 & 0,008 & 17,5 \\
\hline & \multirow{2}{*}{9264} & \multirow{2}{*}{6} & rs7382297 & 14,2 & 31355046 & 0,020 & 18,4 \\
\hline & & & rs16899207 & 29,1 & 31374366 & 0,020 & 8,3 \\
\hline
\end{tabular}

T1D1 Individual

mM 7542

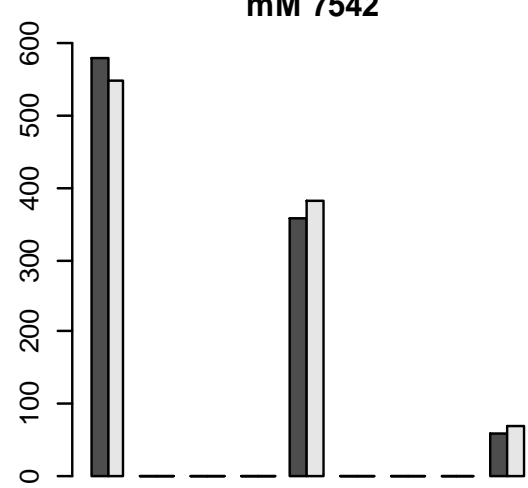

$\begin{array}{lllllllll}00 & 01 & 02 & 10 & 11 & 12 & 20 & 21 & 22\end{array}$
mM 9263

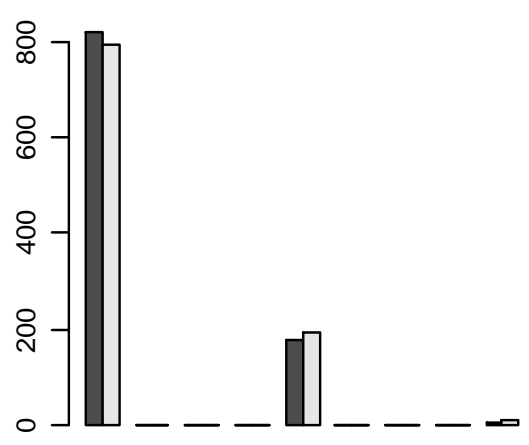

$\begin{array}{lllllllll}00 & 01 & 02 & 10 & 11 & 12 & 20 & 21 & 22\end{array}$

mM 9264

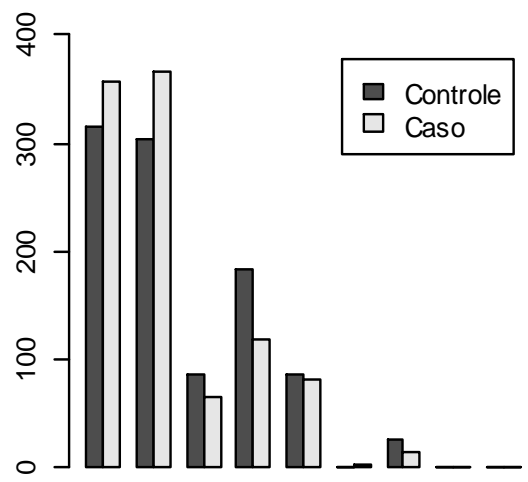

$\begin{array}{lllllllll}00 & 01 & 02 & 10 & 11 & 12 & 20 & 21 & 22\end{array}$

Duplo-haplotipos

Duplo-haplotipos

Duplo-haplotipos

Figura 40 - Trio T1D1 - contagens de amostras em cada duplo-haplótipo de cada mM

Nos gráficos individuais do trio T1D1, mostrados na Figura 40, observamos efeito marginal considerável no mM 9264, genótipos 00, 01 e, principalmente, 10.

Na interação tripla (Figura 41), são evidentes B00-C00-A01, B10-C00-A00, de risco, B01-C00-A10 e B01-C11-A10, protetores. 

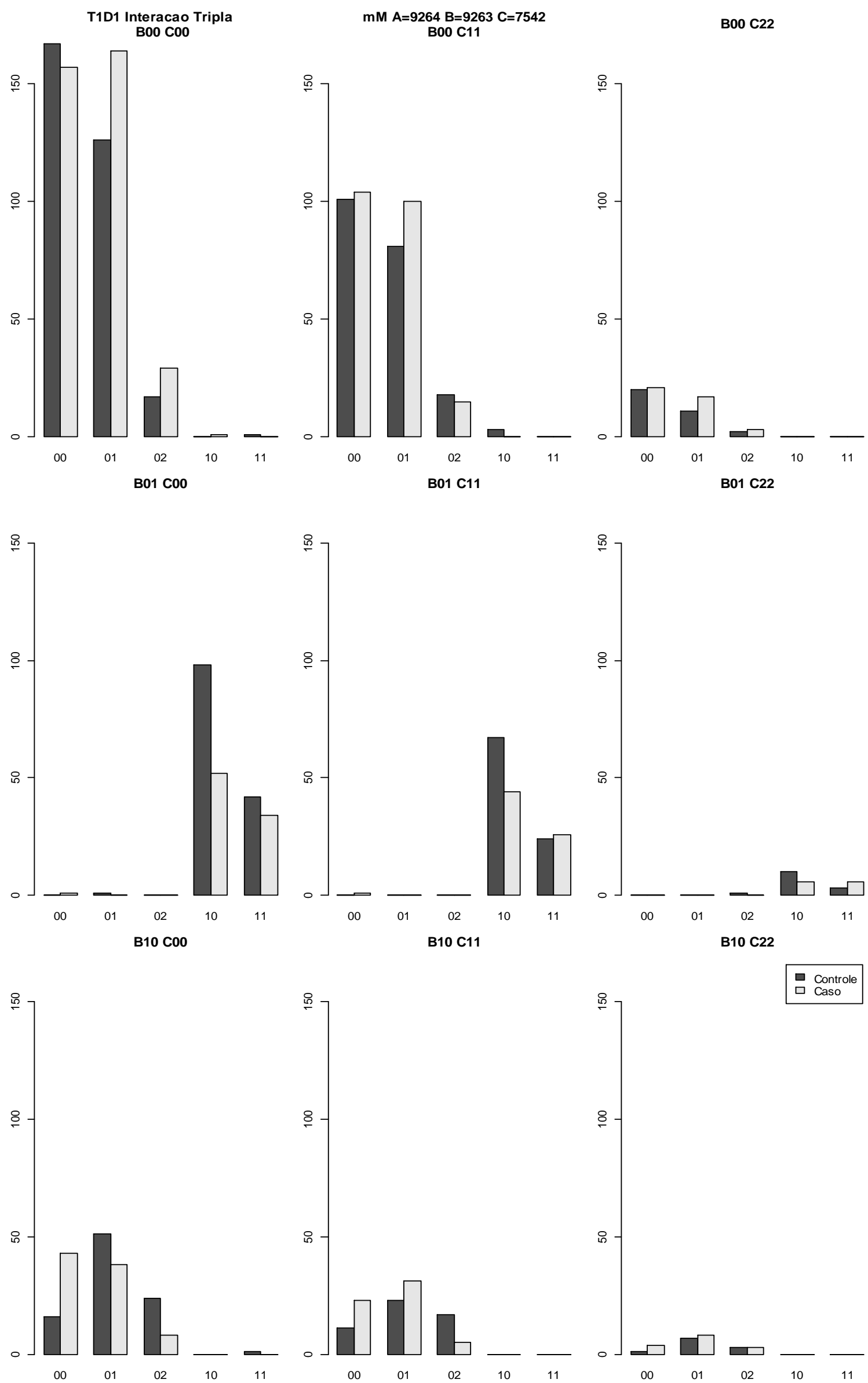

Figura 41 - Trio T1D1 - interação tripla - contagem de amostras em cada genótipo combinado

\section{T1D - Todos os trios}

Na Tabela 49 listamos os 208 trios encontrados para T1D. 
Tabela 49 - T1D - Lista dos trios de mMs encontrados. As letras dos SNPs indicam entradas na Tabela 50. (Continua na próxima página)

\begin{tabular}{|c|c|c|c|c|c|c|c|c|c|c|c|c|c|}
\hline Trio & mMA & SNPs & mMB & SNPs & mMC & SNPs & Trio & mMA & SNPs & $\mathrm{mMB}$ & SNPs & mMC & SNPs \\
\hline T1D1 & 7542 & $\mathrm{a}$ & 9263 & $\mathrm{cb}$ & 9264 & ce & T1D136 & 9262 & ai & 9267 & a & 9274 & $\mathrm{fi}$ \\
\hline T1D2 & 9251 & ba & 9255 & $\mathrm{ca}$ & 9267 & $a b$ & T1D137 & 9262 & $g$ & 9268 & ea & 9270 & $\mathrm{a}$ \\
\hline T1D3 & 9254 & $b$ & 9255 & $d$ & 9268 & aa & T1D138 & 9262 & gc & 9268 & da & 9271 & fa \\
\hline T1D6 & 9255 & $d$ & 9263 & $\mathrm{ce}$ & 9264 & ef & T1D139 & 9262 & jg & 9268 & da & 9272 & da \\
\hline T1D7 & 9255 & bd & 9263 & e & 9266 & hf & T1D140 & 9262 & gc & 9268 & da & 9273 & e \\
\hline T1D8 & 9255 & $c d$ & 9263 & ae & 9267 & fa & T1D141 & 9262 & ag & 9268 & $\mathrm{a}$ & 9274 & gf \\
\hline T1D9 & 9255 & $d$ & 9263 & $\mathrm{ae}$ & 9268 & ba & T1D142 & 9262 & jg & 9270 & a & 9272 & $\mathrm{fa}$ \\
\hline T1D10 & 9255 & $\mathrm{ad}$ & 9263 & de & 9270 & aa & T1D143 & 9262 & gc & 9270 & $\mathrm{a}$ & 9273 & ae \\
\hline T1D12 & 9255 & bd & 9264 & $\mathrm{fd}$ & 9266 & hf & T1D144 & 9262 & ag & 9270 & a & 9274 & gf \\
\hline T1D13 & 9255 & $\mathrm{~cd}$ & 9264 & af & 9267 & $\mathrm{fa}$ & T1D145 & 9262 & $c$ & 9271 & bf & 9273 & be \\
\hline T1D14 & 9255 & $d$ & 9264 & af & 9268 & ac & T1D146 & 9262 & ac & 9271 & fa & 9274 & $f$ \\
\hline T1D15 & 9255 & ad & 9264 & bf & 9270 & aa & T1D149 & 9262 & ac & 9273 & ce & 9274 & $\mathrm{fd}$ \\
\hline T1D17 & 9255 & $\mathrm{cb}$ & 9266 & ch & 9267 & $\mathrm{fa}$ & T1D150 & 9263 & ce & 9264 & ed & 9266 & $f$ \\
\hline T1D18 & 9255 & bd & 9266 & hf & 9268 & aa & T1D151 & 9263 & $\mathrm{ca}$ & 9264 & ae & 9267 & $f$ \\
\hline T1D19 & 9255 & ba & 9266 & hg & 9270 & aa & T1D152 & 9263 & $\mathrm{ca}$ & 9264 & ae & 9268 & $\mathrm{bc}$ \\
\hline T1D21 & 9255 & $c d$ & 9267 & $\mathrm{a}$ & 9268 & ac & T1D153 & 9263 & $\mathrm{~cd}$ & 9264 & be & 9270 & $\mathrm{a}$ \\
\hline T1D22 & 9255 & $\mathrm{ca}$ & 9267 & $\mathrm{ca}$ & 9270 & aa & T1D155 & 9263 & $\mathrm{cb}$ & 9264 & $\mathrm{ce}$ & 9273 & $\mathrm{e}$ \\
\hline T1D24 & 9255 & $\mathrm{ad}$ & 9268 & ea & 9270 & $\mathrm{a}$ & T1D156 & 9263 & cf & 9264 & ed & 9274 & gh \\
\hline T1D25 & 9255 & bd & 9268 & $\mathrm{da}$ & 9272 & de & T1D158 & 9263 & $\mathrm{ce}$ & 9265 & $\mathrm{a}$ & 9266 & $f$ \\
\hline T1D26 & 9255 & ba & 9270 & $\mathrm{a}$ & 9272 & fe & T1D159 & 9263 & $\mathrm{ca}$ & 9265 & a & 9267 & fe \\
\hline T1D27 & 9256 & ba & 9264 & $\mathrm{ad}$ & 9268 & ac & T1D160 & 9263 & ae & 9266 & $\mathrm{cf}$ & 9267 & $f$ \\
\hline T1D28 & 9256 & ba & 9264 & bd & 9270 & $\mathrm{a}$ & T1D161 & 9263 & ae & 9266 & $f$ & 9268 & ba \\
\hline T1D29 & 9256 & $\mathrm{a}$ & 9268 & ea & 9270 & a & T1D162 & 9263 & ge & 9266 & $f$ & 9269 & $c$ \\
\hline T1D30 & 9259 & dc & 9262 & $\mathrm{fg}$ & 9264 & $d$ & T1D163 & 9263 & de & 9266 & $\mathrm{fg}$ & 9270 & a \\
\hline T1D31 & 9259 & $c$ & 9262 & $f$ & 9266 & af & T1D165 & 9263 & be & 9266 & $d f$ & 9273 & e \\
\hline T1D33 & 9259 & $\mathrm{ac}$ & 9262 & jf & 9272 & da & T1D166 & 9263 & fe & 9266 & $f$ & 9274 & ah \\
\hline T1D34 & 9259 & dc & 9264 & $d$ & 9266 & af & T1D167 & 9263 & $\mathrm{a}$ & 9267 & fa & 9268 & $b c$ \\
\hline T1D40 & 9260 & ec & 9262 & $\mathrm{gb}$ & 9264 & $d$ & T1D168 & 9263 & ag & 9267 & $\mathrm{fb}$ & 9269 & c \\
\hline T1D41 & 9260 & $\mathrm{ac}$ & 9262 & $\mathrm{fb}$ & 9266 & ef & T1D169 & 9263 & $\mathrm{ad}$ & 9267 & fc & 9270 & $\mathrm{a}$ \\
\hline T1D42 & 9260 & ec & 9262 & $g b$ & 9268 & $\mathrm{a}$ & T1D171 & 9263 & ba & 9267 & fe & 9273 & ef \\
\hline T1D43 & 9260 & ec & 9262 & $g b$ & 9270 & $\mathrm{a}$ & T1D172 & 9263 & af & 9267 & $\mathrm{fa}$ & 9274 & hi \\
\hline T1D44 & 9260 & dc & 9262 & $\mathrm{bc}$ & 9271 & fa & T1D173 & 9263 & ag & 9268 & $b$ & 9269 & $c$ \\
\hline T1D45 & 9260 & ec & 9262 & $\mathrm{jb}$ & 9272 & da & T1D174 & 9263 & $\mathrm{ad}$ & 9268 & be & 9270 & a \\
\hline T1D46 & 9260 & ec & 9262 & $\mathrm{bc}$ & 9273 & e & T1D176 & 9263 & ba & 9268 & bd & 9273 & e \\
\hline T1D48 & 9260 & ea & 9264 & $d$ & 9266 & ef & T1D177 & 9263 & af & 9268 & ba & 9274 & gh \\
\hline T1D49 & 9260 & e & 9264 & ad & 9268 & ac & T1D180 & 9263 & $\mathrm{bg}$ & 9269 & $\mathrm{bc}$ & 9273 & e \\
\hline T1D50 & 9260 & e & 9264 & $\mathrm{bd}$ & 9270 & $\mathrm{a}$ & T1D183 & 9263 & bd & 9270 & $\mathrm{a}$ & 9273 & ae \\
\hline T1D52 & 9260 & e & 9264 & $\mathrm{~cd}$ & 9273 & e & T1D184 & 9263 & $d f$ & 9270 & $a$ & 9274 & gh \\
\hline T1D54 & 9260 & ea & 9264 & df & 9276 & $b$ & T1D189 & 9263 & bf & 9273 & ce & 9274 & dh \\
\hline T1D55 & 9260 & ea & 9266 & ef & 9268 & a & T1D192 & 9264 & ad & 9266 & $\mathrm{cf}$ & 9267 & $f$ \\
\hline T1D56 & 9260 & ea & 9266 & eg & 9270 & $\mathrm{a}$ & T1D193 & 9264 & $\mathrm{ad}$ & 9266 & $f$ & 9268 & ac \\
\hline T1D57 & 9260 & $\mathrm{ad}$ & 9266 & de & 9271 & ae & T1D194 & 9264 & bd & 9266 & $\mathrm{fg}$ & 9270 & $\mathrm{a}$ \\
\hline T1D59 & 9260 & ea & 9266 & de & 9273 & e & T1D196 & 9264 & $\mathrm{~cd}$ & 9266 & $d f$ & 9273 & $\mathrm{e}$ \\
\hline T1D61 & 9260 & e & 9268 & ea & 9270 & a & T1D197 & 9264 & $d$ & 9266 & $f$ & 9274 & ga \\
\hline T1D62 & 9260 & ed & 9268 & $\mathrm{da}$ & 9271 & a & T1D198 & 9264 & $\mathrm{a}$ & 9267 & fa & 9268 & $c$ \\
\hline T1D63 & 9260 & e & 9268 & $\mathrm{da}$ & 9272 & $d$ & T1D199 & 9264 & ba & 9267 & fc & 9270 & $\mathrm{a}$ \\
\hline T1D64 & 9260 & e & 9268 & $\mathrm{da}$ & 9273 & e & T1D201 & 9264 & $\mathrm{ca}$ & 9267 & fe & 9273 & ef \\
\hline T1D66 & 9260 & ea & 9268 & ac & 9276 & $b$ & T1D202 & 9264 & ad & 9267 & fa & 9274 & gi \\
\hline T1D67 & 9260 & e & 9270 & a & 9272 & $\mathrm{fd}$ & T1D203 & 9264 & ba & 9268 & ec & 9270 & $\mathrm{a}$ \\
\hline T1D68 & 9260 & e & 9270 & a & 9273 & ae & T1D205 & 9264 & $\mathrm{ca}$ & 9268 & dc & 9273 & $\mathrm{e}$ \\
\hline T1D70 & 9260 & ea & 9270 & a & 9276 & $b$ & T1D206 & 9264 & ad & 9268 & ac & 9274 & $g$ \\
\hline T1D71 & 9260 & ed & 9271 & ba & 9273 & be & T1D208 & 9264 & af & 9268 & $c$ & 9276 & $b$ \\
\hline T1D73 & 9260 & ad & 9271 & $\mathrm{ad}$ & 9276 & $b$ & T1D210 & 9264 & $\mathrm{cb}$ & 9270 & a & 9273 & ae \\
\hline T1D76 & 9260 & ea & 9272 & $\mathrm{da}$ & 9276 & $b$ & T1D211 & 9264 & bd & 9270 & a & 9274 & $g$ \\
\hline
\end{tabular}




\begin{tabular}{|c|c|c|c|c|c|c|c|c|c|c|c|c|c|}
\hline Trio & mMA & SNPs & mMB & SNPs & mMC & SNPs & Trio & mMA & SNPs & $\mathrm{mMB}$ & SNPs & $\mathrm{mMC}$ & SNPs \\
\hline T1D78 & 9260 & ea & 9273 & ef & 9276 & $b$ & T1D213 & 9264 & bf & 9270 & $\mathrm{a}$ & 9276 & $b$ \\
\hline T1D80 & 9261 & $\mathrm{ca}$ & 9262 & hd & 9263 & fe & T1D218 & 9264 & $\mathrm{~cd}$ & 9273 & ce & 9274 & $\mathrm{gd}$ \\
\hline T1D81 & 9261 & $\mathrm{ca}$ & 9262 & hg & 9264 & $\mathrm{fd}$ & T1D220 & 9264 & cf & 9273 & ef & 9276 & $\mathrm{~b}$ \\
\hline T1D82 & 9261 & $\mathrm{a}$ & 9262 & he & 9265 & $\mathrm{a}$ & T1D223 & 9265 & $\mathrm{a}$ & 9266 & $\mathrm{cf}$ & 9267 & fe \\
\hline T1D83 & 9261 & $\mathrm{ca}$ & 9262 & hg & 9268 & a & T1D224 & 9266 & $\mathrm{cf}$ & 9267 & fa & 9268 & $\mathrm{ac}$ \\
\hline T1D84 & 9261 & $\mathrm{ca}$ & 9262 & hg & 9270 & a & T1D225 & 9266 & $\mathrm{cf}$ & 9267 & $\mathrm{fb}$ & 9269 & $c$ \\
\hline T1D85 & 9261 & ad & 9262 & hc & 9271 & $\mathrm{fd}$ & T1D226 & 9266 & $\mathrm{cg}$ & 9267 & fc & 9270 & a \\
\hline T1D86 & 9261 & $\mathrm{ca}$ & 9262 & jh & 9272 & $\mathrm{a}$ & T1D227 & 9266 & $\mathrm{~cd}$ & 9267 & fc & 9271 & e \\
\hline T1D87 & 9261 & $a b$ & 9262 & hc & 9273 & ef & T1D229 & 9266 & $\mathrm{~cd}$ & 9267 & fe & 9273 & ef \\
\hline T1D88 & 9261 & $c$ & 9263 & $\mathrm{ce}$ & 9264 & ef & T1D230 & 9266 & cf & 9267 & $\mathrm{fa}$ & 9274 & ai \\
\hline T1D89 & 9261 & $\mathrm{ca}$ & 9263 & $\mathrm{ce}$ & 9265 & $\mathrm{a}$ & T1D231 & 9266 & $f$ & 9268 & ba & 9269 & $c$ \\
\hline T1D90 & 9261 & $c$ & 9263 & ae & 9268 & ba & T1D232 & 9266 & $\mathrm{fg}$ & 9268 & ea & 9270 & a \\
\hline T1D91 & 9261 & $c$ & 9263 & de & 9270 & $\mathrm{a}$ & T1D233 & 9266 & $d f$ & 9268 & da & 9271 & ae \\
\hline T1D93 & 9261 & $\mathrm{cb}$ & 9263 & be & 9273 & ef & T1D235 & 9266 & df & 9268 & da & 9273 & e \\
\hline T1D94 & 9261 & $c$ & 9264 & af & 9268 & ac & T1D236 & 9266 & $f$ & 9268 & $\mathrm{a}$ & 9274 & ga \\
\hline T1D95 & 9261 & c & 9264 & bf & 9270 & $\mathrm{a}$ & T1D239 & 9266 & $d f$ & 9269 & $\mathrm{bc}$ & 9273 & e \\
\hline T1D97 & 9261 & $\mathrm{cb}$ & 9264 & $\mathrm{cf}$ & 9273 & ef & T1D242 & 9266 & $\mathrm{dg}$ & 9270 & $\mathrm{a}$ & 9273 & ae \\
\hline T1D98 & 9261 & $c$ & 9268 & ea & 9270 & $\mathrm{a}$ & T1D243 & 9266 & $\mathrm{fg}$ & 9270 & $\mathrm{a}$ & 9274 & ga \\
\hline T1D99 & 9261 & $c d$ & 9268 & da & 9271 & $\mathrm{ad}$ & T1D244 & 9266 & $d$ & 9271 & be & 9273 & be \\
\hline T1D100 & 9261 & $c$ & 9268 & da & 9272 & da & T1D245 & 9266 & $d f$ & 9271 & ae & 9274 & $\mathrm{fa}$ \\
\hline T1D101 & 9261 & $\mathrm{cb}$ & 9268 & da & 9273 & ef & T1D248 & 9266 & $\mathrm{df}$ & 9273 & $\mathrm{ce}$ & 9274 & $\mathrm{da}$ \\
\hline T1D102 & 9261 & $c$ & 9270 & $\mathrm{a}$ & 9272 & fa & T1D249 & 9267 & $a b$ & 9268 & $\mathrm{bc}$ & 9269 & $c$ \\
\hline T1D103 & 9261 & $\mathrm{cb}$ & 9270 & $\mathrm{a}$ & 9273 & af & T1D250 & 9267 & $\mathrm{ca}$ & 9268 & ec & 9270 & $\mathrm{a}$ \\
\hline T1D104 & 9261 & $\mathrm{db}$ & 9271 & $\mathrm{bd}$ & 9273 & bf & T1D251 & 9267 & $\mathrm{ca}$ & 9268 & dc & 9271 & ae \\
\hline T1D106 & 9262 & gd & 9263 & $\mathrm{cf}$ & 9264 & ed & T1D253 & 9267 & ae & 9268 & dc & 9273 & ef \\
\hline T1D107 & 9262 & de & 9263 & cf & 9265 & $\mathrm{a}$ & T1D254 & 9267 & a & 9268 & $\mathrm{ac}$ & 9274 & gi \\
\hline T1D108 & 9262 & $\mathrm{fd}$ & 9263 & fe & 9266 & $f$ & T1D257 & 9267 & be & 9269 & $\mathrm{bc}$ & 9273 & ef \\
\hline T1D109 & 9262 & id & 9263 & af & 9267 & $\mathrm{fa}$ & T1D260 & 9267 & $\mathrm{ce}$ & 9270 & $\mathrm{a}$ & 9273 & af \\
\hline T1D110 & 9262 & gd & 9263 & af & 9268 & ba & T1D261 & 9267 & $\mathrm{ca}$ & 9270 & $a$ & 9274 & gi \\
\hline T1D111 & 9262 & $g d$ & 9263 & $d f$ & 9270 & $\mathrm{a}$ & T1D262 & 9267 & $\mathrm{ce}$ & 9271 & be & 9273 & bf \\
\hline T1D113 & 9262 & dc & 9263 & bf & 9273 & e & T1D263 & 9267 & $\mathrm{ca}$ & 9271 & ae & 9274 & $\mathrm{fi}$ \\
\hline T1D114 & 9262 & $\mathrm{ad}$ & 9263 & $f$ & 9274 & fh & T1D266 & 9267 & ae & 9273 & $\mathrm{cf}$ & 9274 & $\mathrm{di}$ \\
\hline T1D115 & 9262 & $\mathrm{fg}$ & 9264 & $d$ & 9266 & $f$ & T1D269 & 9268 & bd & 9269 & $\mathrm{bc}$ & 9273 & e \\
\hline T1D116 & 9262 & ig & 9264 & $\mathrm{ad}$ & 9267 & fa & T1D271 & 9268 & ed & 9270 & $\mathrm{a}$ & 9272 & $\mathrm{fd}$ \\
\hline T1D117 & 9262 & $\mathrm{~g}$ & 9264 & ad & 9268 & $\mathrm{ac}$ & T1D272 & 9268 & ed & 9270 & a & 9273 & ae \\
\hline T1D118 & 9262 & $g$ & 9264 & bd & 9270 & $\mathrm{a}$ & T1D273 & 9268 & ea & 9270 & a & 9274 & $g$ \\
\hline T1D120 & 9262 & gc & 9264 & $\mathrm{~cd}$ & 9273 & e & T1D275 & 9268 & ec & 9270 & $a$ & 9276 & $b$ \\
\hline T1D121 & 9262 & ag & 9264 & $d$ & 9274 & gf & T1D276 & 9268 & $d$ & 9271 & ba & 9273 & be \\
\hline T1D122 & 9262 & fe & 9265 & a & 9266 & $f$ & T1D277 & 9268 & da & 9271 & $\mathrm{a}$ & 9274 & gf \\
\hline T1D123 & 9262 & ie & 9265 & $\mathrm{a}$ & 9267 & ae & T1D279 & 9268 & dc & 9271 & $\mathrm{ad}$ & 9276 & $b$ \\
\hline T1D124 & 9262 & if & 9266 & cf & 9267 & fa & T1D283 & 9268 & dc & 9272 & da & 9276 & $b$ \\
\hline T1D125 & 9262 & $\mathrm{fg}$ & 9266 & $f$ & 9268 & $\mathrm{a}$ & T1D284 & 9268 & da & 9273 & ce & 9274 & $g d$ \\
\hline T1D126 & 9262 & $\mathrm{fg}$ & 9266 & $\mathrm{fg}$ & 9270 & $\mathrm{a}$ & T1D286 & 9268 & dc & 9273 & ef & 9276 & $\mathrm{~b}$ \\
\hline T1D127 & 9262 & fc & 9266 & $d f$ & 9271 & fe & T1D297 & 9270 & a & 9272 & $\mathrm{fa}$ & 9276 & $b$ \\
\hline T1D129 & 9262 & fc & 9266 & $d f$ & 9273 & $\mathrm{e}$ & T1D298 & 9270 & a & 9273 & $\mathrm{ca}$ & 9274 & gd \\
\hline T1D130 & 9262 & af & 9266 & $f$ & 9274 & $\mathrm{fa}$ & T1D300 & 9270 & a & 9273 & af & 9276 & $b$ \\
\hline T1D131 & 9262 & ig & 9267 & $a$ & 9268 & $\mathrm{ac}$ & T1D303 & 9271 & ba & 9273 & $\mathrm{cb}$ & 9274 & $\mathrm{fd}$ \\
\hline T1D132 & 9262 & ig & 9267 & $\mathrm{ca}$ & 9270 & $\mathrm{a}$ & T1D305 & 9271 & bd & 9273 & bf & 9276 & $b$ \\
\hline T1D133 & 9262 & ic & 9267 & $\mathrm{ca}$ & 9271 & fe & T1D314 & 9273 & $c d$ & 9274 & $\mathrm{~cd}$ & 9275 & $\mathrm{ca}$ \\
\hline T1D135 & 9262 & ic & 9267 & $\mathrm{ae}$ & 9273 & ef & & & & & & & \\
\hline
\end{tabular}

A Tabela 50 mostra os detalhes dos SNPs dos trios de T1D. 
Tabela 50 - Detalhes dos SNPs que formam os trios de T1D

\begin{tabular}{|c|c|c|c|c|c|c|c|}
\hline $\mathrm{mM}$ & $\begin{array}{l}\text { SNP } \\
\text { no } \mathrm{mM}\end{array}$ & rs ID & Alelos & MAF & Pos BP & $\begin{array}{l}\text { Dist } \\
\text { cM }\end{array}$ & $\begin{array}{l}\text { Assoc, } \\
\text { Marginal }\end{array}$ \\
\hline 7542 & $a$ & rs7701403 & $\mathrm{TG}$ & 25,15 & 23379949 & (cr 5) & 2,25 \\
\hline \multirow{2}{*}{9251} & a & rs2254071 & $\mathrm{TC}$ & 26,75 & 29914041 & (cr 6) & 13,66 \\
\hline & $b$ & rs5013088 & $\mathrm{TC}$ & 25,34 & 29928368 & 0,018 & 1,46 \\
\hline \multirow{2}{*}{9254} & a & rs16896944 & $\mathrm{TC}$ & 2,74 & 30134125 & 0,190 & 1,80 \\
\hline & $b$ & rs9261301 & $A G$ & 46,15 & 30149538 & 0,001 & 0,60 \\
\hline \multirow{4}{*}{9255} & a & rs2517592 & CT & 24,57 & 30201116 & 0,054 & 1,17 \\
\hline & $b$ & rs2517611 & $A G$ & 22,96 & 30277306 & 0,023 & 11,62 \\
\hline & c & rs1264616 & CT & 20,89 & 30372286 & 0,019 & 0,98 \\
\hline & $d$ & rs1264563 & CT & 37,76 & 30476071 & 0,044 & 5,42 \\
\hline \multirow{2}{*}{9256} & a & rs2516675 & CT & 25,69 & 30538499 & 0,023 & 5,94 \\
\hline & $b$ & rs3094694 & $\mathrm{TC}$ & 20,97 & 30559883 & 0,009 & 32,46 \\
\hline \multirow{4}{*}{9259} & $a$ & rs3094121 & CT & 23,49 & 30838939 & 0,091 & 18,62 \\
\hline & $b$ & rs 41521648 & $A C$ & 15,47 & 30847951 & 0,003 & 39,54 \\
\hline & c & rs3131043 & $A G$ & 42,02 & 30866445 & 0,006 & 1,39 \\
\hline & $d$ & rs3131050 & TC & 15,73 & 30868004 & 0,001 & 38,44 \\
\hline \multirow{5}{*}{9260} & a & rs1264344 & $\mathrm{CT}$ & 44,76 & 30908556 & 0,109 & 3,05 \\
\hline & $b$ & rs3095345 & $\mathrm{TC}$ & 16,35 & 30930392 & 0,003 & 8,27 \\
\hline & c & rs753725 & CT & 47,91 & 30998850 & 0,007 & 4,32 \\
\hline & $d$ & rs3131785 & GC & 47,23 & 31009874 & 0,004 & 6,37 \\
\hline & e & rs3132581 & $\mathrm{GA}$ & 16,43 & 31021437 & 0,002 & 37,93 \\
\hline \multirow{4}{*}{9261} & $a$ & rs2530709 & $C G$ & 28,28 & 31048548 & 0,047 & 2,25 \\
\hline & b & rs1634717 & GT & 43,82 & 31080568 & 0,004 & 19,54 \\
\hline & $c$ & rs1634718 & $A G$ & 27,72 & 31080844 & 0,000 & 27,99 \\
\hline & $d$ & rs1632854 & TA & 43,71 & 31083628 & 0,001 & 20,12 \\
\hline \multirow{10}{*}{9262} & a & rs2844670 & $A G$ & 15,07 & 31113705 & 0,060 & 41,24 \\
\hline & b & rs2517538 & $\mathrm{GC}$ & 36,37 & 31121520 & 0,003 & 8,19 \\
\hline & c & rs2523865 & $A C$ & 45,46 & 31126427 & 0,002 & 24,78 \\
\hline & $d$ & rs41328052 & $\mathrm{CA}$ & 45,45 & 31133692 & 0,008 & 18,40 \\
\hline & e & rs9263597 & $\mathrm{GA}$ & 48,12 & 31179526 & 0,007 & 16,88 \\
\hline & $f$ & rs1265048 & $\mathrm{TC}$ & 32,66 & 31189388 & 0,009 & 10,42 \\
\hline & $\mathrm{g}$ & rs3130975 & $\mathrm{CT}$ & 35,11 & 31189817 & 0,003 & 24,59 \\
\hline & $\mathrm{h}$ & rs3130991 & $\mathrm{CT}$ & 32,28 & 31195333 & 0,009 & 2,27 \\
\hline & i & rs9263715 & $\mathrm{GA}$ & 17,21 & 31203780 & 0,017 & 1,60 \\
\hline & j & rs3130564 & $\mathrm{CT}$ & 26,49 & 31209653 & 0,008 & 31,94 \\
\hline \multirow{7}{*}{9263} & a & rs 1265181 & $\mathrm{GC}$ & 24,68 & 31263764 & 0,056 & 24,21 \\
\hline & b & rs3095238 & GT & 14,23 & 31269189 & 0,001 & 17,53 \\
\hline & c & rs2894180 & $\mathrm{GA}$ & 9,37 & 31280634 & 0,008 & 2,83 \\
\hline & $d$ & rs3130953 & $\mathrm{GA}$ & 30,03 & 31285073 & 0,000 & 10,72 \\
\hline & e & rs3869109 & $\mathrm{GA}$ & 44,47 & 31292175 & 0,001 & 3,71 \\
\hline & $f$ & rs3130531 & $\mathrm{GA}$ & 37,7 & 31314595 & 0,018 & 9,87 \\
\hline & $\mathrm{g}$ & rs3130534 & $A G$ & 38,03 & 31317024 & 0,004 & 22,96 \\
\hline \multirow{7}{*}{9264} & a & rs2248880 & TC & 26,54 & 31341489 & 0,039 & 26,38 \\
\hline & $b$ & rs41358948 & $A G$ & 18,27 & 31353800 & 0,028 & 66,84 \\
\hline & c & rs7382297 & GT & 14,23 & 31355046 & 0,004 & 18,40 \\
\hline & $d$ & rs2524095 & $\mathrm{CA}$ & 41,14 & 31374096 & 0,020 & 3,00 \\
\hline & e & rs16899207 & $A G$ & 29,07 & 31374366 & 0,000 & 8,31 \\
\hline & $f$ & rs2524089 & $\mathrm{TG}$ & 41,06 & 31374501 & 0,000 & 2,88 \\
\hline & g & rs3873385 & $\mathrm{CT}$ & 17,68 & 31377287 & 0,009 & 0,72 \\
\hline 9265 & $a$ & rs4394275 & $\mathrm{GA}$ & 23,42 & 31426156 & 0,058 & 16,39 \\
\hline \multirow{6}{*}{$\begin{array}{r}9266 \\
\text { (continua) }\end{array}$} & a & rs7761068 & $A G$ & 40,63 & 31441918 & 0,046 & 1,73 \\
\hline & $b$ & rs3957111 & GA & 11,22 & 31452469 & 0,014 & 4,09 \\
\hline & c & rs3016013 & $A G$ & 27,12 & 31459221 & 0,021 & 0,05 \\
\hline & $d$ & rs2507976 & $\mathrm{CA}$ & 35,67 & 31459866 & 0,002 & 24,73 \\
\hline & e & rs2523693 & $\mathrm{TC}$ & 44,64 & 31526103 & 0,041 & 1,63 \\
\hline & $f$ & rs2516460 & GT & 45,73 & 31526679 & 0,000 & 2,68 \\
\hline
\end{tabular}




\begin{tabular}{|c|c|c|c|c|c|c|c|}
\hline $\mathrm{mM}$ & $\begin{array}{l}\text { SNP } \\
\text { no } \mathrm{mM}\end{array}$ & rs ID & Alelos & MAF & Pos BP & $\begin{array}{l}\text { Dist } \\
\mathrm{cM}\end{array}$ & $\begin{array}{l}\text { Assoc, } \\
\text { Marginal }\end{array}$ \\
\hline \multirow{2}{*}{$\begin{array}{r}\text { (cont.) } \\
9266\end{array}$} & $\mathrm{~g}$ & rs3131622 & TG & 45,8 & 31528479 & 0,001 & 16,34 \\
\hline & $\mathrm{h}$ & rs3131621 & $A G$ & 37,83 & 31533478 & 0,001 & 8,26 \\
\hline \multirow{6}{*}{9267} & $\mathrm{a}$ & rs2248373 & CT & 33,63 & 31554525 & 0,077 & 21,84 \\
\hline & $b$ & rs9267247 & $\mathrm{CA}$ & 38,23 & 31563813 & 0,004 & 7,40 \\
\hline & c & rs3131631 & CG & 22,44 & 31592662 & 0,021 & 45,94 \\
\hline & $d$ & rs41518649 & $A G$ & 11,53 & 31602181 & 0,006 & 1,59 \\
\hline & e & rs2734573 & $A C$ & 42,3 & 31602717 & 0,000 & 7,18 \\
\hline & $f$ & rs1799964 & $\mathrm{TC}$ & 22,1 & 31650287 & 0,011 & 17,89 \\
\hline \multirow{5}{*}{9268} & a & rs486416 & $A G$ & 33,54 & 31964049 & 0,151 & 6,78 \\
\hline & $b$ & rs9267673 & CT & 9,58 & 31991658 & 0,006 & 13,87 \\
\hline & c & rs644045 & $\mathrm{GA}$ & 35,29 & 31991936 & 0,000 & 19,22 \\
\hline & $d$ & rs3130284 & $\mathrm{TC}$ & 22,85 & 32248465 & 0,060 & 22,80 \\
\hline & e & rs204990 & $\mathrm{CA}$ & 21,78 & 32269408 & 0,021 & 43,85 \\
\hline \multirow{3}{*}{9269} & a & rs391755 & $A G$ & 5,89 & 32300414 & 0,051 & 28,44 \\
\hline & $b$ & rs377763 & $\mathrm{CA}$ & 22,26 & 32307122 & 0,013 & 146,73 \\
\hline & c & rs3134926 & CG & 27,65 & 32308125 & 0,001 & 28,63 \\
\hline 9270 & a & rs6936204 & $\mathrm{CT}$ & 33,63 & 32325070 & 0,049 & 19,06 \\
\hline \multirow{6}{*}{9271} & a & rs9268402 & $A G$ & 46,65 & 32449331 & 0,052 & 15,07 \\
\hline & $b$ & rs9391858 & $A G$ & 15,72 & 32449376 & 0,000 & 36,80 \\
\hline & c & rs3129953 & CT & 17,21 & 32469799 & 0,009 & 65,71 \\
\hline & $d$ & rs2076533 & CT & 48,43 & 32471505 & 0,001 & 39,73 \\
\hline & e & rs2076530 & $\mathrm{TC}$ & 48,85 & 32471794 & 0,000 & 36,25 \\
\hline & $f$ & rs3806156 & GT & 40,37 & 32481676 & 0,007 & 69,59 \\
\hline \multirow{7}{*}{9272} & a & rs9268557 & CT & 47,75 & 32497283 & 0,027 & 101,01 \\
\hline & $b$ & rs9268560 & $\mathrm{GC}$ & 44,4 & 32497490 & 0,000 & 76,65 \\
\hline & c & rs3135392 & $\mathrm{CA}$ & 39,28 & 32517220 & 0,016 & 22,20 \\
\hline & $d$ & rs7194 & $A G$ & 36,18 & 32520458 & 0,004 & 33,54 \\
\hline & e & rs9268831 & $\mathrm{TC}$ & 48,32 & 32535726 & 0,004 & 83,52 \\
\hline & $f$ & rs9268856 & $\mathrm{CA}$ & 24,87 & 32537697 & 0,005 & 24,27 \\
\hline & g & rs41331245 & $\mathrm{CT}$ & 23,86 & 32557028 & 0,008 & 190,30 \\
\hline \multirow{6}{*}{9273} & a & rs615672 & $\mathrm{GC}$ & 32,9 & 32682149 & 0,023 & 46,06 \\
\hline & $b$ & rs9272723 & CT & 32,03 & 32717405 & 0,031 & 347,33 \\
\hline & c & rs9275134 & CG & 26,92 & 32758590 & 0,024 & 217,68 \\
\hline & $d$ & rs9469220 & $\mathrm{GA}$ & 47,37 & 32766288 & 0,009 & 189,15 \\
\hline & e & rs2647046 & $\mathrm{CA}$ & 37,16 & 32776314 & 0,023 & 13,41 \\
\hline & $f$ & rs9275572 & $\mathrm{GA}$ & 39,23 & 32786977 & 0,014 & 19,68 \\
\hline \multirow{10}{*}{9274} & a & rs6936863 & CG & 27,98 & 32792007 & 0,054 & 182,93 \\
\hline & $b$ & rs3916765 & $\mathrm{GA}$ & 14,93 & 32793528 & 0,008 & 303,00 \\
\hline & c & rs9275765 & $\mathrm{TA}$ & 25,74 & 32797302 & 0,004 & 69,81 \\
\hline & $d$ & rs9275772 & CT & 25,8 & 32797481 & 0,000 & 69,80 \\
\hline & e & rs9469240 & $\mathrm{CT}$ & 38,37 & 32797979 & 0,000 & 70,02 \\
\hline & $f$ & rs9275793 & $A G$ & 25,77 & 32798005 & 0,000 & 69,81 \\
\hline & $\mathrm{g}$ & rs2859090 & $\mathrm{GA}$ & 21,77 & 32808811 & 0,012 & 18,18 \\
\hline & $\mathrm{h}$ & rs9276429 & $A G$ & 45,75 & 32820082 & 0,009 & 92,03 \\
\hline & $\mathrm{i}$ & rs7768538 & $A C$ & 45,76 & 32837799 & 0,007 & 89,77 \\
\hline & j & rs6902723 & $\mathrm{GA}$ & 46,41 & 32839938 & 0,001 & 65,83 \\
\hline \multirow{3}{*}{9275} & a & rs2857212 & $A G$ & 36,36 & 32848389 & 0,022 & 99,52 \\
\hline & $b$ & rs241438 & CT & 34,64 & 32905598 & 0,035 & 13,62 \\
\hline & c & rs241427 & $\mathrm{GA}$ & 31,42 & 32912392 & 0,031 & 125,87 \\
\hline \multirow{2}{*}{9276} & a & rs4148882 & $A G$ & 32,62 & 32924936 & 0,029 & 113,54 \\
\hline & $b$ & rs9276832 & $\mathrm{CT}$ & 32,54 & 32940378 & 0,011 & 5,94 \\
\hline \multirow{2}{*}{9281} & a & rs439852 & CT & 26,25 & 33113186 & 0,438 & 6,59 \\
\hline & $b$ & rs446853 & $\mathrm{CT}$ & 45,81 & 33126355 & 0,004 & 24,67 \\
\hline
\end{tabular}




\section{T1D - Teste estatístico de cada trio}

Submetido aos testes de homogeneidade de tabela de contingência, o trio T1D1 revelou-se significante, com um valor-P de $7,9 \times 10^{-12}$ pelo teste de Pearson e $1,2 \times 10^{-12}$ pelo teste de Goodman.

\section{Trio T1D1}

Tabela 51 - Trio T1D1 - genótipos em desequilíbrio

\begin{tabular}{lllrr}
\hline Trio: & T1D1 & & & \\
mM 9264 & mM 9263 & mM 7542 & Controle & Caso \\
\hline 10 & 01 & 00 & 98 & 52 \\
20 & 02 & 00 & 23 & 0 \\
00 & 10 & 00 & 16 & 43 \\
02 & 10 & 00 & 24 & 8 \\
\hline
\end{tabular}

A Tabela 51 mostra os genótipos com desequilíbrio pronunciado no trio T1D1.

\section{Teste dos demais trios de T1D, na região MHC}

Excluindo os trios que contém pelo menos um SNP com mau agrupamento, restaram 208 trios, e todos eles foram considerados significantes em ambos os testes. Listamos aqui os 25 trios com menor valor-P, na Tabela 52.

Tabela 52 - T1D - Trios com menor valor-P

\begin{tabular}{lrrrr}
\hline Trio & Genotipos & GenFreq & P-X2 & PGoodman \\
\hline T1D303 & 224 & 30 & $9,8 \times 10^{-106}$ & $3,5 \times 10^{-157}$ \\
T1D276 & 189 & 25 & $1,9 \times 10^{-105}$ & $1,6 \times 10^{-153}$ \\
T1D305 & 243 & 25 & $4,5 \times 10^{-102}$ & $6,1 \times 10^{-147}$ \\
T1D104 & 324 & 24 & $4,7 \times 10^{-101}$ & $2,2 \times 10^{-144}$ \\
T1D244 & 243 & 23 & $6,1 \times 10^{-100}$ & $1,1 \times 10^{-141}$ \\
T1D145 & 189 & 26 & $8,6 \times 10^{-99}$ & $3,5 \times 10^{-141}$ \\
T1D297 & 72 & 21 & $5,7 \times 10^{-87}$ & $2,9 \times 10^{-117}$ \\
T1D71 & 441 & 31 & $2,8 \times 10^{-85}$ & $1,3 \times 10^{-118}$ \\
T1D272 & 243 & 23 & $3,9 \times 10^{-85}$ & $5,6 \times 10^{-115}$ \\
T1D269 & 243 & 23 & $4,4 \times 10^{-84}$ & $3,5 \times 10^{-113}$ \\
T1D102 & 72 & 20 & $2,0 \times 10^{-79}$ & $3,5 \times 10^{-104}$ \\
T1D271 & 216 & 17 & $5,2 \times 10^{-79}$ & $2,5 \times 10^{-102}$ \\
T1D298 & 162 & 32 & $2,4 \times 10^{-75}$ & $8,9 \times 10^{-102}$ \\
T1D314 & 324 & 36 & $3,3 \times 10^{-75}$ & $6,1 \times 10^{-103}$ \\
T1D142 & 192 & 26 & $1,0 \times 10^{-73}$ & $5,1 \times 10^{-97}$ \\
T1D68 & 81 & 25 & $1,7 \times 10^{-71}$ & $4,2 \times 10^{-93}$ \\
T1D67 & 72 & 17 & $8,2 \times 10^{-71}$ & $1,9 \times 10^{-89}$ \\
T1D262 & 729 & 23 & $2,8 \times 10^{-69}$ & $5,5 \times 10^{-89}$ \\
T1D284 & 378 & 24 & $3,9 \times 10^{-69}$ & $4,6 \times 10^{-89}$ \\
T1D300 & 81 & 23 & $5,3 \times 10^{-67}$ & $1,9 \times 10^{-85}$ \\
T1D283 & 216 & 25 & $6,1 \times 10^{-65}$ & $7,4 \times 10^{-83}$ \\
T1D242 & 243 & 29 & $3,4 \times 10^{-64}$ & $8,4 \times 10^{-83}$ \\
T1D103 & 189 & 27 & $1,6 \times 10^{-63}$ & $3,2 \times 10^{-81}$ \\
T1D26 & 243 & 29 & $2,2 \times 10^{-63}$ & $1,5 \times 10^{-81}$ \\
T1D260 & 243 & 23 & $1,5 \times 10^{-61}$ & $3,5 \times 10^{-77}$ \\
\hline
\end{tabular}


T1D - Confirmação com amostras independentes

Tabela 53 - Genótipos de risco com maior razão de chances

\begin{tabular}{|c|c|c|c|c|c|c|c|c|c|}
\hline Trio & $A$ & B & $\mathbf{C}$ & mMA & $\mathrm{mMB}$ & $\mathrm{mMC}$ & Ctrl & Caso & $\begin{array}{l}\text { Razão de } \\
\text { chances }\end{array}$ \\
\hline T1D218 & 11 & 11 & 02 & 9273 & 9274 & 9264 & 2 & 53 & 34,38 \\
\hline T1D127 & 12 & 21 & 00 & 9262 & 9266 & 9271 & 3 & 34 & 14,55 \\
\hline T1D314 & 10 & 00 & 11 & 9273 & 9275 & 9274 & 55 & 421 & 12,04 \\
\hline T1D106 & 11 & 01 & 11 & 9262 & 9264 & 9263 & 4 & 37 & 11,89 \\
\hline T1D298 & 11 & 11 & 11 & 9273 & 9274 & 9270 & 50 & 381 & 11,70 \\
\hline T1D197 & 11 & 22 & 00 & 9274 & 9264 & 9266 & 8 & 71 & 11,60 \\
\hline T1D284 & 11 & 11 & 11 & 9273 & 9274 & 9268 & 46 & 328 & 10,61 \\
\hline T1D239 & 21 & 21 & 22 & 9266 & 9269 & 9273 & 5 & 38 & 9,77 \\
\hline T1D277 & 11 & 11 & 11 & 9274 & 9268 & 9271 & 47 & 305 & 9,52 \\
\hline T1D239 & 12 & 11 & 11 & 9266 & 9269 & 9273 & 8 & 56 & 9,07 \\
\hline T1D110 & 11 & 11 & 11 & 9262 & 9263 & 9268 & 6 & 42 & 9,02 \\
\hline T1D269 & 21 & 11 & 22 & 9269 & 9268 & 9273 & 7 & 48 & 8,86 \\
\hline T1D135 & 10 & 12 & 22 & 9267 & 9262 & 9273 & 5 & 34 & 8,72 \\
\hline T1D248 & 11 & 10 & 11 & 9273 & 9266 & 9274 & 13 & 85 & 8,59 \\
\hline T1D266 & 10 & 11 & 12 & 9267 & 9273 & 9274 & 7 & 46 & 8,48 \\
\hline T1D149 & 20 & 00 & 22 & 9273 & 9262 & 9274 & 5 & 32 & 8,20 \\
\hline T1D218 & 11 & 11 & 01 & 9273 & 9274 & 9264 & 47 & 267 & 8,15 \\
\hline T1D269 & 11 & 10 & 11 & 9269 & 9268 & 9273 & 17 & 104 & 8,11 \\
\hline T1D121 & 11 & 02 & 22 & 9274 & 9262 & 9264 & 7 & 44 & 8,10 \\
\hline T1D266 & 01 & 11 & 12 & 9267 & 9273 & 9274 & 35 & 201 & 7,97 \\
\hline T1D248 & 20 & 01 & 11 & 9273 & 9266 & 9274 & 5 & 31 & 7,94 \\
\hline T1D233 & 21 & 11 & 20 & 9266 & 9268 & 9271 & 7 & 43 & 7,91 \\
\hline T1D184 & 20 & 12 & 11 & 9263 & 9274 & 9270 & 8 & 49 & 7,91 \\
\hline T1D189 & 11 & 12 & 00 & 9273 & 9274 & 9263 & 49 & 264 & 7,71 \\
\hline T1D263 & 22 & 00 & 02 & 9274 & 9267 & 9271 & 6 & 36 & 7,70 \\
\hline T1D261 & 12 & 00 & 11 & 9274 & 9267 & 9270 & 48 & 259 & 7,70 \\
\hline T1D57 & 11 & 21 & 20 & 9260 & 9266 & 9271 & 6 & 35 & 7,49 \\
\hline T1D284 & 11 & 11 & 12 & 9273 & 9274 & 9268 & 6 & 35 & 7,49 \\
\hline T1D152 & 10 & 11 & 11 & 9264 & 9263 & 9268 & 9 & 52 & 7,47 \\
\hline T1D303 & 10 & 01 & 11 & 9273 & 9271 & 9274 & 118 & 524 & 7,29 \\
\hline T1D156 & 01 & 11 & 11 & 9264 & 9274 & 9263 & 8 & 45 & 7,25 \\
\hline T1D235 & 21 & 11 & 22 & 9266 & 9268 & 9273 & 7 & 39 & 7,16 \\
\hline T1D149 & 11 & 01 & 11 & 9273 & 9262 & 9274 & 62 & 303 & 7,12 \\
\hline T1D254 & 12 & 11 & 00 & 9274 & 9268 & 9267 & 54 & 266 & 7,04 \\
\hline T1D202 & 12 & 10 & 11 & 9274 & 9267 & 9264 & 25 & 130 & 6,96 \\
\hline T1D263 & 12 & 00 & 11 & 9274 & 9267 & 9271 & 48 & 233 & 6,82 \\
\hline T1D266 & 00 & 11 & 12 & 9267 & 9273 & 9274 & 18 & 93 & 6,80 \\
\hline T1D230 & 12 & 10 & 11 & 9274 & 9267 & 9266 & 18 & 92 & 6,73 \\
\hline T1D177 & 01 & 01 & 10 & 9263 & 9274 & 9268 & 13 & 67 & 6,71 \\
\hline T1D167 & 12 & 10 & 00 & 9267 & 9268 & 9263 & 7 & 36 & 6,60 \\
\hline T1D314 & 10 & 00 & 00 & 9273 & 9275 & 9274 & 9 & 45 & 6,44 \\
\hline T1D303 & 20 & 00 & 22 & 9273 & 9271 & 9274 & 14 & 68 & 6,32 \\
\hline T1D303 & 10 & 02 & 11 & 9273 & 9271 & 9274 & 13 & 63 & 6,29 \\
\hline T1D235 & 12 & 00 & 11 & 9266 & 9268 & 9273 & 12 & 58 & 6,26 \\
\hline T1D231 & 10 & 22 & 11 & 9268 & 9266 & 9269 & 13 & 62 & 6,19 \\
\hline T1D172 & 10 & 10 & 22 & 9263 & 9267 & 9274 & 29 & 133 & 6,14 \\
\hline T1D165 & 21 & 01 & 22 & 9266 & 9263 & 9273 & 8 & 38 & 6,10 \\
\hline T1D144 & 11 & 01 & 11 & 9274 & 9262 & 9270 & 58 & 250 & 6,09 \\
\hline T1D144 & 11 & 02 & 11 & 9274 & 9262 & 9270 & 17 & 79 & 6,08 \\
\hline T1D180 & 01 & 21 & 22 & 9263 & 9269 & 9273 & 10 & 47 & 6,06 \\
\hline
\end{tabular}


Para confirmar os resultados, usamos os 924 casos não usados como Troost, e todos os 1480 controles do conjunto 58C - 1958 British Birth Cohort. Todos os trios foram confirmados como significantes. Devido à região MHC ser sabidamente relacionada ao diabetes tipo 1, optamos por não listá-los todos aqui, escolhendo alguns grupos que que apresentam a razão de chances mais pronunciada, considerando o conjunto de todos os 2480 controles e 1924 casos. A Tabela 53 mostra os 50 genótipos combinados de risco com a maior razão de chances. Note que, neste conjunto, são esperados bem mais controles do que casos.

A Tabela 54 mostra os 35 genótipos protetores com menor razão de chances.

Tabela 54 - Genótipos protetores com menor razão de chances

\begin{tabular}{|c|c|c|c|c|c|c|c|c|c|}
\hline Trio & A & B & C & mMA & $\mathrm{mMB}$ & $\mathrm{mMC}$ & Ctrl & Caso & $\begin{array}{l}\text { Razão de } \\
\text { chances }\end{array}$ \\
\hline T1D276 & 22 & 02 & 00 & 9273 & 9271 & 9268 & 105 & 0 & 0,00 \\
\hline T1D303 & 02 & 02 & 11 & 9273 & 9271 & 9274 & 72 & 0 & 0,00 \\
\hline T1D176 & 10 & 00 & 22 & 9263 & 9268 & 9273 & 67 & 0 & 0,00 \\
\hline T1D244 & 22 & 00 & 00 & 9273 & 9271 & 9266 & 66 & 0 & 0,00 \\
\hline T1D305 & 22 & 00 & 00 & 9273 & 9271 & 9276 & 66 & 0 & 0,00 \\
\hline T1D297 & 02 & 22 & 00 & 9272 & 9270 & 9276 & 65 & 0 & 0,00 \\
\hline T1D61 & 02 & 22 & 00 & 9268 & 9270 & 9260 & 64 & 0 & 0,00 \\
\hline T1D273 & 02 & 22 & 00 & 9268 & 9270 & 9274 & 64 & 0 & 0,00 \\
\hline T1D272 & 02 & 00 & 22 & 9273 & 9268 & 9270 & 63 & 0 & 0,00 \\
\hline T1D68 & 02 & 22 & 00 & 9273 & 9270 & 9260 & 60 & 0 & 00 \\
\hline T1D298 & 01 & 11 & 22 & 9273 & 9274 & 9270 & 60 & 0 & 00 \\
\hline T1D98 & 02 & 00 & 22 & 9268 & 9261 & 9270 & 57 & 0 & 0,00 \\
\hline T1D145 & 22 & 00 & 11 & 9273 & 9271 & 9262 & 57 & 0 & 0,00 \\
\hline T1D50 & 02 & 22 & 00 & 9264 & 9270 & 9260 & 5 & 0 & 00 \\
\hline T1D137 & 02 & 00 & 22 & 68 & 9262 & 9270 & 5 & 0 & 00 \\
\hline T1D104 & 22 & 00 & 00 & 9273 & 9271 & 9261 & & 0 & 00 \\
\hline T1D118 & 02 & 00 & 22 & 9264 & 262 & 9270 & & 0 & \\
\hline T1 & 02 & 20 & 22 & 68 & 66 & 70 & & 0 & \\
\hline T1 & 02 & 22 & 00 & 64 & 270 & 274 & 4 & 0 & \\
\hline T1D & 22 & 02 & 02 & 273 & 260 & 9271 & 4 & 0 & \\
\hline & 00 & 01 & 11 & 73 & & 270 & & 1 & \\
\hline & 12 & 02 & 11 & 73 & & 68 & & | & \\
\hline & 00 & 00 & 22 & 9269 & & 9273 & 9 & 1 & 01 \\
\hline T1D305 & 12 & 00 & 11 & 9273 & 9271 & 9276 & 90 & 1 & 0,01 \\
\hline T1D272 & 12 & 11 & 22 & 9273 & 9268 & 9270 & 83 & 1 & 0,01 \\
\hline T1D245 & 11 & 10 & 20 & 9266 & 9274 & 9271 & 72 & 1 & 0,02 \\
\hline T1D236 & 00 & 22 & 22 & 9274 & 9266 & 9268 & 65 & 1 & 0,02 \\
\hline T1D26 & 02 & 00 & 22 & 9272 & 9255 & 9270 & 65 & 1 & 0,02 \\
\hline T1D102 & 02 & 00 & 22 & 9272 & 9261 & 9270 & 65 & 1 & 0,02 \\
\hline T1D243 & 20 & 00 & 22 & 9266 & 9274 & 9270 & 65 & 1 & 0,02 \\
\hline T1D71 & 12 & 11 & 02 & 9273 & 9260 & 9271 & 59 & 1 & 0,02 \\
\hline T1D210 & 01 & 10 & 11 & 9273 & 9264 & 9270 & 169 & 3 & 0,02 \\
\hline T1D242 & 11 & 12 & 22 & 9266 & 9273 & 9270 & 57 & 1 & 0,02 \\
\hline T1D248 & 01 & 02 & 10 & 9273 & 9266 & 9274 & 57 & 1 & 0,02 \\
\hline T1D260 & 11 & 12 & 22 & 9267 & 9273 & 9270 & 56 & 1 & 0,02 \\
\hline
\end{tabular}




\section{Discussão}

O conjunto de programas que foram desenvolvidos nessa tese pode ser encarado como um desenvolvimento natural na busca de interações entre efeitos de alelos de locos gênicos individuais na constituição de fenótipos. Logo que se iniciaram os grandes consórcios para a análise de genoma inteiro, não era ainda possível a análise de interações epistáticas de todos os pares de genótipos individuais possíveis por causa das limitações computacionais então existentes. Nessa época, a busca de associação era feita somente com relação àqueles genótipos individuais que apresentavam pelo menos algum efeito marginal. Com a possibilidade de procura exaustiva de interações, o Troost possibilita o incremento dimensional de interações de forma análoga, ou seja, parte de um subconjunto de pares que apresentam pelo menos alguma associação marginal com os fenótipos considerados.

\subsection{Uso das distâncias em centimorgans}

Após o sequenciamento do genoma humano, os marcadores genéticos passaram a ser localizados pelas suas distâncias em bases nitrogenadas, contadas a partir da extremidade do braço mais curto do cromossomo. Os mapas genéticos em centimorgans eram anteriormente bastante grosseiros, com pouca definição, embora já indicassem que as taxas de recombinação não eram uniformes ao longo do genoma. A partir de pesquisas que procuraram mapear a ocorrência de recombinação ao longo do genoma humano, tais como aquelas relatadas por GABRIEL et al., 2002 e JEFFREYS et al., 2004, ficou claro que as taxas de recombinação são altamente variadas conforme a posição no cromossomo, e que existem hot spots - pontos do genoma onde a recombinação meiótica é muito mais frequente que em outros. Também ficou clara a necessidade de mapear os haplótipos comuns na espécie humana, dando origem a projetos como o Hapmap, em sua fase 1 (HAPMAP CONSORTIUM, 2003, 2005) e fase 2 (HAPMAP CONSORTIUM, 2007), e o 1000 Genomas (ABECASIS et al., 2012; DURBIN et al., 2010).

No final de 2010 o projeto HapMap liberou os mapas genéticos da sua fase 2, apropriados para uso com os dados do WTCCC. Os arquivos de mapa genético trazem a distância em bases e em centimorgans para cada SNP, numa escala muito fina. Somando todos os cromossomos, o mapa traz 3,28 milhões de SNPs, numa resolução média aproximada de um SNP para cada mil bases do genoma, cerca de seis vezes mais densa do que a plataforma Affymetrix usada nesta pesquisa. 
A abordagem tradicional para construir haplótipos em estudos de associação e similares é usar os próprios dados genotípicos, calculando o desequilíbrio de ligação e agrupando os SNPs com alto desequilíbrio num mesmo bloco haplotípico. De posse de um mapa fino como o disponibilizado pelo HapMap, optamos por utilizar as distâncias finas em centimorgans para construir os haplótipos, sem depender do desequilíbrio de ligação dos nossos dados.

Consideramos apropriado usar distâncias de mapa genético em centimorgans e não somente a distância em bases. As distâncias em centimorgans contêm uma importante informação a mais que as distâncias em bases não têm: elas estão diretamente relacionadas à probabilidade de um haplótipo ser "quebrado" na passagem entre gerações. Se nosso objetivo é construir haplótipos, e tendo disponíveis as distâncias finas em centimorgans, não seria adequado usar as distâncias em bases.

\subsection{Blocos haplotípicos definidos por pares}

Além de usar distâncias em centimorgans, os blocos haplotípicos foram definidos pela participação dos SNPs em pares e trios. A principal descoberta da análise exploratória inicial foi a estrutura em blocos dos SNPs participantes dos pares com maior medida de interação. Inicialmente selecionamos somente os 11.000 pares mais "fortes". Colocamos todos os SNPs formadores destes pares em ordem de distância em centimorgans, e observamos que eles se agrupavam em muitos pontos, havendo regiões "rarefeitas" entre estes pontos. Mas não conseguimos trios fechados com 11.000 pares. Tentamos então subir este número para 350.000 pares. O que observamos foi que a distribuição em blocos era diluída. Os blocos eram muito menos pronunciados e desencorajavam a análise em haplótipos. Experimentamos uma quantidade intermediária, de 50.000, e ficamos satisfeitos ao verificar que a estrutura em blocos se mantinha, e que agora conseguíamos trios.

O algoritmo de agrupamento de SNPs que utilizamos é muito simples, até primário: intervalos de 0,02 cM sem SNPs separam os blocos. A seleção inicial de mais pares pode produzir resultados, se for utilizado um algoritmo mais sofisticado para o agrupamento dos SNPs. 


\subsection{Desempenho computacional}

O Troost inicia com uma fase preliminar de preparação de dados. Os programas envolvidos são todos rápidos, de complexidade linear. O tempo do SNPdist aumenta linearmente com o número de SNPs e não depende do número de amostras Sua execução, para todos os 22 cromossomos, tomou 26 segundos para 459 mil SNPs. O RefAllele é linear com o número total de amostras e também com o número de SNPs. Ele tomou 5 minutos e 54 segundos, para os mesmos SNPs e 17 mil amostras.

O SelSample e ExcludeSample são lineares com o número de amostras, não dependem dos SNPs e tiveram execução quase imediata, não mensurada. O tped2boost é linear com o número de SNPs e também com o número de amostras. Ele tomou dois minutos para processar cada conjunto de dados.

A próxima fase do Troost consiste na execução do GBOOST (YUNG et al., 2011). É ele que toma mais tempo e determina a complexidade total. O GBoost é quadrático com o número de SNPs e linear com o número de amostras. O GBoost demorou 72 minutos para processar cada estudo com 2.000 amostras.

A parte inovadora do Troost é executada depois do GBoost. O mMreduction.R é linear com o número de pares selecionados, que foi de cerca de 50.000. Sua execução tomou cerca de seis segundos, a maior parte deles lendo arquivos de entrada. Essa velocidade é consequiência de uma implementação totalmente vetorizada, apropriada para o ambiente R. O TriosFromPairs.C é linear com o número de pares de $\mathrm{mMs}$ vindos da fase anterior. Ele tem execução quase imediata, não mensurada. Os programas TabTrio.R e TrioStat.R demoram um pouco mais, cerca de um minuto para cada trio fechado encontrado, pois têm que ler os arquivos GBoost inteiros, mas este tempo só depende do tamanho do arquivo boost, que é linear com o número de SNPs e linear com o número de amostras.

Concluindo, o Troost como um todo é bastante rápido, levando cerca de uma hora e meia para cada estudo, e este tempo varia com o quadrado do número de SNPs e é aproximadamente proporcional ao número de amostras. Estes tempos foram todos obtidos na plataforma descrita no item 5.6. 


\subsection{Sucesso: o Troost encontrou trios, mas não nos controles}

O Troost encontrou poucos trios fechados de blocos haplotípicos. Porém, encontrou-os para todas as doenças (Tabela 8), e mais de um para a maioria delas, demonstrando a viabilidade da ferramenta. Os testes estatísticos comprovaram que os trios estavam associados às doenças, ao menos pelos dados que tínhamos usado. Mais ainda, quando submetido a um estudo de controles contra controles, o Troost não encontrou trio algum, o que é um fator positivo.

\subsection{BD, CAD, RA, T2D - A maldição do vencedor}

O Troost encontrou trios estatisticamente significantes. No entanto, ao testarmos com amostras independentes, para cinco das sete doenças não conseguimos reproduzir os resultados. Isto não chega a ser uma surpresa na história dos estudos de associação. A expressão "a maldição do vencedor" (winner's curse, em inglês) (LOHMUELLER et al., 2003) foi usada nos estudos de associação para nomear um fenômeno estatístico similar àquele que se constata na Economia, onde às vezes os vencedores de leilões fechados pagam um preço muito além daqueles ofertados pelos outros participantes (IOANNIDIS et al., 2009; ZOLLNER; PRITCHARD, 2007). No caso de estudos de associação, efeitos calculados como elevados não são confirmados em estudos posteriores por terem implicado uma sub-estimativa no tamanho da amostra necessário para a confirmação do efeito. Isto indica que a significância anterior teve contribuição de processos estocásticos, o que é esperado quando se realiza um grande número de testes, tal como foi feito com o emprego do GBoost. Não se faz cem bilhões de testes impunemente.

Interpretamos aqui que a busca exaustiva tem suas limitações. Mesmo tendo processamento rápido à disposição, com algoritmos eficientes como o GBoost e plataformas poderosas como as placas de vídeo, os resultados continuam limitados pelo problema dos múltiplos testes. Técnicas de redução do universo inicial podem ser promissoras, talvez com o uso de haplótipos. O Troost, com a abordagem propiciada pela análise centrada nos blocos haplotípicos, pode ser considerado como um passo nesse sentido. 


\subsection{CD - Resultado confirmado, mas rejeitado}

$\mathrm{Na}$ análise da doença de Crohn, ao notar o baixo valor-P obtido para os trios CD4 e CD5, ainda antes da confirmação, perguntamo-nos imediatamente o que estes trios teriam de diferente dos outros. Notamos que:

1. O mesmo par de mMs, 16617 e 19316, repetem-se nos dois trios. Portanto, os trios não são independentes.

2. Todos os quatro mMs destes dois trios são falsos mMs, no sentido de que são formados por um só SNP cada um. Isto é normal e previsto no método adotado, pois foi o mesmo SNP que formou par com os outros mMs. Este caso ocorre em vários outros trios deste trabalho, como por exemplo no estudo do transtorno bipolar.

3. A MAF - frequência do alelo alternativo - dos SNPs que participam dos dois trios é muito baixa, em torno de 6\%, e a MAF dos outros dois SNPs participantes é baixa, na casa de $13 \%$. Isto faz com que muitos genótipos sequer ocorram na amostra e as contagens estejam concentradas em poucos genótipos, como se pode ver pelo gráfico da interação tripla (Figura 29 e Figura 31).

4. Os dois SNPs do par que se repete, rs17116117 e rs10483456, tem alto efeito marginal, alto o suficiente para aparecer também nas análises de interação. Porém, nenhuma das quatro regiões que participam destes dois trios foi considerada significante no estudo do WTCCC, nem tampouco no estudo do BOOST.

Mesmo considerando estes fatores, levamos estes genótipos à análise na amostra independente.

Para nosso espanto, o resultado se confirmou. Desequilíbrios extremos foram observados. Por um lado, lembremos que estes trios incluem SNPs com alto efeito marginal. Por outro lado, estas proporções se manifestaram em duas amostras grandes e independentes, e portanto refletem um risco diferenciado para a contração da doença para os portadores destes genótipos. A razão de chances nos genótipos heterozigotos para os três SNPs atinge 43, um valor muito alto.

A Tabela 55 lista os SNPs dos trios CD4 e CD5. 
Tabela 55 - Detalhes dos SNPs que compõem os trios CD4 e CD5

\begin{tabular}{lrrcrrr}
\hline \multicolumn{1}{c}{ Trio } & mM & Crom & rs Id & MAF & Pos BP & $\begin{array}{c}\text { Assoc. } \\
\text { Marginal }\end{array}$ \\
\hline CD4 & 10917 & 7 & rs1525791 & 16,04 & 39123083 & 24,37 \\
CD4/CD5 & 16617 & 11 & rs17116117 & 6,31 & 113306801 & 47,20 \\
CD4/CD5 & 19316 & 14 & rs10483456 & 6,6 & 35105918 & 34,14 \\
CD5 & 22061 & 17 & rs12150025 & 13,5 & 50287153 & 31,59 \\
\hline
\end{tabular}

Aparentemente, tínhamos um resultado muito significativo. Os marcadores rs17116117, no cromossomo 11, e rs10483456, no cromossomo 14, quando ambos heterozigotos, aumentariam o risco do portador desenvolver a doença de Crohn, em especial quando um dos outros dois marcadores, um no cromossomo 7 e outro no 17 , é também heterozigoto. Estas combinações deveriam explicar cerca de $8 \%$ dos casos da doença. O marcador no cromossomo 14 também aumentaria o risco da doença quando é homozigoto para o alelo mais frequente. Neste caso o efeito no risco é menor, mas esta combinação ainda poderia explicar cerca de $3 \%$ dos casos da doença.

Verificamos novamente as listas de exclusão de SNPs do WTCCC e confirmamos que nenhum destes quatro SNPs está listado como excluído.

Pesquisamos a literatura sobre estes quatro marcadores. Eles não aparecem entre os 71 marcadores listados numa revisão de locos associados à doença de Crohn (FRANKE et al., 2010). Tampouco estão próximos aos marcadores listados.

Os quatro SNPs que encontramos possuem alto efeito marginal. Este efeito é concentrado no genótipo heterozigoto, e pode não ser encontrado em estudos que medem o efeito dos alelos e não dos genótipos. Mesmo assim, era esperado que tivessem sido encontrados antes por outros estudos.

Numa análise mais aprofundada, vimos que estes SNPs apresentam excesso de heterozigotos nos casos, mas isto ainda seria compatível com SNPs de forte efeito. Um deles, o do cromossomo 17, apresenta frequências genotípicas significativamente diferentes nos dois conjuntos de controles, NBS e 58C, e portanto o consideramos descartado. Em seguida notamos que este excesso de heterozigotos aparecia também em outras doenças.

Finalmente, encontramos informação de que estes quatro SNPs foram excluídos pelo WTCCC posteriormente à confecção das listas de exclusão, por exame visual dos gráficos ópticos, que mostraram mau agrupamento. Estávamos analisando, 
portanto, alguns dados de má qualidade. Como estes dados implicavam associação, que foi um artefato neste caso, o algoritmo conseguiu encontrá-la.

Durante este processo, revimos cada aspecto e linha de código dos programas, buscando por erros, mas não conseguimos encontrá-los. O erro estava nos dados. Os resultados reforçam a credibilidade dos programas.

Concluindo, não podemos reportar nenhum dos dois trios como relacionados com a doença de Crohn, mas mostramos que, quando os dados trazem associação, o Troost consegue encontrá-la.

\subsection{HT - Mais um erro nos dados}

Para hipertensão, encontramos uma situação parecida com a apresentada nos trios CD4 e CD5: dois mMs estão presentes nos dois trios. Neste caso são mMs verdadeiros, com dois SNPs cada um, e somente um dos quatro SNPs tem MAF baixa.

$\mathrm{Na}$ análise do trio HT2, obtivemos um valor-P de $1,4 \times 10^{-8}$. Com um valor tão baixo, esperávamos a confirmação, que não ocorreu. Observamos os dados com mais detalhes e notamos o baixo número de amostras em dois genótipos, um no trio HT1 e outro no HT2, ambos com somente um controle e dois casos. Isto não deveria acontecer, pois no teste principal só testamos genótipos com 20 ou mais amostras. De fato, no teste principal as proporções de caso e controle para estes genótipos eram de 20:3 e 23:3. Já havíamos notado que dois mMs estão presentes nos dois trios, e são eles que determinam o resultado semelhante nos dois trios. Os SNPS envolvidos estão listados na Tabela 56.

Os dois mMs são muito ligados, então é esperado que alguns genótipos combinados tenham representação baixa. No entanto, a diferença de representação nos dois estudos continuava sem explicação. Mesmo sendo os marcadores ligados, não víamos razão para certo genótipo ter uma representação mais baixa em um dos estudos. 
Tabela 56 - HT - SNPs que compõe os trios HT1 e HT2

\begin{tabular}{|c|c|c|c|c|c|c|c|c|c|c|c|}
\hline Trio & $\mathbf{m M}$ & Crom & SNP & $\begin{array}{l}\text { Affyme } \\
\text { trixld }\end{array}$ & rs Id & Alelos & MAF & Pos BP & $\begin{array}{l}\text { Dist } \\
\mathrm{cM}\end{array}$ & $\begin{array}{l}\text { Taxa } \\
\text { (cM/Mb) }\end{array}$ & $\begin{array}{l}\text { Assoc } \\
\text { margin }\end{array}$ \\
\hline HT1 & 8774 & 5 & 166751 & $\begin{array}{l}\text { SNP_A- } \\
2278615\end{array}$ & rs4867943 & GT & 32,2 & 169558250 & 0,000 & & 1,21 \\
\hline $\begin{array}{l}\text { HT1, } \\
\text { HT2 }\end{array}$ & 9314 & 6 & 174793 & $\begin{array}{l}\text { SNP_A- } \\
1919197\end{array}$ & rs2747436 & $\mathrm{TC}$ & 29,4 & 29759914 & & & 0,59 \\
\hline HT2 & 9314 & 6 & 174866 & $\begin{array}{l}\text { SNP_A- } \\
2141090\end{array}$ & rs2523408 & $A C$ & 32,7 & 29886088 & 0,068 & 0,54 & 5,57 \\
\hline HT1 & 9314 & 6 & 174904 & $\begin{array}{l}\text { SNP_A- } \\
2180943\end{array}$ & rs1611635 & CT & 19,1 & 29944442 & 0,054 & 0,92 & 2,50 \\
\hline HT1 & 9317 & 6 & 174942 & $\begin{array}{l}\text { SNP_A- } \\
2302189\end{array}$ & rs3129012 & GA & 19,8 & 30096621 & 0,163 & 1,07 & 2,61 \\
\hline $\begin{array}{l}\text { HT1, } \\
\text { HT2 }\end{array}$ & 9317 & 6 & 174960 & $\begin{array}{l}\text { SNP_A- } \\
1985589\end{array}$ & rs10484549 & TC & 5,7 & 30134269 & 0,008 & 0,22 & 0,23 \\
\hline HT2 & 9317 & 6 & 174973 & $\begin{array}{l}\text { SNP_A- } \\
4274364\end{array}$ & rs1264703 & CG & 25,5 & 30173395 & 0,014 & 0,35 & 0,80 \\
\hline HT2 & 18576 & 13 & 351872 & $\begin{array}{l}\text { SNP_A- } \\
1842044\end{array}$ & rs9569549 & TC & 42,5 & 56355405 & & & 0,44 \\
\hline HT2 & 18576 & 13 & 351875 & $\begin{array}{l}\text { SNP_A- } \\
1828706\end{array}$ & rs1413999 & $A C$ & 42,4 & 56384915 & 0,002 & 0,06 & 0,56 \\
\hline
\end{tabular}

Com mais atenção, observamos que o problema devia estar nos controles e não nos casos. Os casos foram retirados do mesmo conjunto de dados - HT - do qual sorteamos mil no primeiro estudo, e usamos os restantes 952 na confirmação. Obtivemos 3 casos nestes genótipos no primeiro estudo, e 2 casos no segundo, números perfeitamente coerentes. Já os controles vieram de conjuntos de dados diferentes. No primeiro estudo sorteamos mil entre os 1458 do conjunto de dados NBS, enquanto no segundo estudo usamos todos os 1480 controles do conjunto de dados 58C. Obtivemos 23 e 20 controles nestes genótipos no primeiro estudo, e somente um no segundo, uma diferença muito alta, indicando uma origem nãoaleatória.

Olhando ainda mais em detalhe, vemos que a diferença se deve especificamente aos dois SNPs que pertencem aos dois trios: rs2747436 e rs10484549. Quando consideramos o genótipo conjunto entre os dois, sem remover amostras inválidas, encontramos 69 amostras no conjunto NBS e somente 3 amostras no conjunto 58C. É como se houvesse uma interação de par.

Como fizemos um estudo de testes colocando os controles 58C como casos, verificar a saída do GBoost para este estudo, em que armazenamos os pares mais fortes. Com efeito, encontramos este par específico na lista, e com uma altíssima estatística InteractionBoost de 60,5, Nenhum dos dois SNPS está na lista de exclusões, 
Após descobrirmos que alguns SNPs deveriam ser excluídos devido a mau agrupamento óptico, verificamos que o SNP rs2747436 é um destes, É um problema causado por má qualidade nos dados de um SNP, Novamente neste caso o Troost detectou que este SNP tinha efeito, mas somente no conjunto usado inicialmente, já que o conjunto usado na confirmação não apresentava o problema.

\subsection{T1D - Novo SNP fora da MHC interage com ela}

O trio T1D1, que inclui um SNP no cromossomo cinco, obteve valor-P de $7,9 \times 10^{-12}$ no teste do Troost e de $4,9 \times 10^{-4}$ na confirmação, e portanto significantes. Numa contagem entre todos os 1963 casos e 2480 controles, um dos genótipos apresenta 31 controles e 73 casos, sendo portanto um genótipo de risco com uma razão de chances de 3,05 .

O mM 7542, situado no cromossomo cinco, é formado somente pelo SNP rs7701403. Não encontramos publicações associadas a este SNP, que não possui associação marginal apreciável. O genótipo responsável pelo aumento do risco é o mais frequente, homozigoto para o alelo de referência.

Os outros dois mMs, 9263 e 9264, na região MHC, estão bastante próximos. Seus SNPs estão listados na Tabela 57.

Tabela 57 - SNPs participantes do trio T1D1

\begin{tabular}{llllrlrrr}
\hline \multirow{2}{*}{$\mathbf{m M}$} & $\begin{array}{l}\text { SNP no } \\
\text { mM }\end{array}$ & rs Id & Alelos & MAF & Pos BP & $\begin{array}{l}\text { Dist } \\
\text { cM }\end{array}$ & $\begin{array}{l}\text { Rate } \\
\text { cM/Mb }\end{array}$ & $\begin{array}{l}\text { Assoc. } \\
\text { Marginal }\end{array}$ \\
\hline \multirow{2}{*}{9263} & $\mathrm{~b}$ & $\mathrm{rs} 3095238$ & GT & 14,23 & 31269189 & & & 17,53 \\
& $\mathrm{C}$ & $\mathrm{rs} 2894180$ & GA & 9,37 & 31280634 & 0,008 & 0,684 & 2,83 \\
\hline \multirow{2}{*}{9264} & $\mathrm{C}$ & $\mathrm{rs} 7382297$ & GT & 14,23 & 31355046 & 0,094 & 1,264 & 18,40 \\
& $\mathrm{e}$ & $\mathrm{rs} 16899207$ & AG & 29,07 & 31374366 & 0,020 & 1,037 & 8,31 \\
\hline
\end{tabular}

Dois dos SNPs do trio T1D1, o primeiro de cada mM, apresentam associação marginal alta, mas ela é menor que em outros SNP de T1D, como podemos ver na Tabela 50. Ambos, rs3095238 e rs7382297, já foram identificados como associados à esclerose múltipla, mas não à diabetes tipo 1. O SNP rs2894180 não é referenciado em estudos de associação. Está presente no site www.t1dbase.org, mas marcado como sem associação. O SNP rs16899207 já foi reportado em um estudo de T1D, no documento suplementar (YANG et al., 2011, doc supl.), interagindo com outro SNP da região $\mathrm{MHC}$. 


\subsection{T1D - Genótipos triplos com alto efeito}

O diabetes tipo 1 é uma doença auto-imune, com muitos SNPs associados na região MHC do cromossomo seis, como já confirmado por vários estudos. O BOOST confirmou muitas interações nesta região, inclusive entre SNPs sem efeito marginal. O Troost, como esperado, encontrou muitos trios nesta região. Neste trabalho, não fizemos pesquisas sobre os SNPs específicos que encontramos nesta região, por não ser parte dos nossos objetivos e podendo ser desenvolvidas por pesquisadores desta área especificamente.

Destacamos a magnitude das razões de chances encontradas. A Tabela 53 mostra genótipos triplos com razões de chances, confirmadas em amostra independente, superiores a seis, um número muito maior do que é costumeiro encontrar em estudos de associação. Caso não haja erros sistemáticos de genotipagem nesta região, estes resultados podem ser importantes para o estudo da diabetes tipo 1, mesmo que muitos dos SNPs tenham efeito aditivo. De modo análogo, observamos genótipos altamente protetores contra T1D na Tabela 54.

Em muitos GWAS, são descobertas variantes significantes, mas elas explicam apenas uma pequena parcela dos casos. Nos trios descobertos pelo Troost para T1D, além das razões de chances pronunciadas, são altos os números de indivíduos envolvidos em muitos dos genótipos combinados. Eles podem explicar um número de casos da doença maior do que o que os GWAS costumam encontrar.

Se para outras doenças os múltiplos testes impediram que o Troost encontrasse variações reais associadas à doença, para T1D obtivemos sucesso, com a ressalva de que não foi ainda analisado por especialistas na doença. Isso pode ter acontecido pelo fato de que cada doença pode ter uma arquitetura genética e ambiental peculiar, e talvez T1D seja a única que possui uma arquitetura que permitiu que as variantes fossem detectadas. 


\subsection{Acerto na escolha do BOOST}

O BOOST (WAN et al., 2010) despertou nossa atenção já na publicação do artigo em 2010. No início de 2011, com a publicação do GBoost, definimos sua escolha como ponto de partida para esta pesquisa. Dois anos e meio depois, o BOOST já conta com 76 citações (fonte: Google Scholar, 29/8/13), sendo uma referência na área de busca de epistasia. Comprovou ser eficiente e de uso simples, mesmo sem interface gráfica ou sofisticações. Não necessitamos de suporte dos autores para o seu uso, nem tampouco da fabricante da placa ou dos compiladores. Outros algoritmos não obtiveram o mesmo sucesso, inclusive outros desenvolvidos pelo mesmo grupo de Hong-Kong, como o SNPHarvester e o MegaSNPHunter. Consideramos portanto que a escolha do BOOST foi acertada.

\subsection{Perspectivas}

Durante o processo de desenvolvimento e testes do Troost, surgiram algumas ideias para pesquisas futuras. As que julgamos mais interessantes são:

- $\quad$ T1D - Comparação dos resultados do Troost com as últimas pesquisas de SNPs e interações na região MHC.

- T1D - Estudo mais aprofundado do SNP rs7701403 no cromossomo cinco.

- Após o GBoost, iniciar a análise com um conjunto maior de pares e usar um algoritmo de agrupamento mais sofisticado. Investigar como o aumento do número de pares na entrada afeta os resultados.

- Trios abertos: buscar trios dos quais somente dois dos três pares possíveis estejam presentes entre os mais fortes. 


\section{Conclusão}

Esperamos que este trabalho tenha trazido contribuições reais à área, entre as quais:

- Completamos o desenvolvimento e os testes da ferramenta, como nos propusemos inicialmente.

- Buscamos conjuntos de três marcadores com interação entre eles na associação com doenças de herança complexa, o que poucos grupos fizeram até agora.

- Introduzimos a ideia da busca de trios a partir dos pares de marcadores associados epistaticamente a doenças.

- Construímos haplótipos com um método original, usando relação entre pares e as distâncias de mapa do HapMap.

- Nosso método é rápido e de fácil compreensão.

- Analisamos com o Troost todas as sete doenças do WTCCC, num teste realmente extenso.

- O Troost encontrou trios fechados em todas as doenças. Quando testamos com um conjunto de controles contra controles, nenhum trio foi encontrado.

- A composição dos trios encontrados, com mais de um SNP em cada bloco na maioria dos blocos, mostra que a abordagem de haplótipos contribuiu para a descoberta de trios.

- Submetemos nossos resultados à confirmação com amostras independentes, evitando reportar falsos positivos e trazendo mais confiabilidade aos resultados

- Mostramos que técnicas de busca exaustiva têm limitações, dependendo da complexidade genética da doença.

- Encontramos trios de marcadores associados ao diabetes tipo 1 em região já conhecida, confirmando a utilidade do método.

- As razões de chance encontradas para T1D são muito pronunciadas, indicando uma contribuição possivelmente importante de interações múltiplas de locos gênicos nessa doença.

- Encontramos um marcador associado a T1D fora da região MHC em epistasia com dois blocos da região MHC. 


\section{Referências Bibliográficas}

ABECASIS, G. R.; AUTON, A.; BROOKS, L. D.; et al. An integrated map of genetic variation from 1,092 human genomes. Nature, v. 491, n. 7422, p. 56-65, 2012. Disponível em:

<http://www.pubmedcentral.nih.gov/articlerender.fcgi?artid=3498066\&tool=pmcentr ez\&rendertype=abstract $>$. Acesso em: 6/8/2013.

AGRESTI, A. Categorical Data Analysis. 2nd ed. 2002.

ALTSHULER, D. L.; DALY, M. J. Guilt beyond a reasonable doubt. Nature, v. 447, n. 7148, p. 1087-93, 2007. Disponível em:

<http://www.ncbi.nlm.nih.gov/pubmed/17529967>. .

BATESON, W.; MENDEL, G. Mendel's principles of heredity. Cambridge University Press, 1909.

BELLMAN, R. E. (PRINCETON U. Dynamic Programming. Princeton University Press, 1957.

BELlMAN, R. E. (PRINCETON U. Adaptive Control Processes: a guided tour. Princeton University Press, 1961.

BREIMAN, L. Random Forests. Machine Learning, v. 45, p. 5-32, 2001.

CARDON, L. R.; CRADDOCK, N.; DELOUKAS, P.; et al. Genome-wide association study of 14,000 cases of seven common diseases and 3,000 shared controls. Nature, v. 447, n. 7145, p. 661-678, 2007. Disponível em:

<http://scholar.google.com/scholar?hl=en\&btnG=Search\&q=intitle:Genomewide+association+study+of +14,000+cases+of+seven+common+diseases+and+3,000+ shared+controls\#0>. Acesso em: 29/5/2011.

CHAPMAN, J.; CLAYTON, D. Detecting association using epistatic information. Genetic epidemiology, v. 31, n. 8, p. 894-909, 2007. Wiley Online Library. Disponível em: <http://onlinelibrary.wiley.com/doi/10.1002/gepi.20250/abstract>. Acesso em: 29/5/2011.

CHEN, L.; YU, G.; LANGEFELD, C. D.; et al. Comparative Analysis of Methods for Detecting Interacting Loci. BMC genomics, v. 12, n. 1, p. 344, 2011. Disponível em: <http://www.ncbi.nlm.nih.gov/pubmed/21729295>. Acesso em: 19/7/2011.

CHEN, L.; YU, G.; MILLER, D. J.; et al. A Ground Truth Based Comparative Study on Detecting Epistatic SNPs. Proceedings. IEEE International Conference on Bioinformatics and Biomedicine, v. 1-4, n. Nov 2009, p. 26-31, 2009. Disponível em:

<http://www.pubmedcentral.nih.gov/articlerender.fcgi?artid=2998769\&tool=pmcentr ez\&rendertype $=$ abstract $>$. . 
CORDELL, H. J. Epistasis: what it means, what it doesn't mean, and statistical methods to detect it in humans. Human molecular genetics, v. 11, n. 20, p. 2463-8, 2002. Disponível em: <http://www.ncbi.nlm.nih.gov/pubmed/12351582>. .

CORDELL, H. J. Detecting gene-gene interactions that underlie human diseases. Nature Reviews Genetics, v. 10, n. 6, p. 392-404, 2009. Disponível em: <http://www.nature.com/nrg/journal/v10/n6/abs/nrg2579.html>. Acesso em: 29/5/2011.

DURBIN, R. M.; ALTSHULER, D. L.; ABECASIS, G. R. A map of human genome variation from population-scale sequencing. Nature, v. 467, n. 7319, p. 1061-1073, 2010. Disponível em: <http://www.nature.com/doifinder/10.1038/nature09534>. Acesso em: 27/10/2010.

EVANS, D. M.; MARCHINI, J.; MORRIS, A. P.; CARDON, L. R. Two-stage twolocus models in genome-wide association. PLoS genetics, v. 2, n. 9, p. e157, 2006. Disponível em: <http://www.ncbi.nlm.nih.gov/pubmed/17002500>. .

FALCONER, D. S.; MACKAY, T. F. C. Introduction to quantitative genetics. Benjamin Cummings, 1996.

FISHER, R. A. The correlation between relatives on the supposition of Mendelian inheritance. Transactions of the Royal Society of Edinburgh, v. 52, p. 399-433, 1918.

FOULKES, A. S. Applied statistical genetics with R: for population-based association studies. 2009.

FRANKE, A.; MCGOVERN, D. P. B.; BARRETT, J. C.; et al. Genome-wide metaanalysis increases to 71 the number of confirmed Crohn's disease susceptibility loci. Nature genetics, v. 42, n. 12, p. 1118-25, 2010. Nature Publishing Group. Disponível em:

$<$ http://www.pubmedcentral.nih.gov/articlerender.fcgi?artid=3299551\&tool=pmcentr ez\&rendertype $=$ abstract $>$. Acesso em: 1/8/2013.

GABRIEL, S. B.; SCHAFFNER, S. F.; NGUYEN, H.; et al. The Structure of Haplotype Blocks in the Human Genome. Molecular Biology, v. 738, n. May, 2002.

GAO, H.; GRANKA, J. M.; FELDMAN, M. W. On the classification of epistatic interactions. Genetics, v. 184, n. 3, p. 827-37, 2010. Disponível em:

<http://www.ncbi.nlm.nih.gov/pubmed/20026678>. .

GOODMAN, L. Simultaneous confidence intervals for contrasts among multinomial populations. The Annals of Mathematical Statistics, v. 35, n. 2, p. 716-725, 1964. Disponível em: <http://www.jstor.org/stable/10.2307/2238523>. Acesso em: 24/8/2013.

HALLGRÍMSDÓTTIR, I. B.; YUSTER, D. S. A complete classification of epistatic two-locus models. BMC genetics, v. 9, p. 17, 2008. Disponível em:

<http://www.ncbi.nlm.nih.gov/pubmed/18284682>. . 
HAPMAP CONSORTIUM, T. I. The International HapMap project. Nature, v. 426, n. 18/25 December 2003, p. 789-796, 2003. Disponível em:

<http://www.ncbi.nlm.nih.gov/pubmed/17575464>. .

HAPMAP CONSORTIUM, T. I. A haplotype map of the human genome. Nature, v. 437, n. 7063, p. 1299-320, 2005. Disponível em:

<http://www.ncbi.nlm.nih.gov/pubmed/16255080>. .

HAPMAP CONSORTIUM, T. I. A second generation human haplotype map of over 3.1 million SNPs. Nature, v. 449, n. 7164, p. 851-61, 2007. Disponível em:

<http://www.pubmedcentral.nih.gov/articlerender.fcgi?artid=2689609\&tool=pmcentr ez\&rendertype=abstract $>$. Acesso em: 15/3/2011.

HIRSCHHORN, J. N.; DALY, M. J. Genome-wide association studies for common diseases and complex traits. Nature reviews. Genetics, v. 6, n. 2, p. 95-108, 2005. Disponível em: <http://www.ncbi.nlm.nih.gov/pubmed/15716906>. .

IOANNIDIS, J. P. A; THOMAS, G.; DALY, M. J. Validating, augmenting and refining genome-wide association signals. Nature reviews. Genetics, v. 10, n. 5, p. 318-29, 2009. Disponível em: <http://www.ncbi.nlm.nih.gov/pubmed/19373277>. .

JEFFREYS, A. J.; HOLLOWAY, J. K.; KAUPPI, L.; et al. Meiotic recombination hot spots and human DNA diversity. Philosophical transactions of the Royal Society of London. Series B, Biological sciences, v. 359, n. 1441, p. 141-52, 2004. Disponível em:

<http://www.pubmedcentral.nih.gov/articlerender.fcgi?artid=1693298\&tool=pmcentr ez\&rendertype=abstract $>$. Acesso em: 21/9/2010.

KILPATRICK, J. R. Methods for detecting multi-locus genotype-phenotype association.Methods, 2009. Rice.

LOHMUELLER, K. E.; PEARCE, C. L.; PIKE, M.; LANDER, E. S.; HIRSCHHORN, J. N. Meta-analysis of genetic association studies supports a contribution of common variants to susceptibility to common disease. Nature genetics, v. 33, n. 2, p. 177-82, 2003. Disponível em:

<http://www.ncbi.nlm.nih.gov/pubmed/12524541>. Acesso em: 6/8/2013.

MCCARTHY, M. I.; ABECASIS, G. R.; CARDON, L. R.; et al. Genome-wide association studies for complex traits: consensus, uncertainty and challenges. Nature reviews. Genetics, v. 9, n. 5, p. 356-69, 2008. Disponível em:

<http://www.ncbi.nlm.nih.gov/pubmed/18398418>. .

MOORE, J. H.; GILBERT, J. C.; TSAI, C.-T.; et al. A flexible computational framework for detecting, characterizing, and interpreting statistical patterns of epistasis in genetic studies of human disease susceptibility. Journal of theoretical biology, v. 241, n. 2, p. 252-61, 2006. Disponível em:

<http://www.ncbi.nlm.nih.gov/pubmed/16457852>. Acesso em: 16/11/2010.

MORTON, N. E. Methods in genetic epidemiology. 1983.

NETER, J.; KUTNER, M.; WASSERMAN, W.; NACHTSHEIM, C. Applied linear statistical models. McGraw-Hill/Irwin, 1996. 
PARK, M. Y.; HASTIE, T. Penalized logistic regression for detecting gene interactions. Biostatistics (Oxford, England), v. 9, n. 1, p. 30-50, 2008. Disponível em: <http://www.ncbi.nlm.nih.gov/pubmed/17429103>. .

PURCELL, S.; NEALE, B.; TODDBROWN, K.; et al. PLINK: A Tool Set for Whole-Genome Association and Population-Based Linkage Analyses. The American Journal of Human Genetics, v. 81, n. 3, p. 559-575, 2007. Disponível em: <http://linkinghub.elsevier.com/retrieve/pii/S0002929707613524>. .

RITCHIE, M. D.; HAHN, L. W.; ROODI, N.; et al. Multifactor-dimensionality reduction reveals high-order interactions among estrogen-metabolism genes in sporadic breast cancer. The American Journal of Human Genetics, v. 69, n. 1, p. 138-147, 2001. Elsevier. Disponível em: <http://linkinghub.elsevier.com/retrieve/pii/S0002929707614530>. Acesso em: 29/5/2011.

WAN, X.; YANG, C.; YANG, Q.; et al. BOOST: A fast approach to detecting genegene interactions in genome-wide case-control studies. The American Journal of Human Genetics, v. 87, n. 3, p. 325-340, 2010. Elsevier. Disponível em: <http://linkinghub.elsevier.com/retrieve/pii/S0002929710003782>. Acesso em: 29/5/2011.

WANG, K.; ZHANG, H.; HAKONARSON, H. Common genetic variants on 5p14.1 associate with autism spectrum disorders. Nature, v. 459, n. 7246, p. 528-33, 2009a. Disponível em: <http://www.ncbi.nlm.nih.gov/pubmed/19404256>. .

WANG, K.; ZHANG, H.; MA, D.; et al. Common genetic variants on 5p14.1 associate with autism spectrum disorders. Nature, v. 459, n. 7246, p. 528-33, 2009b. Disponível em:

<http://www.pubmedcentral.nih.gov/articlerender.fcgi?artid=2943511\&tool=pmcentr ez\&rendertype=abstract $>$. Acesso em: 10/6/2011.

WANG, Y.; LIU, X.; ROBBINS, K.; REKAYA, R. AntEpiSeeker: detecting epistatic interactions for case-control studies using a two-stage ant colony optimization algorithm. BMC research notes, v. 3, n. 1, p. 117, 2010. BioMed Central Ltd. Disponível em: 〈http://www.biomedcentral.com/1756-0500/3/117>. Acesso em: 29/5/2011.

YANG, C.; HE, Z.; WAN, X.; et al. SNPHarvester: a filtering-based approach for detecting epistatic interactions in genome-wide association studies. Bioinformatics, v. 25, n. 4, p. 504, 2009a. Oxford Univ Press. Disponível em: <http://bioinformatics.oxfordjournals.org/content/25/4/504.short>. Acesso em: 29/5/2011.

YANG, C.; HE, Z.; WAN, X.; et al. SNPHarvester: a filtering-based approach for detecting epistatic interactions in genome-wide association studies. Bioinformatics (Oxford, England), v. 25, n. 4, p. 504-11, 2009b. Disponível em:

<http://www.ncbi.nlm.nih.gov/pubmed/19098029>. Acesso em: 6/8/2013.

YANG, C.; WAN, X.; YANG, Q.; et al. Supplementary document - A hidden twolocus disease association pattern in genome-wide association studies. BMC bioinformatics, , n. 4, p. Supl doc to pages 1-16, 2011. 
YUNG, L. S.; YANG, C.; WAN, X.; YU, W. GBOOST: a GPU-based tool for detecting gene-gene interactions in genome-wide case control studies.

Bioinformatics, v. 27, n. 9, p. 1309, 2011. Oxford Univ Press. Disponível em: <http://bioinformatics.oxfordjournals.org/content/27/9/1309.short>. Acesso em: 29/5/2011.

ZHANG, Y.; LIU, J. S. Bayesian inference of epistatic interactions in case-control studies. Nature genetics, v. 39, n. 9, p. 1167-1173, 2007. Nature Publishing Group. Disponível em: <http://www.nature.com/ng/journal/vaop/ncurrent/full/ng2110.html>. Acesso em: 29/5/2011.

ZOLLNER, S.; PRITCHARD, J. K. Overcoming the winner's curse: estimating penetrance parameters from case-control data. American journal of human genetics, v. 80, n. 4, p. 605-15, 2007. Disponível em:

$<$ http://www.pubmedcentral.nih.gov/articlerender.fcgi?artid=1852705\&tool=pmcentr ez\&rendertype=abstract $>$. Acesso em: 23/8/2013. 


\section{Apêndice - Programas-fonte}

As variáveis e comentários dos programas abaixo estão em inglês.

\section{SNPdist.c}

/*

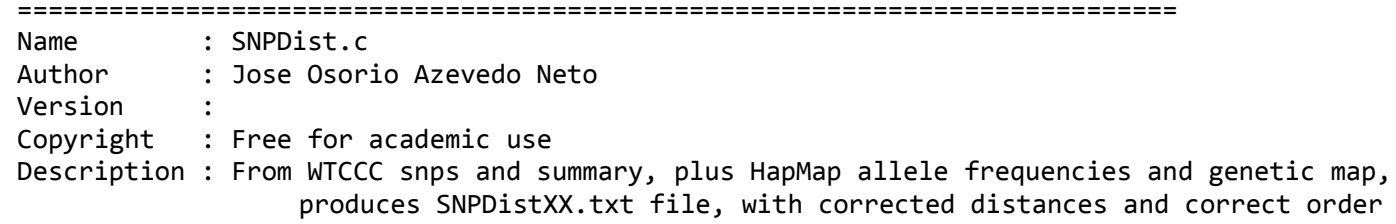

\#define MAXSNPS 41500

\#define MAXZERO 1600

\#define MAXLINE 300
// Max number of SNPs (WTCCC1, Affymetrix, chromosome 2)

// Max number of zeroed positions in snps \& tepd files

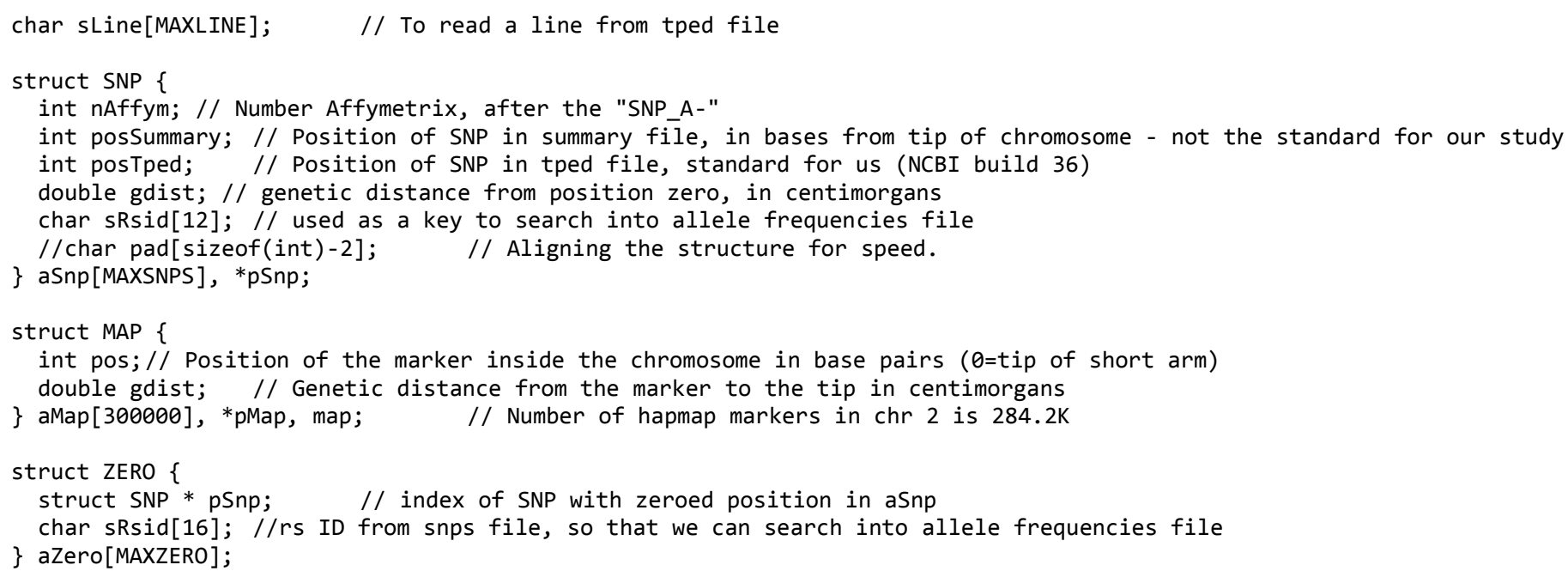


// continually narrow search until just one element remains while (imin < imax)

$$
\{
$$

int $i m i d=(i m i n+i m a x) / 2$;

// code must guarantee the interval is reduced at each iteration assert(imid < imax);

// note: $\theta<=$ imin < imax implies imid will always be less than imax

$/ /$ reduce the search

if (pMap[imid].pos < key)

else

$$
\text { imin = imid }+1 \text {; }
$$

\}

$$
\text { imax = imid; }
$$

// At exit of while:

$/ /$ if $A[]$ is empty, then imax < imin

$/ /$ otherwise imax $==$ imin

// deferred test for equality

if (imax $==$ imin) \{

if (pMap[imin].pos $==$ key) \{

printf("Position not found and then found index\%d pos\%d", imin, key);

\} exit( EXIT_FAILURE);

else $\{/ /$ Found upper neighbor. Now interpolate to return gdist(key) beta $=(\operatorname{aMap}[$ imin $] \cdot$ gdist-aMap $[$ imin-1].gdist $) /($ aMap $[$ imin $] \cdot p o s-a M a p[i m i n-1] \cdot p o s) ;$

\} return aMap[imin-1].gdist + beta * (key-aMap[imin-1].pos);

else return 0 ;

int main( int argc, char **argv) \{

int $i, j$;

char sFile[260];

FILE *fSumm, *fSnpw, *fMap, *fSnps, *ffreq;

char sChrom[4], sChr[12]; //Supports chromosome up to 99, plus X, Y and XY. Chr3 file brings wrong long chromosome char sSnpId[16], sRsid[16];

int iPosition, pos;

int nSnps;

char ${ }^{*} p$;

int nAffym, nExcluded, nZeros, nSolved;

int nMap, zeroed, interpolated; // Number of markers in the HapMap genetic map file; number of positions corrected with genetic map

setvbuf(stdout, NULL, _IONBF, $\theta$ ); // Workaround to avoid fflush(stdout) in Eclipse console.

// I hope it won't hurt normal console. If it does, I'll enclose this in \#ifdef DEBUG

// Greetings and print parameters

puts("Generates SNPs files with correct distances");

printf("argc=\%d Exe=", argc);

$\operatorname{puts}(\operatorname{argv}[0])$;

for $(i=1 ; i<\operatorname{argc} ;++i)$

printf("\n");

printf("p\%d=\%s ",i, argv[i]);

if( argc !=5) \{

puts("Usage: snpdist summary_snp_file geneticmapfile snpsfile allelefrequenciesfile");

puts("summary_snp_file is the WTCCC summary file for a disease and a chromosome. Example:");

puts ("WTCCC_7_Diseases $\backslash$ WTCCC_summary_data $\backslash \backslash 7$ Diseases $\backslash \backslash B D \backslash \backslash$ snptest_BD_22.txt") ; puts("geneticmapfile is the Hapmap file with recombination rates. Ex:

C: \\HapMap \\GeneticMap \genetic_map_chr22_b36.txt"); puts("snpsfile is the WTCCC SNPS file that accompany the tped file.");

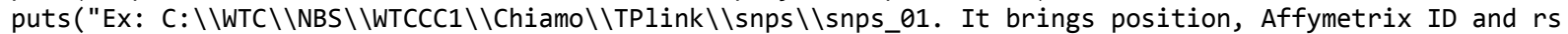

ID"); puts("allelefrequenciesfile comes from Hapmap. Ex:

C: \\HapMap \\Frequencies \\allele_freqs_chr22_CEU_r28_nr.b36_fwd.txt"); // We need a different summary SNP file for each chromosome, but the disease is not important, // since all 7 diseases datasets and the two controls datasets have the same set of included SNPs \} return EXIT_FAILURE;

strcpy( sFile, argv[3]);

$\mathrm{p}=\mathrm{sFile}+\mathrm{strlen}(\mathrm{sFile})-2 ; / /$ assumes snps filename ends in chromosome, with no extension

strcpy ( sChrom, p);

printf("Chromosome $=\% s \backslash n "$, sChrom);

fSumm $=$ fopen $(\operatorname{argv}[1], " r ")$;

if ( fSumm $==$ NULL) \{

printf("Error opening summary file \%s $\backslash n ", \operatorname{argv}[1])$;

return EXIT_FAILURE; 
// Read summary SNP file into array aSNP, in order to get reference alleles and not excluded SNPs if $($ fgets ( sLine, MAXLINE, fSumm) $==$ NULL) $\{$ // skip first line - do not parse; will work only with WTCCC1 data puts("Error skipping 1st line of SNP file");

\} return EXIT_FAILURE;

$i=0 ; / / i$ count SNPs here

while (!feof(fSumm) \&\& (fscanf(fSumm, "\%29s\%15s\%d", sSnpId, aSnp[i].sRsid, \&iPosition) == 3)) \{ aSnp [i].nAffym = strtol(sSnpId+6, NULL, 10);// +6: skip "SNP_A-" aSnp [i].posSummary = iPosition;

$++i$;

if (fgets ( sLine, MAXLINE, fSumm) $==$ NULL) $\{/ /$ skip the rest of the line puts("Error when reading SNPs of file");

\} return EXIT_FAILURE;

\}

nSnps $=i$

fclose ( fSumm);

printf("Summary file read with \%d SNPs \n",nSnps);

qsort( aSnp, nSnps, sizeof(struct SNP), \&compareSnp); // Sort by Affym ID to allow binary search

//Reads snps file with distances and alternative rsID

// snps file brings distances identical to tped file

fSnps = fopen $(\operatorname{argv}[3], " r ")$;

if (fSnps $==$ NULL) \{

printf("Error opening snps file \%s\n", argv[3]);

\} return EXIT_FAILURE;

$i=n E x c l$ luded $=0$;

while (!feof(fSnps) \&\& (fscanf( fSnps, "\%9s\%d\%*s\%29s\%15s", sChr, \&iPosition, sSnpId, sRsid) == 4)) \{ // Search sSnpId in asnp. If not found, ignore. If found, fills in posTped. nAffym = strtol(sSnpId+6, NULL, 10); // +6: skip "SNP_A-" pSnp = bsearch(\&nAffym, aSnp, nSnps, sizeof(struct SNP), \&compareSnp); if $(\mathrm{pSnp}==\mathrm{NULL}) / /$ SNP not found ++ nExcluded;

else $\{$ // SNP found pSnp->posTped = iPosition; // If posTped is zero or sChr is wrong, store index into PosZero array and store sRsid in it if $(\operatorname{strlen}(s C h r)==1)\{/ /$ If Chromosome is one digit only, tranforms in two to compare $\operatorname{sChr}[2]=0$; $\mathrm{sChr}[1]=\mathrm{sChr}[0]$;

\} $\operatorname{schr}[0]=' 0$ ';

if(strcmp( sChr, sChrom) || iPosition == $\theta)\{$ aZero[i].pSnp = pSnp; // These pointers are valid only while aSnp is sorted by Affym ID strcpy( aZero[i].sRsid, sRsid); $++i$;

if $(i>=\operatorname{MAXZERO})\{$

puts("Numero de zeros maior que MAXZERO"); \} return( EXIT FAILURE);

\}

nZeros = $i$;

fclose(fSnps);

printf("Distances read from snps file. \%d positions are zero; \%d are excluded \n", nZeros, nExcluded);

// Reads allele frequency file to find positions that are zeroed on snps file

fFreq $=$ fopen $(\operatorname{argv}[4], " r ")$;

if ( fFreq $==$ NULL) \{

printf("Error opening allele frequencies file \%s", argv[4]);

\} return( EXIT_FAILURE);

if (fgets( sLine, MAXLINE, fFreq) $==$ NULL) $\{$ // skip first line - do not parse; will work only with wTCCC1 data puts("Error skipping 1st line of allele frequencies file");

\} return EXIT_FAILURE;

$j=n$ Solved $=0$;

while (!feof(fFreq) \&\& (fscanf( fFreq, "\%15s\%*s\%d", sRsid, \&iPosition) == 2)) \{

$++j$;

if ( fgets ( sLine, MAXLINE, fFreq) $==$ NULL) \{

printf("Error reading remainder of line in allele frequencies file \%s line \%d \n", argv[6],i);

\} return EXIT_FAILURE;

p = strstr ( sLine, "SNP A-"); // Searches for Affym ID inside assay field if $(p)$

nAffym $=\operatorname{strtol}(p+6$, NULL, 10); // +6: skip "SNP_A-" 
else nAffym $=-1$;

for ( $i=0 ; i<$ nZeros; $++i)$

if $($ (pSnp = aZero[i].pSnp) != NULL) // Only compares if not solved yet

if( !strcmp( sRsid, pSnp->sRsid) || !strcmp( sRsid, aZero[i].sRsid) || nAffym == pSnp-

$>$ nAffym) \{

// For most cases, all three comparisons will be done and will be unsuccessful pSnp->posTped = iPosition;

aZero[i].pSnp = NULL; // Marks as solved

$++n S o l v e d$;

printf("pfix SNP_A-\%d \%s \%s \%s SNP_A-\%d \%d\n", pSnp->nAffym, pSnp->sRsid,

aZero[i].sRsid, sRsid, nAffym, iPosition);

break; // if it solved this zeroed position, it will not solve any other

\}

fclose ( fFreq);

printf("Allele Freq file \%d lines could solve \%d cases of zeroed positions \n", j, nSolved);

// Process HapMap genetic map file to get centimorgans

fMap = fopen $(\operatorname{argv}[2], " r ")$;

if $($ fMap $==$ NULL $)\{$

printf("Error opening genetic map file \%s \n", argv[2]);

\} return EXIT_FAILURE;

// Read genetic map file into array aMap, with positions and genetic distances

if ( fgets( sLine, MAXLINE, fMap) $==$ NULL) $\{/ /$ skip first line puts("Error skipping 1st line of MAP file"); return EXIT_FAILURE;

$i=0 ; / / i$ count HapMap markers here

while( !feof(fMap) \&\& (fscanf(fMap, "\%d\%*f\%lf\n",\&aMap[i].pos,\&aMap[i].gdist) == 2)) $++i$

nMap $=i$;

fclose( fMap);

printf("Genetic map file read with \%d markers $\backslash n$ ", nMap);

// First, re-sort SNP file by position

qsort ( aSnp, nSnps, sizeof(struct SNP), \&comparePos);

zeroed $=$ interpolated $=0$;

for $(i=0$; $i<n S n p s ;++i)\{/ /$ Search only after 1 because it will need previous SNP data if (aSnp[i].postped $=0$ ) $\{/ /$ if tped position is zeroed (few cases), infer it from summary position and previous SNP positions

$$
\text { pos }=\operatorname{aSnp}[i] \cdot \operatorname{posSummary} ;
$$

if( $i<$ nSnps-1 \&\& aSnp[i+1].posTped $!=0$ \&\& aSnp[i+1].posSummary-pos< pos-aSnp[i-1].posSummary) \{ // Fix based on next SNP

aSnp [i].posTped = aSnp [i+1].posTped - (pos-aSnp [i+1].posSummary)

printf("Fix per next SNP_A-\%d i\%d ps\%d pt\%d baseSNP_A-\%d \n",aSnp[i].nAffym, i, pos,

aSnp[i].posTped, aSnp[i+1].nAffym);

\} else $\{/ /$ Fix based on previous SNP

aSnp $[i] \cdot$ posTped $=$ aSnp $[i-1] \cdot$ posTped $+($ pos-aSnp $[i-1] \cdot \operatorname{posSummary})$;

printf("Fix per previous SNP A-\%d i\%d ps\%d pt\%d baseSNP A-\%d\n",aSnp[i].nAffym, i, pos,

aSnp[i].posTped, aSnp[i-1].nAffym);

\}

++ zeroed;

map.pos $=$ aSnp $[i] \cdot$ posTped;

pMap = bsearch(\&map, aMap, nMap, sizeof(struct MAP), \&compareMap);

if $($ pMap $==$ NULL $)$ ?

// printf("Could not find tped pos\%d into genetic map - ", map.pos);

// Redo binary search in order to find neighbor positions and interpolate

aSnp[i].gdist = binary_search ( aMap, map.pos, 0, nMap);

\}

++ interpolated;

else aSnp [i].gdist = pMap->gdist;

qsort( aSnp, nSnps, sizeof(struct SNP), \&comparePos); // With all posTped filled, now sort is stable.

printf("TPed positions corrected with gen map: \%d zeroed; \%d interpolated \n", zeroed, interpolated);

// Write SNP distances file

strcpy (sFile, "snpdist");

strcat (sFile, sChrom);

strcat(sFile, ".txt");

fSnpw = fopen (sFile, "w");

if ( fSnpw $==$ NULL $)\{$

printf("Error opening SNP output file $\backslash n ")$;

\} return EXIT_FAILURE;

for ( $i=0 ; i<n S n p s ;++i)$

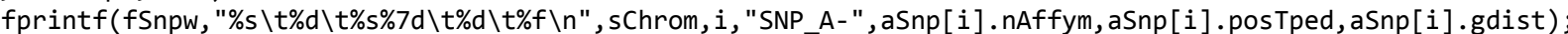

fclose(fSnpw);

puts("SNP file with distances generated."); 


\section{RefAllele.c}

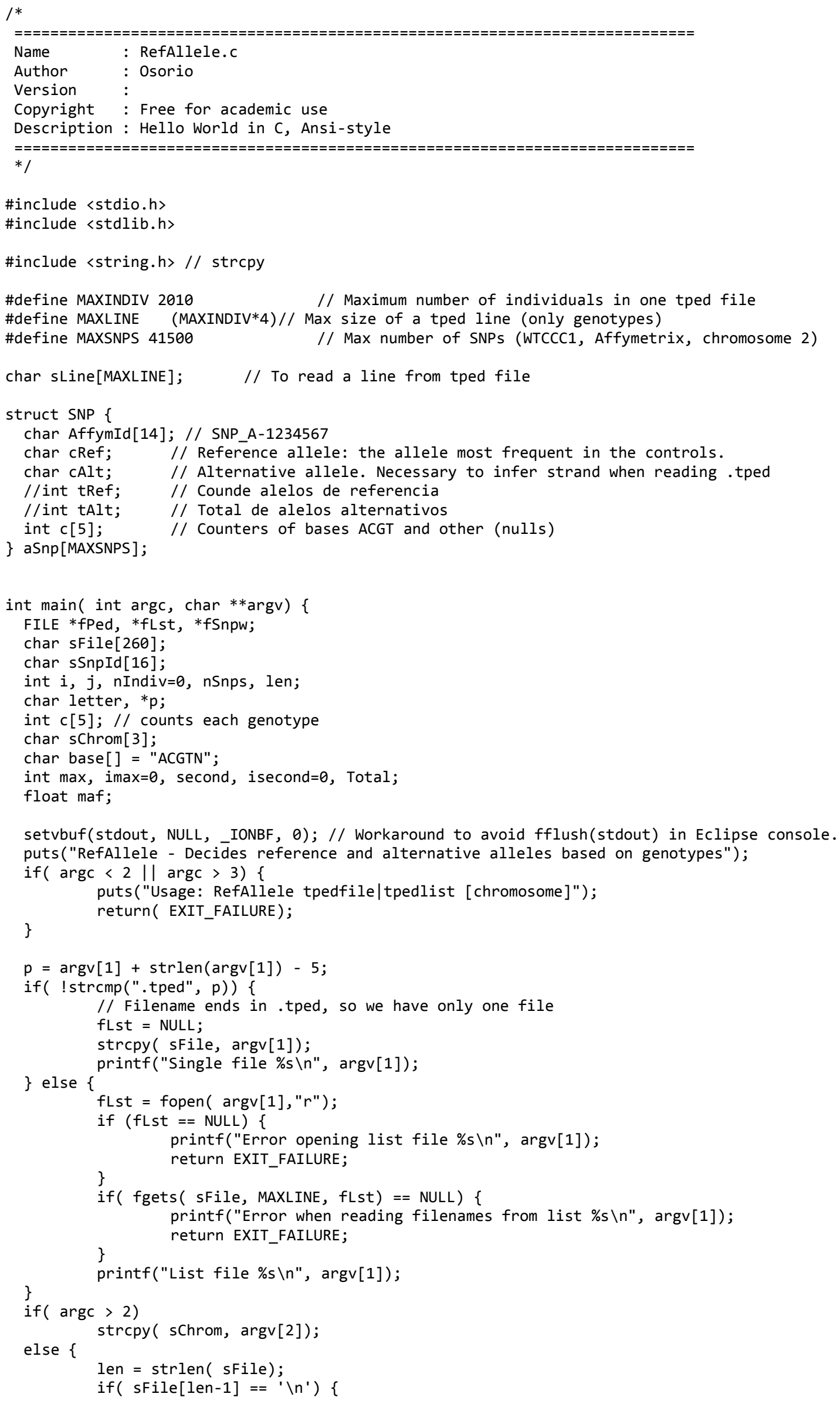




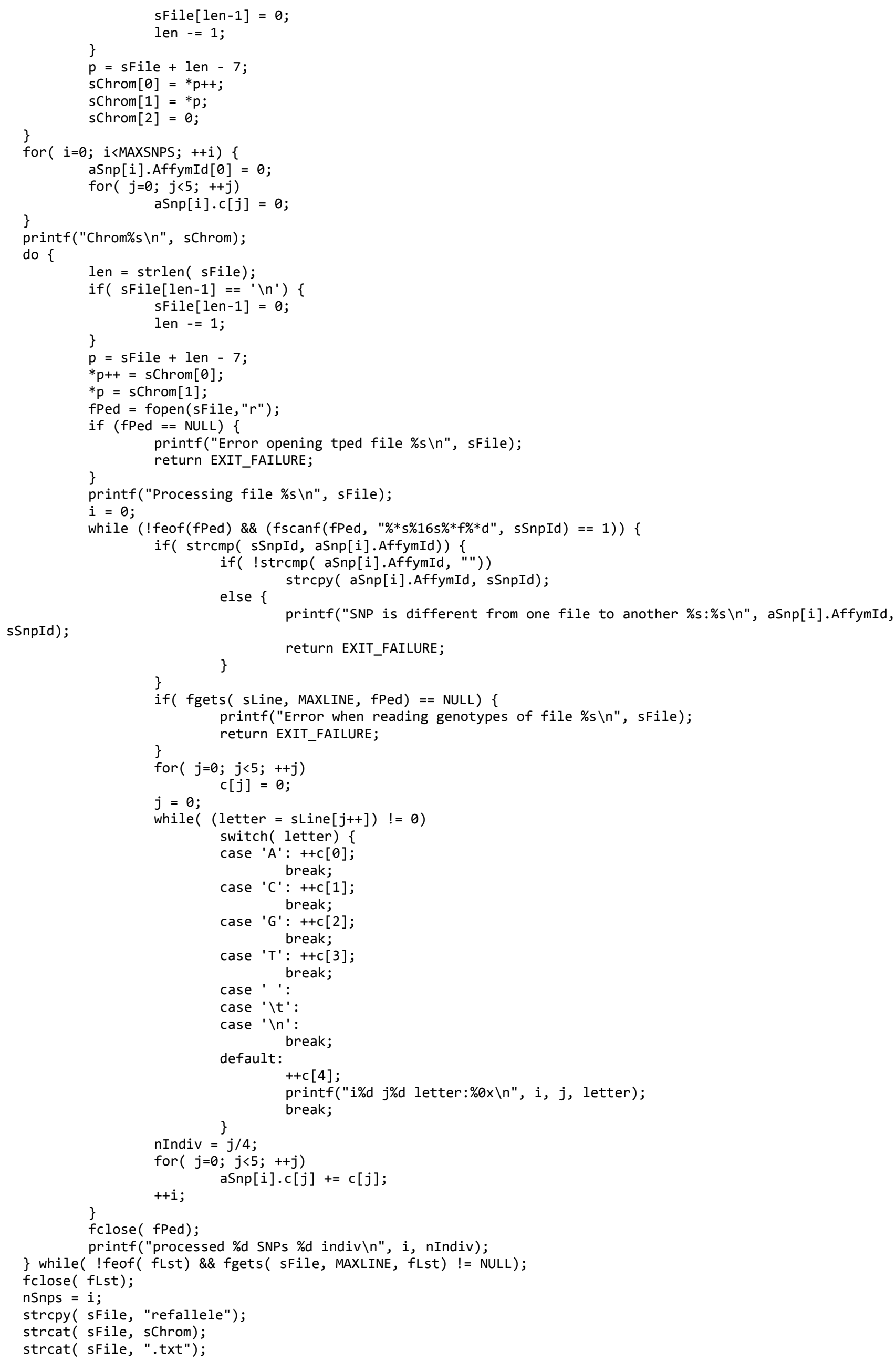




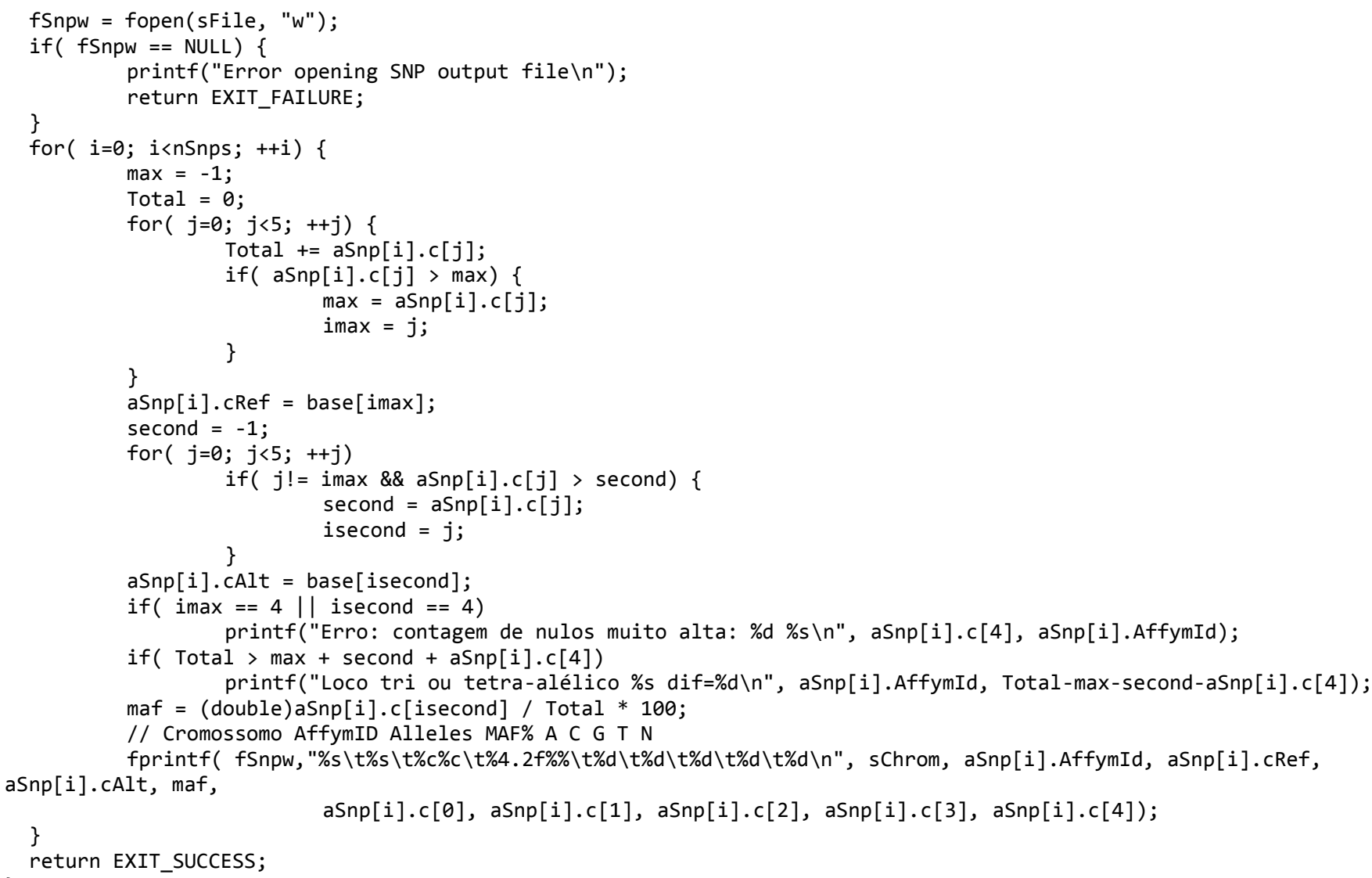

\section{MakeSNPsFile.R}

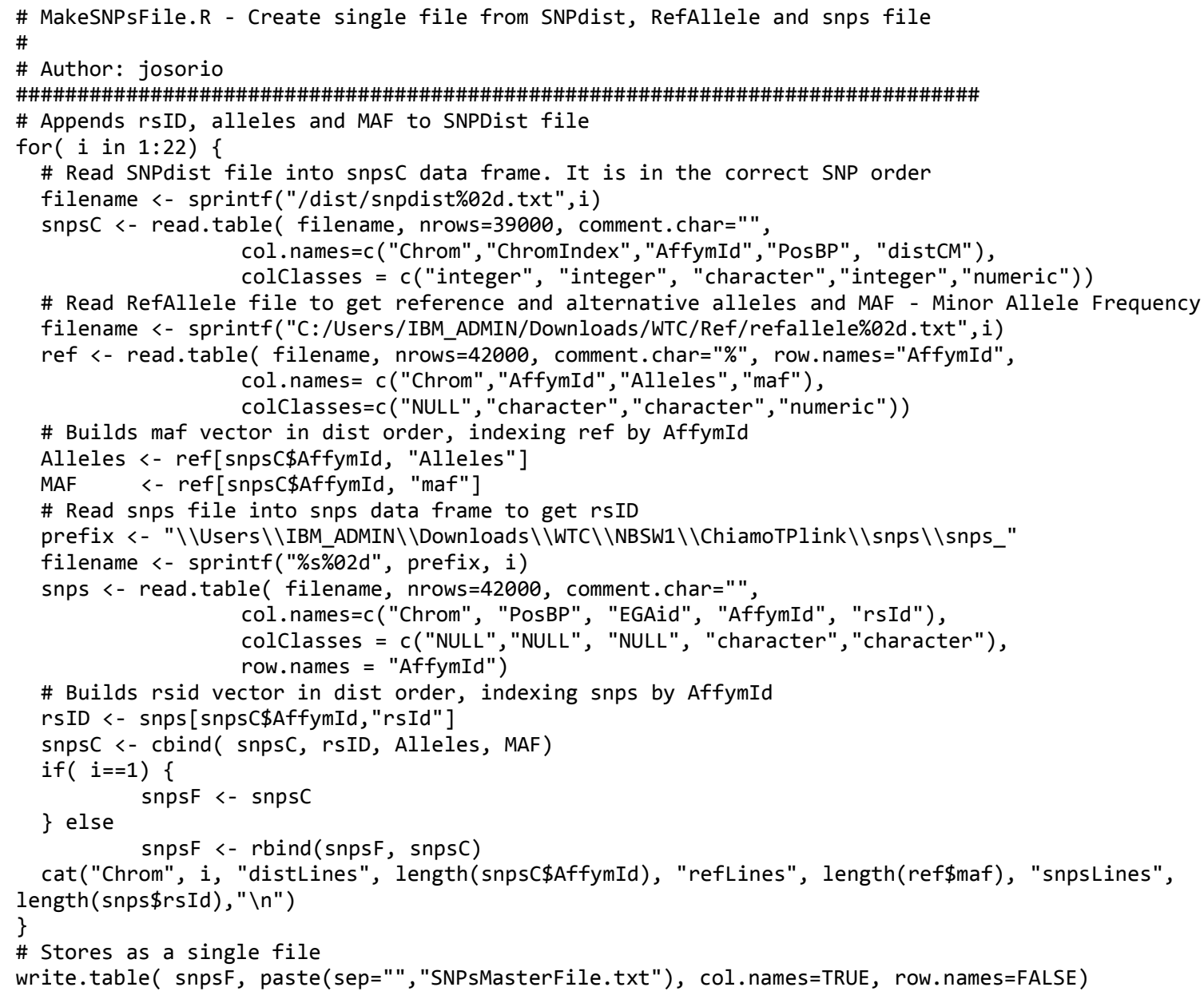




\section{SampleDisease. $R$}

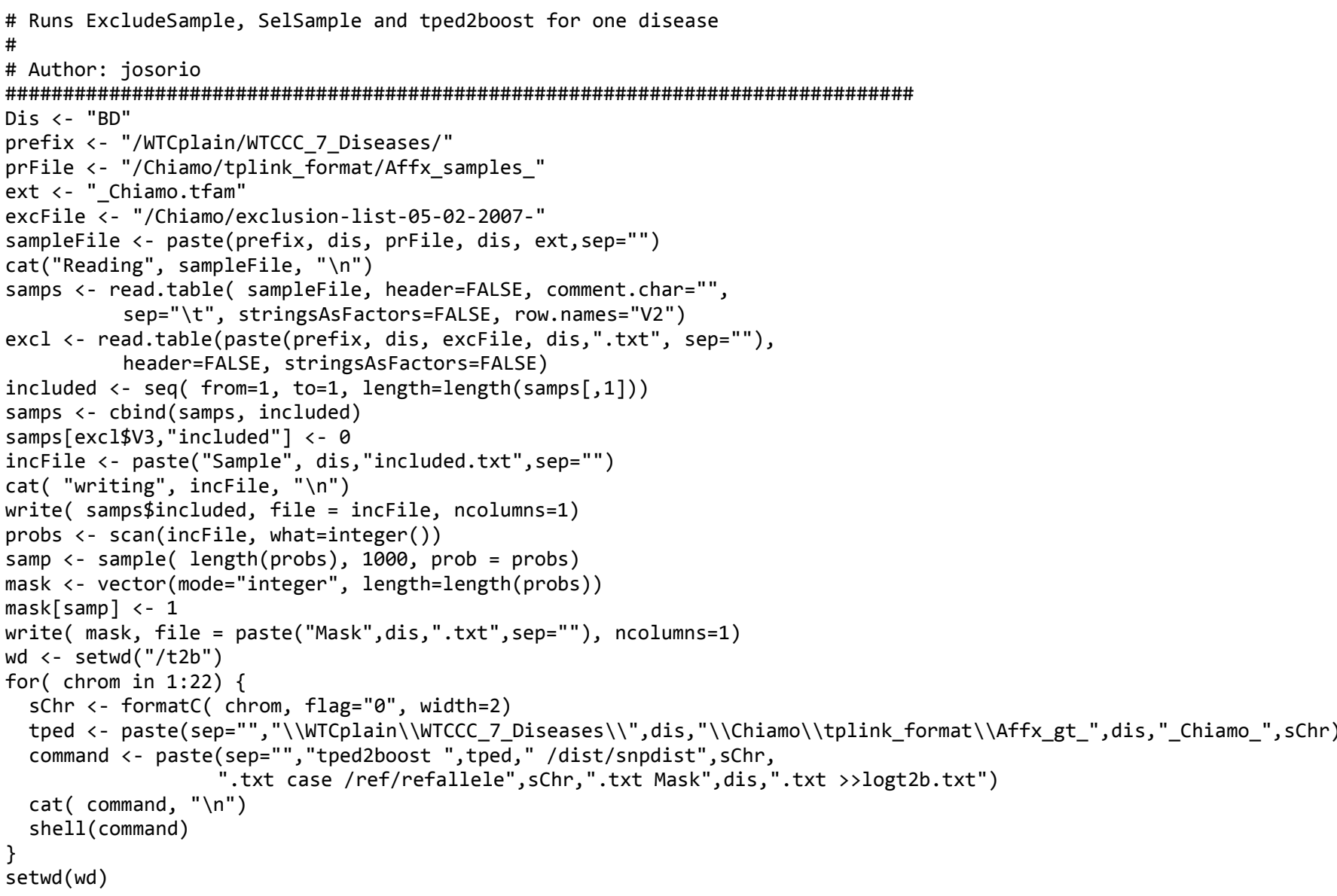

\section{tped2boost.c}

/*

\begin{tabular}{|c|c|}
\hline Name & : tped2boost.c \\
\hline Author & : Jose Osorio Azevedo Net \\
\hline Version & $:$ \\
\hline Copyright & : Free for academic use \\
\hline
\end{tabular}

Description : Convert genotypes from tped (transposed Plink pedigree - 1 line per SNP) - to Boost format - 1 line per individual

2012-10-17 Refactored - stripped out of SNPDist and RefAllele functions. Now supports sample exclusion $* 1$

\#include 〈stdio.h〉

\#include <stdlib.h>

\#include <string.h>

\#include <search.h〉

\#include 〈time.h〉

\#include <assert.h〉

\#define MAXINDIV 2010 // Maximum number of individuals in one tped file

\#define MAXLINE (MAXINDIV*4)// Max size of a tped line (only genotypes)

\#define MAXSNPS 41500 // Max number of SNPS (WTCCC1, Affymetrix, chromosome 2)

char sLine[MAXLINE]; // To read a line from tped file

char mGeno[MAXINDIV][MAXSNPS*2+4]; // Genotype matrix. Filled column by column with data from tped file, then written line by line into .boost file

int SelSample[MAXINDIV]; // 0 if sample should be excluded from boost file; 1 otherwise.

struct SNP \{

int nAffym; // Number Affymetrix, after the "SNP A-"

int index; // To preserve column number after sorting by Affym ID

//char pad[sizeof(int)-2]; // Aligning the structure for speed.

\} aSnp [MAXSNPS], *pSnp;

int comparesnp ( const void *a1, const void *a2) \{ // Compare function to sort and search const struct SNP *p1 = (const struct SNP *) a1;

const struct SNP $* \mathrm{p} 2=$ (const struct SNP *) a 2 ; 
int main( int argc, char **argv) \{

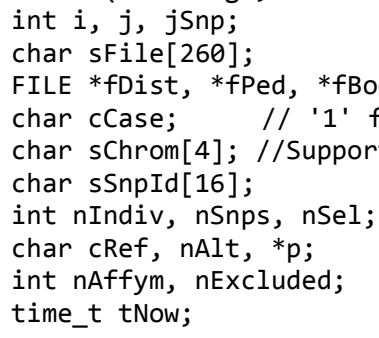




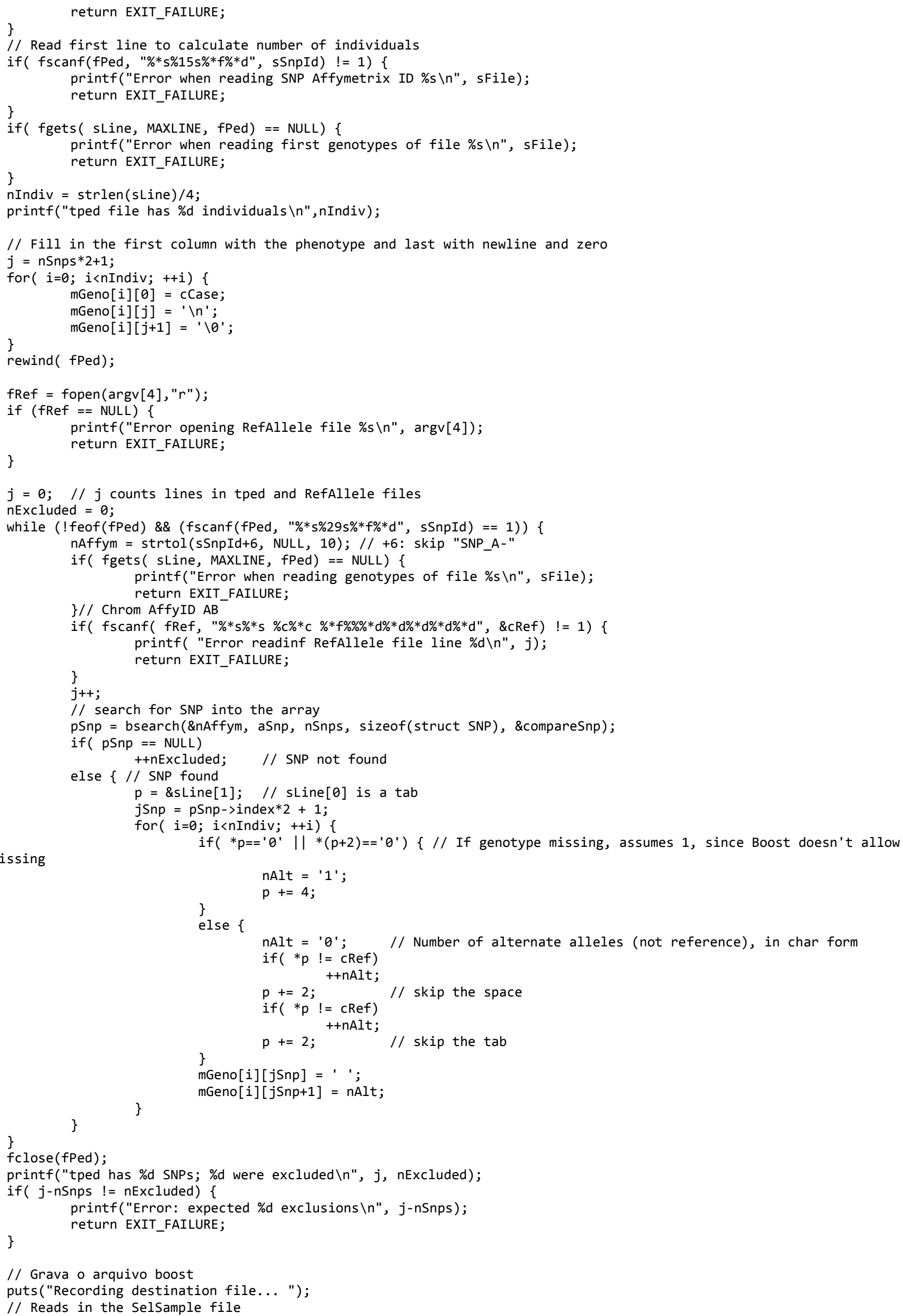




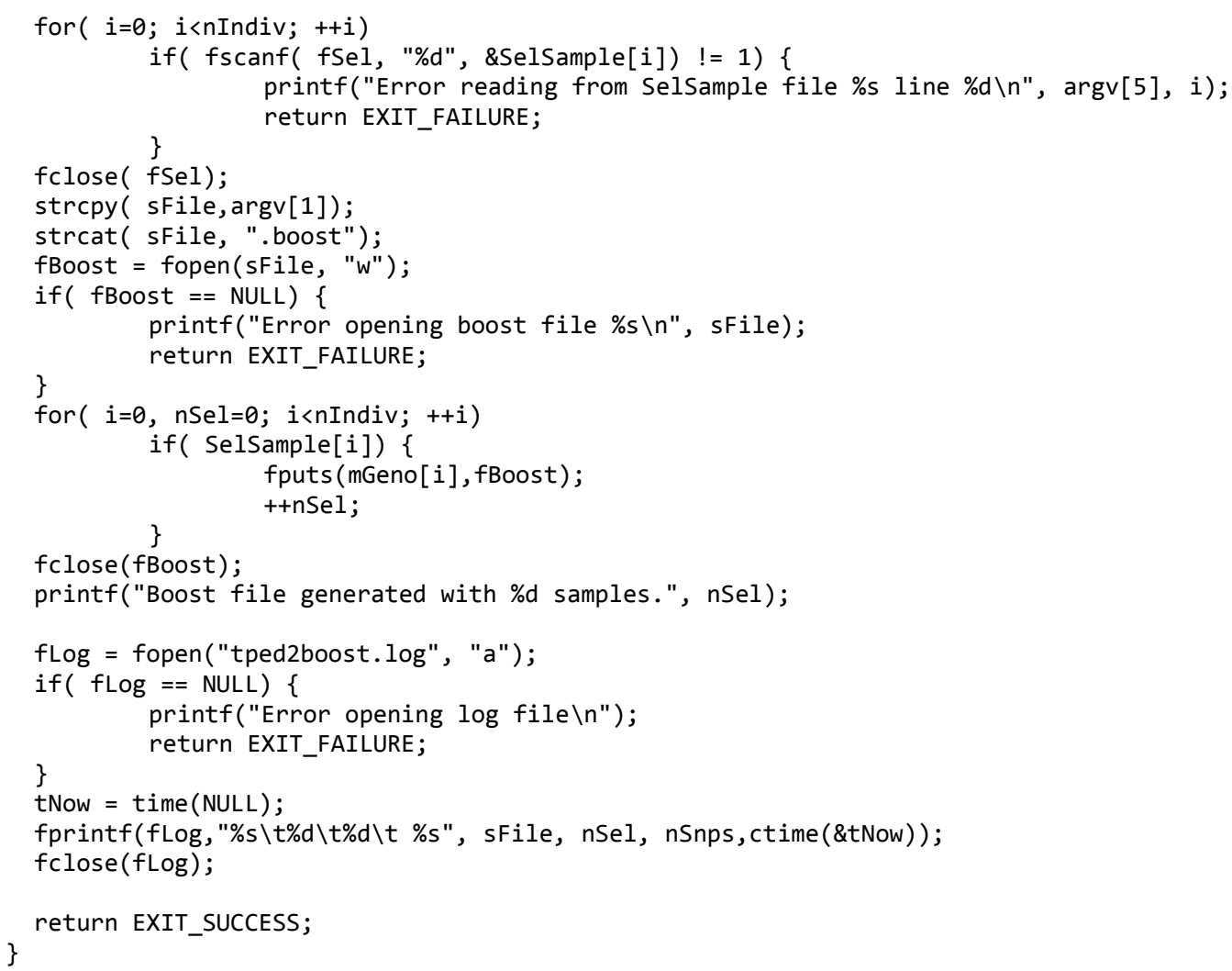

\section{Troost. $R$}

\# Search from interacting trios from pair information

\# Run the whole cycle for a single disease

\# Concatenate boost files, run GBoost, run mMreduction.R and TriosFromPairs.exe

\# Author: josorio

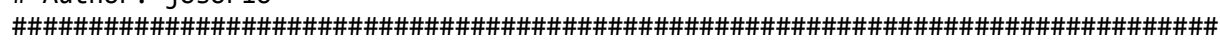

dis <- "58C"

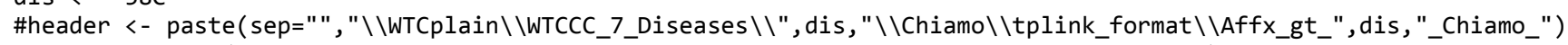

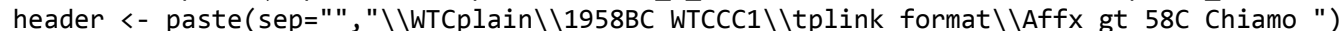

\#Concatenate case and control boost files

wd <- setwd("/t2b")

for ( chrom in 1:22) \{

sChr <- formatC( chrom, flag="0", width=2)

tped <- paste (sep="", header, sChr)

command <- paste(sep=" ", "copy tped \\Affx_gt_NBS_Chiamo_", sChr, ".boost + ", tped, cat ( command, "\n")

\# Assemble boost input file <Dis>full.txt setwd("/Users/Osorio/Documents/GBoost")

full <- vector (mode="character")

for ( chrom in 1:22) \{

sChr <- formatC ( chrom, flag=" $0 "$, width=2) \} 
\}

else allsnps <- rbind(allsnps, snpsC)

$\mathrm{rm}(\mathrm{snpsC})$

nsnps <- length(allsnps\$Chrom)

row.names(allsnps) <- $c(0:(n s n p s-1))$ \# This allows to index snps by the Boost index even after reducing the table \#Calculates absolute distance

allsnps <- cbind(allsnps, absdist=allsnps\$Chrom*1000 + allsnps\$DistcM)

cat("Analyzing disease:", dis," $\backslash n "$ )

\#Read pairs from GBoost

IntRecords <- read.table(paste(sep=" ", "GPUInteractionRecords", dis, ".txt"), col.names=c("PairIndex", "SNP1", "SNP2",

"Effect1", "Effect2", "IntBoost", "IntPlink"),

nrows $=420000$, comment. char $="$ ", row. names $=1$, colclasses $=c($ "integer",

"integer", "integer", "numeric", "numeric", "numeric", "NULL"))

Pairs <- IntRecords[IntRecords\$IntBoost >= 34, ] \# Select only strong pairs

cat( "Pairs:", length(IntRecords\$SNP1), "; strong:", length(Pairs\$SNP1), "\n")

rm(IntRecords)

\#Remove pairs with mutual distance too small

PairDist <- allsnps\$absdist [Pairs\$SNP2+1] - allsnps\$absdist [Pairs\$SNP1+1]

Pairs <- Pairs[PairDist >= 0.1 , ]

cat("Distant pairs:", length(Pairs\$SNP1), "; close pairs:", sum(PairDist < 0.1 ), "\n")

rm(PairDist) \# Does not keep pair distances in pair table. It is easy to keep if we need

\# Select only SNPs present in the strong Pairs

InPairs <- c(Pairs\$SNP1, Pairs\$SNP2)

InPairs <- sort(unique(InPairs)) \#Boost indices of snps present in the strong Pairs

snpsp <- allsnps[InPairs+1,] \# add 1 because $R$ indices start in 1

cat( "SNPs:",nsnps, "; In Pairs:", length(snpsp\$Chrom), "\n")

\#Calculate milimorgans - regions with many SNPs

isDbig <- diff(snpsp\$absdist) $>=0.02$

snpsp <- cbind ( snpsp, $\mathrm{mM}=\mathrm{c}(1$, cumsum(isDbig $)+1))$

\#Measure how big is each milimorgan

mMsize <- snpsp\$absdist[c(isDbig, TRUE)] - snpsp\$absdist[c(TRUE, isDbig)]

cat("mMs:", length(mMsize)," $\max$ size:", $\max (m M s i z e), ">0.1: "$, sum(mMsize >0.1)," $\backslash n "$ )

\# snpsp contains only snps in pairs, so it cannot be indexed directly by snp number.

\# However, the row names in snpsp are the snp numbers, so let's index by name

$\mathrm{mM}<-$ snpsp[paste(Pairs\$SNP1), "mM"]

Pairs <- cbind(Pairs, mM1=mM)

mM <- snpsp[paste(Pairs\$SNP2), "mM"]

Pairs <- cbind(Pairs, mM2=mM)

$\mathrm{rm}(\mathrm{mM})$

\#Remove pairs in the same milimorgan

cat("Pairs in same mM:", sum(Pairs\$mM1 == Pairs\$mM2), "\n")

Pairs <- Pairs[Pairs\$mM1 != Pairs\$mM2, ]

\#Eliminate redundant pairs of milimorgans. First, sort Pairs by mMs and IntBoost

Pairs <- Pairs [order (Pairs\$mM1, Pairs\$mM2, -Pairs\$IntBoost), ]

nPairs <- length (Pairs\$mM1)

redundant $<-$ vector $($ mode $=$ "logical", length = nPairs $)$

redundant [1] <- FALSE

redundant [-1] <- Pairs\$mM1[-nPairs]==Pairs\$mM1[-1] \& Pairs\$mM2[-nPairs]==Pairs\$mM2[-1]

mM1 <- Pairs\$mM1[! redundant]

mM2 <- Pairs\$mM2[! redundant]

cat ("Non-redundant pairs:", length (mM1), "\n")

\#Write pairs of milimorgans to be read by program TriosfromPairs

write.table( data.frame( mM1, mM2), paste( sep="", "mMR", dis,".txt"), row.names=FALSE, col. names=TRUE)

write.table( Pairs, paste(sep="", "Pairs", dis,".txt"), row.names=TRUE, col.names=TRUE)

write.table( Pairs[!redundant, ], paste(sep=" ", "nrPairs", dis, ".txt"), row.names=TRUE, col. names=TRUE)

write.table( snpsp, paste(sep="", "SNPsInPairs", dis,".txt"), row. names=TRUE, col.names=TRUE)

cat("TriosFromPairs for disease:", dis, "\n")

shell(paste(sep="", "TriosFromPairs ", "mMR", dis,".txt", " triosr",dis,".txt"))

\# Now runs mM2SNP

mM2snp <- function ( $\mathrm{mm} 1, \mathrm{~mm} 2)$ \{

cat("Pair of mMs:", mm1, mm2, "\n")

par <- nrPairs[nrPairs $\$ m M 1==m m 1 \&$ nrPairs $\$ m M 2==m m 2$,

\}

$c($ par\$SNP1, par\$SNP2) \# return vector snp

maf <- scan ("MAF.txt")

\#Diseases <- c("CAD", "CD", "HT", "RA", "T2D", "T1D")

\#for( dis in Diseases) \{

trios <- as.matrix(read.table(paste(sep="","triosr", dis, ".txt"))) \# Output from TriosFromPairs.exe

ntrios <- length(trios [,1])

cat(ntrios, "trios read from", paste(sep="","triosr", dis, ".txt"), "\n")

nrPairs <- read.table(paste(sep="", "nrPairs", dis, ".txt"))

same <- data.frame $(\mathrm{mM}=\mathrm{c}(1: 3), \operatorname{SNP} 1=\mathrm{c}(1: 3), \operatorname{SNP} 2=\mathrm{c}(1: 3))$

for ( $\operatorname{tr}$ in 1:ntrios) \{

cat("Processing trio", tr, "\n")

same \$mM <- trios [tr, ]

same\$SNP1[1:2] <- mM2snp(trios[tr,1], trios[tr, 2])

snp <- mM2snp(trios[tr, 1], trios[tr, 3]) 


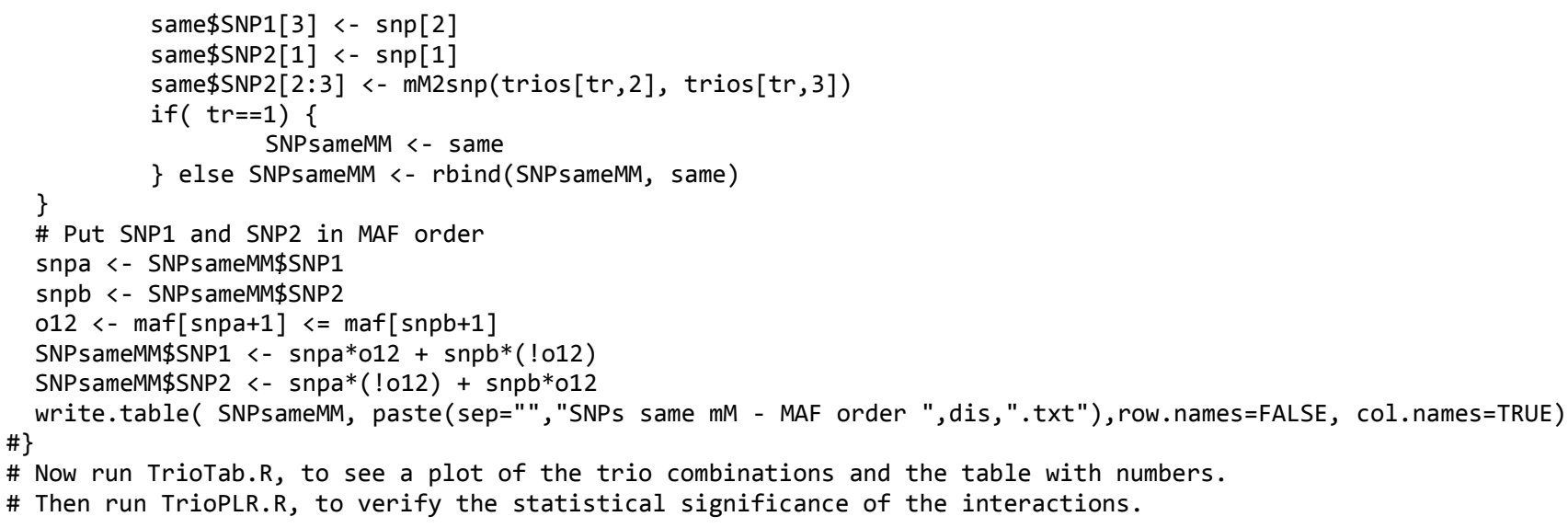

\section{TriosFromPairs.c}

/*

\begin{tabular}{|c|c|}
\hline Name & : TriosFromPairs.c \\
\hline Author & : Jose Osorio Azevedo-Neto \\
\hline Version & : \\
\hline Copyright & : Free for academic use \\
\hline $\begin{array}{l}\text { Description } \\
\text { list of pa }\end{array}$ & $\begin{array}{l}\text { : Generate potential interacting trios of genetic markers from a } \\
\text { rs with signs of interaction }\end{array}$ \\
\hline
\end{tabular}

* /

$1^{*}$ The pairs and trios we deal hear are not pairs of SNPs, although they are closely related with them.

* They are pairs and trios of small chromosomic regions called milimorgans, which include one or more SNPs

* Input file: text, tab-separated, with two milimorgans in each line. At least one pair of SNPs, one in

* each milimorgan, passed an InteractionBoost treshold

$* /$

\#include 〈stdio.h〉

\#include 〈stdlib.h〉

\#define MAXMMS 40000 // max number of milimorgans

\#define MAXPAIRS 140 // max number of pairs for one milimorgan

int mMPair[MAXMMS][MAXPAIRS]; // One row for each mM, listing all mMs which pair with it

int nPairs[MAXMMS]; // Number of pairs for each $\mathrm{mM}$.

int main( int argc, char **argv) \{

int $i, j, k, 1$;

FILE *fPairs, *fTrios;

int $\mathrm{mM} 1, \mathrm{mM} 2$;

int maxmM; // Largest $\mathrm{mM}$ in pair file

int $\mathrm{np} ; / /$ number of pairs in pair file

int nTrios=0; // Number of trios found

int nmM2pairs=0; // Number of mMs that show up in 2 or more pairs

\#ifdef DEBUG

setvbuf(stdout, NULL, _IONBF, 0); // Workaround to avoid fflush(stdout) in Eclipse console. \#endif

puts("Triosfrompairs - Find potential trios of genetic markers from a list of pairs");

if $(\operatorname{argc} !=3)\{$

puts("Usage: TriosFromPairs pairfile triofile");

puts( "Reads pairfile and generates triofile, both tab-separated");

\} return( EXIT_FAILURE);

fPairs = fopen $(\operatorname{argv}[1], " r ")$;

if ( fPairs $==$ NULL) \{

printf("Error opening pairfile \%s\n", argv[1]);

\} return EXIT_FAILURE;

if( fscanf( fPairs, "\%*s\%*s") != 0) \{ // skip first line puts("Error skipping 1st line of pair file");

\} return EXIT_FAILURE;

for $(i=0 ; i<M A X M M S ;++i)$

$\operatorname{maxmM}=0$;

nPairs $[i]=0$;

$\mathrm{np}=0$;

while (!feof(fPairs) \&\& (fscanf(fPairs, "\%d\%d", \&mM1, \&mM2) == 2)) \{// At each pair read

if ( mM1 > MAXMMS ||$m M 2>$ MAXMMS $)\{$

printf( "mMs \%d \%d maior que o permitido \%d \n", mM1, mM2, MAXMMS);

\}

return (EXIT_FAILURE); 
if( nPairs[mM1] $>=$ MAXPAIRS || nPairs[mM2] $>=$ MAXPAIRS $)\{$

MAXPAIRS); printf( "Estourou nro de pares $m M 1 \% d$ n\%d mM2\%d n\%d max\%d $\backslash n$ ", mM1, nPairs[mM1], mM2, nPairs[mM2],

\} return( EXIT_FAILURE);

$\mathrm{mMPair}[\mathrm{mM} 1][\mathrm{nPairs}[\mathrm{mM} 1]]=\mathrm{mM} 2 ; / /$ Adds second $\mathrm{mM}$ in the list of first $\mathrm{mM}$

++ nPairs [mM1];

if ( mM1 > maxmM)

$\operatorname{maxmM}=\mathrm{mM1}$

$/ / \mathrm{mMPair}[\mathrm{mM} 2][\mathrm{nPairs}[\mathrm{mM} 2]]=\mathrm{mM1} ; / /$ Adds first $\mathrm{mM}$ in the list of second $\mathrm{mM}$

$/ /++n P a i r s[\mathrm{mM2}]$;

$/ /$ if ( mM2 > maxmM)

$/ / \quad \operatorname{maxmM}=\mathrm{mM} 2$;

\}

$\mathrm{np++}$;

printf("\%d pairs read; maximum=\%d\n", $n p$, maxmM);

fclose( fPairs);

// Now seek pairs of form $A B-A C$ - BC.

fTrios = fopen $(\operatorname{argv}[2], " w ")$;

if $($ fTrios $==$ NULL) \{

printf("Error opening trio file \%s\n", $\operatorname{argv}[2])$;

\} return EXIT_FAILURE;

for $(i=1 ; i<=$ maxmM; $++i) / /$ For each milimorgan with at least 2 pairs if( nPairs[i] $>=2)\{$

++ nmM2pairs;

for $(j=0 ; j<\operatorname{nPairs}[i]-1 ;++j)\{$

$\mathrm{mM1}=\operatorname{mMPair}[i][j]$;

$/ /$ if( nPairs[mM1] $>=2)$

for $(k=j+1 ; k<n P a i r s[i] ;++k)\{$

$\mathrm{mM2}=\operatorname{mMPair}[\mathrm{i}][\mathrm{k}]$

//if( nPairs[mM2] $>=2)\{/ /$ Verify if pair mM1-mM2 exists

// printf("Testa trio \%d \%d \%d \n",i, mM1, mM2);

for $(1=0 ; 1<$ nPairs [mM1]; ++l)

if ( mMPair[mM1][1] ==mM2) \{ // Reports trio i, mM1, mM2 printf("Trio \%d \%d \%d\n", i, mM1, mM2);

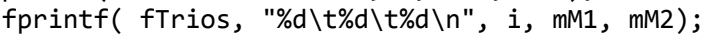
++nTrios;

$/ /\}$

\} break;

\}

\}

\}

printf("Done: \%d trios found in \%d milimorgans in more than 2 pairs $\backslash n "$, nTrios, nmM2pairs);

fclose( fTrios);

\}

return EXIT_SUCCESS;

\section{mM2snp.R}

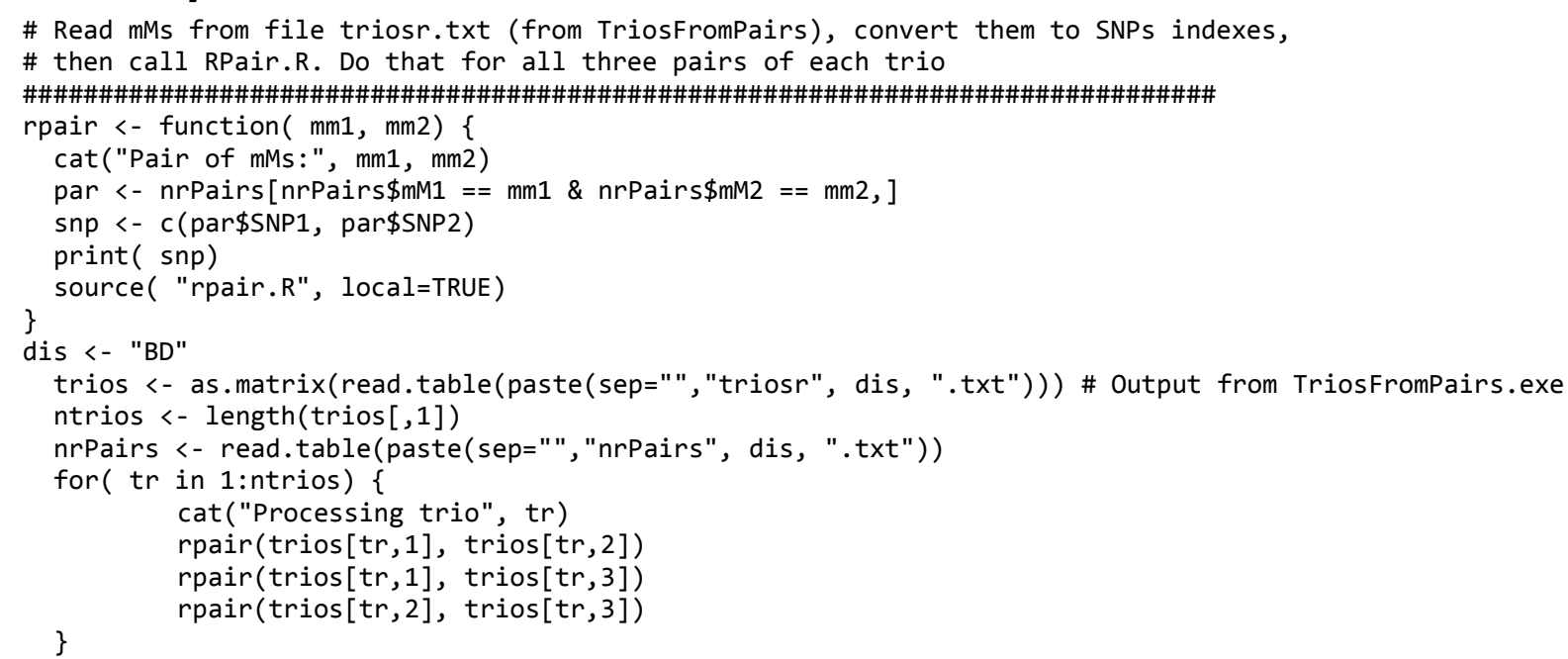




\section{TabTrio.R}

\# Calculates contingency tables of double haplotypes for trios and barplots them

\# Reads mM trios from triosr.txt, output from TriosFrompairs.exe.

\# Reads pairs of SNPs in same mM from file "SNPs same mM - MAF order [dis].txt"

\# For each $\mathrm{mM}$, creates a new factor with the double haplotype for every sample. Then counts all 9

\# double haplotypes, prints table and produces one bar chart for each mM with 9 pairs of bars

\# Then excludes those double haplotypes that represent less than $3 \%$ of the total

\# Then analyze the tree pairs: one table $A \times B, 3<=A B<=9$, and $B$ barcharts for each

\# Then analyze the trio: with $3 \mathrm{mMs}$ represented by its double haplotypes, calculate the contingency

\# table $\sim 5 x \sim 5 x \sim 5 \times 2$. Reorder the dimensions with lower number of levels first (outside loop)

\# and higher number of levels last (inside)

\# Barplot the table

\# Supports mMs with a single SNP

\# Author: josorio

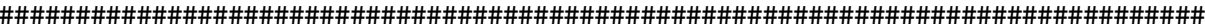

dis $<-$ "CD"

InmM <- read.table(paste(sep="", "SNPs same mM - MAF order ", dis,".txt"), header=TRUE)

nmMs <- length (InmM[,1])

boostprefix <- paste(sep=" ", "C:/Users/IBM_ADMIN/Downloads/WTC/Boost/Affx_gt_", dis)

Chromstart <- scan("Initial SNP indexes.txt")

trios <- as.matrix(read.table(paste(sep="", "triosr", dis, ".txt")))

ntrios <- length(trios $[, 1])$

\#source("subtable.R")\#, echo=TRUE)

dhs <- c("00", "01", "02", "10", "11", "12", "20", "21", "22")

\# AABB AABb AAbb AaBB AaBb Aabb aaBB aaBb aabb

Maior5pc <- vector (mode="integer", length=3)

Maior2pc <- vector (mode="integer", length=3)

HapFreq <- matrix ( nrow=3, ncol=9)

cc <- c("Controle", "Caso")

\#for ( $\operatorname{tr}$ in 1:ntrios) $\{\# \operatorname{tr}$ is the index of the trio

tr $<-1$

trio <- paste (sep="", dis, tr)

windows ( title = paste ( trio, "Individual mM effects"), height=3, width=8.5)

$\operatorname{par}(\operatorname{mfrow}=\mathrm{c}(1,3))$

for ( imM in 1:3) \{

$\#$ imM $<-3$

$\mathrm{mM}<-\operatorname{trios}[\mathrm{tr}, \mathrm{imM}]$

snp <- c(InmM\$SNP1[3*(tr-1)+imM], InmM\$SNP2[3*(tr-1)+imM])

\# Vector snp should contain boost indexes in positions 1 and 2 , with the smaller MAF first print(snp)

chrom $=$ findInterval (snp, Chromstart)

indChrom <- snp - Chromstart [chrom]

cat ("mM=", mM, "Chrom=", chrom[1], "snps:", snp, "indChrom:", indChrom, "\n")

if( chrom[1] != chrom[2]) \{ cat("Error: SNPs are not in the same chromosome")

\} stop( )

chrom <- chrom[1]

file <- paste( boostprefix, formatc(chrom,flag="0", width=2), ".boost", sep=" ")

cnames <- c("Gen1", "Gen2")

ind $<-$ indChrom

Colclass <- c("factor", "integer", "integer")

if( $\operatorname{snp}[1]>\operatorname{snp}[2])\{$

cnames <- c("Gen2", "Gen1")

ind [1] <- indChrom[2]

ind $[2]<-$ indChrom [1]

\} else if( $\operatorname{snp}[1]==\operatorname{snp}[2])\{\#$ single SNP case

cnames <- "Gen1"

Colclass <- c("factor", "integer")

cnames <- c("Case", cnames)

width <- 1 \# Always Read first column, case/control, even if it will not use it

if ( ind[1] !=0) \# If first SNP is not the first in the cromosome width <- c(width, $-2 *$ ind $[1])$ \# Skip columns up to first SNP

width <- c(width, 2) \# read genotype of first SNP. Consider the blank before as one column

if ( ind[2] $>$ ind[1]+1) \# if SNPs are not consecutive, width <- c(width, $-2 *($ ind[2]-ind[1]-1)) \# skip columns between SNPs

if ( ind[2] != ind[1]) width <- c(width, 2) \# read genotype of second SNP, except if single SNP

if (Chromstart[chrom]+ind[2] < ChromStart[chrom+1]) \#If SNP is not the last one of the chromosome, width <- c(width, $-2 *($ Chromstart [chrom+1]-(ChromStart[chrom]+ind[2]))) \#Skip columns after SNP 2

df2 <- read.fwf ( file, width, colclasses=ColClass, header=FALSE, col.names=cnames, sep=" $\backslash \backslash "$, $n=2500$, buffersize $=100$ )

$\mathrm{n}<-$ length (df2\$Gen 1$)$

if ( ind[2] == ind[1]) \#if single snp, copy Gen1 into Gen2. Levels should be 00,11 and 22 df2\$Gen $2<-$ df $2 \$$ Gen 1

comb <- paste $(d f 2 \$$ Gen $1, d f 2 \$$ Gen 2 , sep $="$ ") 


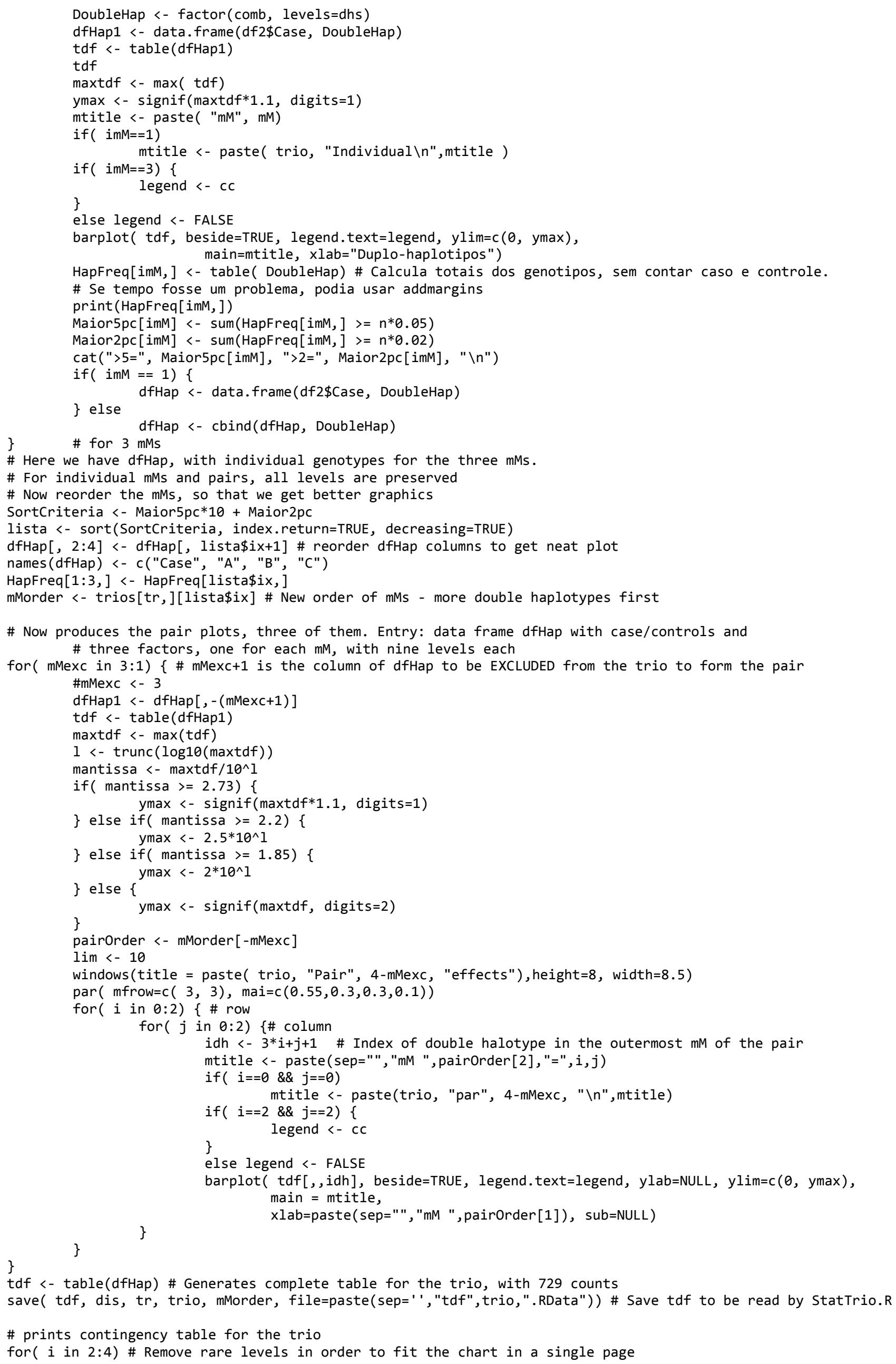




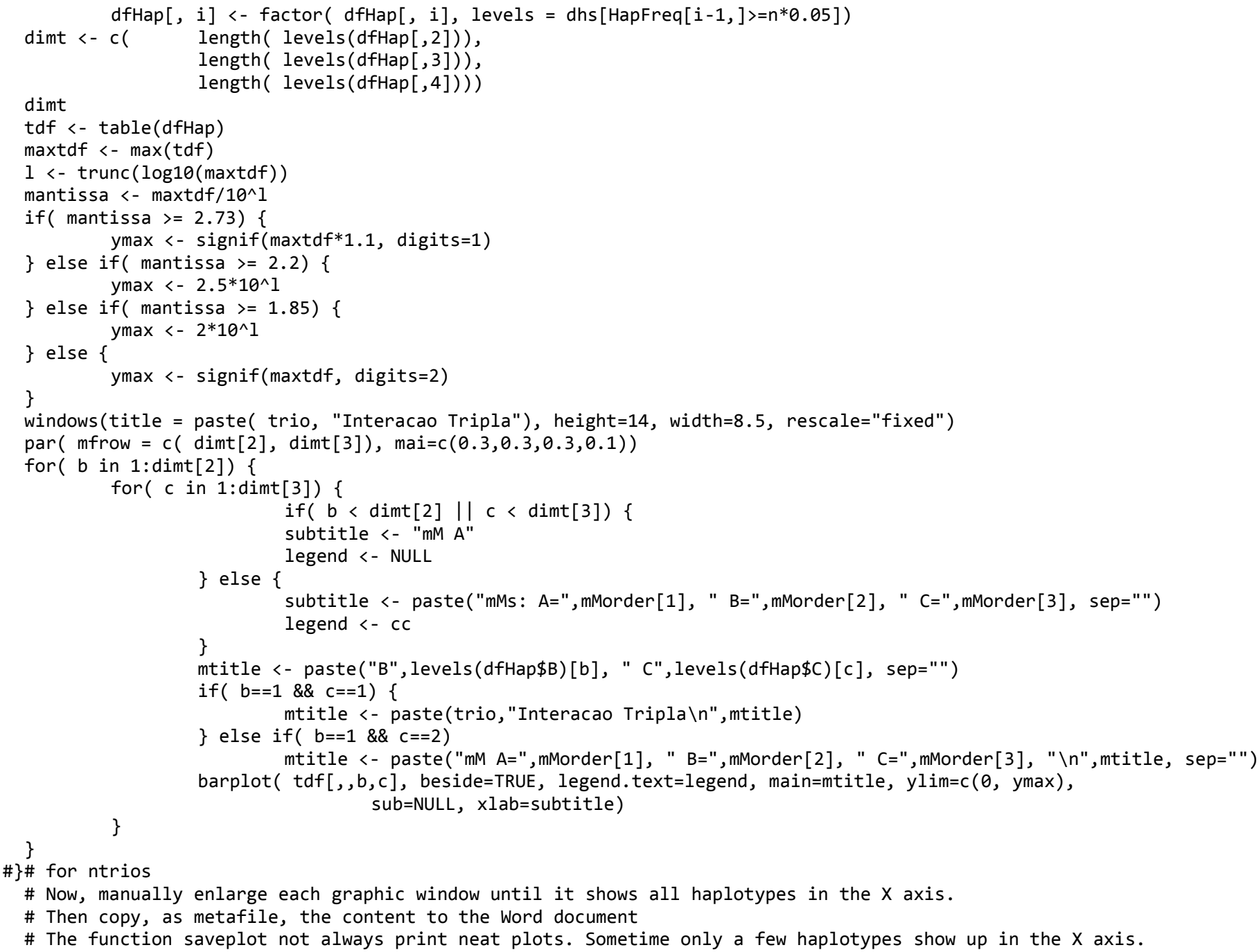

\# The function saveplot not always print neat plots. Sometime only a few haplotypes show up in the $\mathrm{X}$ axis. 


\section{TrioStat. $R$}

\# Calculate significance of each genotype of a trio

\# For regular stats, read tdfDIS. RData and write ResGoodX2DIS.txt

\# For confirmation, read tdfconfDIS. RData and write ConfGoodX2DIS.txt

\# Author: josorio

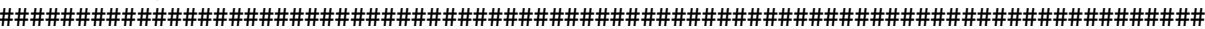

source ("subtable.R")

dhs <- c("00", "01", "02", "10", "11", "12", "20", "21", "22")

\# AABB AABb AAbb AaBB AaBb Aabb aaBB aaBb aabb

Diseases <- C("BD", "CAD", "CD", "HT", "RA", "T2D", "T1D")

trios <- $c(2,3,5,2,1,1,315)$

for (idis in $1: 7$ )

dis <- Diseases[idis]

ntrios <- trios [idis]

\#resFile <- paste(sep="", "ResGoodX2", dis,".txt")

resFile <- paste(sep="", "ConfGoodX2", dis,".txt")

cat ( file=resFile, "Trio SignGood SignX2 Genotipos GenFreq PGood PX2 $\backslash n$ ")

for ( $\operatorname{tr}$ in 1:ntrios) \{

\#infile <- paste(sep=" ", "tdf", dis, tr, ".RData")

infile <- paste (sep="", "tdfconf", dis, tr,".RData")

if ( Ifile.exists(infile))

next

load( infile)

tdfm <- addmargins ( tdf) \# Count mM totals

\# Exclude zeros from table

subnam <- list $c(" 0 ", " 1 ")$,

$$
\begin{aligned}
& \text { dhs[tdfm["Sum", "Sum", } \\
& \text { dhs[tdfm["Sum", "Sum", "Sum", }
\end{aligned}
$$

stdf <- subtable( tdf, subnam)

\# Reduce dimensions to two

ftab <- ftable( stdf, row.vars=1, col.vars=c $(4,3,2))$

$\mathrm{n}<-\operatorname{sum}(\mathrm{ftab})$

gAntes <- length (ftab $[1$,$] )$

\# Maps cells with less than $1 \%$ of representation

lowfreq <- ftab $[1]+,f t a b[2]<,n * 0.01$

fred <- ftab[,!lowfreq] \# Groups low frequency genotypes in a single category

others <- matrix (nrow $=2$, ncol=1)

others $[1,1]<-\operatorname{sum}($ ftab $[1$, lowfreq $])$

others $[2,1]<-\operatorname{sum}(f \operatorname{tab}[2$, lowfreq $])$

fred <- cbind ( fred, others)

\#Implement Goodman's (1964) Chi-square homogeneity test

n1 $<-\operatorname{sum}($ fred $[1]$,$) \quad \# Total controls$

$\mathrm{n} 2<-\operatorname{sum}($ fred $[2]$,$) \quad \# Total cases$

ptj $<-n /(n 1 /($ fred $[1,] / n 1)+n 2 /($ fred $[2,] / n 2))$

$\mathrm{Y} 2<-\mathrm{n} *(1 / \mathrm{sum}(\mathrm{ptj})-1)$

df $<-$ length (fred $[1])$,

pvalue <- pchisq ( Y2, df, lower.tail = FALSE)

pvX2 <- chisq.test ( fred)\$p.value \# Checks with traditional chi-square test as well

cat ( file=resFile, trio, pvalue $<=0.05 /$ ntrios, $p v X 2<=0.05 /$ ntrios, gAntes, df+1, pvalue, pvX2, "\n", append=TRUE)

cat("Trio:", trio, "sigG:", pvalue<=0.05/ntrios, "sigX2:", pvX2<=0.05/ntrios, "gAntes:", gAntes, "gDepois:",df+1, "PGoodman:", pvalue, "PX2:", pvX2, "PX2/PG:", pvX2/pvalue, "\n") 